



\section{BRIDGING THE DISTANCE: ACCOMMODATING WILDLIFE INTERACTION IN AN URBAN SETTING}

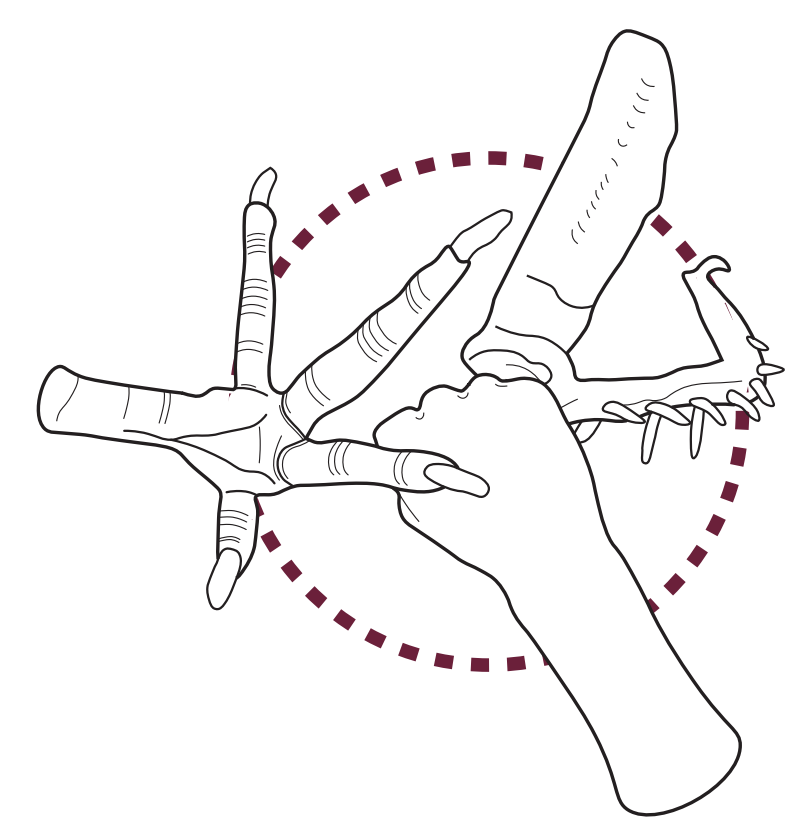




\section{BRIDGING THE DISTANCE: ACCOMMODATING WILDLIFE INTERACTION IN AN URBAN SETTING}

by Michaela Clare Thomson

A 120-point thesis submitted to the Victoria University of Wellington in partial fulfilment of the requirements for the degree of Master of Landscape Architecture

Victoria University of Wellington

School of Architecture

2020 
+ DEVOTION

This is for my parents. And Lucky. 


\section{+ PREFACE}

Growing up within New Zealand, I have always had a connection to wildlife. Often this has been actualised through a love for pets and domestic animals but a supplementary curiosity for other species has always pushed through. Living across the road from horses, birds and other small mammals, has enforced this fascination.

A highlight of my childhood has always been visits to the zoo, where exploration and education is encouraged and the discovery of new animal behaviours is expected. However, limitations around accessibility to zoos, where it often takes around 1 hour to reach, has decreased the desire for this discovery. Instead sightings of sparrows and seagulls have been the extent of visualising New Zealand's biodiversity. Moving down to Wellington was definitely and eye opener, where it was the call of the Tūi that became recognisable within everyday adventures, a new species to observe.
Past papers at university allowed me to start exploring topics around wildlife, but course requirements and site location consistently limited the depth that could be achieved. Therefore the motivation around this thesis is to bring back wildlife curiosity in everyday life. Where there is no need to visit the zoo to experience unique and exciting species, they are already all around us. I feel that New Zealand as a whole is heading in this direction, especially with acts in motion to protect and enhance biodiversity, this thesis will be my interpretation on ways this could be achieved with a Landscape Architecture focus. 


\section{+ AbStract}

Currently within the Wellington region there is an abundance of green spaces hosting a variety of native and exotic wildlife species (Rastandeh, Brown, \& Pedersen Zari, 2018; "The Sanctuary," 2018). These species are somewhat confined to a 'home' green space, in that travel between habitats involves difficult navigation between dense urban and residential structures (Forman, 1995; Rastandeh, Brown, et al., 2018). Many native species are not able to make long distance flights (Wittern \& Berggren, 2007); and as a result habitat fragmentation is occurring at a rapid ecological level. The built form is limiting and discouraging wildlife movement, as well as being dangerous for smaller animals (Forman, 1995; Santiago, 2014). Currently tiny patches of vegetation provide wildlife with a directional indication of intended movement, but overall urban planning is designed for humans only.

Aside from the lack of possible movement between habitats, there is also an absence of human connections to these spaces. There is a missed opportunity to introduce humans to ecological spaces, in that it allows a physical link and understanding to be achieved, as well as additional wellbeing benefits (Ell, 1981a; Santiago, 2014).

With these two existing elements; the lack of wildlife movement between established habitats and the connectivity of humans to these spaces, there is also a third element of how interaction between people and wildlife within urban locations is absent. People are stuck with contributing towards the rapid decline of habitat, there are very limited positive interactions that are being utilised (Rastandeh, Brown, et al., 2018; Santiago, 2014). Infrastructure and specific designed elements that provide the correct facilities to allow for interactions between wildlife and humans is largely non-existent and crucial in the face of biodiversity loss and fragmentation.

This thesis aims to establish a set of design guidelines towards understanding how interaction can be utilised within the design profession, as a way to reduce biodiversity loss, fragmentation and to increase exposure to unique species. Exploration at different scales, macro, meso and micro will be addressing different issues to answer the question of what types of interactions will be occurring within these spaces. 


\section{+ ACKNOWLEDGEMENTS}

The continual overwhelming support from everyone around me has been so, so, helpful.

Thanks to $\mathrm{Ma}$ and $\mathrm{Pa}$ for being my number one supporters and sending me care packages when you can't be in Wellington. It helped a lot more than you think.

To my supervisors, thank you for always offering constructive feedback, for lending me your passion and steering me in the right direction.

Thanks to all the friends that have been gained throughout these years at uni, I definitely wouldn't have passed some of my papers without the Landi lot. To Suzy, thanks for keeping me humble and always being down for a walk at any time of the day.

To my flatties, past and present, thanks for understanding that sometimes you'll never see me but still be ready for a yarn whenever I' $m$ in the flat. 


\section{+ ETHICS}

In order to complete this thesis, Victoria University of

Wellington's Human Ethics Committee was contacted to

obtain ethics approval,

No. 0000027637 .

Documents pertaining towards this acceptance are located within the appendix. 
+ CONTENTS PAgE

\section{\begin{tabular}{ll|l} 
PHASE & 1 & INTRODUCTION
\end{tabular}}

+ Chapter 1 - Introduction

13. Introduction

17. The Question

18. Scope

19. Clients

20. Aims and Objectives

22. Role of Design

23. Design Methodology

24. Thesis Structure

\section{PHASE 2 | SPATIAL RESEARCH/ANALYSIS}

+ Chapter 2 - Spatial Site

28. Wellington Wider Scale

SWOT Analysis

34. Avain Life and Movements

36. Existing Points of Interaction

+ Chapter 3 - Wildlife Analysis

42. Literature Review

48. Kererū

50. Tūi

52. Hihi 


\section{PHASE 3 DESIGN PHASE}

+ Chapter 4 - Initial Design Attempts

56. Three Week Thesis

60. Review \#1

+ Chapter 5 - Macro Level Testing

66. Literature Review

80. Precedent Review

82. Critical Reflection

+ Chapter 6 - Meso Level Testing

86. Literature Review

91. Critical Reflection

+ Chapter 7 - Micro Level Testing

94. Literature Review

156. Fresh $\mathrm{H} 2 \mathrm{Go}$

100. Precedent Study

158. Site Analysis

104. Design Typologies

108. Nesting Hide-Aways

118. Design

128. Review 2

130. Ethics

154. Critical Reflection
164. Design

206. Critical Reflection

208. Other Locations

210. Conclusions

214. Amendments
PHASE 4 | APPENDICES

+ Chapter 8 - References

225. Bibliography

229. Figure References

236. Appendices 


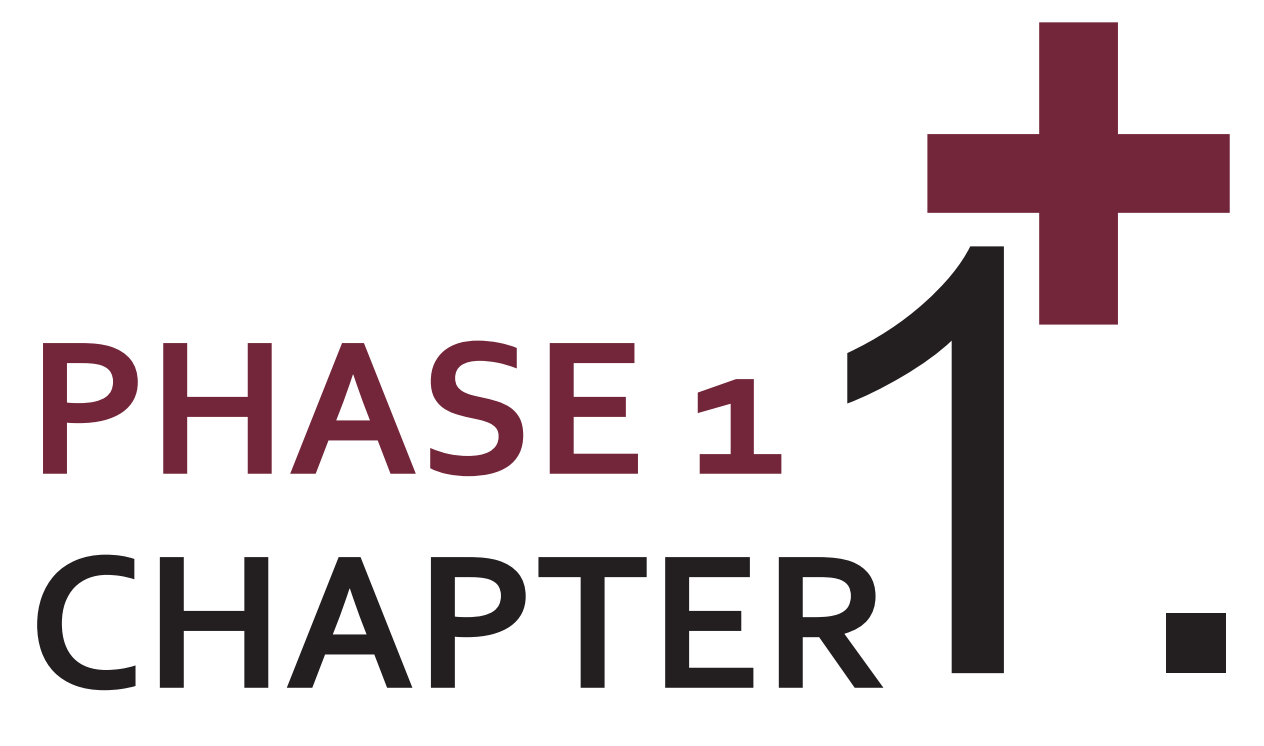




\section{+ INTRODUCTION}

Growing up in the New Zealand environment, where a multitude of biomes and land conditions are very prevalent, exposure to a vast variety of native wildlife species is a given. It is well known that as development towards human infrastructure has expanded, these biomes have grown smaller and smaller and urban green spaces have been affected the most, resulting in habitat loss. Native flora and fauna is suffering, resulting in people becoming disconnected from these spaces and exposure to natural systems isn't occurring (Santiago, 2014). Effort has shifted from people being constantly surrounded by an abundance of species, towards actively planning to experience wildlife; where people have to travel just to visit a zoo or active habitats (Santiago, 2014).

Therefore the issue lies within the urban realm, the built environment is dominating, severely limiting the amount of available space to dedicate towards green infrastructure and habitat. Comparing lush vegetation and fauna life in areas such as botanical gardens to forgotten urban space, such as a singular tree pit devoid of leaves, results in a visual and physical disparity. There is typically no designed accommodation for wildlife in urban areas, and parks are too overpowered by humans to offer much protection and safety to warrant habitation (Forman, 1995). Contrasting to this, heavily designed areas that encourage humans and animals to engage together within one space, such as a zoo, are completely biased to the human agenda. Observation techniques crowd and control wildlife, resulting in people looking down at the wildlife, there is no freedom. Ideally a balance of the above mentioned issues is where design potential lies.

This thesis examines two key areas that will be addressing 
this problem, by identifying smaller issues and solving them in conjunction with the overarching issues. These issues are as follows:

+ Biodiversity Loss

New Zealand has a rich history of being a natural paradise. However this all changed with the introduction of indigenous Maori people and European settlers (Wellington City Council, 2015). With people came dominating infrastructure and the negative loss of natural systems (Ministry for the Environment, 2019; Wellington City Council, 2015). Currently, New Zealand has lost 70,000ha of land, to urban development and farming within 16 years (Ministry for the Environment, 2019). Only 2\% of the land within New Zealand can be classified at being native and conductive towards habitat provision (Ministry for the Environment, 2019). Not only can people be the main contributor towards biodiversity loss, introduced animals and exotic plants can as well (Ministry for the Environment, 2019). The Environment Aotearoa 2019 Summary (2019) state that pests such as "stoats, possums, and rats were present on more that 94 percent of New Zealand land in 2014". This is a pressing issue that can only be addressed with the continual support of all New Zealand.

Within New Zealand, Wellington used to be a densely covered Podocarp and Broadleaf forest, with numerous wetlands within the flatter areas (Wellington City Council, 2015). This source also discusses how this has been reduced to $5 \%$ of the total Wellington area and the wetlands have all been piped. The Wellington City Council are aware of these issues and have set up urban and rural strategies to bring back some of the life that used to be so prevalent within the city before human influence (Wellington City Council, 2015). 
Species such as "saddleback, piopio robin, kokako, stitchbird, banded rail, little spotted kiwi, weka, and huia" were very common throughout Wellington (Wellington City Council, 2015). It is only through rigorous conservation monitoring from the community and Zealandia, that these species are rising in numbers and still visible in everyday life ("The Sanctuary," 2018).

$+\quad$ Why it's bad

Biodiversity loss has a lot more negative side effects than good ones. Ecosystem services, such as food provision, water regulation and habitat allocation are some of the main losses that are attributed to changes in the environment (Ministry for the Environment, 2019; Pedersen Zari, 2018). They are critical to all species' everyday life, such as cleaning water for drinking and providing spaces for wildlife to have a home (Ministry for the Environment, 2019).
Not only are ecosystem services at risk there is also the added disadvantage of "degraded habitats and a loss of species can make ecosystems less resilient to other changes and lead to further declines in biodiversity" (Ministry for the Environment, 2019). This is a vicious cycle of continual negative effects that won't change unless urgent action is taken.

\section{Fragmentation}

Working closely with biodiversity loss is fragmentation. This is the separation of habitats, through spatial isolation (Santiago, 2014). Similar to biodiversity loss, causes of fragmentation can be attributed towards changing in land cover from natural to urban development (Santiago, 2014). There are many negative effects to fragmentation, such as "cause[ing] populations to become isolated, which can lead to inbreeding and declines in genetic diversity" (Santiago, 2014). The 
easiest way to exterminate fragmentation is to reconnect habitats through a variety of methods, such as green corridors and stepping stone locations (Santiago, 2014).

$+\quad$ Thesis application

This thesis aims to explore ways to increase biodiversity within Wellington. Adding to the work that Zealandia has already achieved, considering biodiversity at the forefront of design decisions will start to allow for a dense population of bird species to be protected within the urban realm. 
+ QUESTION

HOW CAN URBAN HABITATS ACCOMMODATE NATIVE WILDLIFE SPECIES AS WELL AS PROVIDING ELEMENTS FOR HUMAN/WILDLIFE INTERACTION? 


\section{+ SCOPE}

The proposed site is Wellington as a whole. Within that area, five individual locations have been chosen as places of potential influence and adaptation for biodiversity enhancement. They have been selected as they show the most promise towards acting as stepping stones amid existing green spaces. The locations have been determined by a rigorous site wide biodiversity analysis, where report investigations and physical recordings have been conducted.

Of all of these locations, a connective journey or looping pathway will join them all on the ground. The actual design will be a series of conceptual typologies that can be placed into street spaces as determined by the existing street conditions. This will act as a natural ecological corridor that funnel people and wildlife to each stepping stone location. Like the City to Sea bridge, these pathways will be a 'Fly to Walk' journey for all of Wellington to enjoy, particularly the wildlife.

Of the five proposed locations, two of them have been defined within this thesis. Location 3, Fresh H2Go, looks into the different ways that cleaning and drinking fresh water can be both interactive for people and wildlife. There are multiple interventions along the reconfigured Kent and Cambridge Terrace. Location 4, the Nesting Hide-Aways, has been defined as having the program of providing various ways of nesting for wildlife. There are four interventions along Vogletown's ridgeline, each spatialising different ways to design and encourage settling in a home base.

The other three locations, have been conceptualised in plan and the site programs have been set. Location 1, Pecking Picnics, focused on eating, providing vegetable gardens and native vegetation that both wildife and humans can eat. Location 2, Sheltered Huts explores ways to implore 


\section{$+C L I E N T S$}

structural elements that can provide natural and man-made shelter in the steep topography of Te Aro. Finally, Location 5, Social Species, explores the intricate relationships between different birds and people within one space. Working around Pohill, this space brings people to reflect and utilise other senses, such as hearing, to understand how different species communicate.
The way the overall question is framed, results in two important factors in the future design. Interaction between avian species and humans can only be achieved through a thorough investigation of both 'clients'. Not only does attention need to be focused towards humans and potential design opportunities, but there is no thesis without birds being considered within the same space. Therefore, human parameters and limitations can only be assessed in correlation with the restrictions and freedoms that come with individual wildlife. Human elements cannot be deemed successful without equal comparison to avian interaction aspects. To summarise, the design needs to benefit not only the people but also the wildlife, by engaging and providing for both clients. 


\section{+ AIMSANDOBJECTIVES}

Overall, what this thesis aims to achieve is a cohesive design that:

1. Provide stepping stones in the wider scheme of existing Wellington green spaces, that allow for wildlife species to congregate and rest between travel.

2. Introduce linkages to these spaces, creating a looping pathway that physically joins all of the stepping stones. Each of these pathways will have different intentions, typologies and demographics that differentiate them from other parts of the system. People are intended to be the users of these pathways.

3. Investigate ways that wildlife and humans can co-exist within an urban environment. Focus is shifted towards exploring how they can co-inhabit one space, so that relationships and positive interactions are enforced and encouraged. Discovery regarding different demographics, species and environments will allow for different points and means of contact.

Fig 1.01 | Diagram of design intentions. 


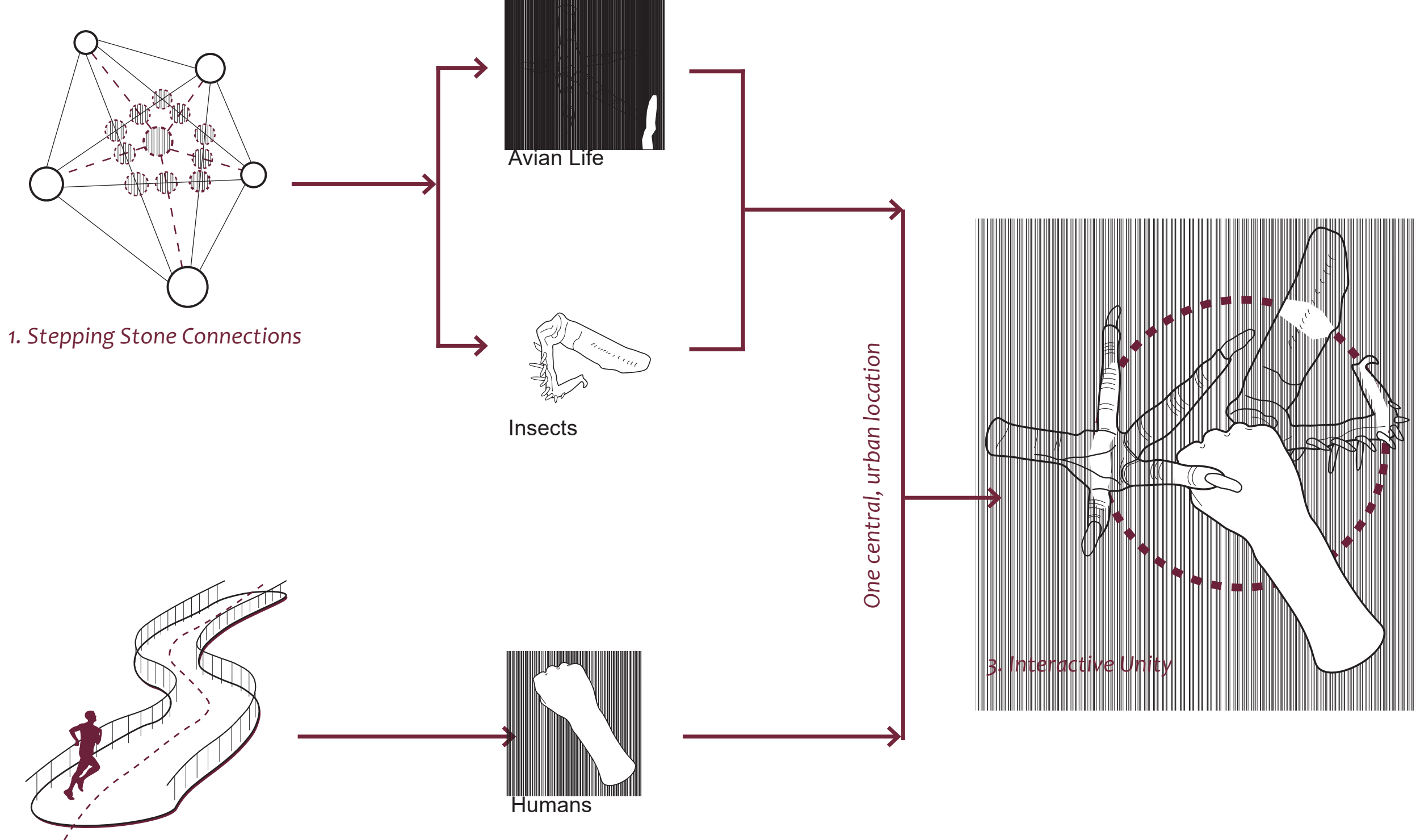

2. Moveable Journeys 


\section{+ ROLEOFDESIGN}

The main intention of this thesis is to achieve the merging of human and wildlife priorities in a series of urban areas. It seems that in past built environments, consideration to native wildlife has been ignored, or only secondary, in that it is the priority of the people to come first. The role of a landscape architect is to "create places and spaces for people" with consideration to the "management and conservation of natural and heritage landscapes" (NZILA, 2019). Therefore focusing on the landscape and smaller categories such as wildlife inclusion falls below conservation of landscapes and less attention is paid as a result. This could be attributed towards lack of outside help, particularly with ecologists that have knowledge around wildlife behaviour in urban environments.

Recent changes are emerging however, in that habitat and wildlife consideration is starting to become a design tool.
Isthmus have completed recent work around the Wellington waterfront, Kumutoto, that provide penguins with a safe place to nest (Barrett, 2015). This is becoming a trend that is showing positive results in built designs.

Landscape Architects have the ability to work within large systems, jumping scales easily and understanding a network of interlinked issues. This design led research thesis aims to bridge this distance by placing wildlife at the forefront of design decisions by utilising research to become knowledgeable in wildlife behaviours. Doing this will result in a series of developed designs that work to bring wildlife and people together through the landscape form. This approach will try to prove the value of working closely with wildlife, which could become a precedent towards other practices within their own design processes. 


\section{+ DESIGN METHODOLOGY}

This thesis employs a design led research methodology,

where five key design milestones have been established. The

milestones are made up of:

\section{MILESTONE ONE}

Milestone One starts with spatial

analysis of typologies and

form, derived from visual and

theoretical readings.

\section{MILESTONE TWO}

This stage narrows down the role of the macro scale down, establishing site wide plans that provide reasoning towards allocation of stepping stone locations.

\section{MILESTONE THREE}

Getting closer in scale, the application of the meso scale explores connective corridors that bring people to these stepping stones.

\section{MILESTONE FOUR}

Going even closer, the micro stage starts to explore these interaction points. Theoretical analysis and precedent studies help to determine what they should look like, as well as consultation with the wider community in a series of interviews judging the designs. 


\section{+ THESIS STRUCTURE}

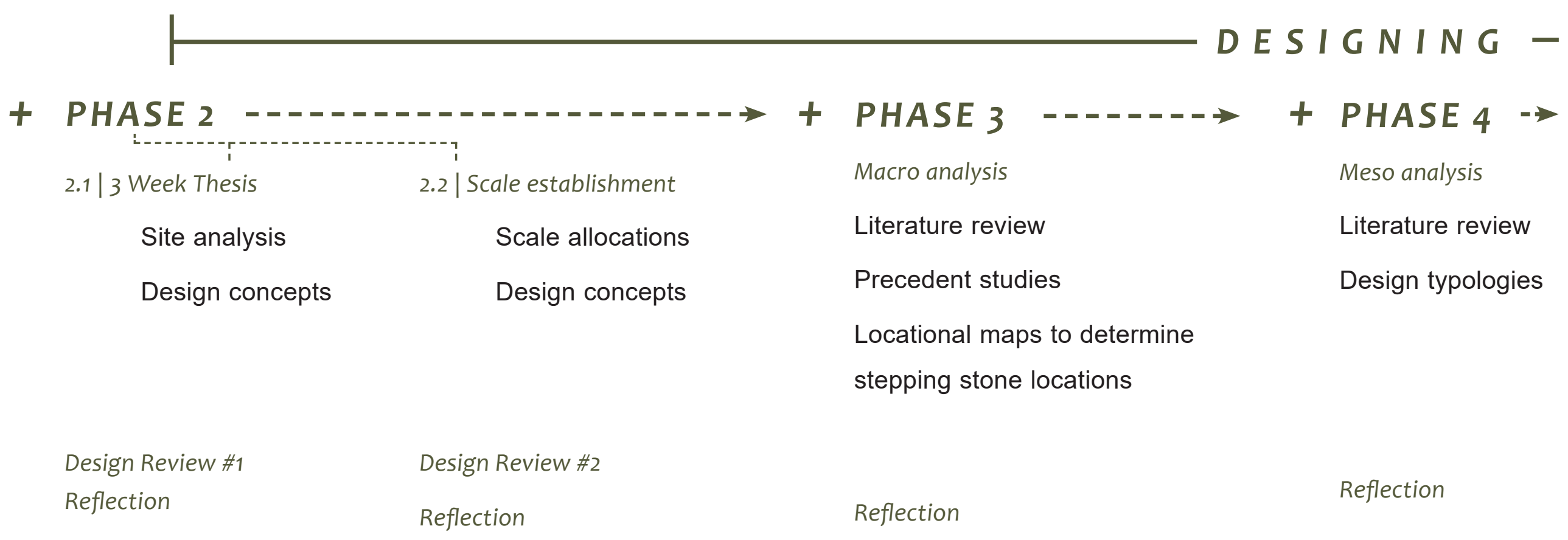




\section{FS ITE ANALYSIS}

\section{+ PRE-PHASE}

Proposal

Establishing the issue

\section{Site analysis}

Regional analysis (New Zealand wide)

Local analysis of Wellington

Green space

Water systems

Bird species

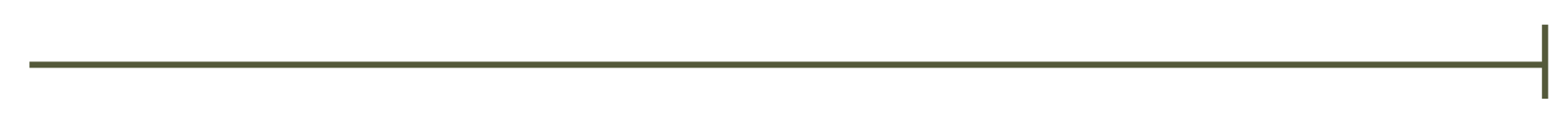

\section{+ PHASE 5}

Micro analysis

Literature review

Precedent studies

4.1 Nesting Hide-Aways

Site analysis

Design concepts
4.2 | Fresh $\mathrm{H}_{2} \mathrm{Go}$

Site analysis

Design concepts

Final design

Design Review \#3

Ethics Interviews

Final design

Reflection 


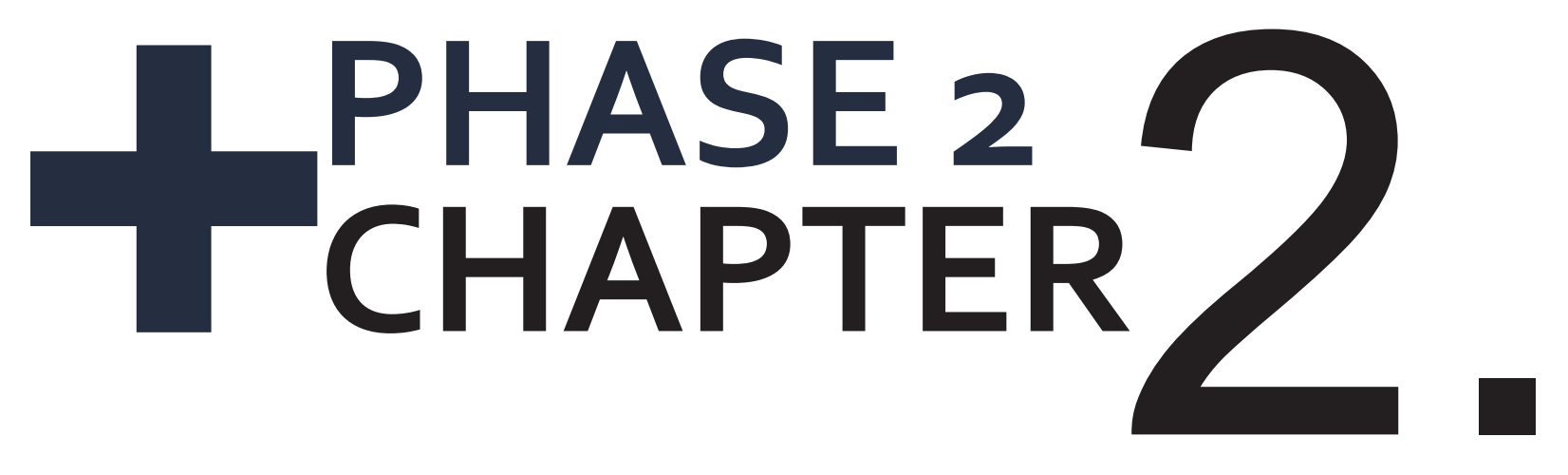


Site allocation was a very crucial part of the thesis research. Due to the numerous green spaces and multiple avian life forms within Wellington city, it was an obvious choice to expand upon the urban realm to better connect physically, interactively and ecologically.

Understanding that these spaces individually work very successfully, but not as a whole connected ecosystem, was where the inspiration towards stepping stone locations stemmed from.
Why Wellington?

The Wellington City Council have proudly called themselves a "Natural Capital" (Wellington City Council, 2015) regarding the multitude of green ecosystems. There are many policies in place to continue this care and conservation of the natural environment, as per the Wellington City Council strategy guide (2015). However, Wellington used to be a densely covered Podocarp and Broadleaf forest, with numerous wetlands within the flatter areas (Wellington City Council, 2015). However over time this has now been reduced to $5 \%$ of the total Wellington area and the wetlands have all been piped.

There is an obvious issue with loss of existing habitat that has only just started to be addressed in design strategies, such as the efforts of Zealandia and Wellington City Council ("The Sanctuary," 2018; Wellington City Council, 2015). There are areas to improve upon within Wellington, as well as areas to replicate and connect to, with future designs. 


\section{+ EXISTING VEGETATION TYPES}

Knowing the general types of environments within the green

zones is fundamental to understanding potential species that

will establish well within future designs. Although this does not

provide the specific vegetation species in question, there is

still value in knowing the umbrella terms.
(D) Wellington Vegetation Species Fig 2.01 | Scale 1:50,000

Broadlead Indigenous Hardwoods

Built-up Settlements

Exotic Forest

Gorse and Broom

Gravel and/or Rock

Herbaceous Freshwater Vegetation

High Producing Exotic Grasslands

Indigenous Forest

Lake and/or Pond

Low Producing Grasslands

Manuka and/or Kanuka

Matagouri or Grey Scrub

Sand and/or Gravel

Surface Mine/Dump

Transport infrastructure

Urban Parkland and Open Space

Land Parcels

Sea 


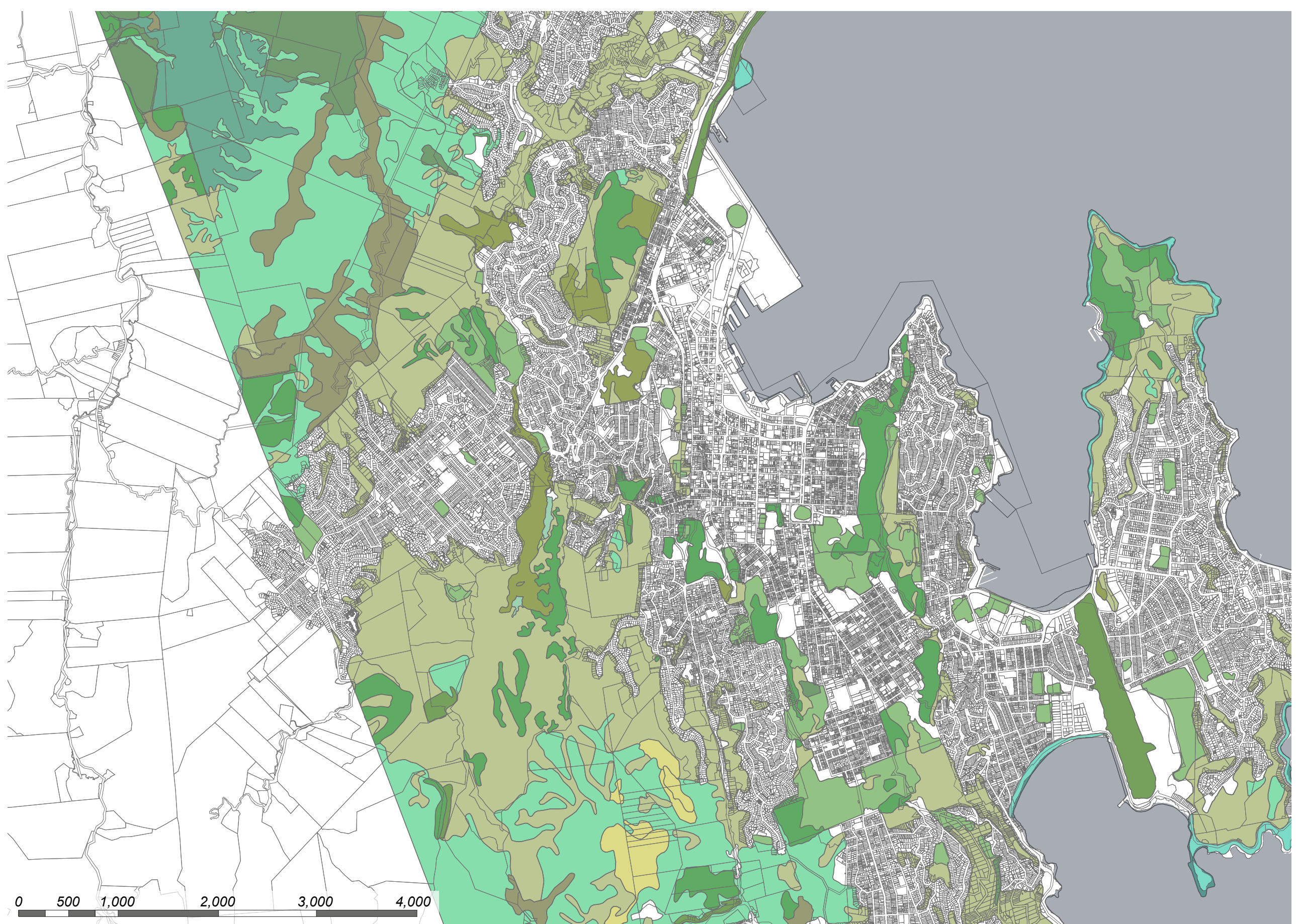




\section{+ EXISTING GREEN SPACES}

The benefits of this analysis is to understand spatial sizing when comparing urban and rural sites. From this it is very clear that urban green locations are limited in access and size compared to the green spaces in rural areas which are large and plentiful.
D. Wellington's Existing Parks and Green Spaces Fig 2.02 | Scale 1:50,000

Parks and Green Space
Main Ecological Spaces
$5 m$ Contour Lines
Land Parcels
Sea




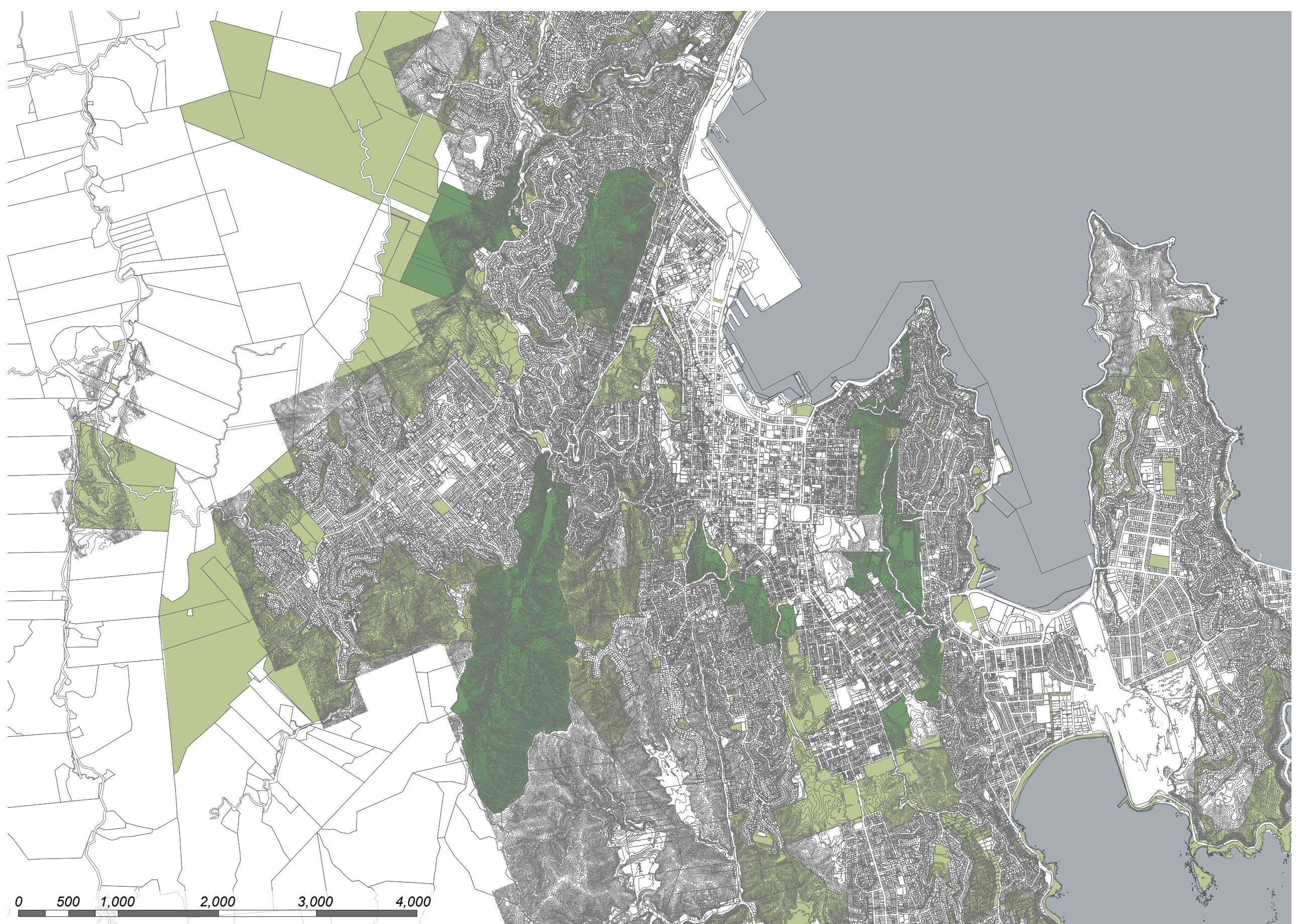




\section{+ Wellington WATER SYSTEMS}

Knowing focus was going to be on vegetation types, it became

obvious that looking into water systems was also necessary in terms of variety and differing functions.
1. Wellington Water Systems

Fig 2.03 | Scale 1:50,000
River Lines
Ponds
Flooding Plains
Land Parcels
Sea 


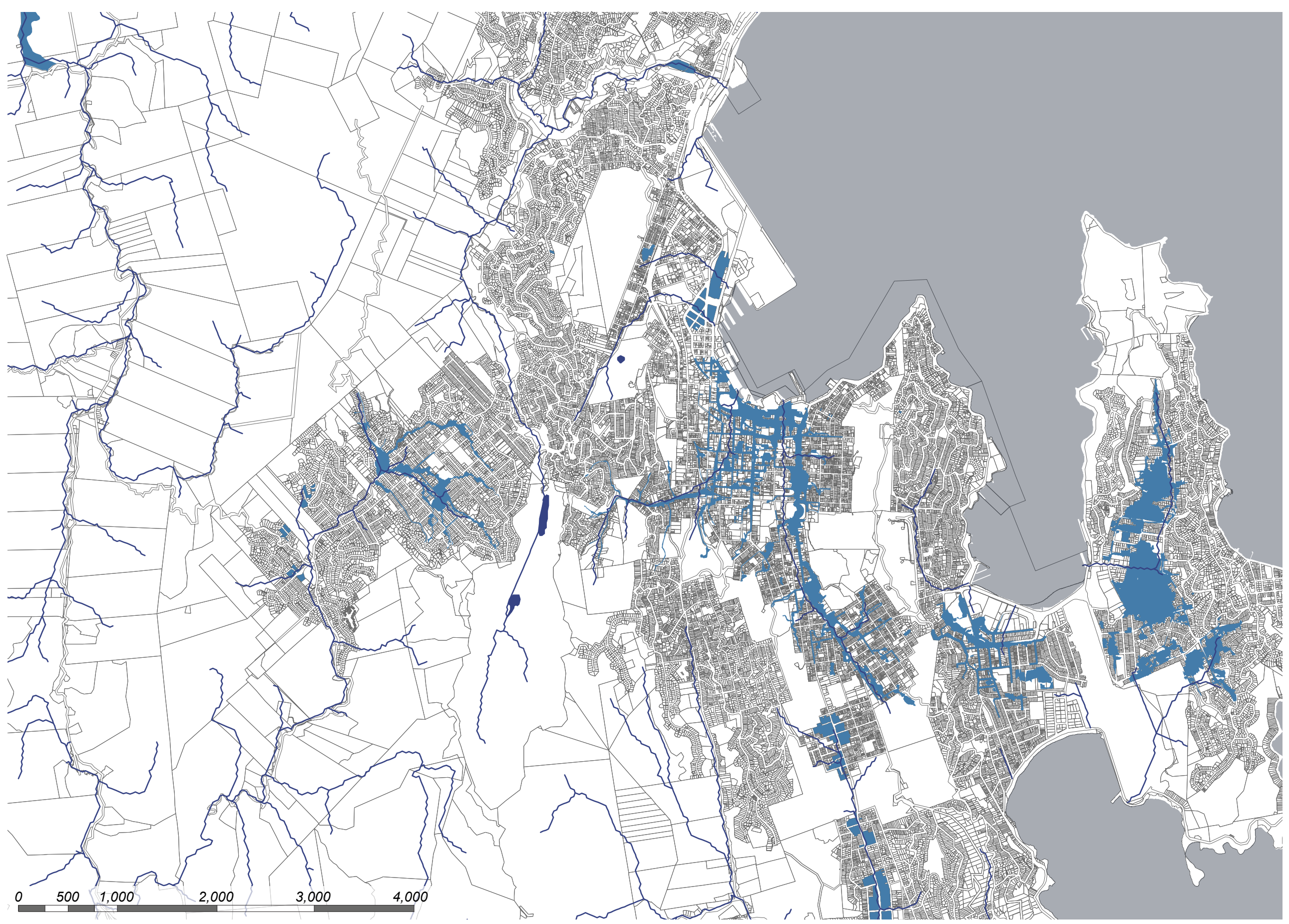


Table 2.01 | Showing the species that were found inhabiting the

\section{+ AVAIN LIFEAND MOVEMENT}

Looking into what birds are within each existing green space is important as it helps to define what species are traveling to each area (Fig 2.05). Information was sourced from Wellington City Council in a report that collated data collected from a range of organisations, such as five-minute bird counts (McArthur, Flux, Harvey, \& Ray, 2018)(Table 2.01). It aims to understand "diversity, abundance and distribution of native forest birds throughout Wellington City's reserve network" (McArthur et al., 2018). Zealandia, due to the immense conservation methods, ("The Sanctuary," 2018) identifies the most species, 16 at the least. The town belt, although one of the largest and spread out, had the least amount of variety, only 8.

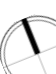

Wellington's Existing Parks and Green Spaces

Fig 2.04 | Scale 1:50,000

Main Ecological Spaces Sea

Land Parcels

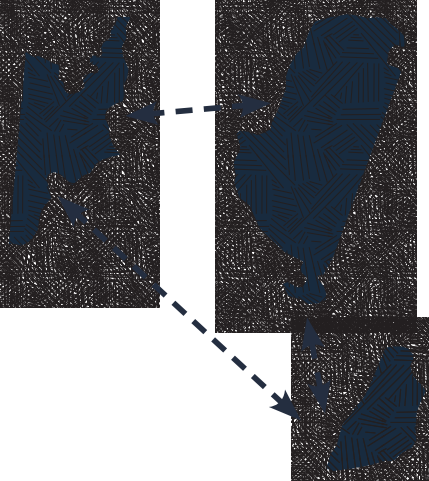

Fig 2.05 | Understanding of the species location can lead towards assumptions of what birds are flying where and potential pathways that they are taking. existing green sites.

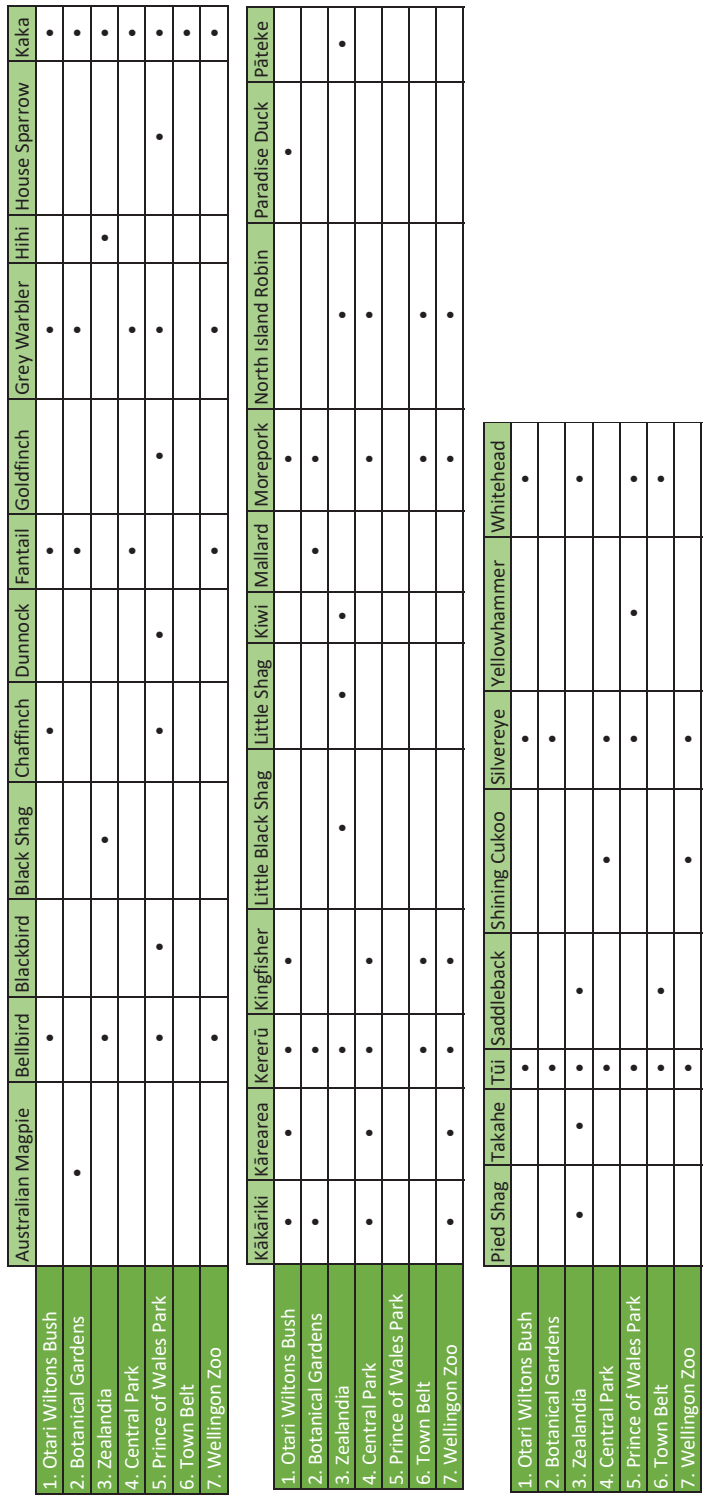




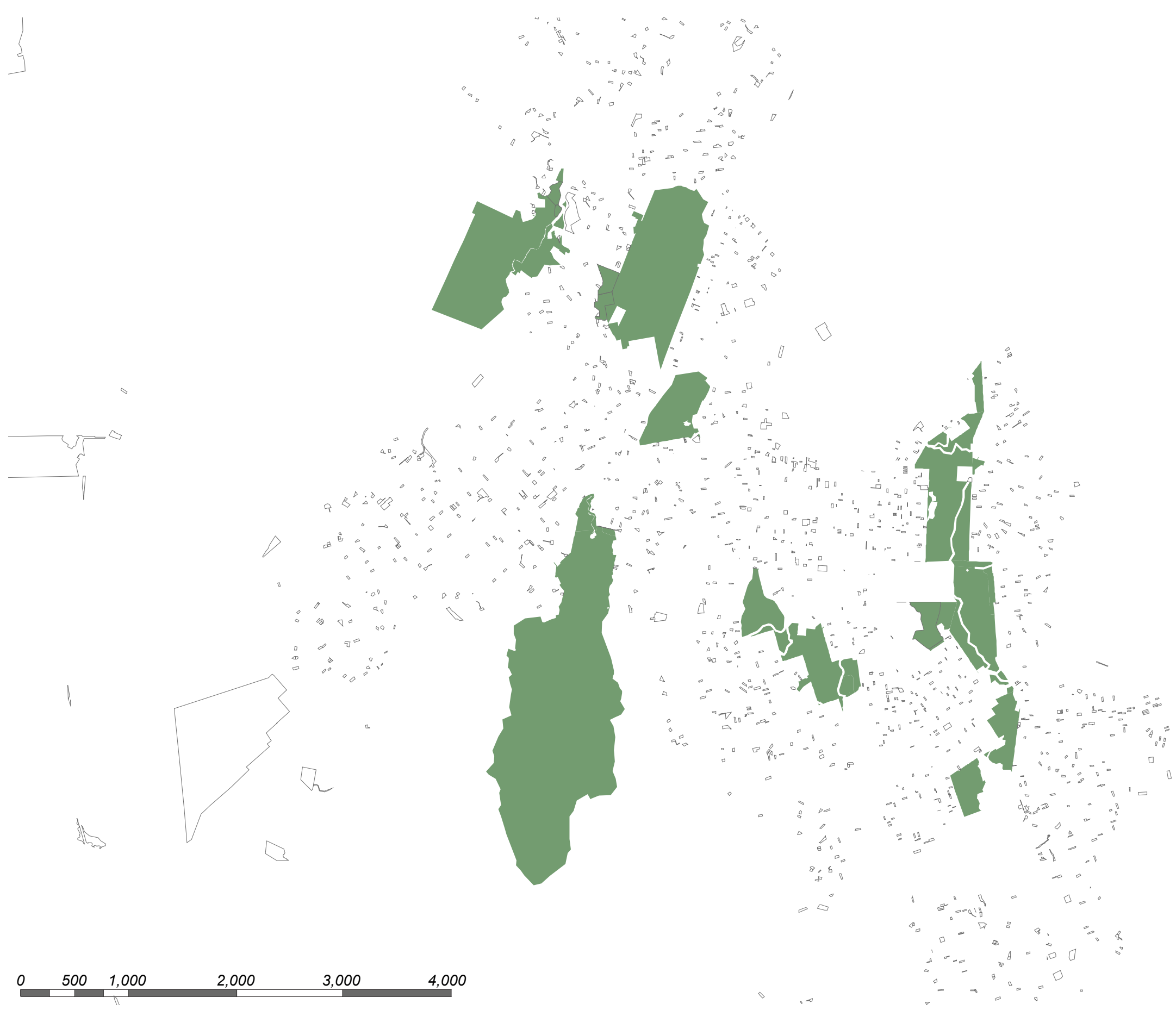




\section{+ EXISTING POINTS OF INTERACTION}

As the design process was going to be heavily influential

towards interactions between people and birds, it was

important to understand this in relation to the Wellington

context. Small sectional studies were performed in urban

locations throughout Wellington, to understand different

ways to achieve success, by utilising and enhancing existing

design strategies. 


\section{+ BOYDWILSON WALKWAY}

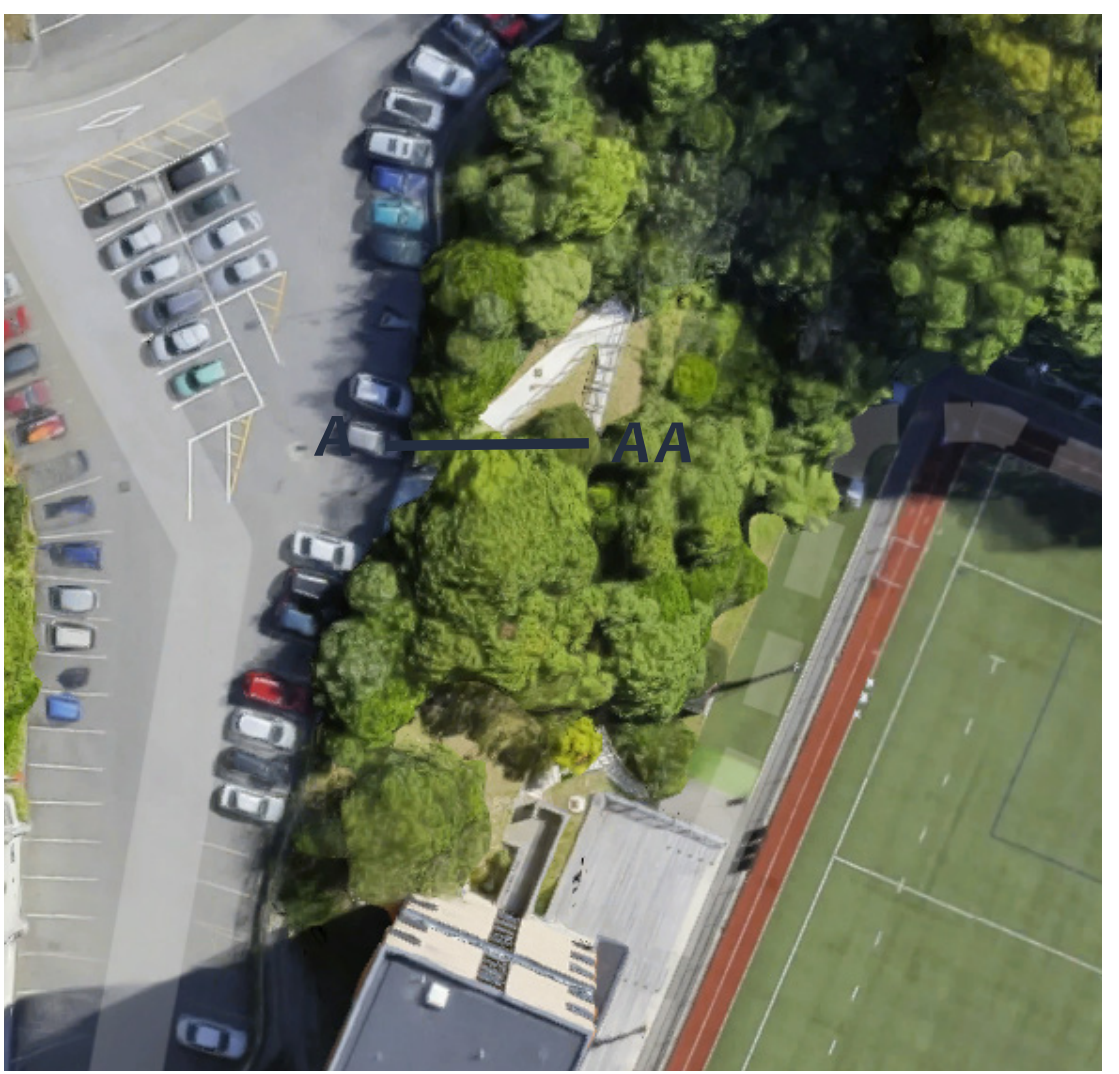

Fig 2.06 | The location of Boyd Wilson Walkway.

Fig 2.07 | Sectional diagram of Boyd Wilson Walkway. Section A-AA.

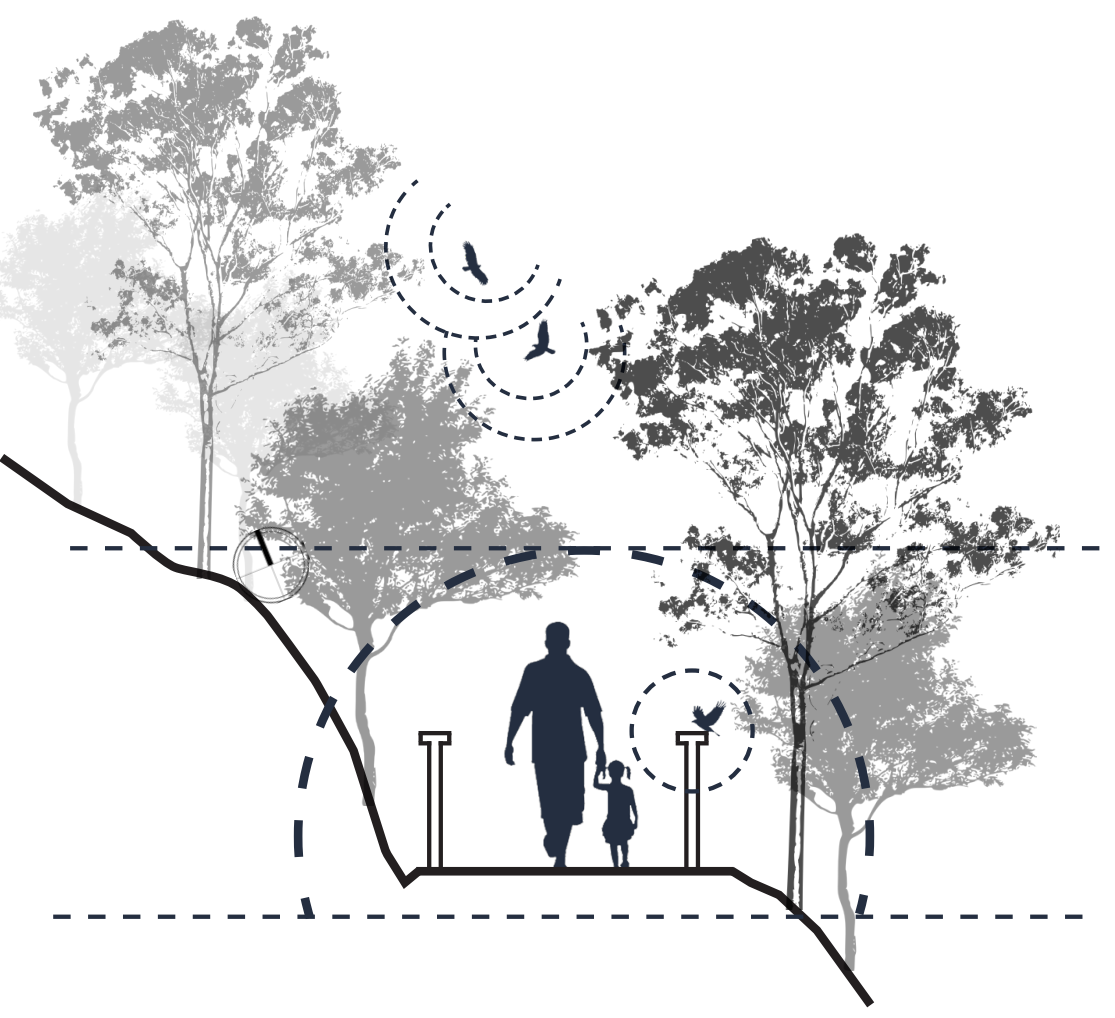

$+\quad$ Dense vegetation makes it difficult to visualise birds, but sounds are prominent.

$+\quad$ The canopy of vegetation creates a small intimate 'world' where all participants are within close quarters.

$+\quad$ The structure of the handrails creates a perching platform for birds to frequent. 
+ Willis ST

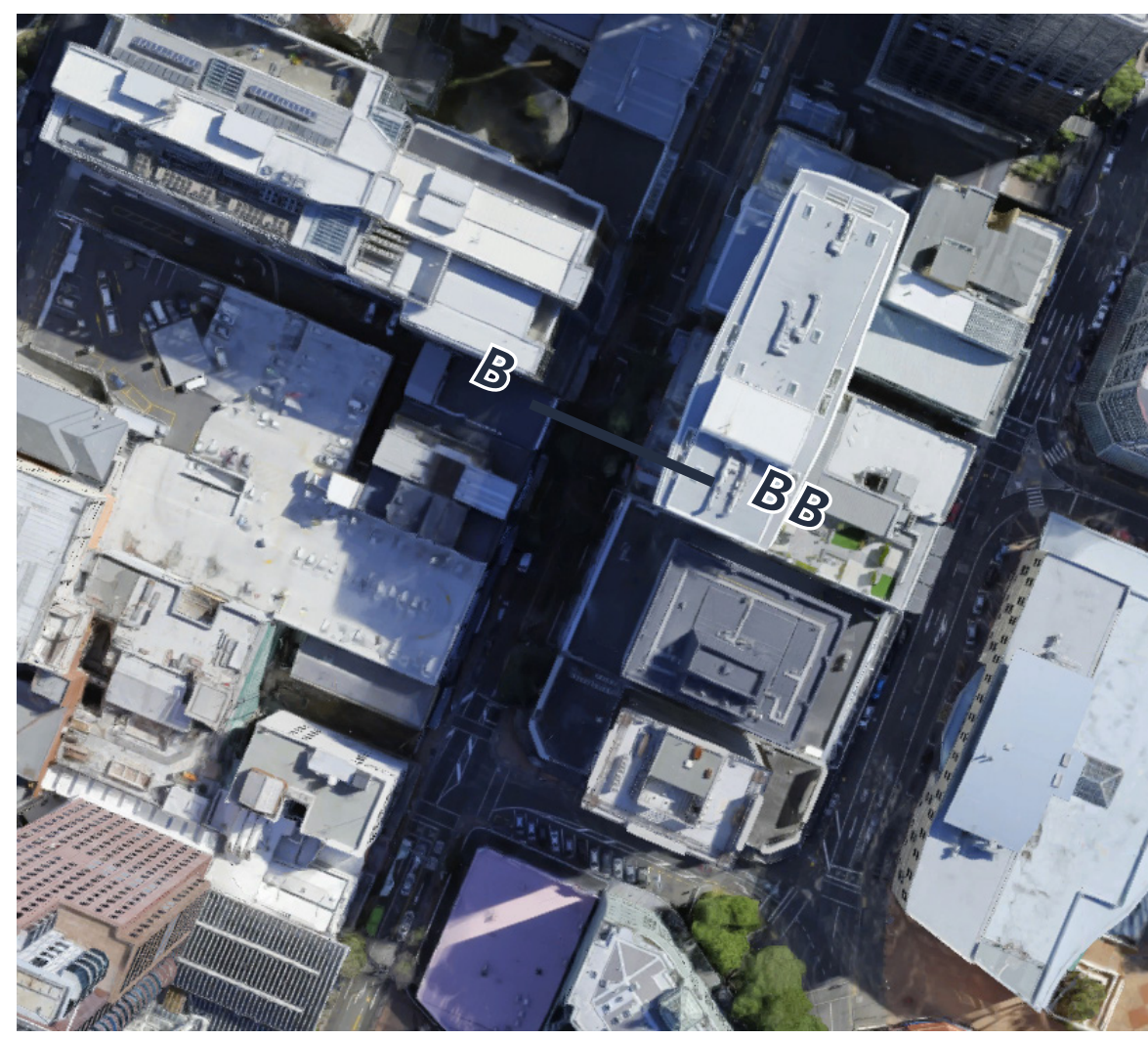

(1) Fig 2.08 | Plan of Willis St

Fig 2.09 | Sectional diagram of Willis St. Section B-BB.

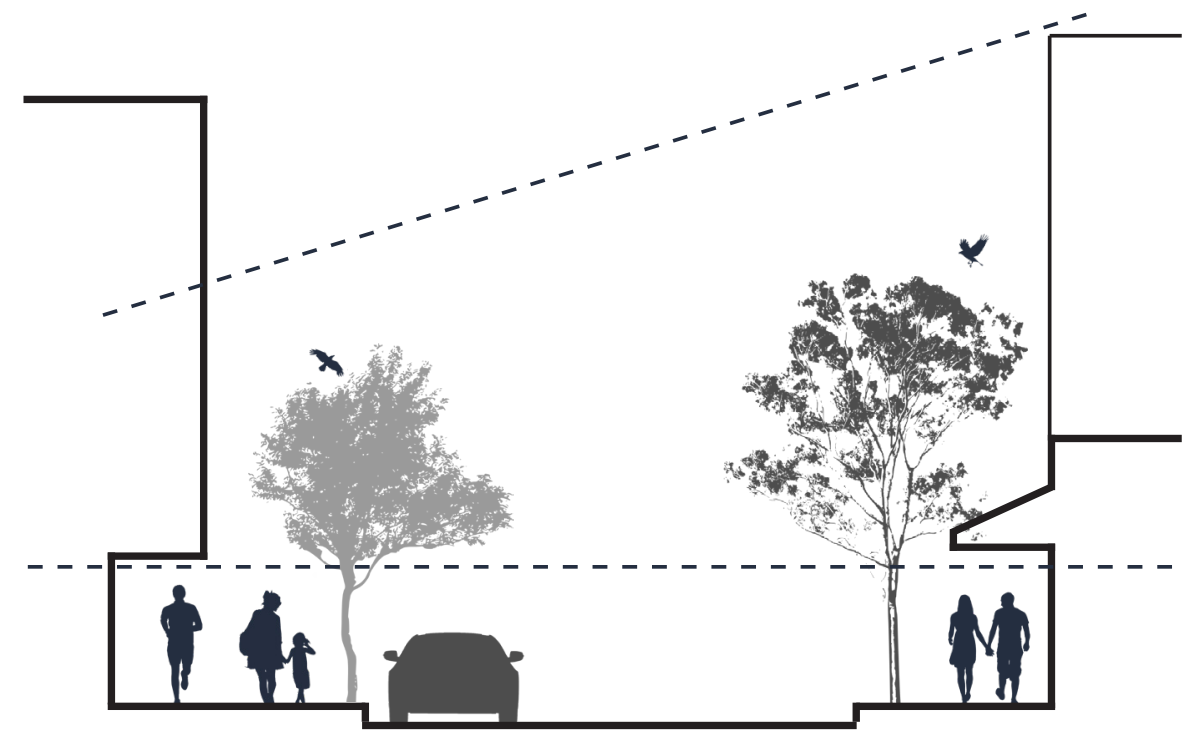

+ The buildings help to provide shelter to the select trees, making them desirable to birds as a wind free hotspot.

+ Elevation of the building coverage, secludes the trees from view, eliminating humans from interference. Sound is the most telling aspect of bird life.

+ Long trunk means there is no human access to leaves, further separating humans from the vegetation. 


\section{+ COBBLESTONE PARK}

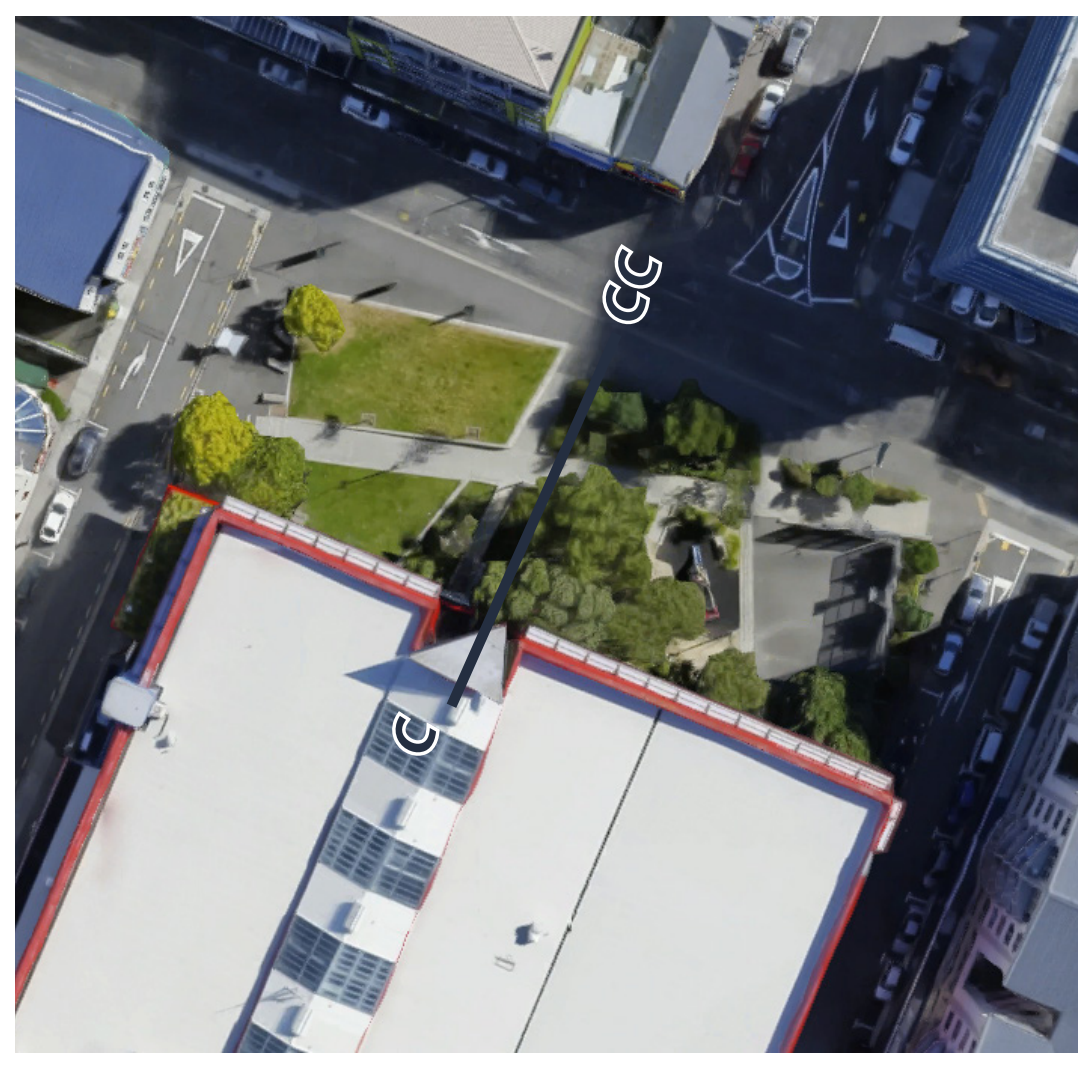

1) Fig 2.10| Plan of Cobblestone Park.

Fig 2.11| Sectional diagram of Cobblestone Park. Section C-CC.

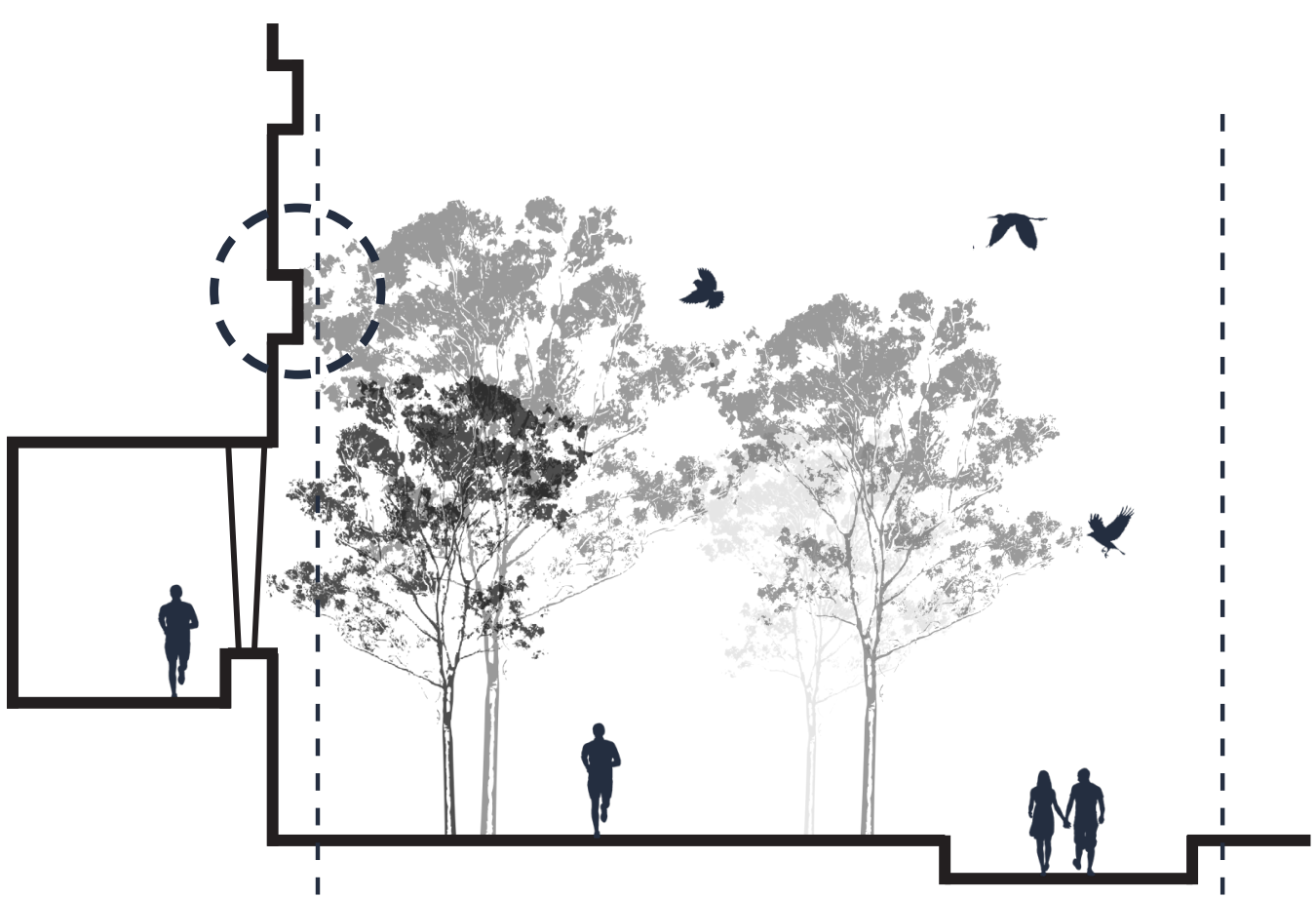

+ Due to the changing of exterior edge conditions, the birds are now more visible on the ground level. They often act territorial as a result.

$+\quad$ Individuals feed the birds often, so the birds feel more comfortable being close to humans. 


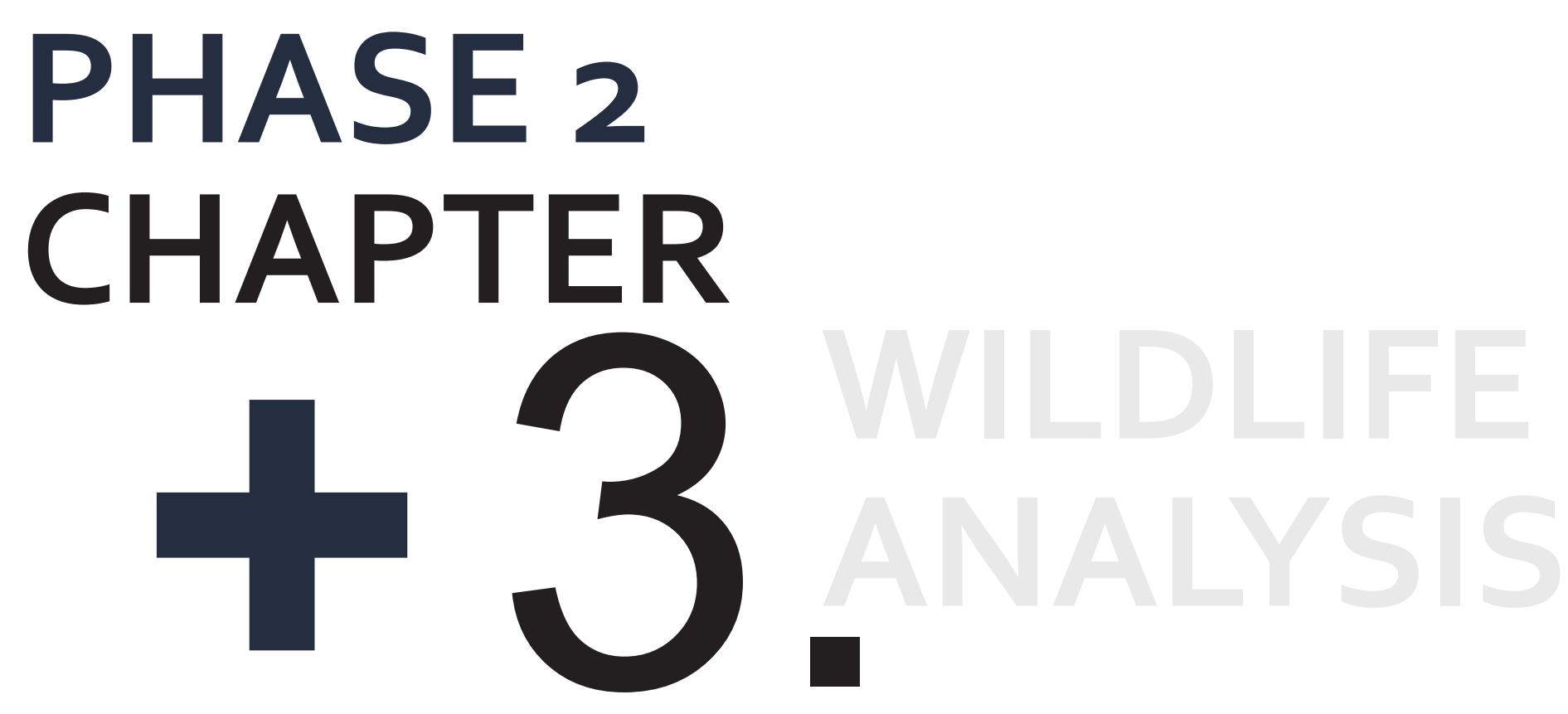




\section{+ WHY B IRDS?}

In all of New Zealand, there are around 300 diverse bird varieties (Power et al., 1996). Particularly within Wellington, there is a heavy bird influence, due to the conservation work of Zealandia ("The Sanctuary," 2018). However, there are limitations around birds being within the urban realm, as some birds are only visible within Zealandia ("The Sanctuary," 2018). The bird focus within this thesis has stemmed from wanting to enhance this visibility and interaction, working with the efforts already initiated. 


\section{+ SELECTION OF THE SPECIES: KEYSTONEAND WELLINGTON INFLUENCE:}

Initially the intention of the thesis was to design infrastructure that worked at facilitating interaction for all types of bird species and humans. However, there was no selection process for which birds would be included and instead it was intended to be inclusive to all. However, that leads towards a large assumption of perceived potential successfulness, as there is no specific way of judging whether the final design will be utilised by birds. Therefore, starting out with a variety of carefully chosen species is thought to be a more successful way to finalise an accurate design that responds to the needs of the species directly.

Correctly narrowing down this scope, is critical. First, there needs to be a framework devised for species selection. This has been organised into two categories: working with enhancing the existing Wellington biodiversity; and/or targeting endangered species. Ideally, working with both categories will have positive outcomes for the future of Wellington's biodiversity. 


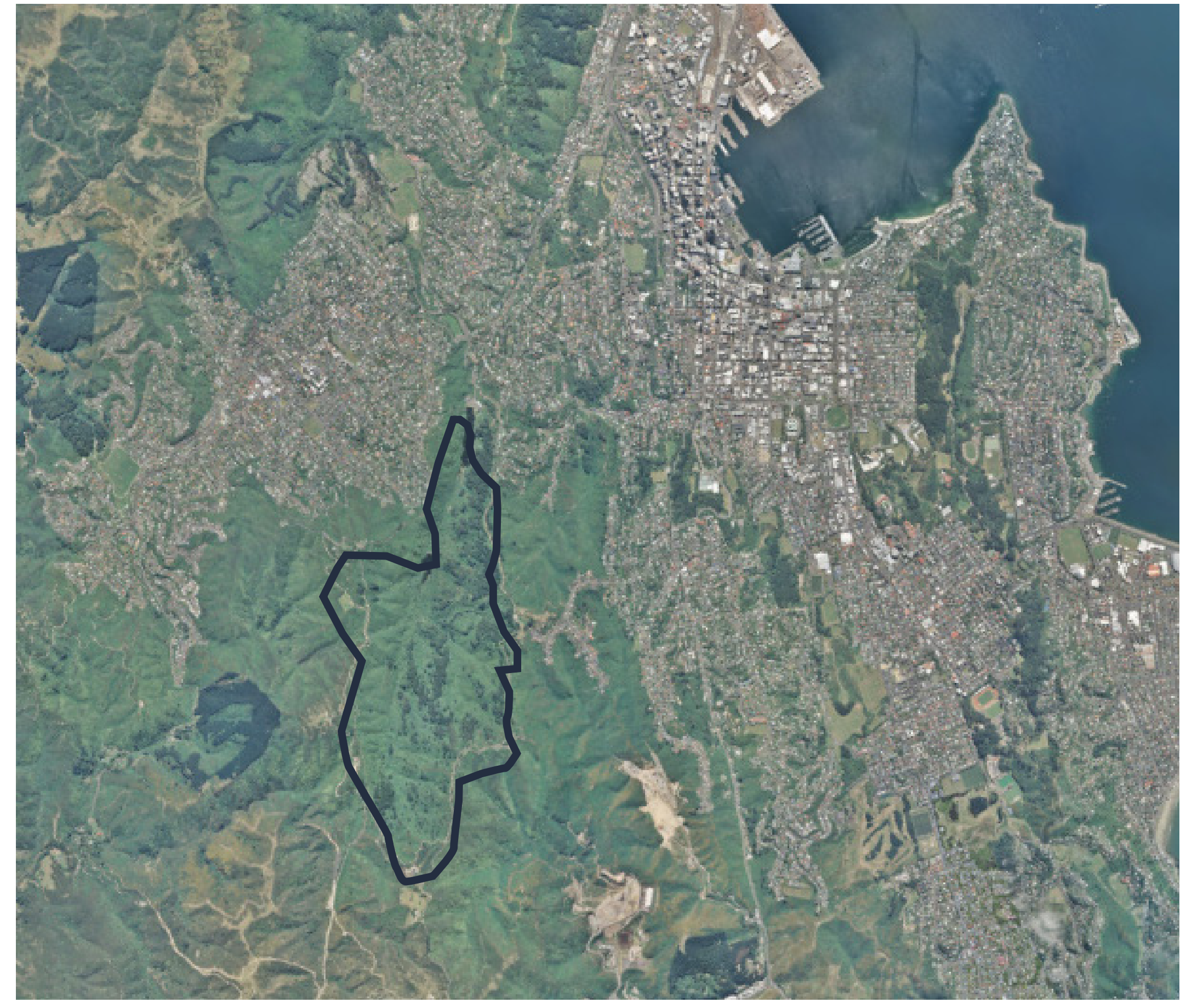




\section{+ EN DA nered SPECIES OF AOTEAROA}

The Ministry for the Environment New Zealand ("The

Sanctuary," 2018)(2019) released a report concerning the current ecological issues in New Zealand. This report brings sharp focus towards biodiversity loss, stating that "75 animal and plant species have become extinct since humans arrived in New Zealand" with a further "90 percent of seabirds, 76 percent of freshwater fish, 84 percent of reptiles, and 46 percent of vascular plants" potentially set to join them (Ministry for the Environment, 2019). Of the 4000 threatened species, ecosystems themselves, vegetation and wildlife fall under this number. (Ministry for the Environment, 2019).

Organisations such as Zealandia (Fig 3.01), located within Wellington, are actively working with endangered species, trying to increase population safely with pest eradication and habitat regeneration techniques ("The Sanctuary," 2018).

However, for all of the success that places like Zealandia offer, ("The Sanctuary," 2018) there are also additional long term efforts that need to be considered.

Once the species numbers are within a safe range, there has to be continuous monitoring, to ensure they do not fall below the line again (Ministry for the Environment, 2019). They state Kakapō as being a prime example of this ongoing relationship.

As the predicted sites for this thesis are going to be on urban public land, there will need to be contact with the Department Of Conservation, DOC, to establish monitoring schedules. Objectives must be in place, to limit the amount of additional monitoring that organisations like DOC need to perform however. 


\section{+ KEYSTONE SPECIES}

A concept within the world of ecology, is 'keystone species'. Freedman (2014) labels this as "a species that has a great influence on the structure or function of an ecological community" Powers et al. (1996) defines keystone species as "one whose effect is large, and disproportionately large relative to its abundance" Keystone species can only be understood when in relation to a community; "an assemblage of populations of different species that occur together in the same place and at the same time" (Freedman, 2014). The keystone species is the one that offers the most unique and dependable function within the community, without them, often through the negative influence of humans, the entire community can be negatively affected (Freedman, 2014). Payton (2002) suggests the human focused built environment within New Zealand can be a resulting factor towards specific species now leading a superior role within the community. Understanding keystone species is important as it provides critical information around encouraging biodiversity and ecosystems in an urban scale (Payton, Fenner, \& Lee, 2002).

Powers et al. (1996) states, "the diversity or particular species that conservation managers seek to preserve may be lost if the dynamic fragility of communities and ecosystems contained within preserves is not taken into account in managing them." Knowing the importance of keystone species suggests that applying an equal focus on not only endangered species but also keystone species.

\section{Possible candidates}

There are many ways to determine whether different species are in fact considered keystones. It lies within the practical benefits that they will be offering to the wider ecological community. Payton (2002) suggests four labels that define the new roles: 
1. Organisms controlling potential dominants;

2. Resource providers;

3. Mutualists;

4. Ecosystem engineers.

Alternatively, (Power et al., 1996) suggests a calculation that can figuratively determine keystone species. The main defining trait that the species are being measured against, is the overall community value or importance, noted as $\mathrm{Cl}$ (Power et al., 1996). The full measurement;

$C l=[d($ trait $) / d p][1 /($ trait $)]$

relies on a lot of knowledge of each species, with not as many strict guidelines (Power et al., 1996). They define trait as "a quantitative trait of a community or ecosystem.
Potential community or ecosystem traits include productivity, nutrient cycling, species richness, or the abundance of one or more functional groups of species or of dominant species" (Power et al., 1996). This offers differing results as it could be difficult to measure the importance of a nutrient cycling speciality compared to a species that solely contributes group productively.

Of the two methods that have been discussed, a more relevant analysis was needed, specifically with consideration towards the New Zealand context. Amin Rastandeh,

(Rastandeh \& Pedersen Zari, 2018) conducted six interviews with local experts to narrow down a list of potential candidates for native keystone species. The top four that were decided upon where the Kererū , Tūī, Bellbird and Hihi (Rastandeh \& Pedersen Zari, 2018). They were chosen due to their role of "support[ing] vital ecosystem services such 
as pollination and seed dispersal mechanisms" (Rastandeh

\& Pedersen Zari, 2018). Specifically, Kererū "are the only species that can disperse the seeds of large-fruited trees endemic to New Zealand" (Rastandeh \& Pedersen Zari, 2018). Payton (Payton et al., pg 18, 2002) lists Tūī and Bellbird as belonging to the mutualists category, stating that "Flowers, [Peraxilla mistletoes] not visited by the birds fail to open and only a minority set seed. In both cases seed production and hence the long-term survival of the plant species is heavily, but not entirely, dependant on a single pollinator or pollinator-group."

Due to the discussed importance of the keystone species within the ecosystem, it can be summarised that protection of them should be paramount in all future urban scale design planning. Upsetting the ecological community can have vast negative effects, so effort towards facilitating spatial needs within the design will be justified.

Why these are the species that should be used.

Protecting the wildlife allows for the certainty of survival for communities and ecosystems, excluding large climate effects, and stops other species from stepping up into these roles and shifting relationships (Freedman, 2014). It aims to continue the ecological status quo. 


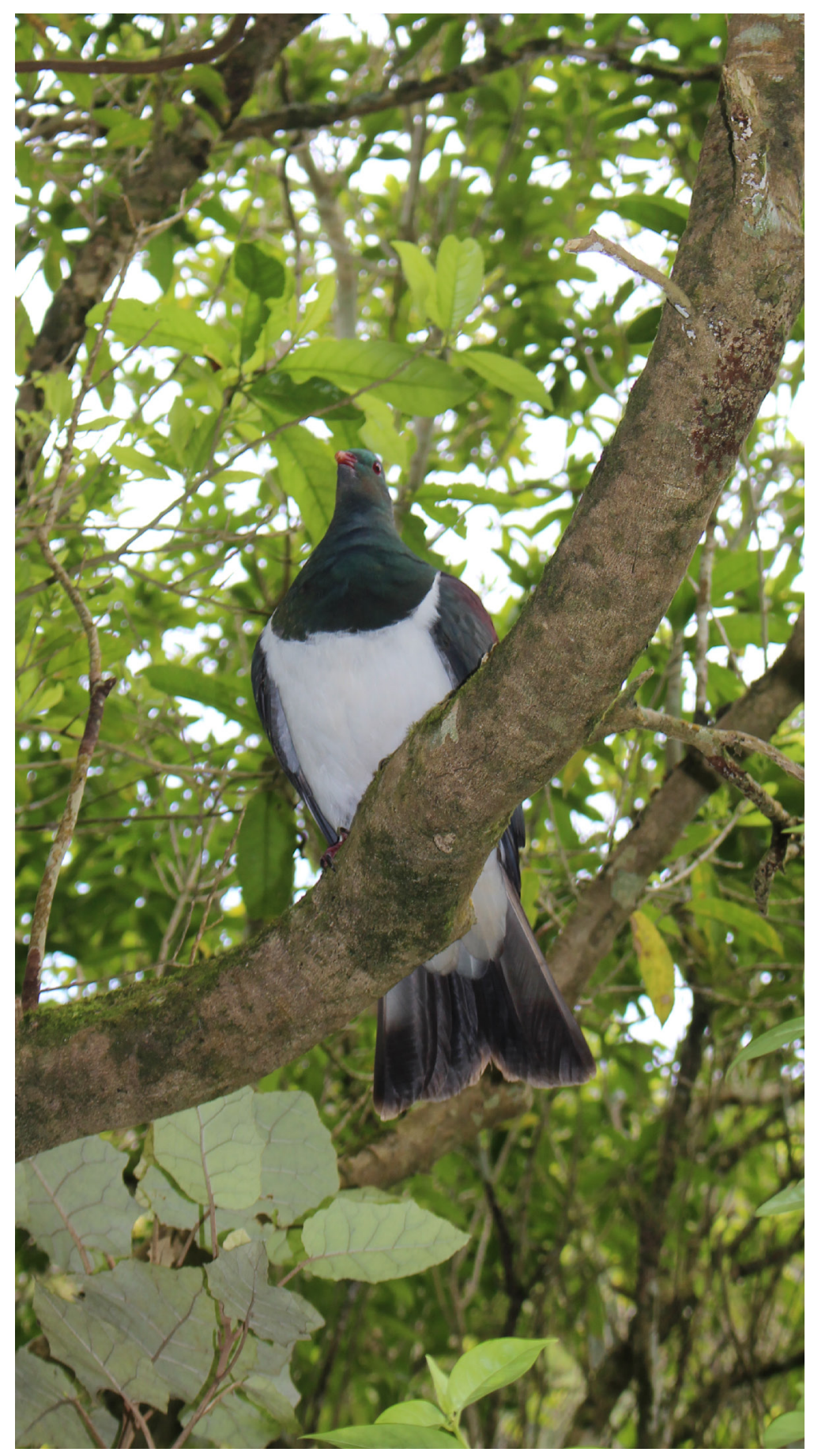

\section{+ KERER U \\ Hemiphaga novaeseelandiae}

Physical

A very large bird, it can grow to $51 \mathrm{~cm}$ (Penguin Pocket

Guides, 1996; Riley, 2005).

Natural

They are normally found within native forest habitats.

(Penguin Pocket Guides, 1996; Riley, 2005) They prefer the interior habitat of the chosen site (Rastandeh \& Pedersen

Zari, 2018). They eat fruit and leaves, particularly from the Miro tree (Penguin Pocket Guides, 1996).

Lifestyle

Breeds late spring and summer on a bed of twigs or native vegetation (Penguin Pocket Guides, 1996; Riley, 2005).

The Kererū is considered a keystone species (Payton et al., 2002; Rastandeh \& Pedersen Zari, 2018) and is very 


\section{+ PREFERRED VEGETATION}

active within Wellington. Flight average is $77 \mathrm{~m}$ (Rastandeh \&

Pedersen Zari, 2018), with a record of $1,469 \mathrm{~m}$ being recorded as a maximum distance they will fly to deposit a seed for pollination (Wotton, 2007).

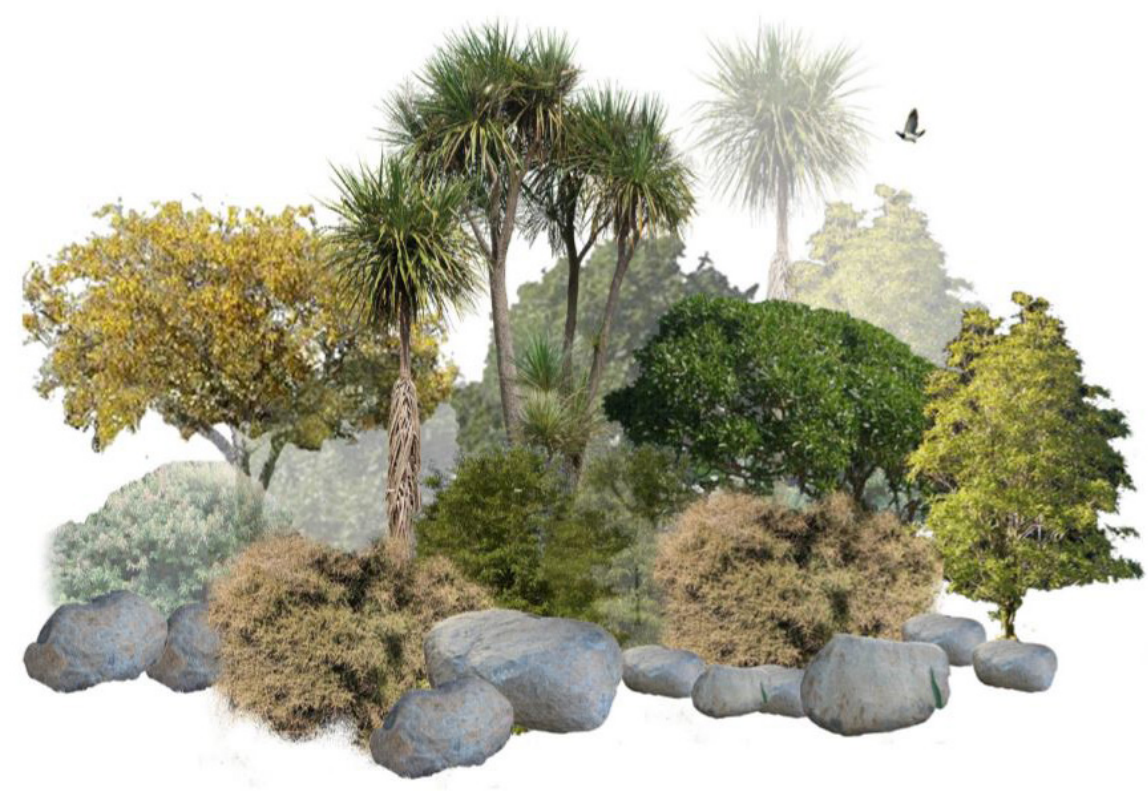

Fig 3.03 | A collage showing a few preferred vegetation species for the Kererū.
Alectryon excelsus

Aristotelia serrata, Wineberry Makomako

Beilschmiedia tawa Tawa

Coprosma lucida, Glossy Karamu, Karamu

Cordyline australis, Cabbage Tree, Ti kouka

Hedycarya arborea, Pigeonwood, Porokaiwhiri

Myoporum laetum, NZ Ngaio Ngaio

Nothofagus menziesii, Silver Beech, Tahina

\section{Podocarpus totara}

Totara

Prumnopitys ferruginea, Brown Pine, Miro
Corynocarpus laevigatus Karaka

Dacrycarpus dacrydioides Kahikatea

Dacrydium cupressinum, Red Pine, Rimu

Fuchsia excorticata, Tree Fuchsia, Kotukutuku

Griselinia littoralis, Broadleaf Papauma

Prumnopitys taxifolia, Black Pine, Matai

Pseudopanax crassifolius, Horoeka, Lancewood

Sophora microphylla Kowhai

Vitex lucens

Puriri

Weinmannia racemosa Kamahi 


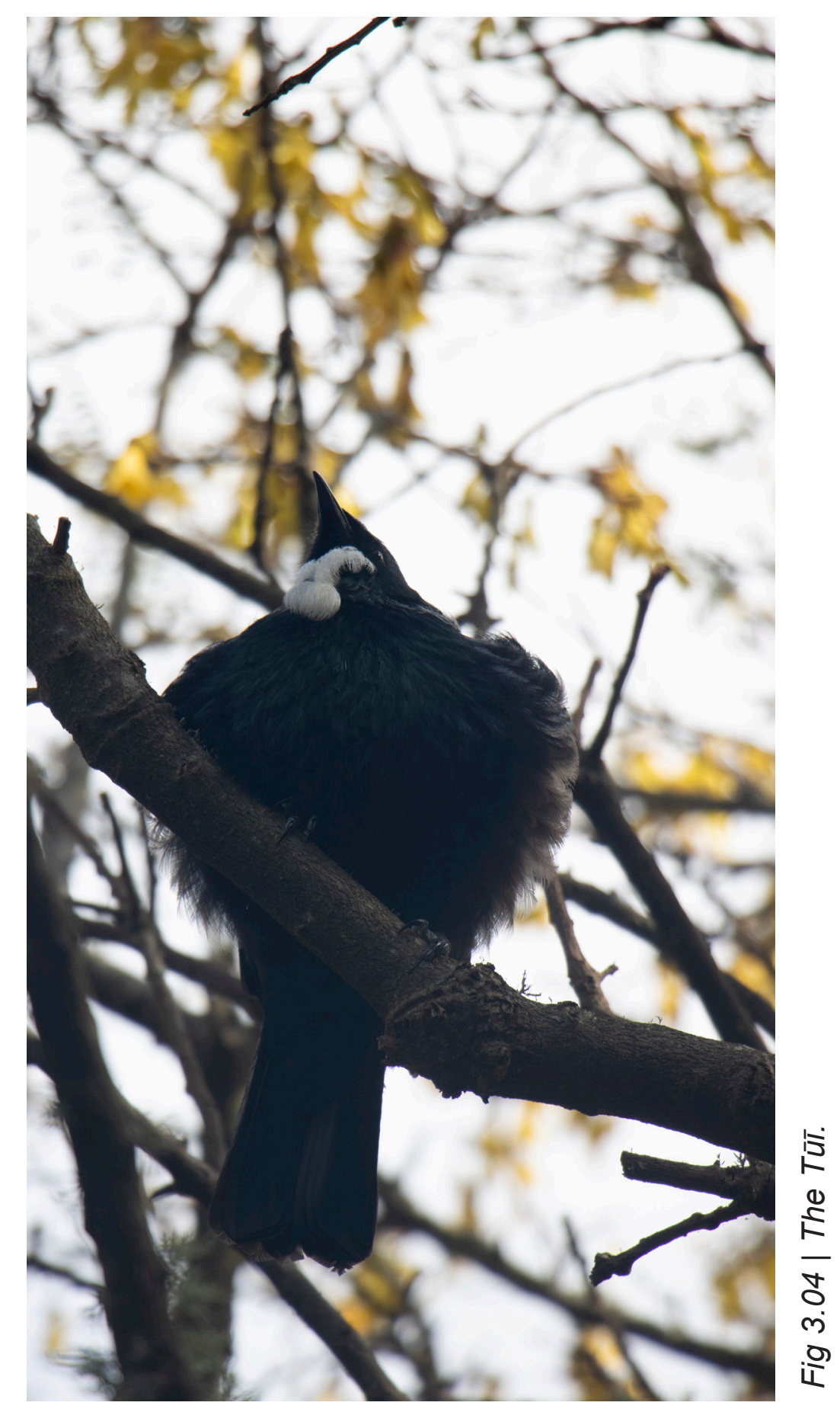

\section{$+\quad T \bar{U} \bar{I}$}

Prosthemadera novaeseelandiae

Physical

A very large bird, it can grow to $30 \mathrm{~cm}$, however the males are larger (Penguin Pocket Guides, 1996)

Natural

They are normally found within native forest habitats.

(Penguin Pocket Guides, 1996; Riley, 2005) They prefer the edge habitat for feeding and nesting within the interior of the chosen site (Rastandeh \& Pedersen Zari, 2018). They eat nectar, particularly from the Kōwhai tree (Riley, 2005).

Lifestyle

Breeds late November to Janurary on a bed of twigs or native vegetation (Penguin Pocket Guides, 1996; Riley, 2005). The tūī is considered a keystone species (Payton et al., 2002; Rastandeh \& Pedersen Zari, 2018) and is very active within Wellington. 


\section{+ PREFERrED VEGEtation}

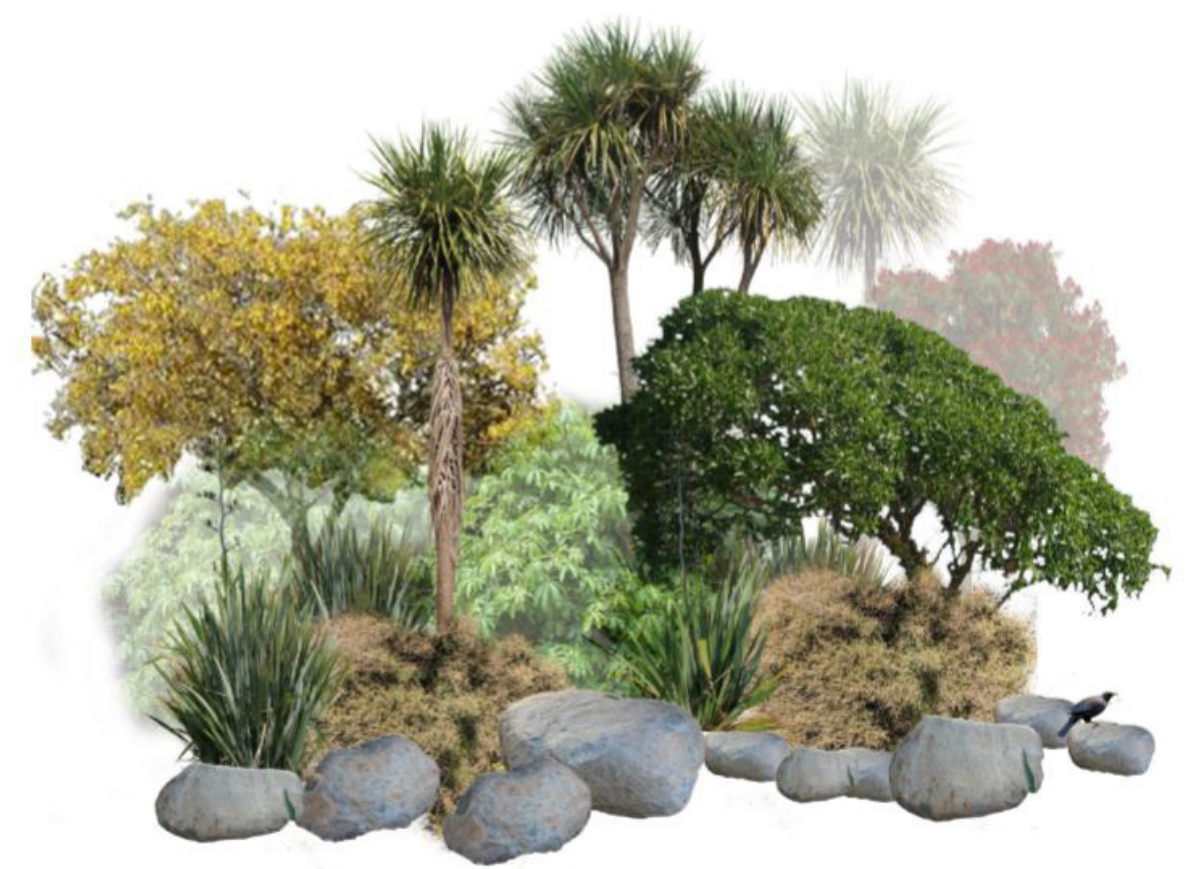

Fig 3.05 | A collage showing a few preferred vegetation species for Tūī.
Carpodetus serratus, Marbleleaf Putuputaweta

Coprosma propinqua var

propinqua, Mingimingi

Corokia cotoneaster, Wirenetting bush, Korokio

Dacrycarpus dacrydioides Kahikatea

Elaeocarpus hookerianus Pokaka

Metrosideros excelsa Pohutukawa

Myoporum laet

Ngaio

Passiflora tetrandra, NZ

Passionfruit, Kohia

Pennantia corymbosa Kaikomako

Phormium tenax, NZ Flax Harakeki
Fuchsia excorticata, Tree Fuchsia, Kotukutuku

Grevillea robusta, Silky Oak

Griselinia littoralis, Broadleaf Papauma

Lophomyrtus obcordata, Native Myrtle, Rohutu

Metrosideros diffusa, Climbing Rata, Akatea

Pseudopanax arboreus, Fivefinger, Whauwhaupaku

Pseudopanax colensoi, Mount Fivefinger

Pseudowintera colorata, Pepperwood, Horopito

Schefflera digitata, Sevenfinger Pate

Sophora microphylla Kowhai 


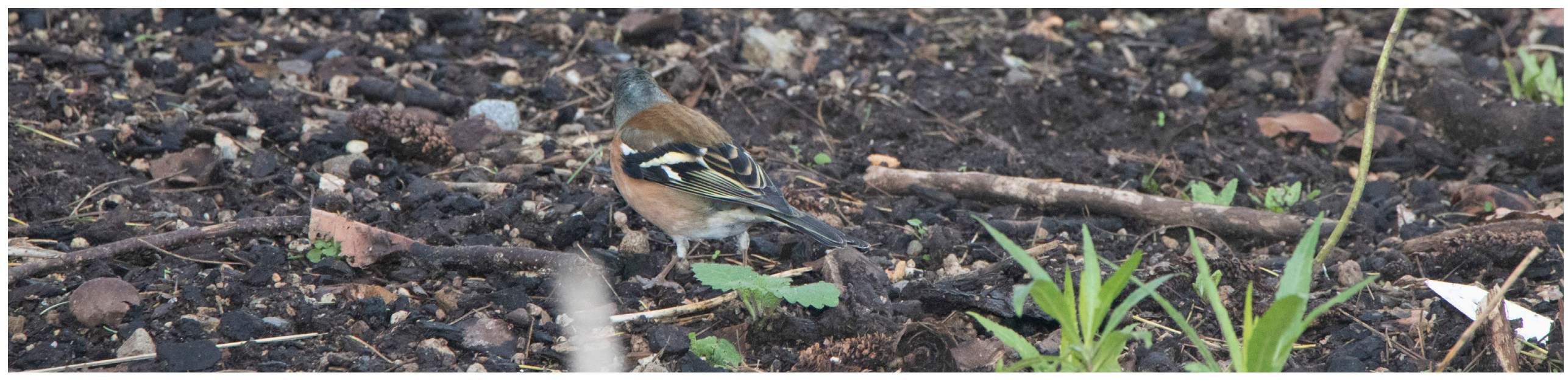

\section{$+\mathrm{HIH} \mathrm{I}$}

Fig 3.06 | Female Hihi.

Notiomystis cincta

\section{Physical}

A rather small bird at $19 \mathrm{~cm}$ (Penguin Pocket Guides, 1996).

\section{Natural}

They are normally found within native forest habitats.

(Penguin Pocket Guides, 1996) They eat nectar, particularly from the Kōwhai tree (Penguin Pocket Guides, 1996).

Lifestyle

Breeds within branches and truncks of trees (Penguin Pocket
Guides, 1996). The hihi is considered a keystone species (Rastandeh \& Pedersen Zari, 2018) and is very active within Wellington. 


\section{+ Preferred VEGEtat I ON}

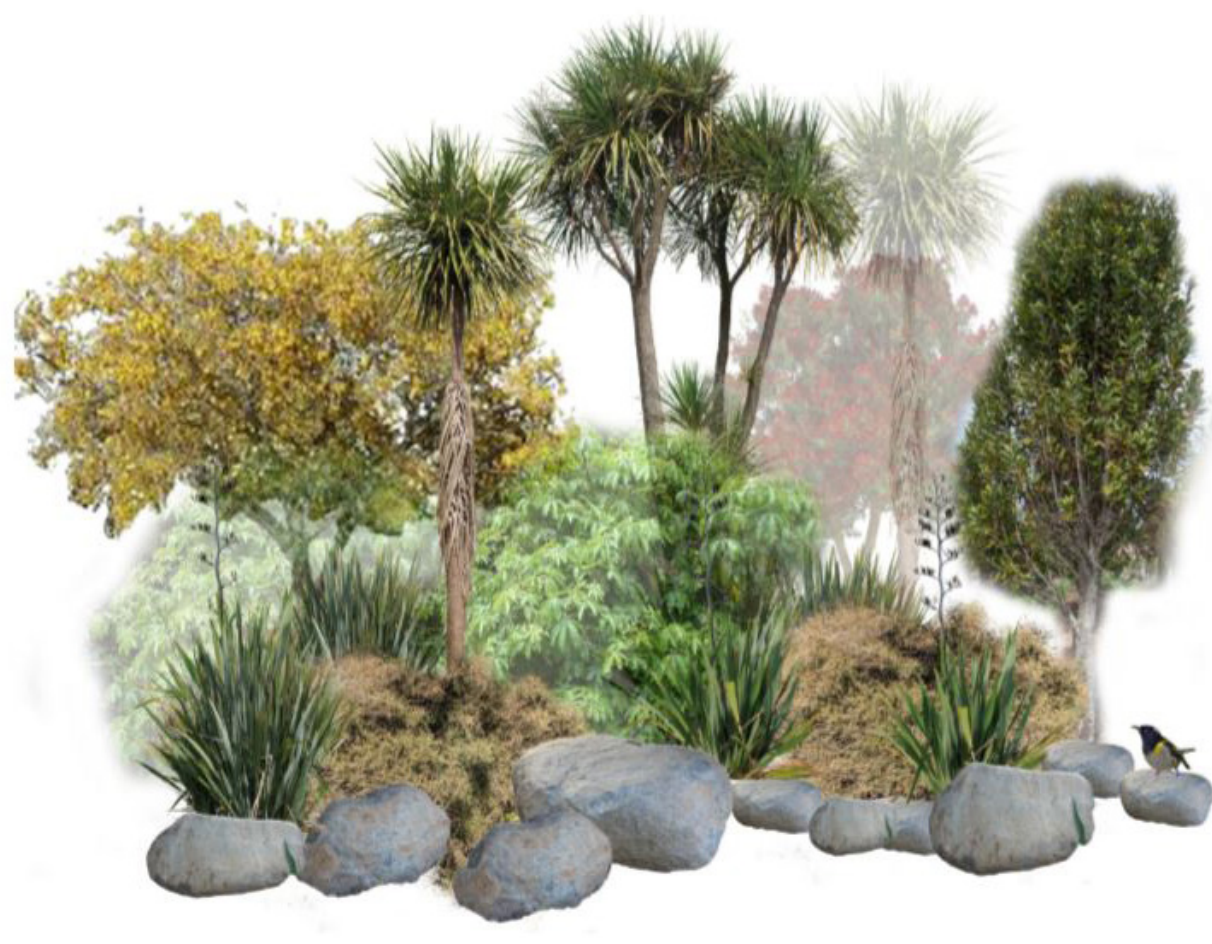

Fig 3.07| A collage showing a few preferred vegetation species of the Hihi.
Carpodetus serratus, Marbleleaf Putuputaweta

Coprosma propinqua var propinqua, Mingimingi

Metrosideros excelsa Pohutukawa

Myoporum laet Ngaio

Pennantia corymbosa Kaikomako
Pseudopanax arboreus, Fivefinger, Whauwhaupaku

Pseudopanax colensoi, Mount Fivefinger

Schefflera digitata, Seven Finger, Pate

Sophora microphylla Kowhai

Phormium tenax, NZ Flax Harakeki 


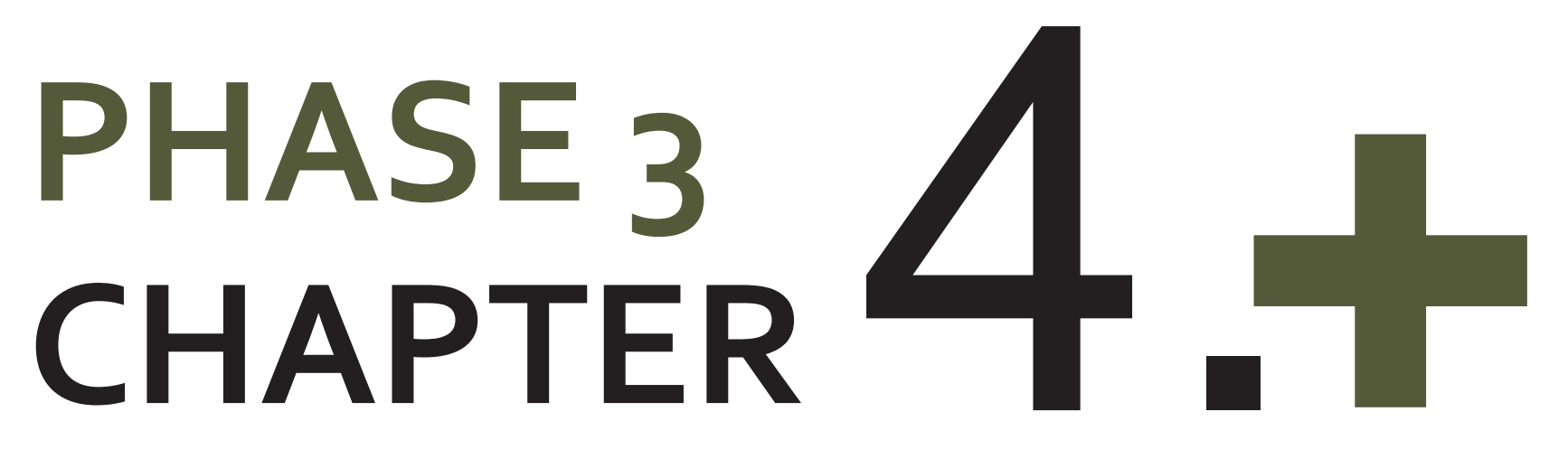


This phase consists of the initial designs that were created early in the year. They were iterative designs, experimenting around basic spatial bird interactions and the establishment of stepping stones within a Wellington context.

Starting with the three week thesis, designs are separate from a collective theme and therefore are only conductive by forming typologies to address later in the thesis. This was the first unofficial review of the year.

The second review was where the first attempts at starting to work with a theoretical basis began. More formal than the last, it still did not contain specific locational designs. 


\section{+ ThREE WEEK THESIS}

\section{Purpose:}

Belonging to the Master's stream EDL, Ecologies Design Lab, there is a process that is undertaken to kick start the year. During the Three Week Thesis, the goal is to do as much as possible within the three weeks and then lead a seven minute presentation to the other supervisors and students in the stream.

The aim of this process is to complete a wide range of work in a short amount of time, with less restraints than what designing further along in the year will entail. However what this quick start really emphasises is pushing a tiny idea into tangible design iterations. As it is so early on in the year, no site allocation had occurred or even a common theme established, so this was a way to really experiment with how the year could advance.

\section{Key findings:}

$+\quad$ There is an abundance of existing green spaces with Wellington, with a variety of flora that creates a diverse range of habitats, each targeting the requests of individual species.

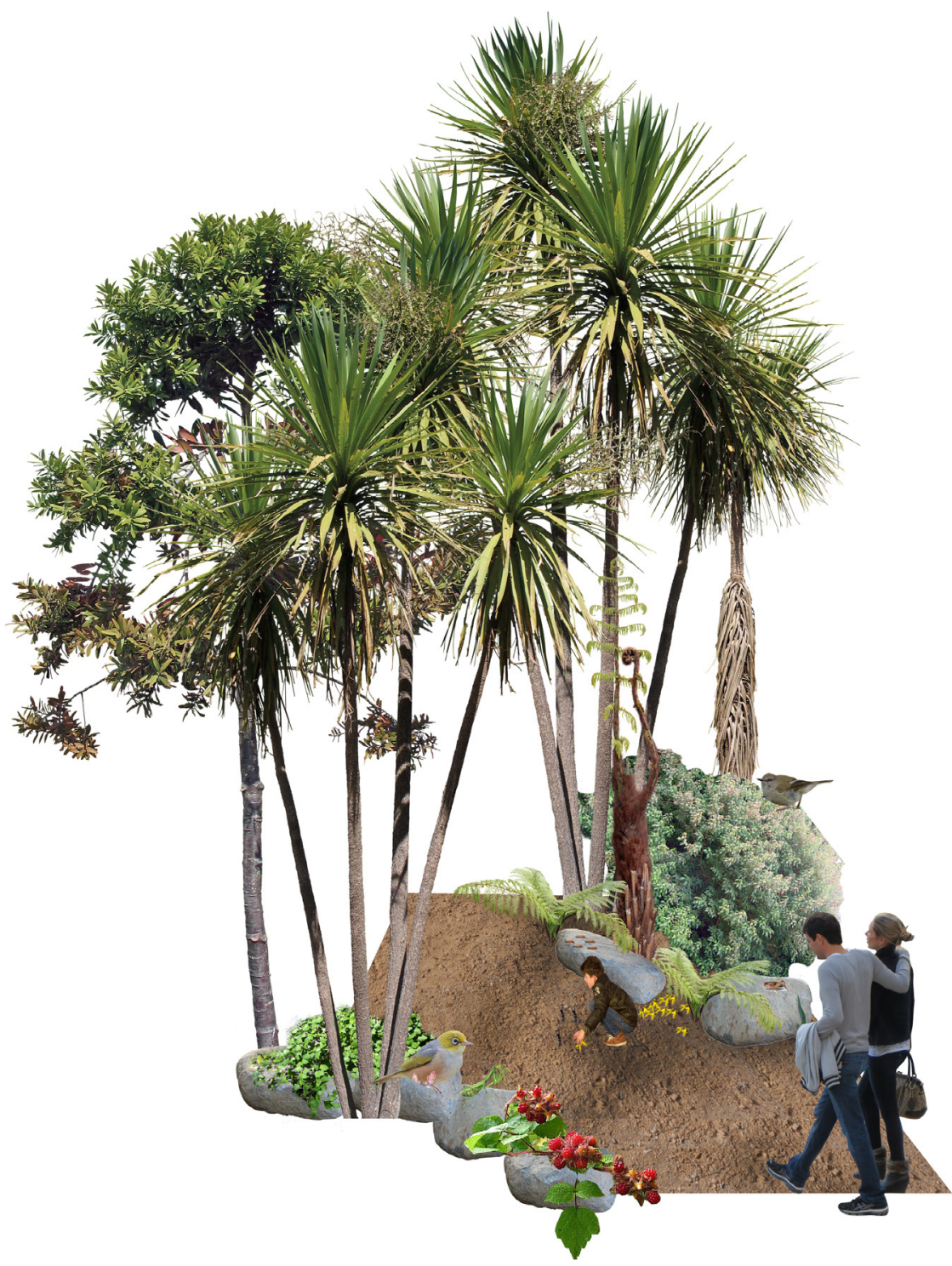

Fig 4.01 | A spatial render that aims to communicate an informal pathway within vegetation. 
+ Birds do not go everywhere; looking into sightings of different irds proved that some species either are not able to travel far distances or the natural environment does not provide for them.

+ There is already a large collection of native bird species in Wellington, it is not something that needs to be gained. However, what needs to occur is designing and allocating spaces for them.

$+\quad$ There are no direct walking links to the existing green spaces, as the distances are far. However, smaller locations link, coupling them in small groups.

$+\quad$ Looking within existing green spaces, formal pathways guide towards locations to observe wildlife, however informal pathways and personal investigation can lead towards the chance of accidental interaction with wildlife (Fig 4.01 and 4.02) This is going to play a huge role in future design iterations as it can differentiate one site from another.

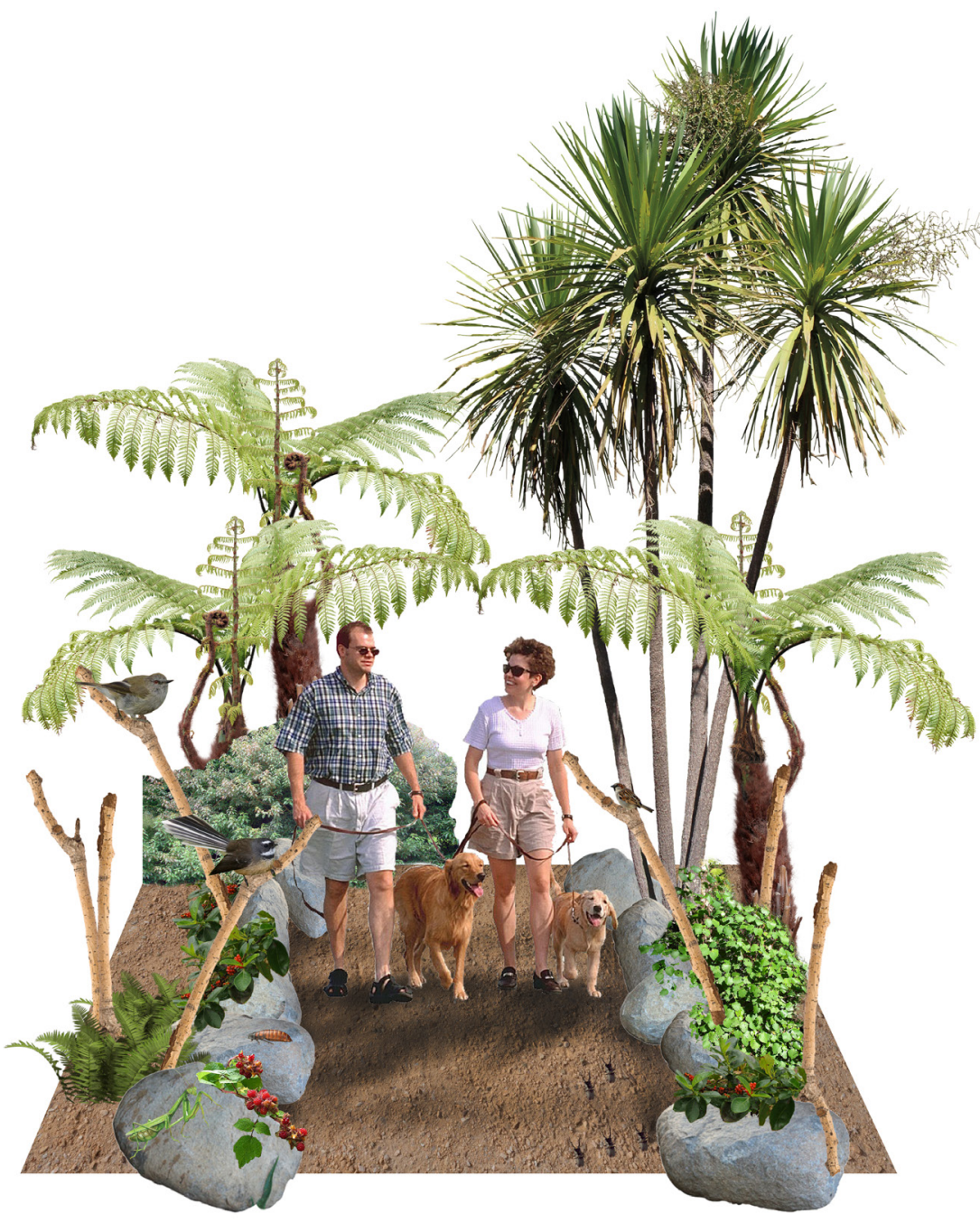

Fig 4.02 | A spatial render that aims to explore ways people can move along a pathway within an under story. 


\section{Results/Critical Insight:}

One of the main areas of feedback that was given, pertained towards more consideration around the drivers and benefits that this type of research could have, not only for wildlife, but also for the future of Wellington. Knowing this, future iterations will be linking back to the wider ecological, physiological and nationwide benefits for both humans and wildlife.

What designs were presented were very simple and similar to some of the precedents that were shown. Therefore the most important information that was discovered, were the typologies that were derived from the information the literature and precedent studies summarised (Fig 4.03). They provided parameters that limited the designs but also showed the most potential that was possible.

Perhaps the most crucial of discoveries was the development and growth from one single location to a series connected via
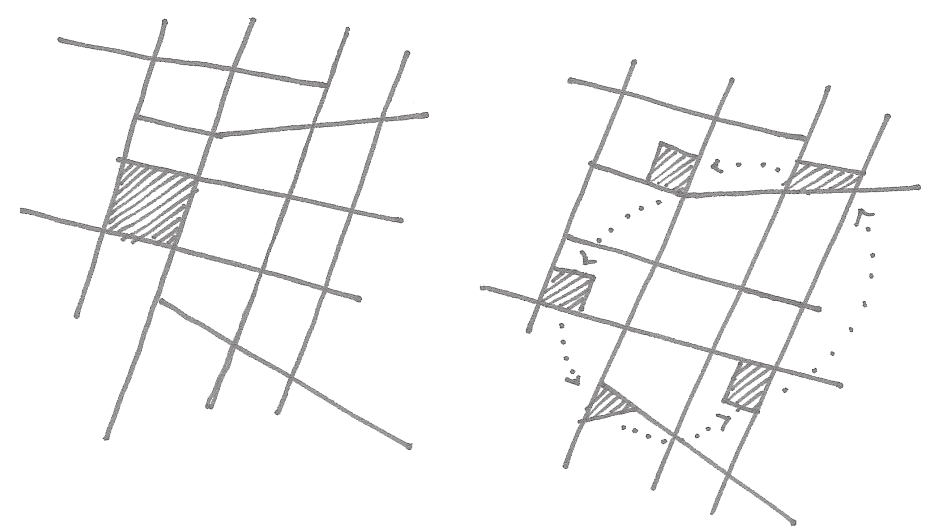

Fig 4.03.1 | Networked Green Spaces
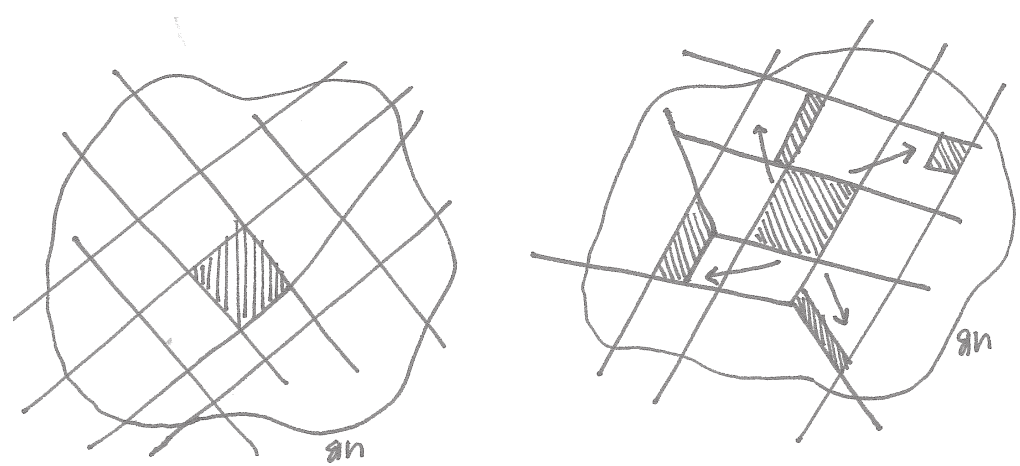

Fig 4.03.2 | Dispersed Hubs

Fig 4.03 | Drawings of the typologies that were gathered from an initial precedent analysis.

a multi-use pathway. As this took place towards the end of the quick start to establish, it was not explored fully, therefore making it the next to explore. This helps to provide different scales to work at, to have a multi-layered design that relies on different levels of interaction (Fig 4.04). 


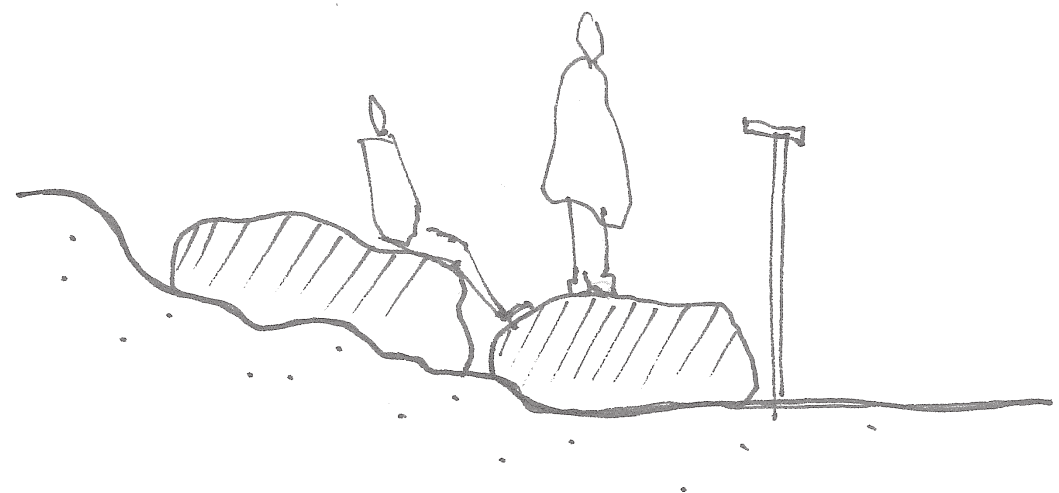

Fig 4.03.3 | Informal Pathways

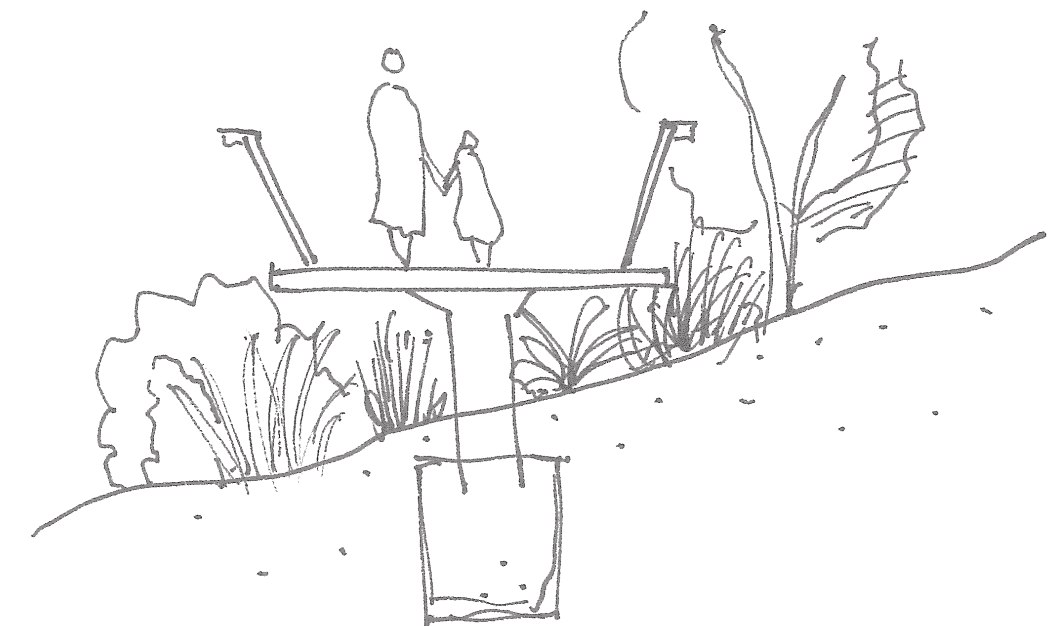

Fig 4.03.4 | Formal Pathways

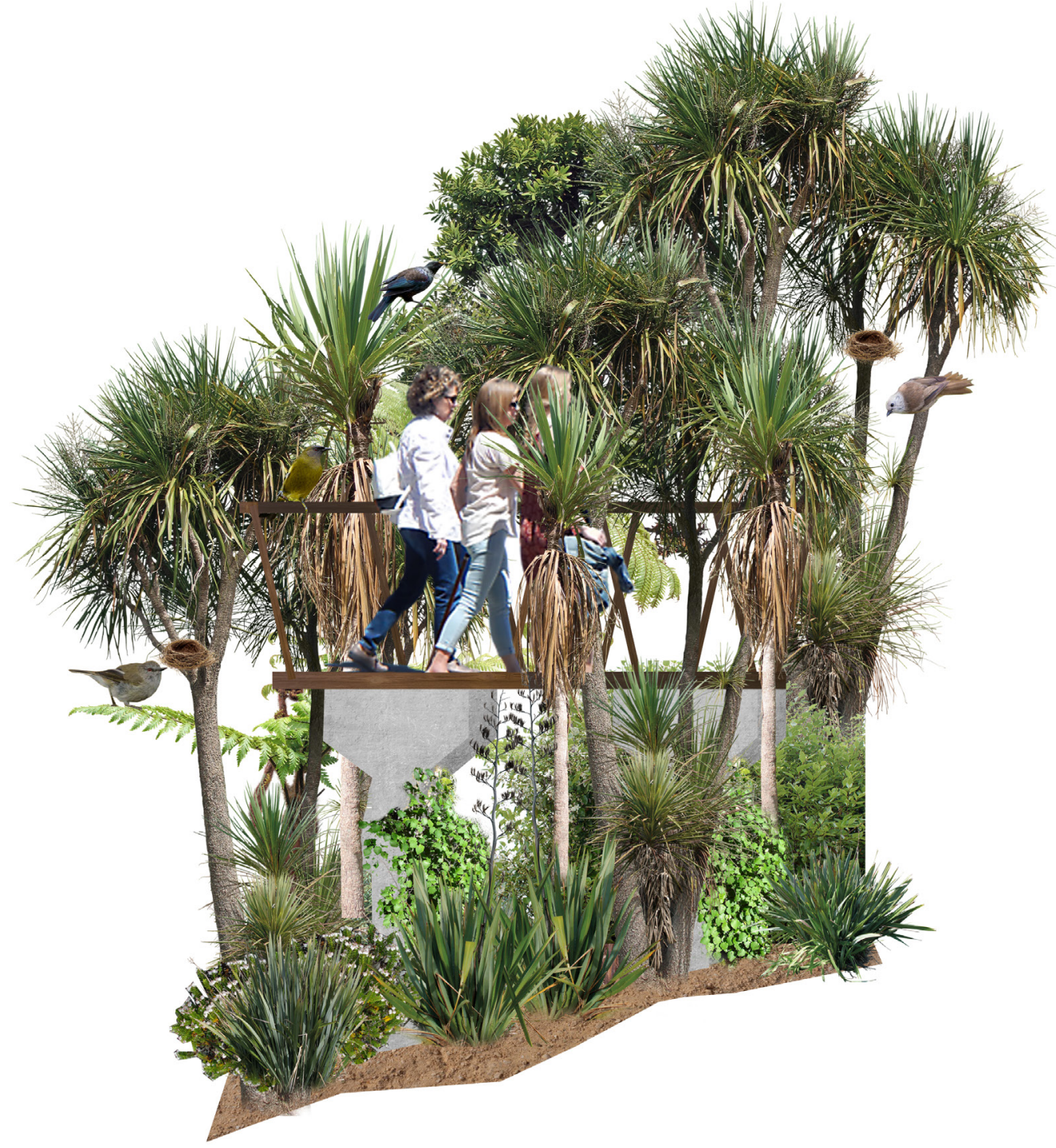

Fig 4.04 | Another spatial render that aims to communicate facilitating different levels of interaction in vegetation. 
+ REVIEW \# 1

Purpose:

The aim of this presentation was to present to senior members of staff that are not aware of the project thus far, to work on communicating ideas and testing the perceived viability of design. As a Landscape Architecture student, this was an opportunity to see if these ideas were able to cross disciplines, by having reviewers that were within the Architectural field.

At this stage of the design process, there was establishment of three design scales, with heavy focus towards the macro and meso. Changes from the last review mainly focused on the scope and site locations for the design. More attention was given to literature that had worked with stepping stones previously, to provide a guideline to determine possible sites with a species orientated focus. Working within the meso scale was very general, establishing typologies that can then

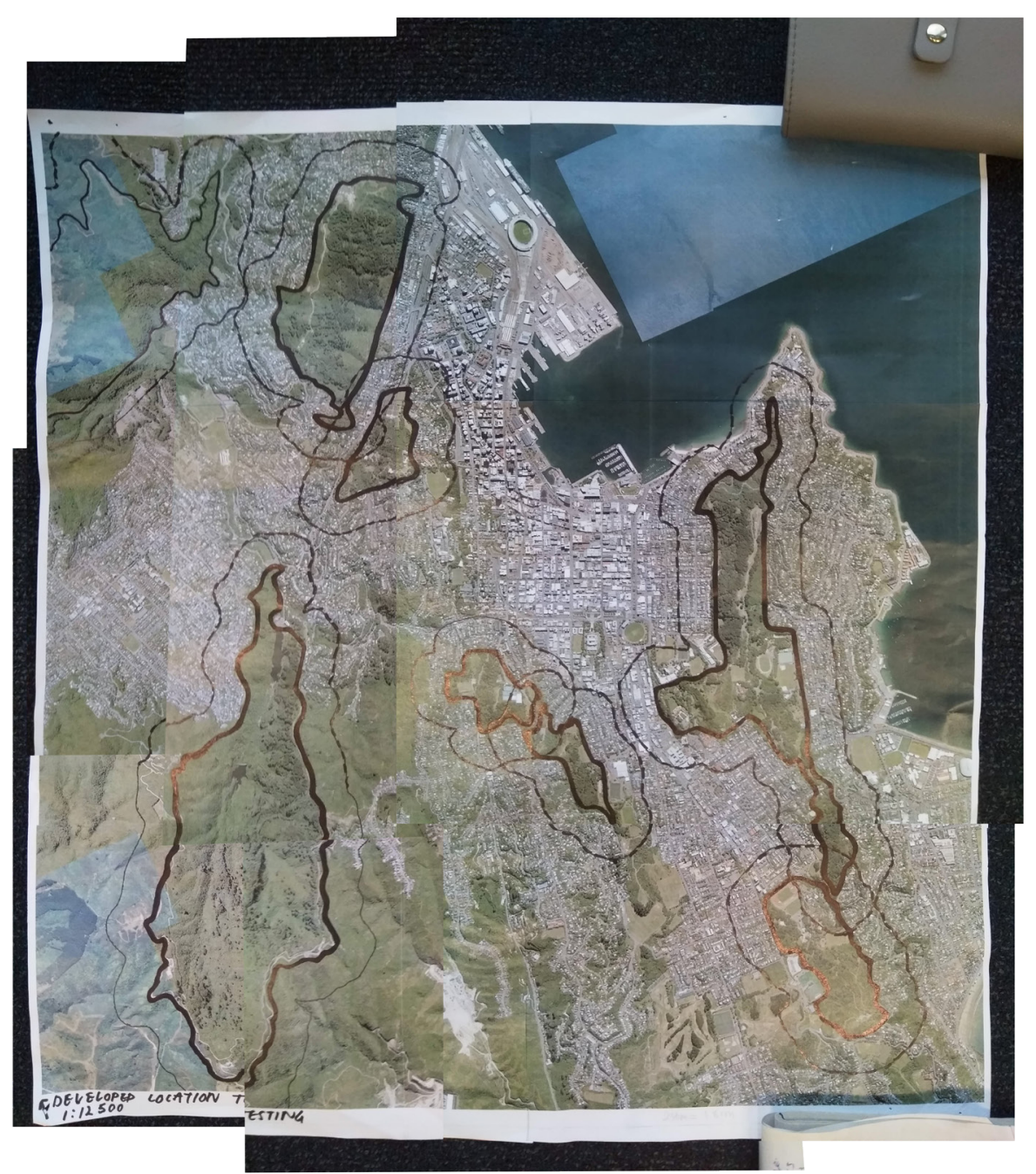

Fig 4.05 | The initial attempt at using Kererū flight patterns to determine five stepping stone locations.

later be applied into accurate site locations, fitting the same specifications. Not much development from the Three Week Thesis had occurred for the micro scale. 
Feedback:

\section{People:}

$+\quad$ There needs to be more merging of both scientific ecological information and human parameters. Looking back at the sites to understand what they offer for interaction, not just assuming that everything needs to start from scratch.

$+\quad$ Taking this to a wider scale, there needs to be some base analysis that understands how Wellington as a whole provides for wildlife. What design potentials exist that could be utilised and manipulated was also crucial information to explore.

\section{Scope:}

$+\quad$ At this stage, the scope of the design intentions are very wide. There are five sites with connective journeys between them, (Fig 4.05) with large focus being applied towards the small scale of these spaces. More selection towards the areas that need the most attention should be applied to create a more direct project.

+ More application towards a rigorous structure that provides a set of specifications for actual site requirements should be considered. This is needed to really understand the needs of the species.

\section{Wildlife:}

+ Some suggested that the scope towards birds as a whole could be narrowed down further to a few or one species. To analyse what species are currently offering interaction within Wellington, and use them as a basis for further design decisions. 


\section{Conclusion:}

Going forward with this project, it became clear that attention needed to be paid to the above mentioned issues. Incorporating them into the design process or at least exploring them will provide more rigour, leading towards a more justified and explored topic. Working back through the different scales and continuing to add upon with what has already been accomplished are the areas that need the most attention (Fig 4.06) It is still at a very basic and underdeveloped stage, however this feedback that was given has allowed for the identification of holes and new unexplored opinions to be apparent.

From the review, it has become clear that there needs to be more attention towards the benefits of this type of project. Basic attempts to link humans towards welfare and health positivity should be more grounded in theoretical discourse.

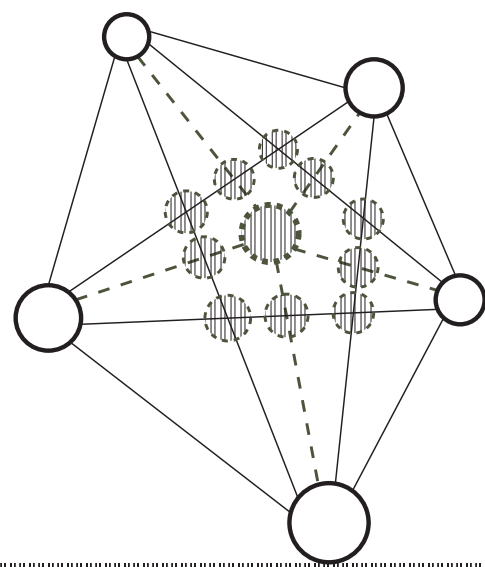

1. Stepping Stones - Macro The actual intended stepping stone location, in the scheme of the wider existing green spaces

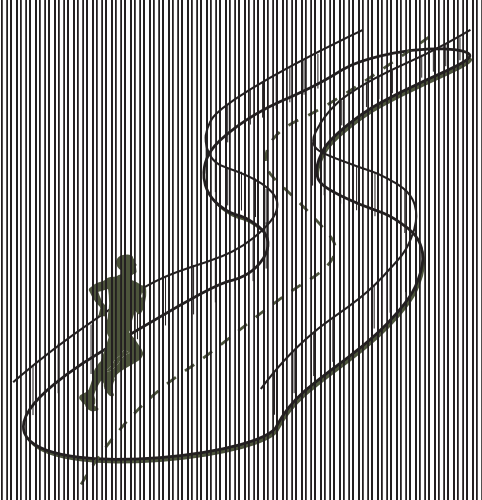

2. Moveable Journey - Meso The journey, or the route between the stepping stone locations, intended to move individuals and wildlife to the SS locations.

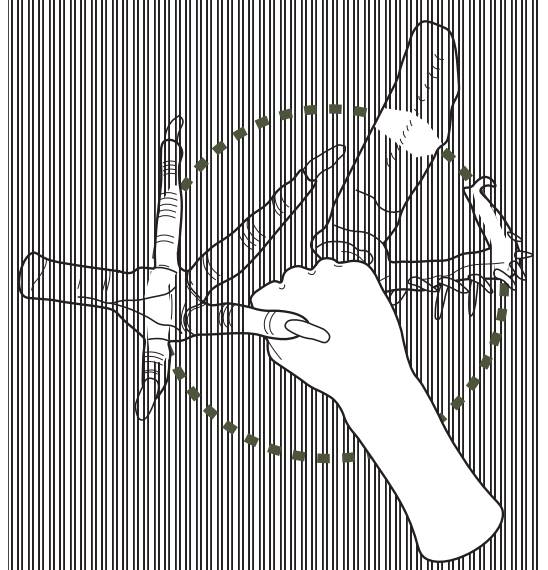

3. Interactive Unity - Micro

Locations where the interactions with humans and wildlife will be occurring. 


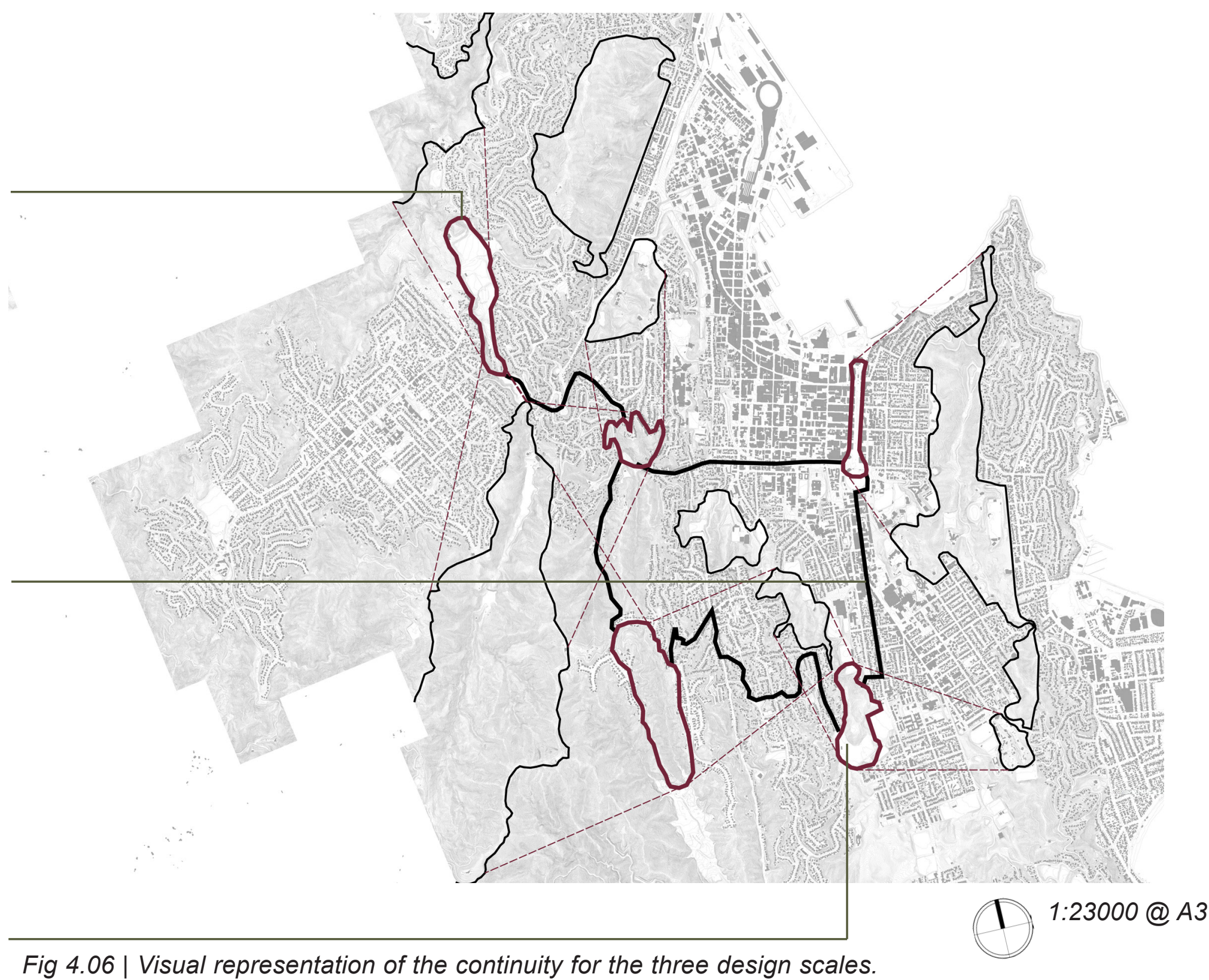

Fig 4.06 | Visual representation of the continuity for the three design scales. 


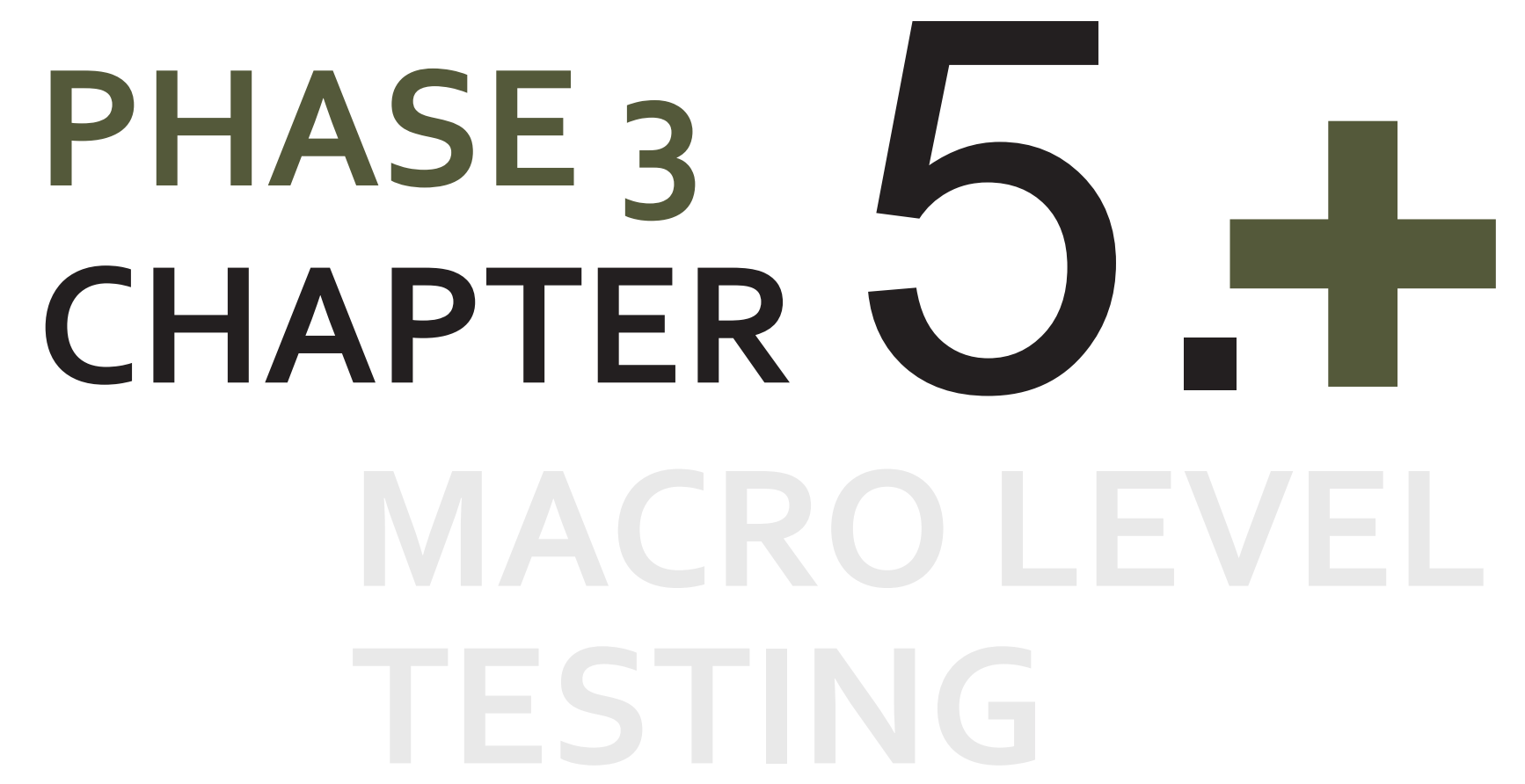



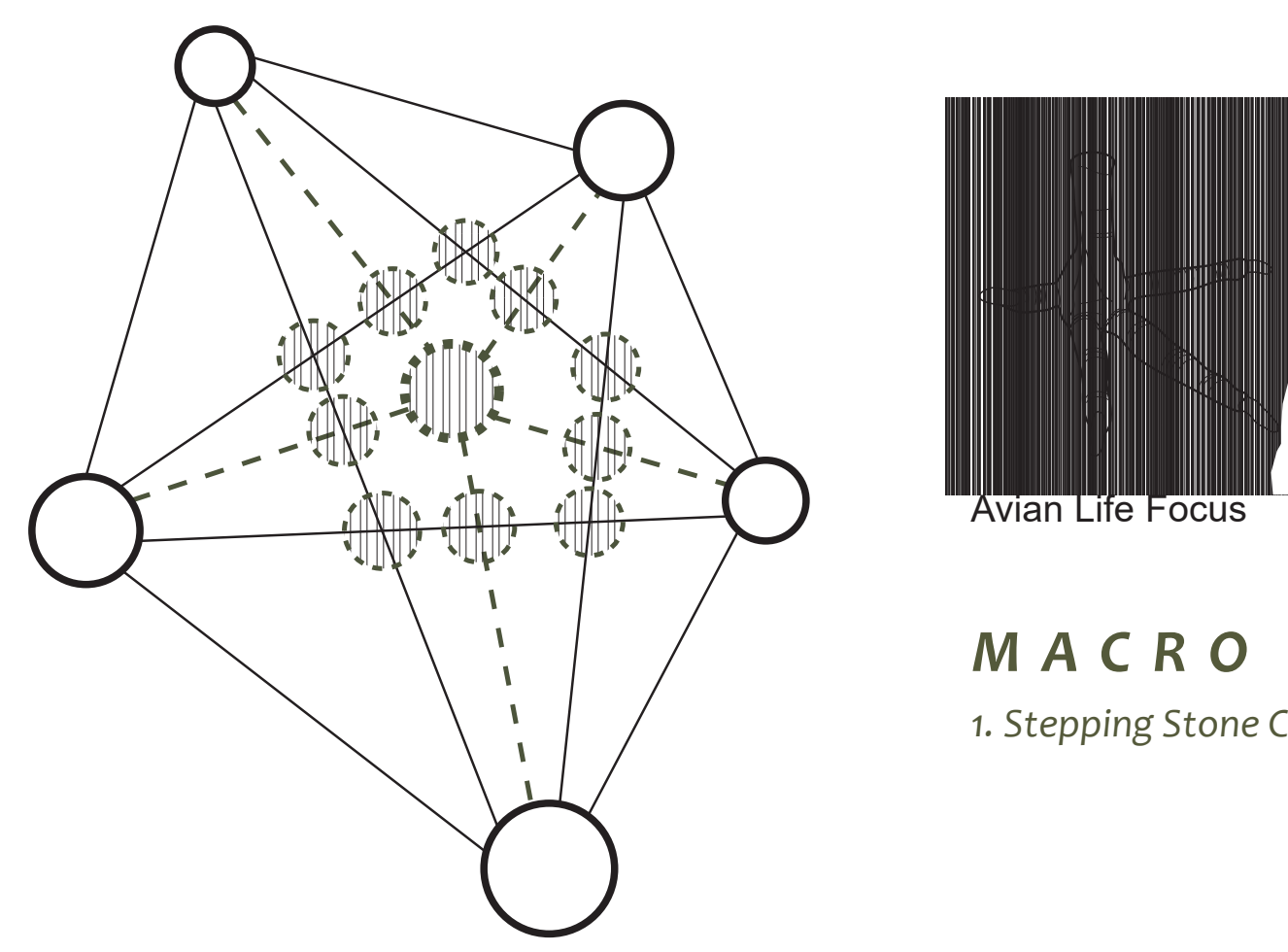

Avian Life Focus

\section{A C R O}

1. Stepping Stone Connections 


\section{+ L I TERATURE REVIEW}

The next question to answer is where within Wellington are the prime locations to develop and adjust further. Considering that one of the two clients are avian species, lead to the decision that they should be the guiding force that determines selection of site. People are curious and exploratory in nature. They can and will travel anywhere, it is the birds that need the justification and scientific reasoning of how and why they might arrive at different locations. With a thesis concerning habitat spatialisation, it became important to apply some reasonable logic towards understanding why specific birds go to specific areas, to determine whether they will arrive at the designated designed locations, as a way to gauge the successfulness of the final design.

A result of the investigation around existing green spaces lead to the visualisation of non-green spaces, especially within urban areas where there were little to no public accessible ecological sites (Fig 2.01 and 2.02) A cause of this could be linked towards habitat fragmentation; where past ecologically lush environments have changed to dense urban settlements, resulting in lost connections between ecological zones (Santiago, 2014). This leads to the understanding that everywhere there is no public urban green space, there is the chance to change the urban fabric to reflect past habitats.

Therefore, the approach must be more subtle, working cohesively with the urban fabric, to maintain the life that currently flourishes. This narrows the scope for finding a site, instead of deciding a location with no restrictions, there are certain limitations that the built form offers, which can frame the selection process. However, there still needs to be a common theme that addresses the problem of how to get avian species to travel and stay in these spaces. 


\section{Stepping stones}

An emerging strategy that starts to address these issues are stepping stone locations. Stepping stones act as a bridge, the in-between of existing ecological habitats, which direct and guide wildlife from one home to another (Santiago, 2014). They can come in many different shapes and forms, from singular 'sites' to a series of corridors that directly funnel the movement of species (Santiago, 2014). This solution works as a piece of a puzzle, where multiple 'stones' work cohesively together, the more numerous, the more successful the spaces will become (Forman, 1995).

This can also be applied to the numbers of individual species, as a way to measure the overall influence the stone can have (Forman, 1995). If this thesis design was going to be enacted in the built world, keeping a record of species count would be a great way to determine whether the site is being used.
However, as this will be a conceptual design, there needs to be other ways to judge the stepping stones related to whether they are achieving the goal of attracting wildlife to an urban site.

Not only determining whether stepping stone locations would work to circulate avian movement, further research around spatial qualities to define potential spaces needs to be considered. Richard T. T. Foreman (1995) labels the stepping stones as patches and suggests a range of measurements that can define the spatial area of these patches which will be discussed below. 
Many or Singular?

Foreman brings forth the debate around patch sizes, arguing the benefits and drawbacks around each approach (1995). He states that when continuing from a larger base, small patches will always have the same habitat conditions as the original, whereas large patches have the ability to grow additional ecosystems (Forman, 1995). However, this applies only if they are individual in nature, only one patch before it reaches the second major existing green space (Forman, 1995). A series of small patches, all intricately linked together, offer the opportunity for diverse habitats to be equal to that of a singular large patch (Forman, 1995). This results in two different ways to have ecological diversity, one singular large patch or a series of small linked patches (Fig 5.01). Forman summaries this with a quick statement: "the bottom line, large patches, large benefits, and small patches, small supplemental benefits" (Forman, 1995).
The current Wellington environment favours a more connective approach. The urban fabric is dense and without demolishing the entire built environment there is no conceivable way to achieve this, however, working within the gaps and unused spaces will offer a more systematic and realistic approach. Gaps could be places that are considered as neglected, such as abandoned buildings, temporary spaces such as carparks or even entire streets.

As with all types of spatial experiences that are closely related to a client, they will differ with slight changes in the client species. Foreman writes, "insectivores (insect-feeders) are more patch size sensitive than seed eaters or omnivores, and long distance migrants are suggested to be more patchsize sensitive than residents or short distance migrants" (Forman, 1995). Therefore, any decision that is made needs to be closely tied to the species in question, crucially 
stating the importance of knowing the species that are being analysed, to design the environment to be exactly what is required. The small details are going to be what defines the space as being habitational to the targeted wildlife (Table 5.01).

\begin{tabular}{c|c|c|c|c} 
& Vegetation | & Water & Shelter & Food \\
\hline Birds & + & + & + & +
\end{tabular}

Table 5.01 | Crucial details that need to be considered when choosing sites for birds.
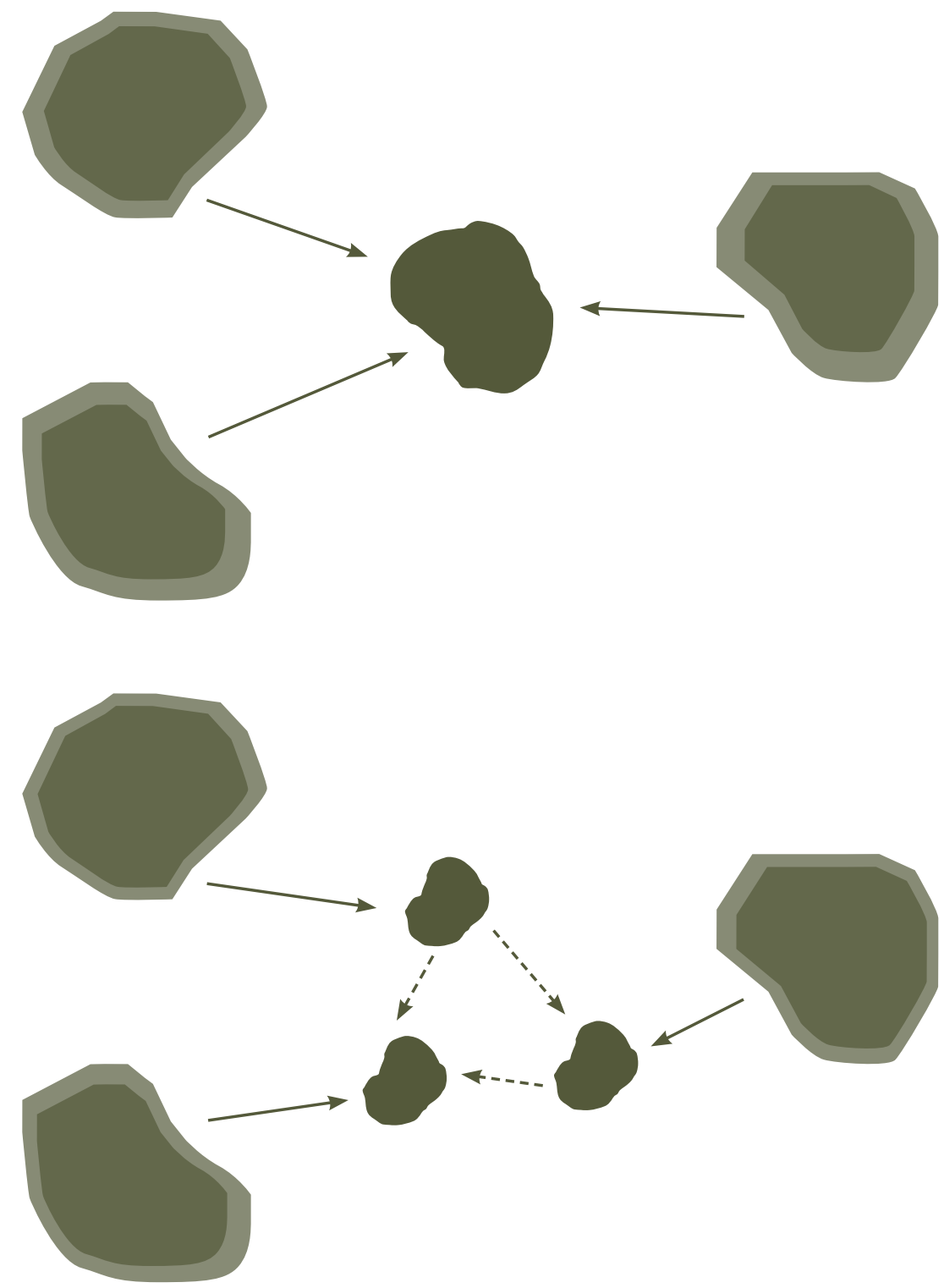

Fig 5.01 | Visual representation of the spatial stepping stones, either one large central stepping stone or a variety of several smaller ones. 
Fig 5.02 | Visualisation of the rings of interaction.

1. Edge conditions, both humans and birds

2. A mixture, more birds than humans

3. Interior, bird focused

Size

With the human side of urban habitats, Foreman suggests that there should be layers of interaction (1995). People should not be allowed to journey within the centre of the site, it should be completely free from any human influence (Forman, 2010). Narrowing it down to three rings, the outer is where both humans and wildlife can roam together, the second is where wildlife becomes more prominent and the inner contains only a varying array of species, no humans (Ecological Urbanism)(Fig 5.02). The differing of patch sizes becomes relevant with this analysis, when Forman states that species which are attracted to smaller sized locations will only be seen in the outer edge of the larger patches, ie different birds are attracted to different layers of the circle (Forman, 1995). Working within this somewhat abstract framework, it can then be assumed that for these rings to make a difference, there needs to be a decent width to them.
3. 2.

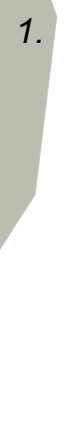

This has been numerically configured when analysing one of New Zealand's favoured birds, the kōkako, that prefers to be within patch sizes that are around 500 ha in area (Meurk \& Hall, 2006). A private bird, this can be excused as avoiding the urban realm.

Looking towards a physical representation of this, Forman (1995) states desired total area of the stepping stone can be different for each type of bird species, "The minimum area point for insect-feeding birds was estimated to be at least 
40 ha (100 acres)[400,000m], in contrast to 2 ha (5 acres) [20,000m]for trees, as well as for seed-eating birds." However, this is not to say that any patch that is smaller will not be successful, just that there are levels of species richness that larger patches are more abundant with (Fig 5.03).

Although the best fit for Wellington is smaller and more numerous patches, this does not exclude the premise for leaving most of the interior of patches for species only habitation. This provides a sense of the scale that needs to be considered when choosing the location within the urban fabric. Therefore the location of the patch, according to volume needs to shift. Numerous small locations will not achieve the density and layers required in comparison to the Wellington context. One central large patch, that connects two existing green spaces, will be more abundant in species diversity. This current issue henceforth, is discovering a location within Wellington that can accommodate this size.

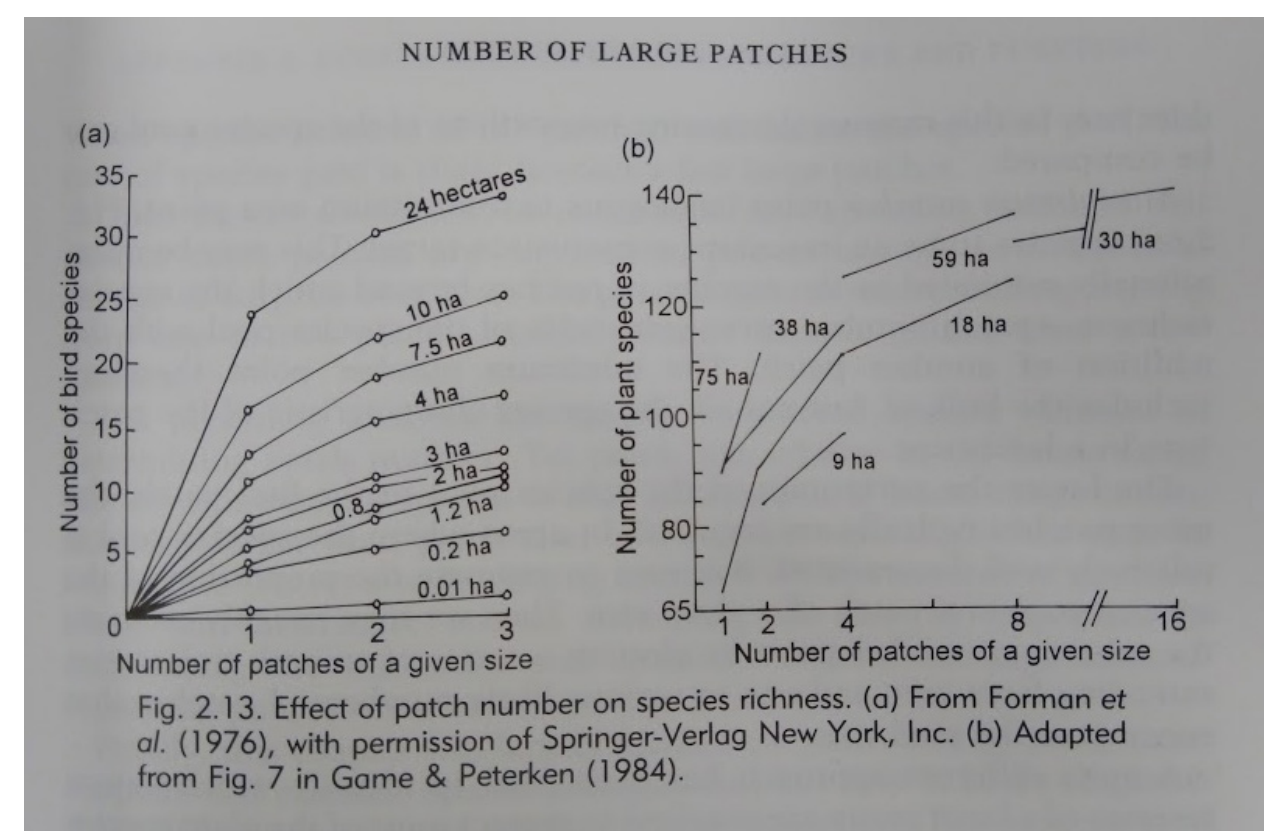

Fig 5.03 | Species richness compared to patch size.

To determine the appropriate form for a Wellington context, research was conducted around whether attempts of the same issues were currently being undertaken locally. Rastandeh (2018) provides some crucial analysis around the importance of allowing the chosen bird species to guide the selection process. He states that: "patch size should not be regarded as the single most important factor in the process of site selection because even small patches of vegetation may provide indigenous fauna with spatially suitable habitats in the face of some impacts imposed by climate change." (Rastandeh, Brown, \& Pedersen Zari, 2018). Therefore this thesis will focus on balancing patch size and species needs. 


\section{Distance}

An area that has not been touched upon yet, is the space between all of the stepping stone locations. Due to the mixture of clients, humans and birds, avian specifications will be the primary defining method of distance. This is a result of the locations being within urban areas, places that people are currently abundant in. Rastandeh (2018) talks briefly upon this where he mentions that distance is going to be relative to the species in question, as different birds can fly different distances. Therefore the distances that birds can fly should be the leading measurement that defines where the stepping stone locations will be in relation to the starting existing green space.

Looking closer to the species that will be investigated within this thesis, consideration will be applied to the differing in overall size. Larger birds can fly a lot further than smaller ones and that needs to be supplemented in the selection of the locations. A thesis that was conducted around the New Zealand Kererū tracked the distance they would fly before depositing a seed (Wotton, 2007). There was a very marginal difference between the minimum and maximum, $61 \mathrm{~m}$ compared to $1469 \mathrm{~m}$, which can be attributed to a variety of different reasons that cannot be defined (Wotton, 2007). This information ended up not being very critical to the productivity of discovering flight patterns, as the reason the bird was flying was because it needed to drop a seed. The data collected would be very different if no seeds were present and the Kererū was flying merely for eating or nesting purposes. Consequently this resulted in requiring a method towards judging flight patterns.

As not all birds are key pollinator species, seed dispersal was excluded. Activities that all birds participate in can be 
simplified down to eating and nesting. Natal dispersal, as defined by (Wittern \& Berggren, 2007), is the movement a species takes when travelling from the original home base towards a different area, as a way to avoid birth defects. An analysis of the North Island Robin, conducted by Wittern and Berggren, resulted in data that showed the main gathering of robins was found in patches that were less than $95 \mathrm{~m}$ from the original nesting base, with most of the data belonging to less than 40m (Fig 5.04). For a very rare bird species, that relies upon conservation methods for survival, this data offers the minimum flight distance when considering natal dispersal. The New Zealand bellbird will fly around $250 \mathrm{~m}$ away from the original home base in search of new breeding partners and environments (Meurk \& Hall, 2006).

This data is very small when compared to Brunton et al,, that state that most native species can average around $50 \mathrm{~km}$
A

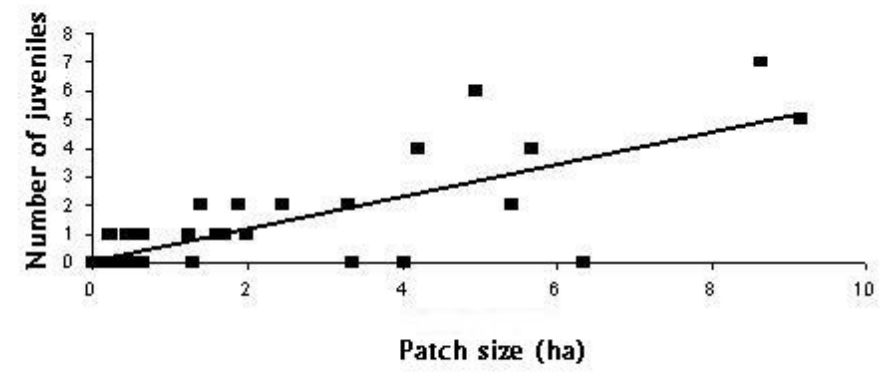

B

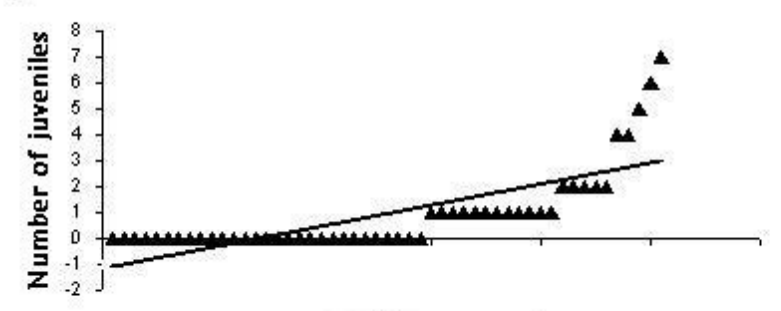

Forest age classes

C

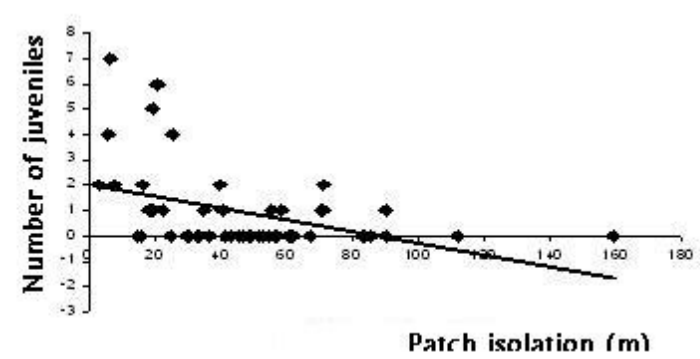

Fig 5.04 | C = Species richness compared to patch distance. 
of flight distance, 50,000m total. Large birds, such as the Tūī, have been classified as "not necessarily constrained by dispersal" (Brunton et al., n.d.) so it is difficult to compare the difference of large bird natal dispersal to smaller birds. Due to this, using natal dispersal as the primary definer of patch distance can be excluded. Habitat fragmentation and stepping stone locations aim towards accommodating species that cannot fly far in individual runs (Santiago, 2014). Natal dispersal is not confined by how far a bird can fly in one go, it relies on total distance from the start to settling space, there is too much data in the middle that is missed. That data could show birds flying and stopping, or even backtracking in distance, there is no way to be certain, therefore natal dispersal will not be used.

Eating, the other factor that can be measured for flight distances can be calculated through simple observations.
Meurk, tracked a Kererū that flew from Christchurch Botanical Gardens to a smaller patch that was approximately $2 \mathrm{~km}$ away from the source (2006). He accredited this towards the Kererū finding plants it needed for feeding purposes away from home base (Meurk \& Hall, 2006). Issues are also becoming apparent around utilising flight distances in relation to feeding habits. If the home space is rich in plant life, specific to the needs of the species, there is not much need for the bird to travel far at all. Another method must be analysed.

Meurk has done a lot of work towards establishing a framework that works within the New Zealand context (Meurk \& Hall, 2006). Fig 5.05 refers to a hexagonal shape that shows general measurements around the balance of patch distance and size (Meurk \& Hall, 2006). When considering that the central patch that all other spaces branch off has an 


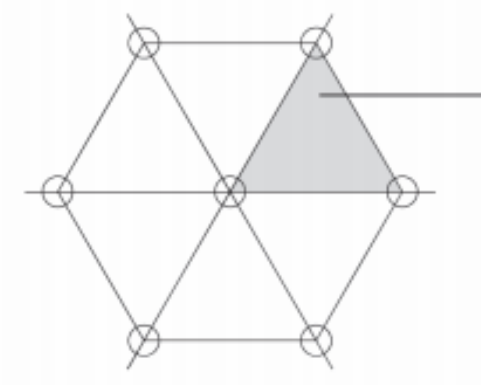

Percentage Patch Area Calculation

Thus $3 / 6$ of patch size in whole triangular area for $6.25 \mathrm{ha}$ at $5 \mathrm{~km}$ spacings -

Area $=1 / 2 \times 5 \times 433 \mathrm{~km}$

$\times 100$ ha

$=1082.5 \mathrm{ha}$

$\%$ area occupied by patches

$=\underline{6.25 \times 3 / 6} \times 100 \%$

1082.5

$=0.29 \%$
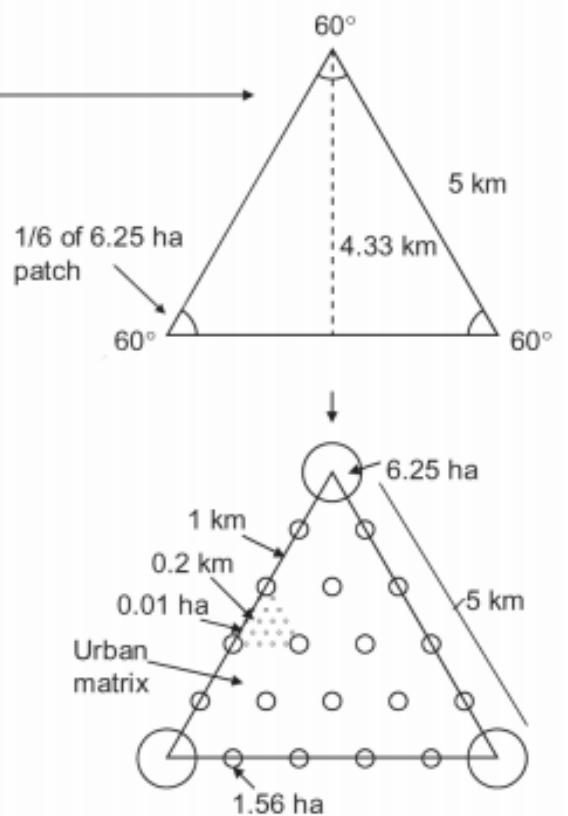

Figure 12. An idealised, nested forest patch configuration of three patch sizes; and method of calculation of percentage area occupied by patches, applied to the largest patch size of 6.25 ha.

Fig 5.05 | A New Zealand focused framework for stepping stone distances and size. area of $6.25 \mathrm{ha}, 62,500 \mathrm{~m}^{2}$ in area, there should be another green space that is equal in size 5000 m away (Meurk \& Hall, 2006). Through this distance smaller locations are scattered between, with a size of $15,600 \mathrm{~m} 2$ in area (Meurk \& Hall, 2006).

Applying these measurements to a Wellington context is rather interesting, as the changes in size impact the effectiveness of the framework. Considering that Zealandia is 225ha in size ("The Sanctuary," 2018) one sixth of this is $37.5 \mathrm{ha}$, a total of six times the extent that the graph is showing, throws the scale of the framework out of proportion. Especially when you consider that the nearest large wildlife habitat, Otari Wiltons Bush, is located only $2 \mathrm{~km}$ away, nearly half of the distance.

Therefore propositions have been made to this existing 
model, to make it more appropriate to the scale of Wellington (Fig 5.06). The original base size has increased from 6.25ha to 22.47 ha, the average of all the existing green spaces in Wellington. Secondly, the spacing between all of the existing green spaces have deceased from $5 \mathrm{~km}$ to $1.177 \mathrm{~km}$, to accommodate for the compactness of Wellington. The average distance between all of the stepping stones is $8.239 \mathrm{~km}$ and when divided by the four, has a distance of $294 \mathrm{~m}$ between each stone.

The main and final issue that came about in this process, is that having four small patches between the existing green spaces as the dense urban fabric would not allow this, as mentioned above. Changing to one larger patch will be is more conductive to restoring biodiversity. Multiplying the small stones by four to create one larger patch makes the final overall size to be 6.24ha in area, as seen in Fig 5.06. 

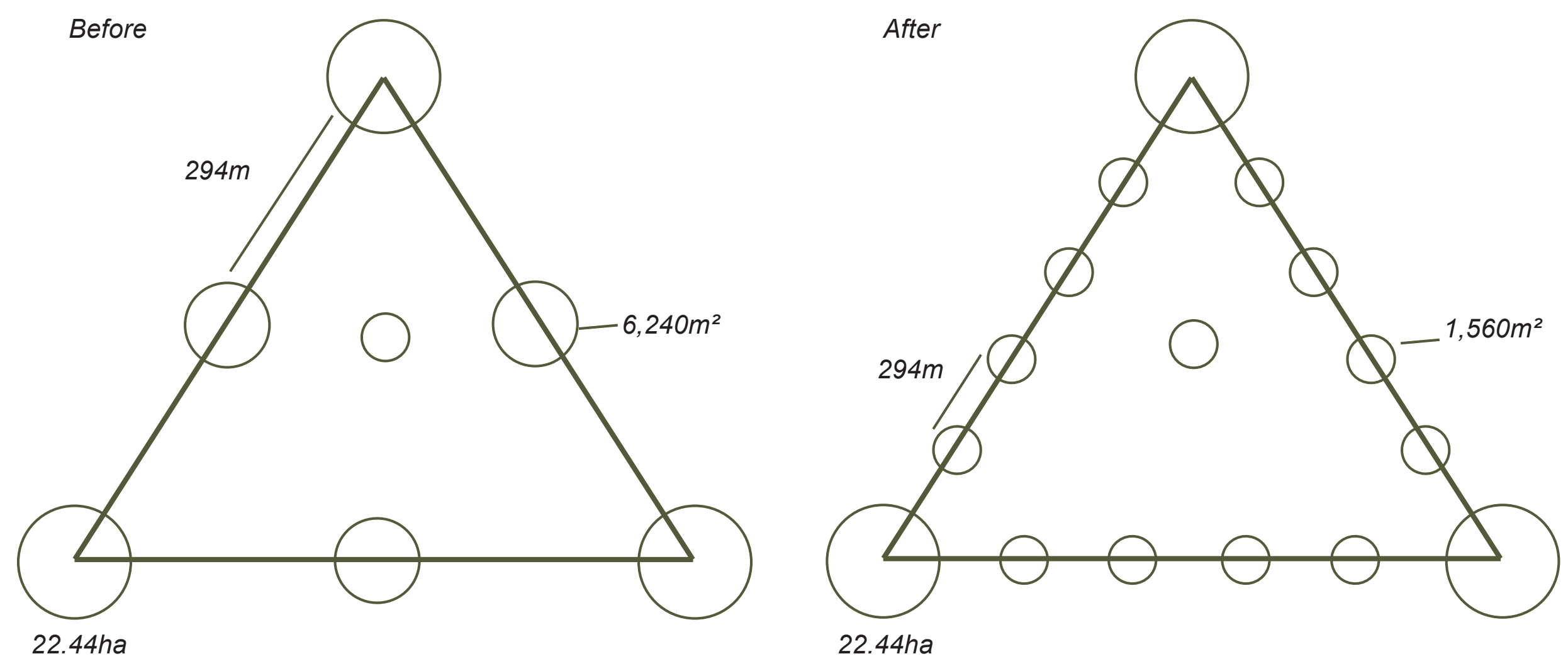

Fig 5.06 | A New Zealand focused framework for stepping stone distances and size. The first is a diagram within the additional changes in area, the second is the final sizes and spacing. 


\section{+ Finallocations}

Overall, this literature based analysis has provided a very thorough final design for determining space within Wellington to locate stepping stones. Adaptation of the literature to formulate how and why this method is the best grounds the project in a way that works well with both clients, particularly the birds. This leads to the final image, (Fig 5.07) to show the five stepping stone locations, as determined by this analysis. A reward of this process is a large variety $n$ urban and rural locations with different configurations.
(D) Wellington's Stepping Stone Locations Fig 5.07 | Scale 1:50,000

\section{Existing Green Space}

Stepping Stone Locations

SS Locational Flight Distance, $294 m$ EGS Locational Flight Distance, $294 \mathrm{~m}$ Sea 


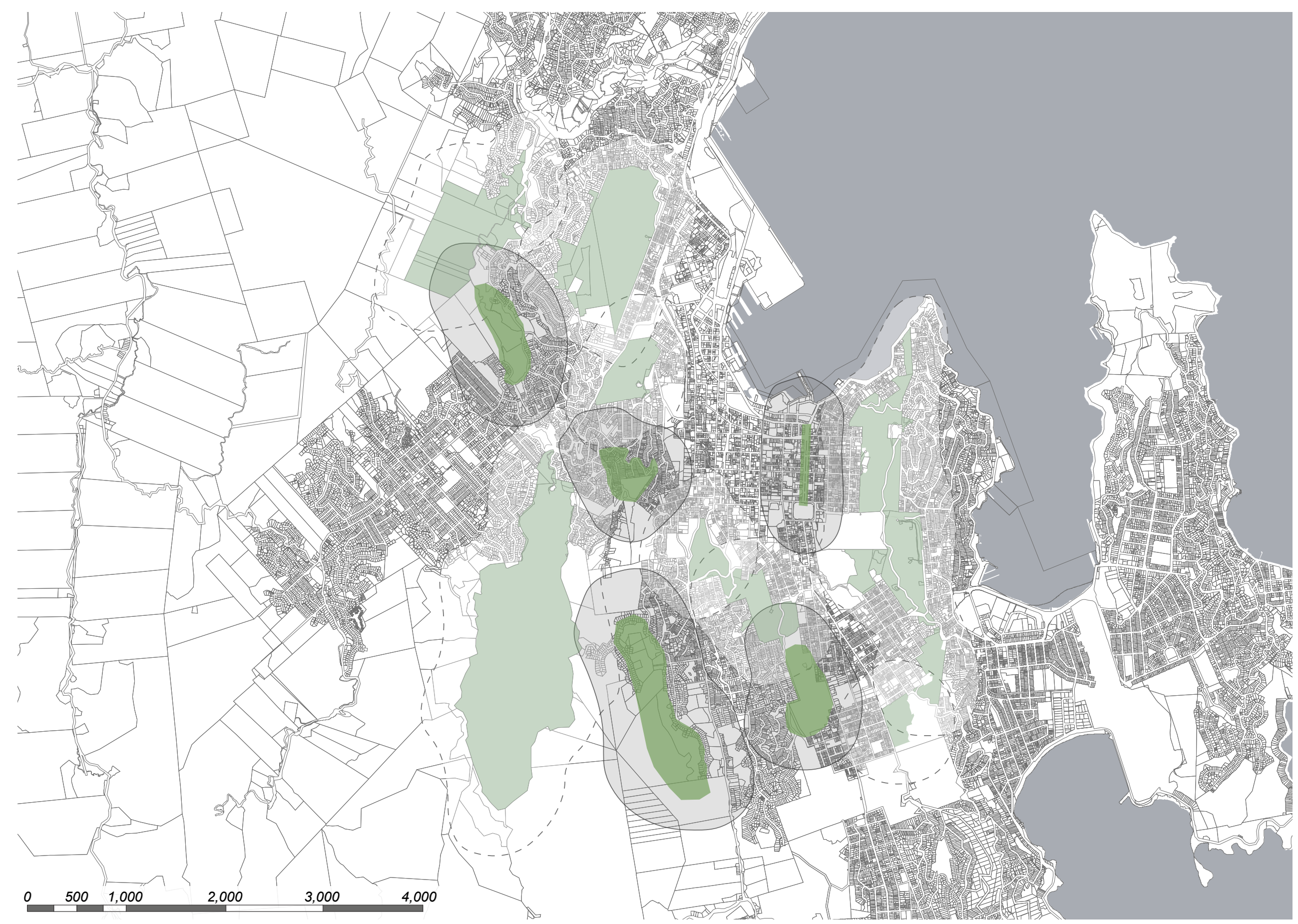




\section{+ PRECEDENTREVIEW}

\section{Stockholm}

Stockholm lies within a unique geographical location, in that the configuration is limited to a series of islands scattered through the Baltic Sea (Fig 5.08). These islands are heavily vegetated with an estimated $40 \%$ of space contributing towards making Stockholm the 7th ranked city in maintained green space (Daniel Maina Wambugu, 2018). As urban growth advances, it became more important to protect these green areas, to which the 'Regional Planning Office' of Stockholm began the Green Wedge programme (Ulrika Akerlund, 2019). This aims to provide a "framework that respects the need to preserve the natural environment, both for ecological and human health" (Alyse Nelson, n.d.). Split into ten different sectors, or wedges, they all have unique spatial qualities that afford different types of experiences, for both humans and wildlife (Ulrika Akerlund, 2019). Due to the openness of the spaces and dual ownership, there is a very large sense of community and togetherness within the city, contributing towards the well-kept natural environment (Ulrika Akerlund, 2019).

\section{Strengths:}

+ Due to the vastness and multiplicities of the wedges, there is a huge emphasis towards biodiversity, both intentionally and unintentionally.

+ With wildlife being a crucial participant in these spaces, Stockholm's council have put in place specific infrastructures that aim to further connect these locations where is has been identified as too large of a travelling distance (Ulrika Akerlund, 2019). They have approached this in two different design methods, with park typologies and heavy vegetation as a visual link mixed with green hubs that work to improve the awareness and access to sites that act as a human utilised physical link (Ulrika Akerlund, 2019). Overall the council are 
working towards providing stepping stone locations and green corridors to further link spaces together for the benefit of human permeability and increasing biodiversity movement.

\section{Weaknesses:}

$+\quad$ As not all of the green space is protected, there is always the slim chance that the land could be used in future urban development (Ulrika Akerlund, 2019). As Stockholm's projected growth aims to increase $4.3 \%$ by 2035 , this will always be a pressing issue (World Population Review, 2019). However, Stockholm have started to discover ways to mitigate this by initiating development strategies that aim to minimise detrimental effects (Alyse Nelson, n.d.).

+ Due to the numerous spread out locations, it is difficult to contain the amount of exposure that nesting wildlife might have to native/local pests.

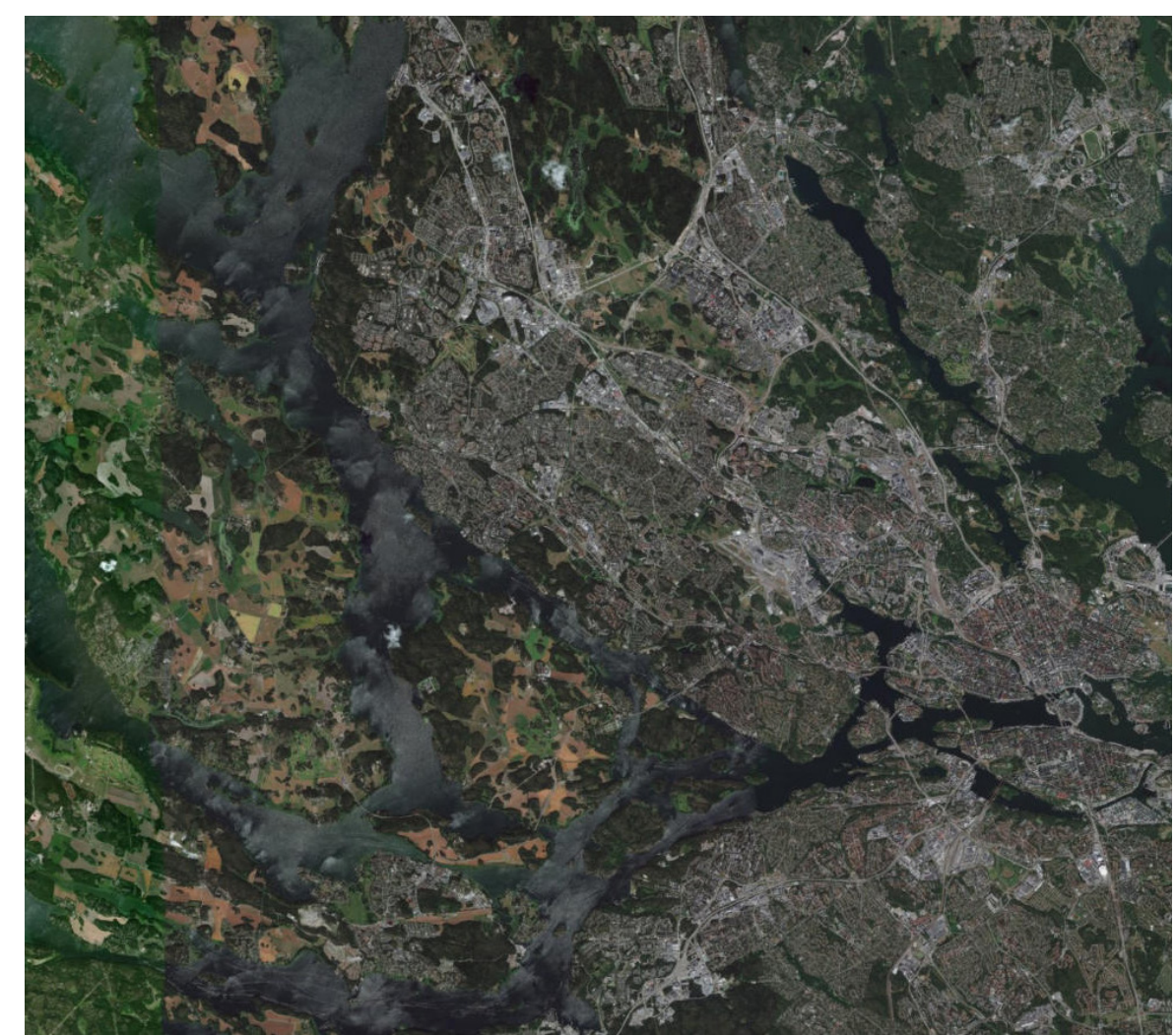

T Fig 5.08| Stockholm map and the visual green wedges. $1: 200,000$ at $A 4$. 


\section{+ PRECEDENTSUMMARY}

From the precedent, a series of spatial suggestions and typologies can be extracted that do not define the spatial configuration with numerical values, like the literature review, but offer suggestions that are relevant when built. The addition of smaller connective corridors are a must, as they provide the physical link to the stepping stones. Although this was already decided, the knowledge that this data is backed up by built form, affirms its relevance. Additionally, the importance of pest management still needs to be addressed in this thesis.

\section{+ CRITICALREFLECTION}

This section of the thesis, although not the most spatially designed, is the most critical regarding the final design. The allocation of space, with complete consideration towards the needs of birds allows the stepping stones to be grounded in fact, therefore theoretically proving them to be successful if implemented, regardless of the interior spatial qualities. The time that it took to establish the facts and provide alternative numerical methods was very long, limiting the amount of time that was spent in other areas of the thesis.

The four main findings are as follows:

$+\quad$ Stepping stone locations are much more complex than initially thought. Considering spacing, size, function and species was a lot to understand in a short amount of time. However, this needed to occur as all other decisions rely on this area being accurate. 
$+\quad$ Although using a framework that has been made for the New Zealand environment, changes still needed to occur. The framework now acts as a guideline that informs the spatial boundaries with a specific Wellington context. If the adaptation of the framework did not occur, patch size, spacing and function would not be accurate, contradicting the effort to understand how it works.

$+\quad$ Bird flight patterns are sporadic and rely heavily upon the intention of flight. It is difficult to judge the behaviour of the species in this regard. Therefore the additional theoretical information, particularly around New Zealand species, was invaluable.

$+\quad$ There should be layers within each stepping stone that allow birds to be solitary within the interior. Some of the locations, particularly along Kent and Cambridge Terrace, have no space for interior habitats. If this process went into more depth, analysis around the different widths of these circular spaces, (Fig 5.05) would have been documented and played a part towards the final selection of the five spaces. Perhaps even excluding Kent and Cambridge Terrace due to the lack of interior habitat. However, for the process of this thesis, this site has been included and even designed, (Chapter 7.2) as it offers unique challenges that have tried to be addressed. 


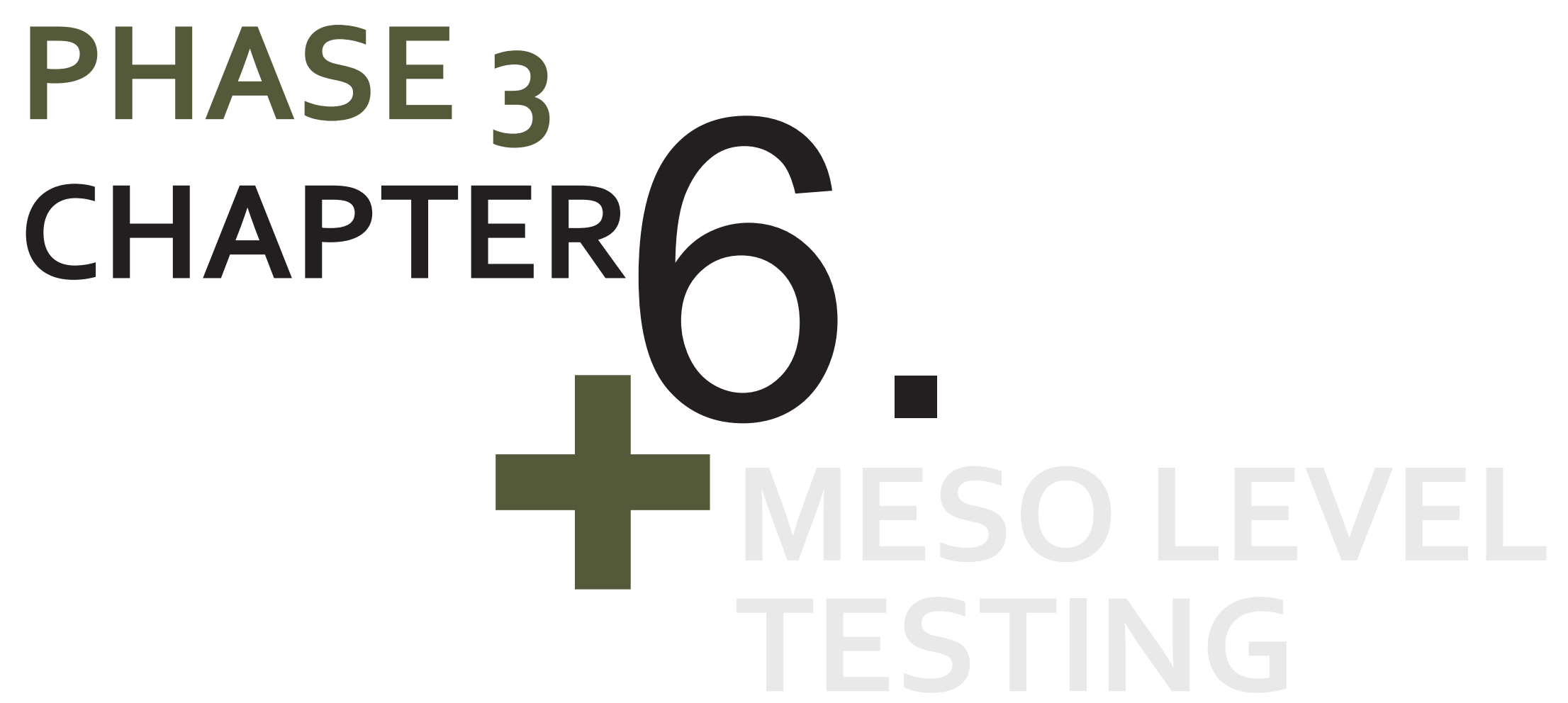



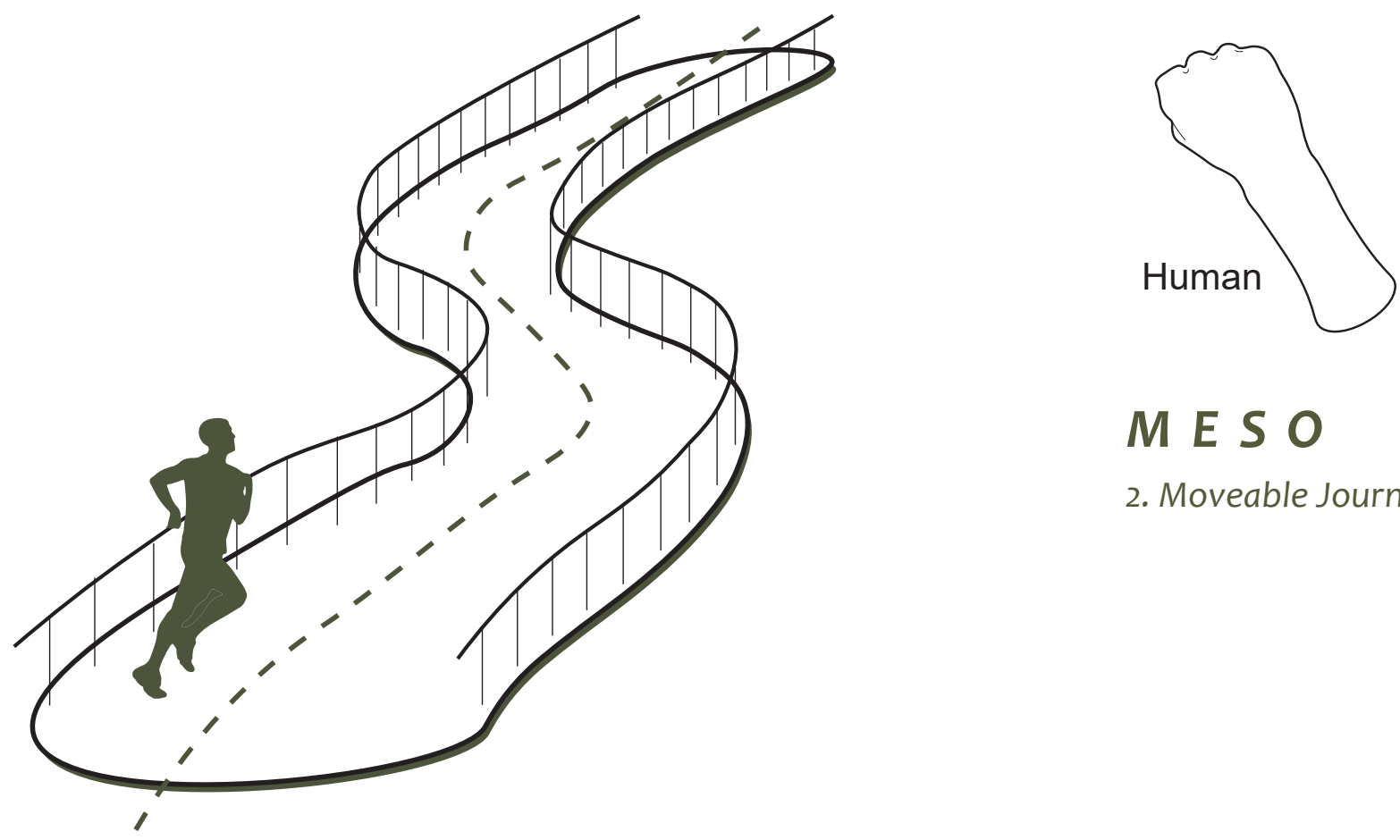

ME SO

2. Moveable Journeys

85 


\section{+ LITERATURE REVIEW}

Supplementary to stepping stones, is the implementation of 'wildlife corridors' which acts as a pathway to bridge the distance between larger habitats (Santiago, 2014). This method acts as a design tool that directly addresses fragmentation of habitat and green environments by providing the missing pieces (Santiago, 2014). It is well known that more green space, particularly when measuring area, has a direct relationship towards biodiversity increases (Rastandeh, Pedersen Zari, \& Brown, 2018). This is a great tool when realising that most species, specifically birds, need to migrate to continue surviving (Fabos, 2004) or like mentioned previously, natal dispersal to find new populations (Wittern \& Berggren, 2007). Green corridors are the safest way to encourage this movement when crossing within the urban realm (Santiago, 2014).

Forman suggests that there are five main roles that a natural corridor plays when implemented, these are habitat, conduit, filter, and source and sink (1995). The most pressing of these is habitat and conduit. Where habitat concerns has been defined as having two different sub categories, line corridors and strip corridors (Fig 6.01)(Forman, 1995). Strip corridors contain interior habitats, like what was mentioned in the Macro Chapter (5) and line corridors do not, it only consists of edge conditions (Forman, 2010). Therefore strip corridors are larger than line corridors to accommodate for the difference in layers. Due to the Wellington context, it can be assumed that line corridors will be utilised, as the streets that will be used are mostly within urban areas, too small to establish an interior habitat.

Additionally to the effects of wildlife population, this thesis aims to maximise people within these corridors. Due to the fact that the corridors are not specifically habitats themselves, 
Fig 6.01| The piecing together of the different connective corridor conditions. The physical representation of these connections will be visible in the model.

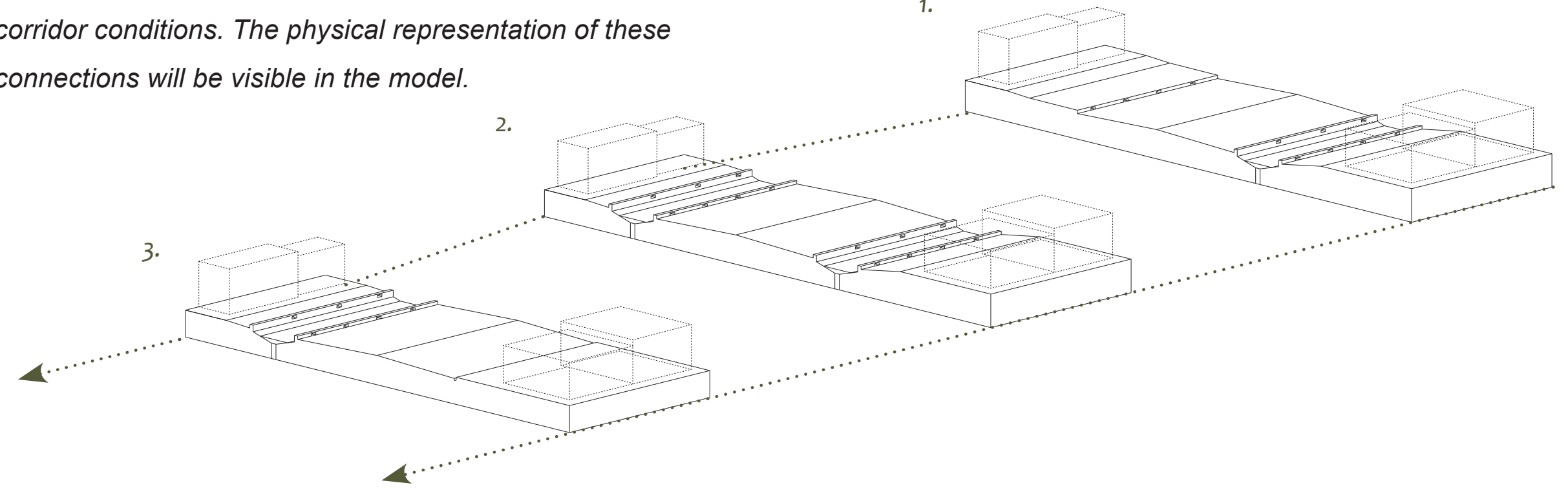

it is very easy to include people within these spaces without many marginal effects. Like a pathway for wildlife, it can also be a pathway for people, unique from the dense urban realm (Fabos, 2004). Various activities, such as cycling and running can be accommodated within these corridors (Fabos, 2004). Fabos, (2004) also suggests that these spaces can become areas that have a lot of cultural identity, due to the location and influence of native vegetation, a connection to the past environment.
1.
Therefore, a strong community and pedestrian focus will be implemented in this section of the design. Due to this, attention needs to be paid to the pedestrian realm. Loops or trails need to have a sense of continuity to them, pedestrians need to feel safe when walking (Engwicht, 1992). This results in a design that places people over vehicular movements, giving power to the pedestrians, specifically around heavy intersections. 


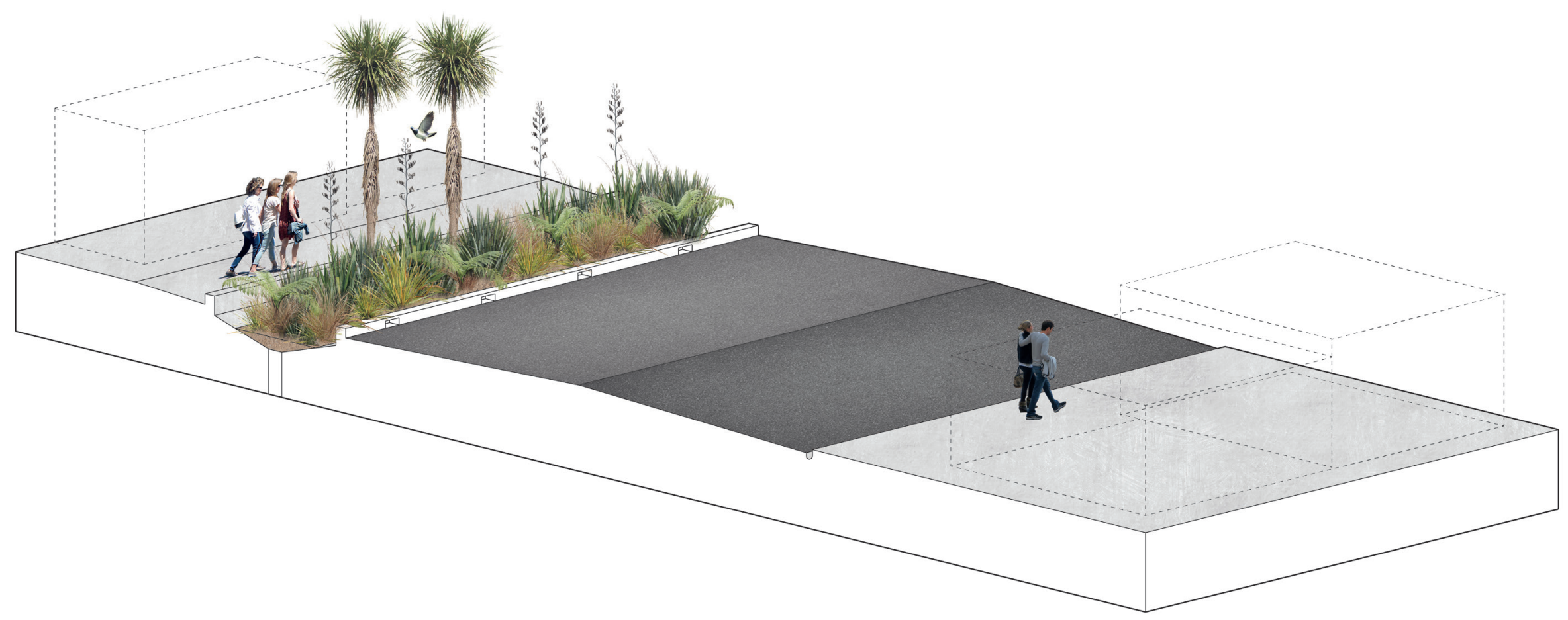

Fig 6.02 | Configuration 1| Taking one side of the road that was used for parking, adaptation of the road has resulted in a completely vegetated area. It is a small habitat, but still acts as a physical funnel to the patches. 


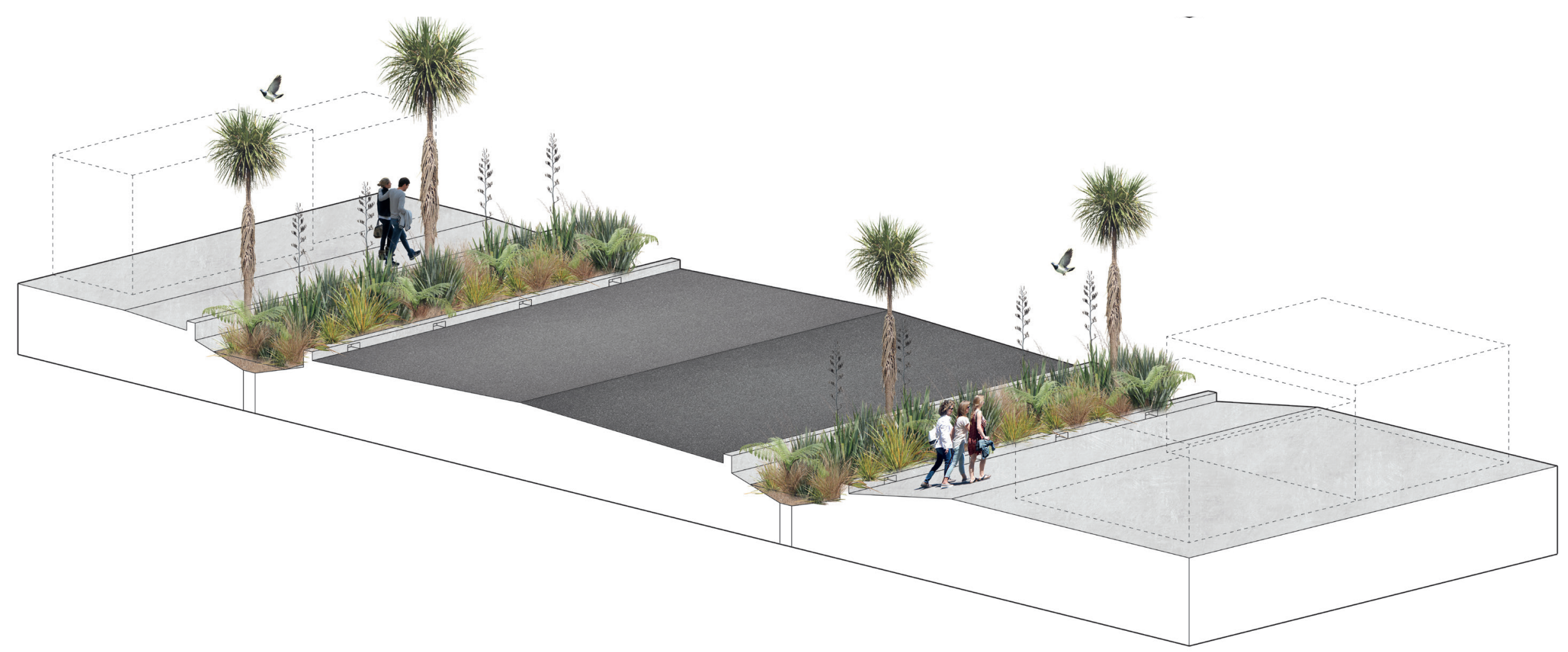

Fig 6.3 | Configuration 2 | Taking both sides of the road that

was used for parking, this habitat is denser and more effective

towards biodiversity issues than Configuration 1. 


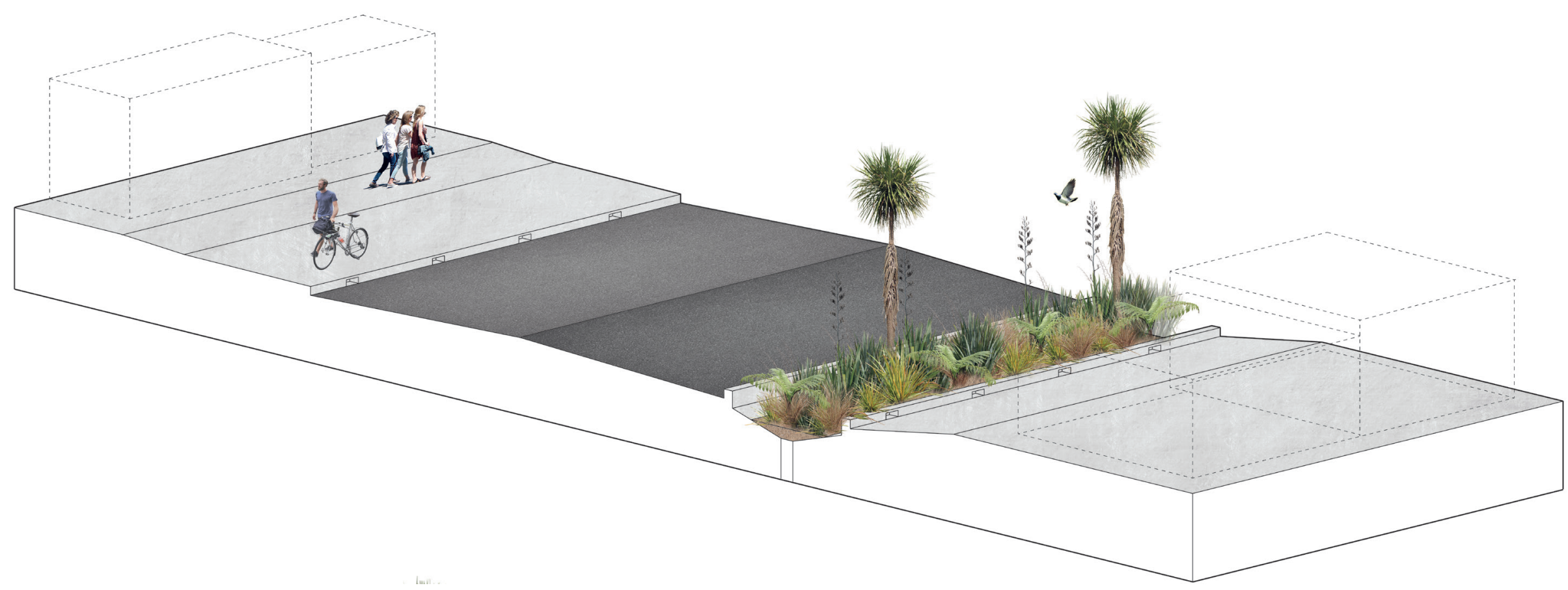

Fig 6.4 | Configuration 3| Taking one side of the road that was used for parking, this habitat is small. But the opposite side of the road has been utilised towards funnelling people, keeping the proximity of birds and humans close together. 


\section{+ CRITICALREFLECTION}

Comparing this literature review to that of the macro, it is obvious that the meso scale comes secondary to the wildlife. As the urban realm is already heavy with human focused directional movement, it is only through small adjustments that inclusion of native vegetation can provide, that these spaces become successful for birds as well.

Of this section, the main findings are as follows:

+ One, pedestrians need be prioritised, as this scale aims to put both humans and wildlife in the same space. The action of interaction cannot occur without them both being in the same space.

$+\quad$ Two, there are different types of connective corridors. Line corridors, the ones that have been employed, are smaller in scale and provide less habitat provisions, but achieve the overall goal of connective movement within the system of stepping stone locations.

+ If more time was available, there would have been more focus around this area, going more in depth with dimensions and scale of the created spaces. 

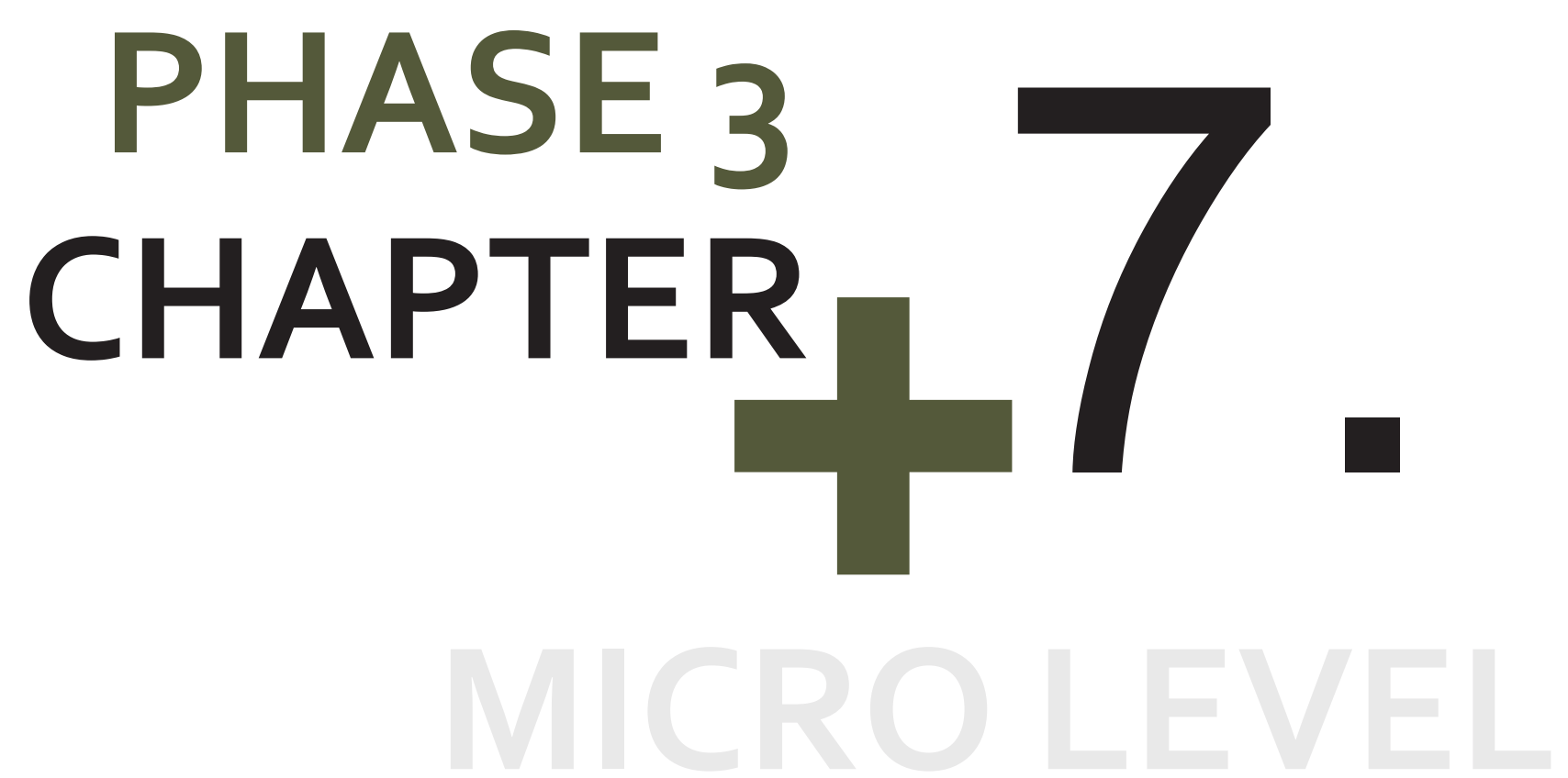


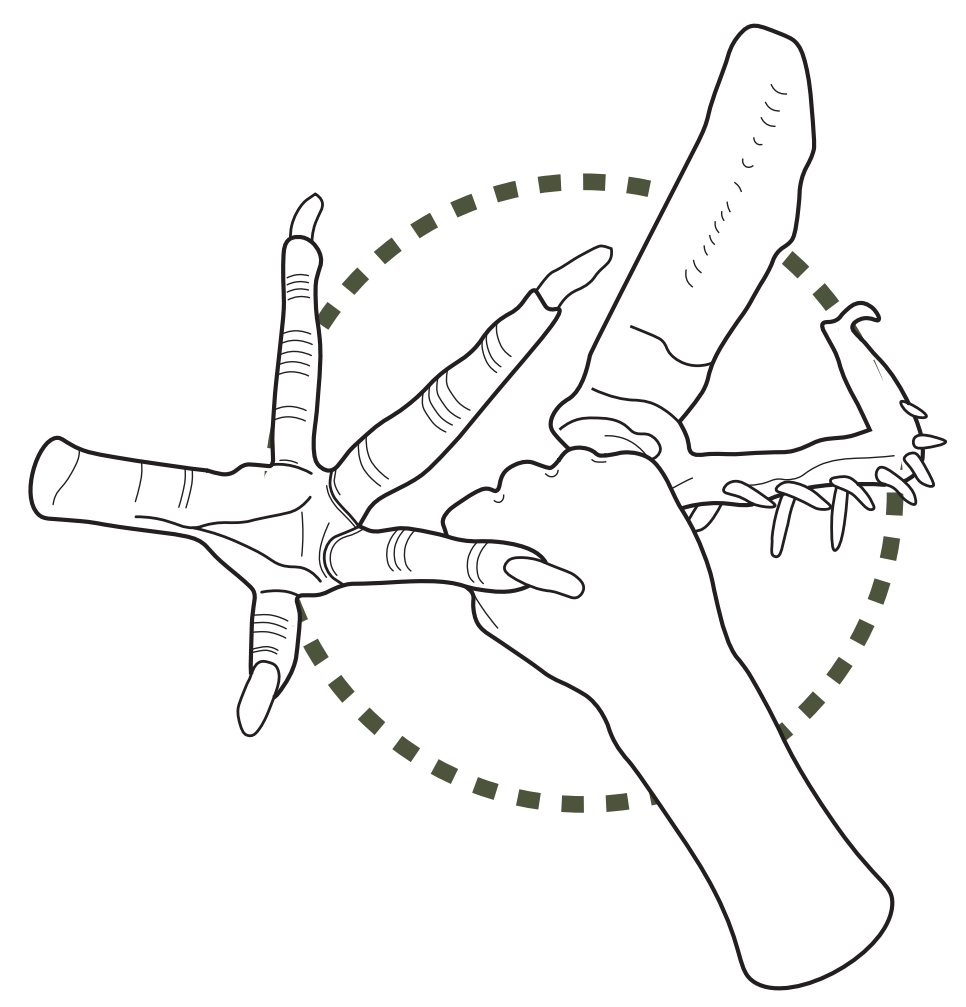

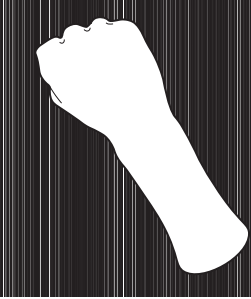

Humans

\section{I C R O}

3. Interactive Unity

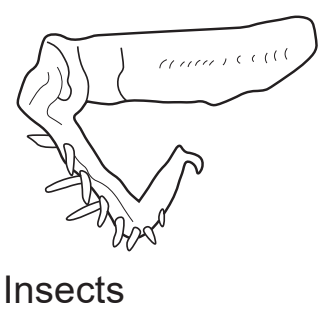

Avian Life

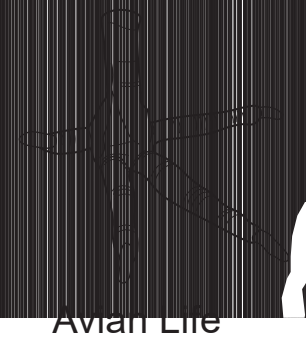

Insects 


\section{+ L I TERAt URE REVIEW}

An important element of designing within the micro scale for a series of potential of design interactions, is to understand the avian species as a whole. It is difficult to understand how to cater for the birds when comprehension of how birds go about everyday life is limited to sporadic sightings throughout a week. The first step towards designing interaction points is to build upon this existing knowledge, to then understand the constraints and liberties that can be taken when working with wildlife. Knowing this, will lead towards enabling and designing specific infrastructures, hopefully answering the question of how infrastructures can be utilised for human and wildlife interactions.

Ell suggests that there is at least a minimum of three physical elements that birds need to survive. Similar to people, it can be simplified into the basic necessities of water, food and shelter (Ell, 1981). Knowing this, he suggests that providing these elements should result in a space that is attractive to avian wildlife (Ell, 1981).

+ Food:

The first, and perhaps most important element is food. When actively establishing a constant food source, there should be some consideration of who and what species this is going to benefit. This can split in two different directions, catering for all or just one specific species. Identifying that each bird has a different preference towards types of food will help to create a space that is specific to the desired wildlife (Ell, 1981).

Ell suggests ensuring birds have a constant source of food all year round, especially in the wet winter months, is to provide feeding tables that offer an alternative towards natural vegetation (EII, 1981). Consideration to the life cycle of birds should also be considered according to Ell. If people are 
placing items of food around newly hatched chicks, it could be very dangerous to their fragile health (EII, 1981). This emphasises the importance of knowing the wildlife species prior to targeting and providing feeding infrastructure, such as, birds like the Kererū prefer large seeds, a source not readily available to put out on a table (Riley, 2005).

Fuller and co. have completed a thorough analysis that examines the affects of human induced feeding techniques and discovered positive results on the avian community, stating "Garden bird feeding therefore represents a large resource input that, coupled with other forms of management, might be used as a conservation option in urban environments." (Fuller, Irvine, Davies, Armsworth, \& Gatson, 2012, p. 264). Although not directly relating to the wider stepping stone location, it does imply that there are specific ecological benefits that have been observed when employing feeding stations within an urban site. Relating back to areas of interaction between humans and the birds, it can also cultivate a connection through the act of supplying a food source, similar to the deep relationship that pet owners have with their animals. The aim is to allow a wide community to feel and experience this type of relationship so that they can then understand and work together with the wildlife.

However, more recently, during an interview with a member of the Zealandia team, talk evolved around how feeding tables can be quite negative towards species health (Michel, 2019). Feeding is not encouraged as wildlife can become dependant on the source, detracting them from the natural environment (Michel, 2019). Bringing this issue back to Ell, he puts emphasis on food that has been supplied by humans being secondary to the natural diet that is scattered throughout the landscape (Ell, 1981). This suggests that the location of 
feeding equipment needs to be appropriate in location, such as areas that is lacking in natural food producing vegetation, to ensure and encourage usage. It would be considered a waste of resources to provide apple juice underneath an apple tree for example. Therefore, this conflict has resulted in a disuse of including feeding stations in the design realm.

+ Water:

Equal to food, water is also a crucial element that can set apart a site from a standard street design, as it is more attractive to birds. Like humans, avian wildlife use water in two different manners, to consume and to clean. As a result of this, a series of built elements need to be provided to facilitate this activity. There are many different ways to introduce water in a specific site, it is completely dependent on the existing environmental conditions that are related to it. Ideally, the water should be fresh, as this allows for the dual action of cleaning and drinking within the same location (Ell, 1981). There have been many summer days when the opportunity to watch a Tūī clean itself in a gutter has occurred (Fig 7.01).

Additionally to providing water, there needs to be small built elements to complete this action. The water should ideally be shallow, to allow for standing and cleaning, if not possible, rocks should be implemented in the centre (Ell, 1981). Creating an edge or manipulating the rocks can be a way to encourage the action of perching, a ritualistic routine that birds will perform while preening feathers after getting clean (Ell, 1981). 


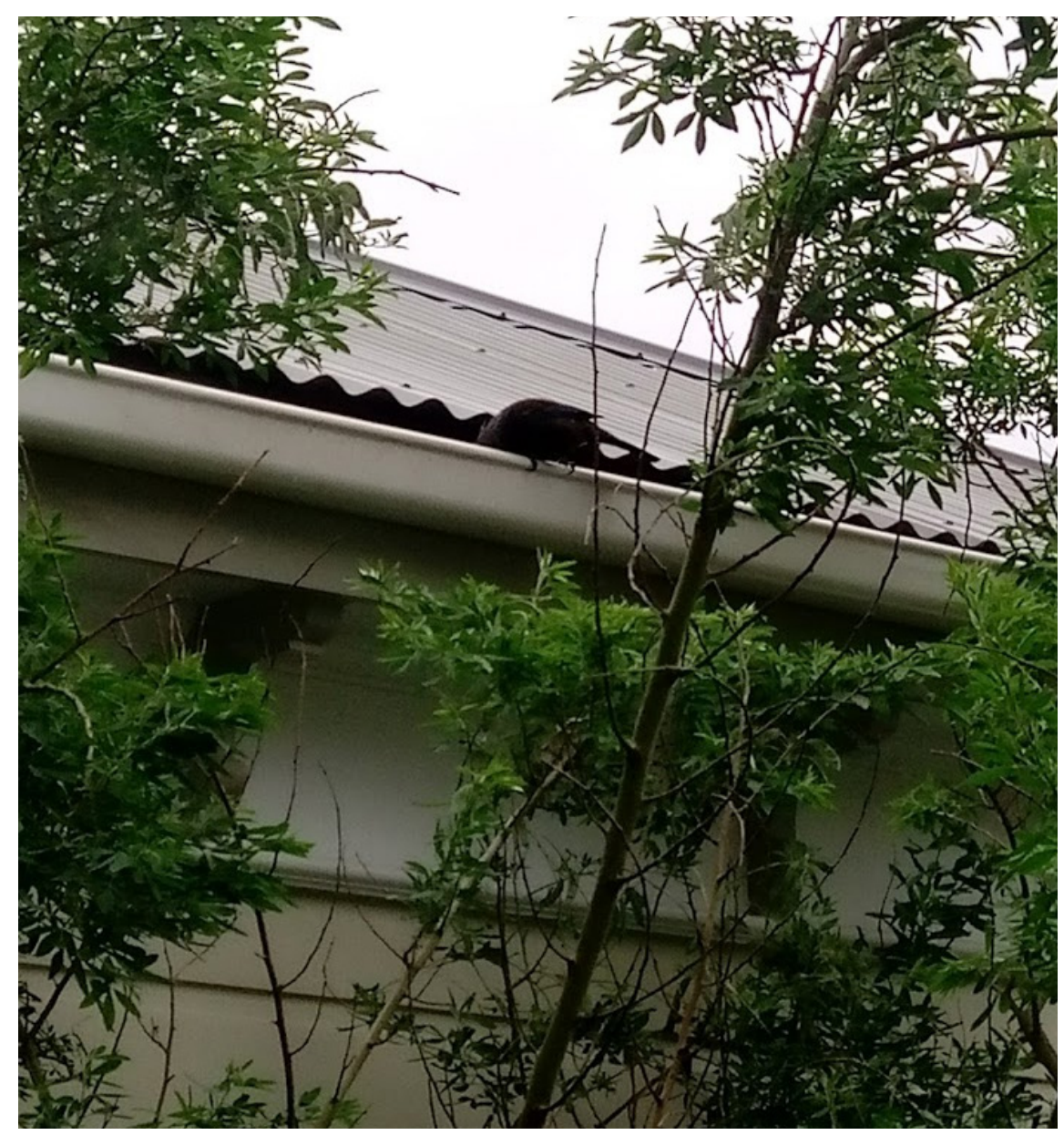

+ Pests

Although pest control can be difficult to manage and maintain, it is going to have a large impact on the perceived safety of the area. Birds will not venture to sites that have a large pest presence, particularly dogs and stoats (Ell, 1981; Michel, 2019). It is very difficult to manage sites to be completely pest free, especially within urban areas (Ell, 1981). Zealandia, a pest free eco-sanctuary, is world leading in managing to design a safe haven for wildlife through the utilisation of a large fence ("The Sanctuary," 2018). It is hard to replicate but smaller techniques such as leashing dogs and having gated areas can achieve similar levels of supervision (Michel, 2019; Park, 2019).

Fig 7.01 | A TŪī cleaning itself in a gutter. 
+ Shelter

Shelter is a tricky space to accommodate for. Birds are not refined to 'houses' as such, it is the natural vegetation that they call home, and not an area that needs to be replicated (Ell, 1981). However, Ell does suggest that there are smaller techniques, such as nesting boxes, that can provide this in lieu of natural vegetation (Ell, 1981). He does recognise that birds are naturally drawn to vegetation for nesting, but offers these as an alternative when this is lacking.

Nesting boxes can be used for conservation methods, as a way to monitor threatened young species, which has been utilised within Zealandia (Michel, 2019; "The Sanctuary," 2018). Specific formation of nesting boxes depends heavily upon the species that have been targeted, large birds cannot use the smaller boxes etc (Fig 7.02) (Ell, 1981).
Attending a research symposium revealed the relationship between nesting locations and pest management. With species like the North Island Robin, that has a complicated history with being threatened, information around why this has occurred has been established (Fea, 2019). Placing the nest on thicker branches allows for it to be more stable but at a higher chance for predator invasion (Fea, 2019). In contrast, thinner branches results in more chance for the nest to drop but it is more protected from fatter predators that cannot scale the twigs (Fea, 2019). This relationship is good to understand as it provides spatial qualities to how birds nest, when avoiding predators, but also provides a reasoning to where nesting boxes could be appropriate. 


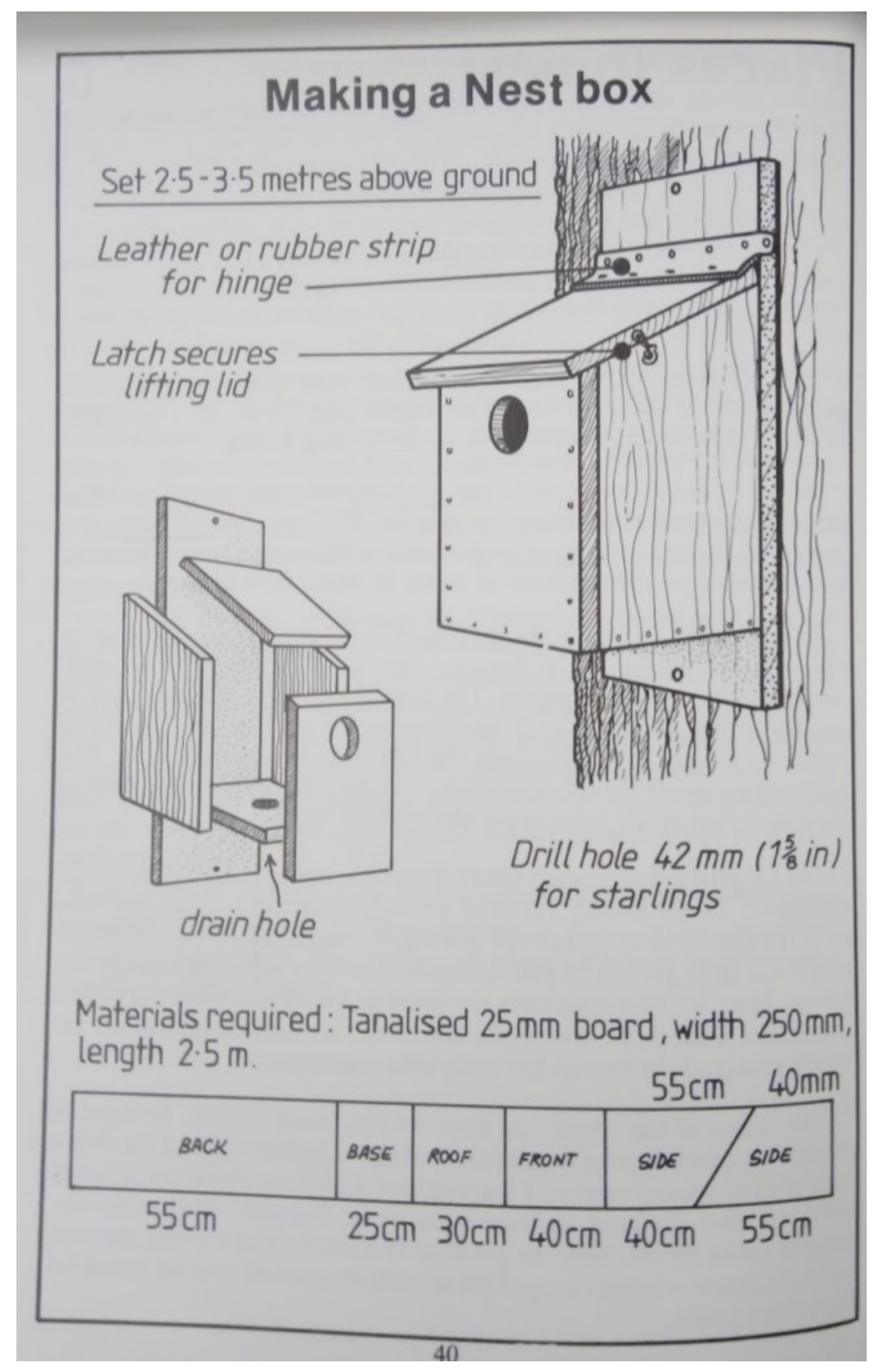

Fig 7.02 | Nesting box requirements. 


\section{+ PRECEDENTSTUDY}

\section{Zealandia}

Located within Wellington, Zealandia, is the "world's first fully-fenced urban eco-sanctuary" ("The Sanctuary," 2018).

The large grounds, approximately 250 hectares, is completely enclosed, creating an actively protected sanctuary for wildlife and vegetation (Campbell-Hunt, 2002). Invasive vegetation and animals are eliminated from the interior, to protect and conserve the threatened species that it aims to shelter safely ("The Sanctuary," 2018). Zealandia leads as an example for any future large scale sites, not only in species conservation but also in the approach of safely integrating people into these spaces.
Strengths:

$+\quad$ The overall main strength of this site is the vast range of wildlife species present. Not only does Zealandia nourish bird life, insects also play a large role in the ecological cycle that is protected (Campbell-Hunt, 2002). There are at least 10 bird species that are celebrated as being the forefront of conservation, with many more that have been positively affected by Zealandia's efforts.

$+\quad$ The rich range of ecological processes present in their forests and lakes, accommodate for a varying group of species, creating unique environments and habitats. The more different the spaces are, the wider range of species that will be attracted to the area (Fig 7.03). 


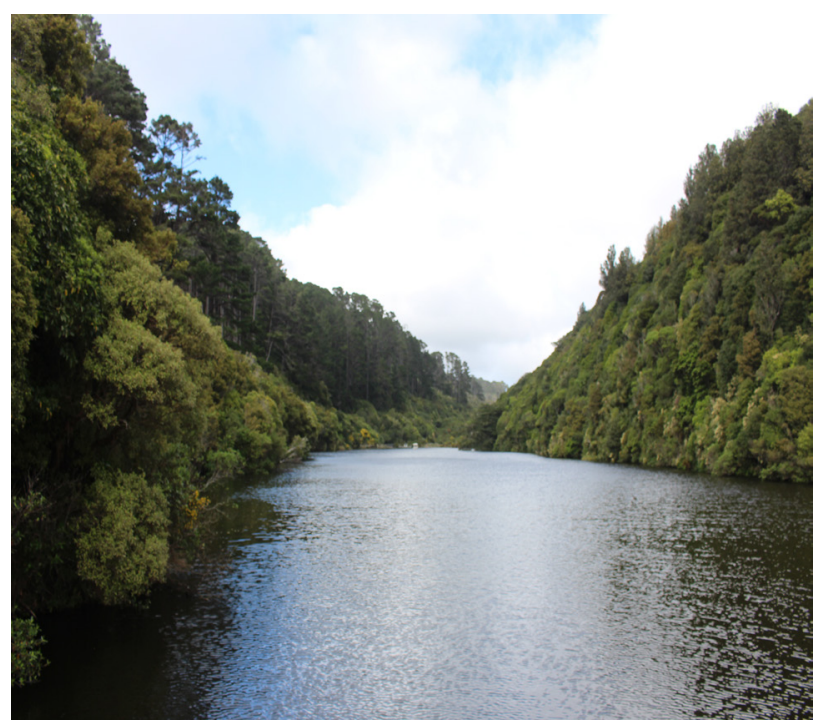

Fig 7.03 | Different ecological environments.

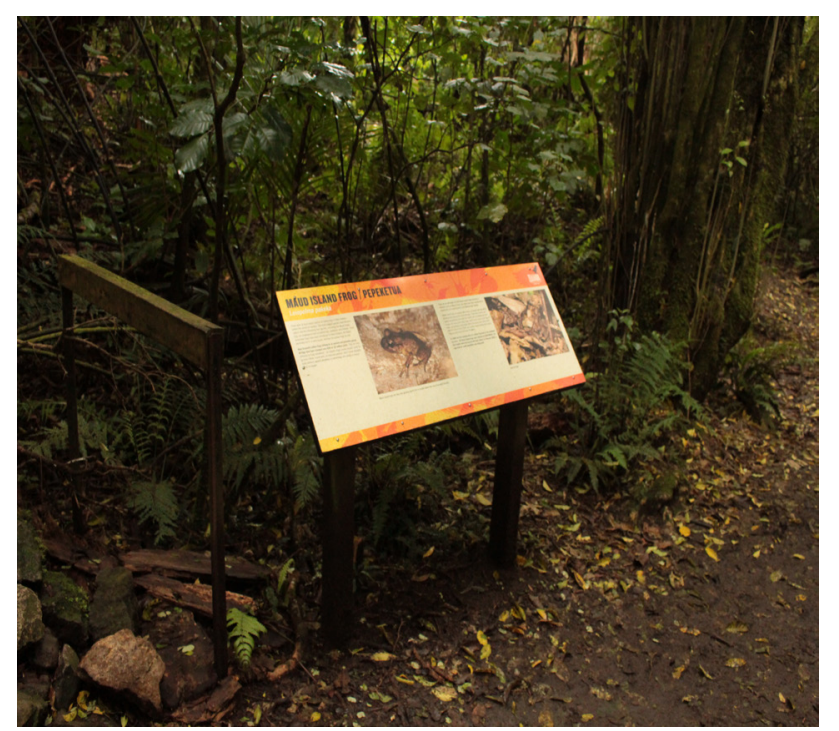

Fig 7.04 | Signage for education

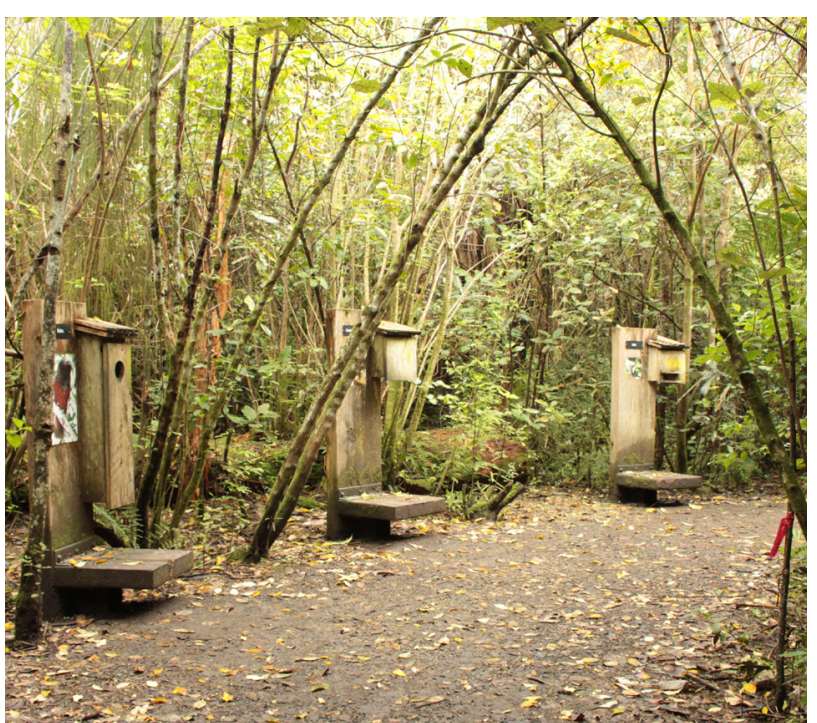

Fig 7.05 | Fake nesting boxes for education 
+ One of the main ways Zealandia encourages interaction between humans and avian species, is the prominent effort they put towards education. Guided tours, museum like displays and clever signage, all work to inform and educate people to take lessons out of the confines of the sanctuary (Fig 7.04, 7.05, 7.06)(Campbell-Hunt, 2002).

$+\quad$ There is a lot of exploration that the layout of Zealandia encourages. Pathways direct and guide people, but if a bird calls far off, the vegetation invites rugged movement to find that one specific bird (Fig 7.07).

\section{Weaknesses:}

$+\quad$ Whether this is seen as a weakness depends on the perspective of the judger, but increased numbers of kaka, a direct result of the great work that has been undertaken by Zealandia, are now starting to disrupt city life and infrastructure.

There are many design features that can be taken from Zealandia, to then replicate and utilise with the theme of interactions between humans and wildlife. 


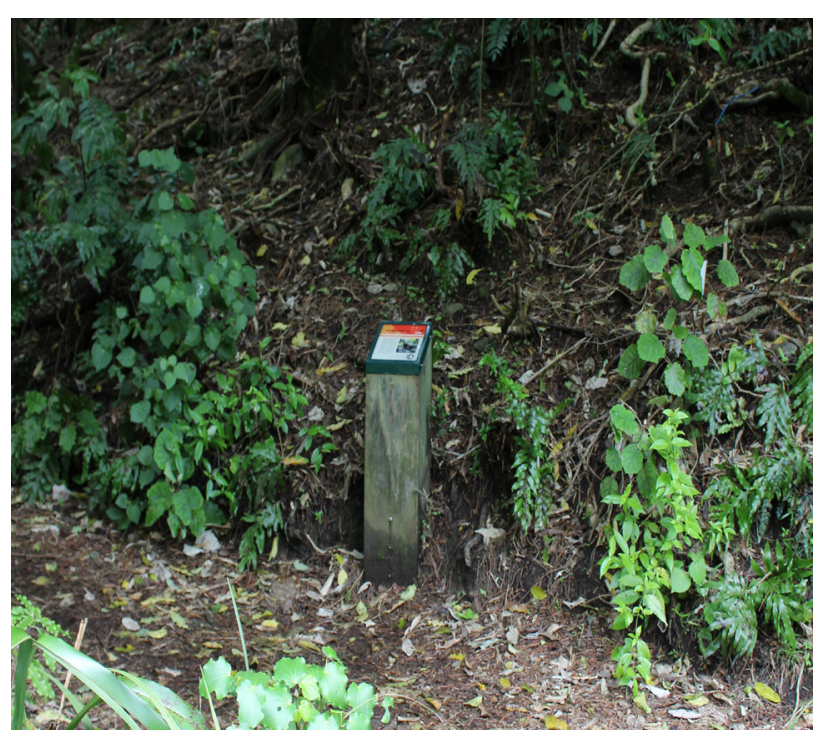

Fig 7.06 | Sound ques attract species.

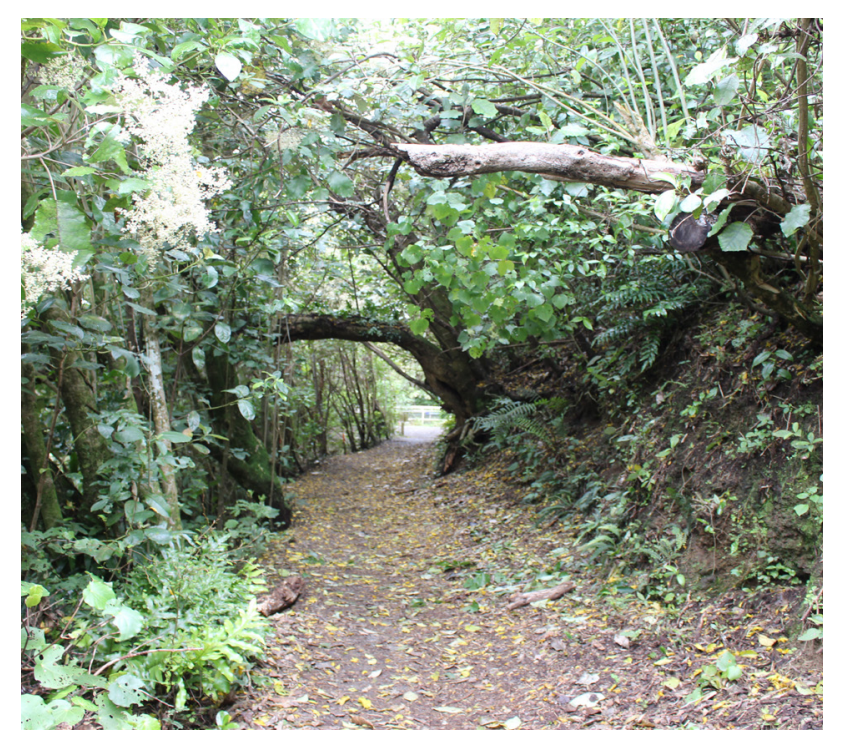

Fig 7.06.01 | Overhanging vegetation.

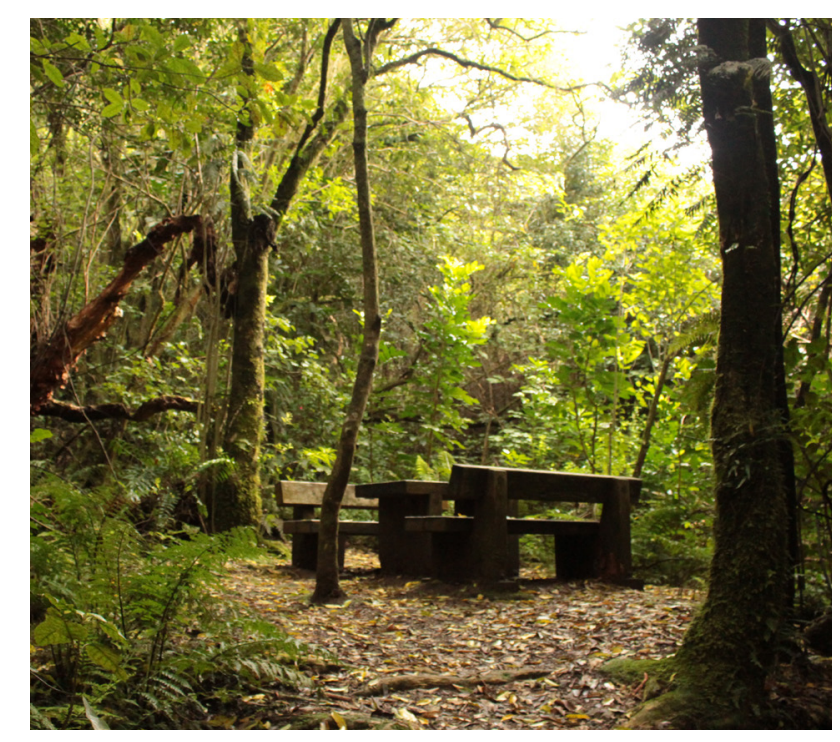

Fig 7.06.02 | Hidden pathways to unique social spaces. 


\section{+ DESIGNTYPOLOGIES}

Fig 7.06.03 | From both the literature and precedent analysis, these seven typologies were extracted to understand spatial qualities when designing.

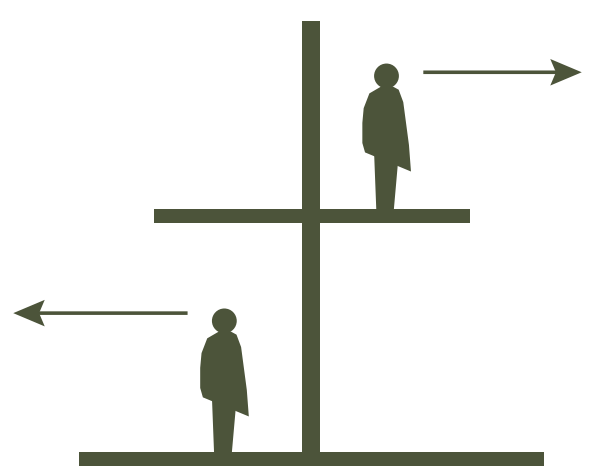

Heights

Varying heights offer different visual experiences and sight lines.

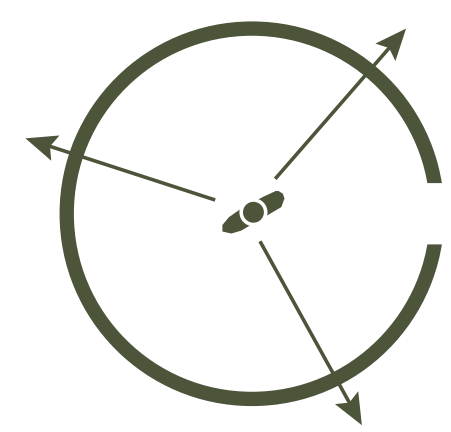

Views

360 views, more chance to see wildlife in various activities.

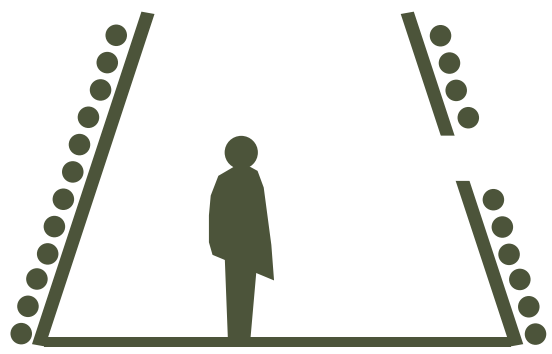

Exterior

Material covered walls can help conceal the structure for the species.

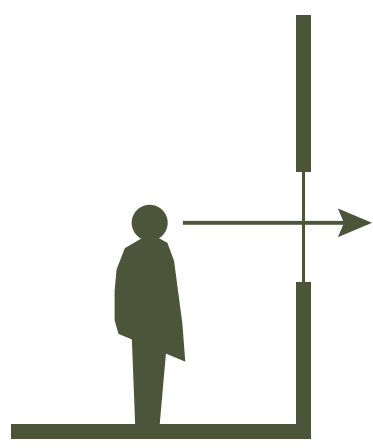

Openings

Different openings to direct the focus of the viewer to different activities of the species. 


$$
\text { İ工 }
$$


+ LOCATION 1 |PECKING PICNICS

+ LOCATION 2 |SHELTERED HUTS

+ LOCATION 3 |FRESH H2GO

+ LOCATION 4 |NESTING HIDE-AWAYS

+ LOCATION 5 | SOCIAL SPECIES

(D) Fig 7.06.04 | Wellington's Stepping Stone Locations Scale 1:50,000

Existing Green Space

Stepping Stone Locations

SS Locational Flight Distance, $294 \mathrm{~m}$

EGS Locational Flight Distance, $294 m$

Sea 


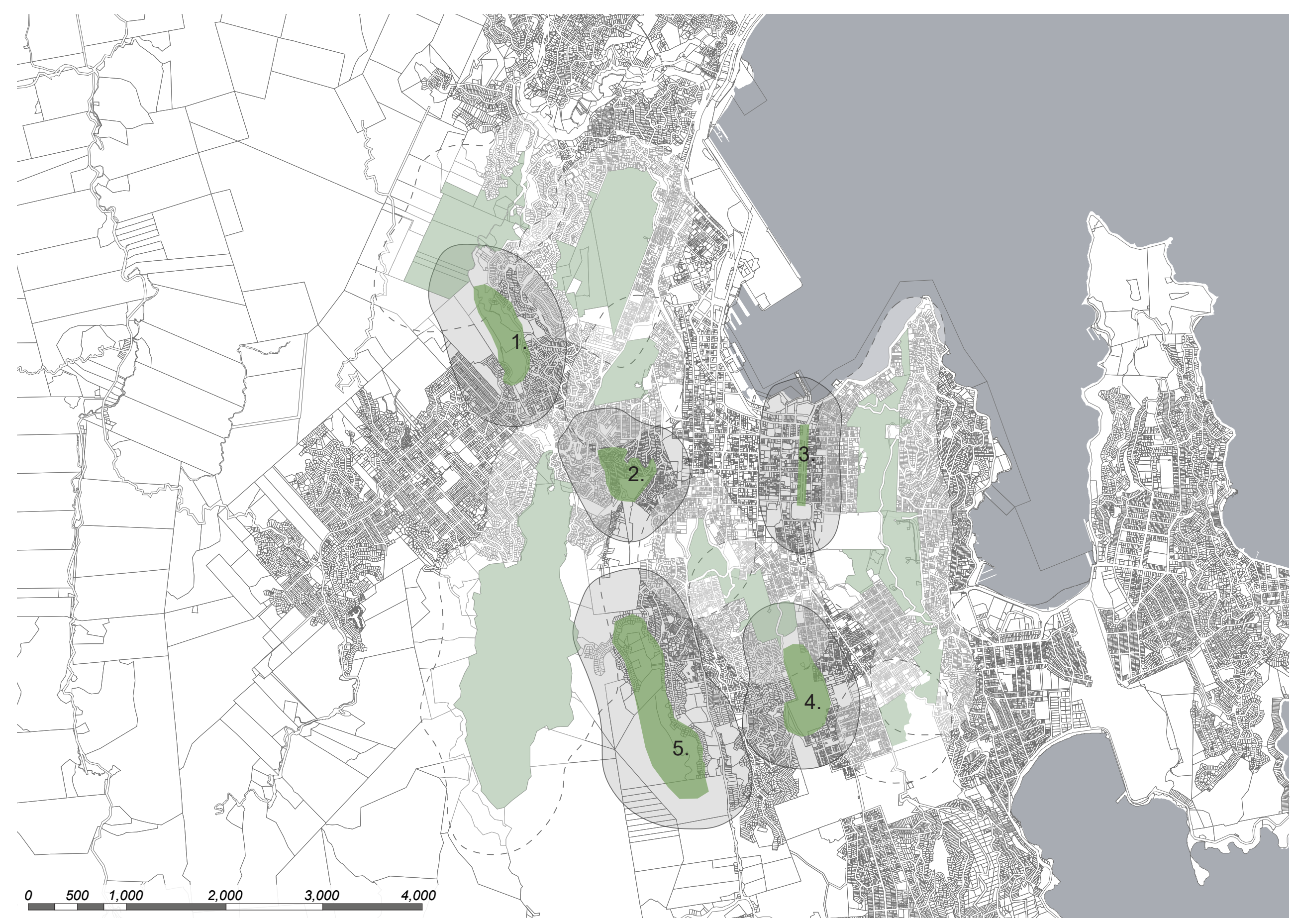




\section{+ LOCATION 4 |NESTING HIDE-AWAYS}

Located on the edge of four suburbs, Newtown,

Berhampore, Mornington and Vogeltown, it is a very

residential location.

This location was chosen first as it is in a suburban area,

the idea was to gain a footing with understanding and

spatialising design intent without the dense urban fabric.
(1) Location 4 - Nesting Hide-Aways

Fig 7.07 | Location 4 


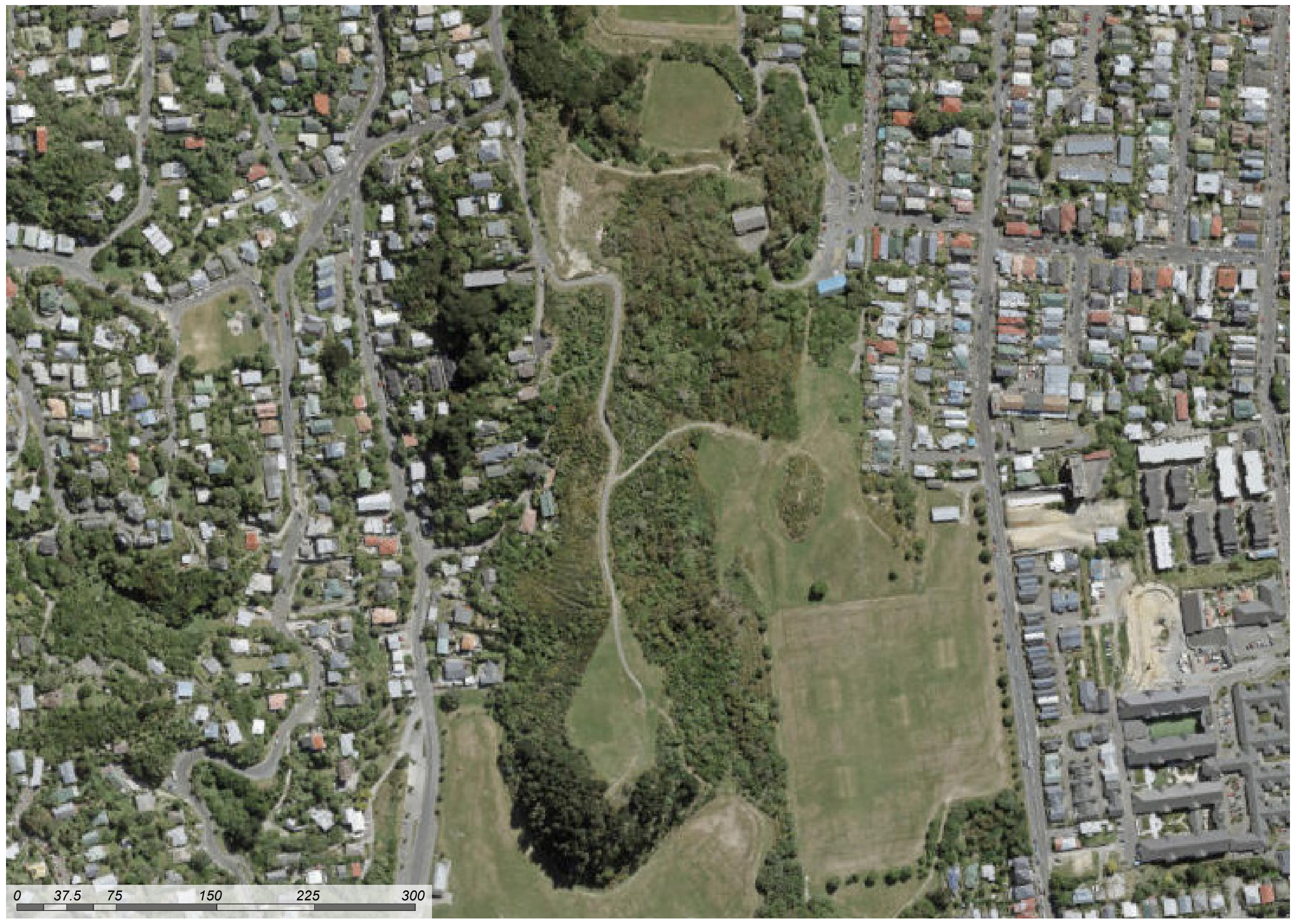


+ Site analysis

(1) Fig 7.07.01 | Contours and Water Lines Scale 1:3,000@A3

Sightline Barrier

Main Pathway

Sub Pathway

Water Line

- - - - Ridge Line

10m Line

$5 \mathrm{~m}$ Line

$1 \mathrm{~m}$ Contours

Residential Housing

Educational Buildigs

Cricket Fields

Rugby/Soccer Fields

Sightlines

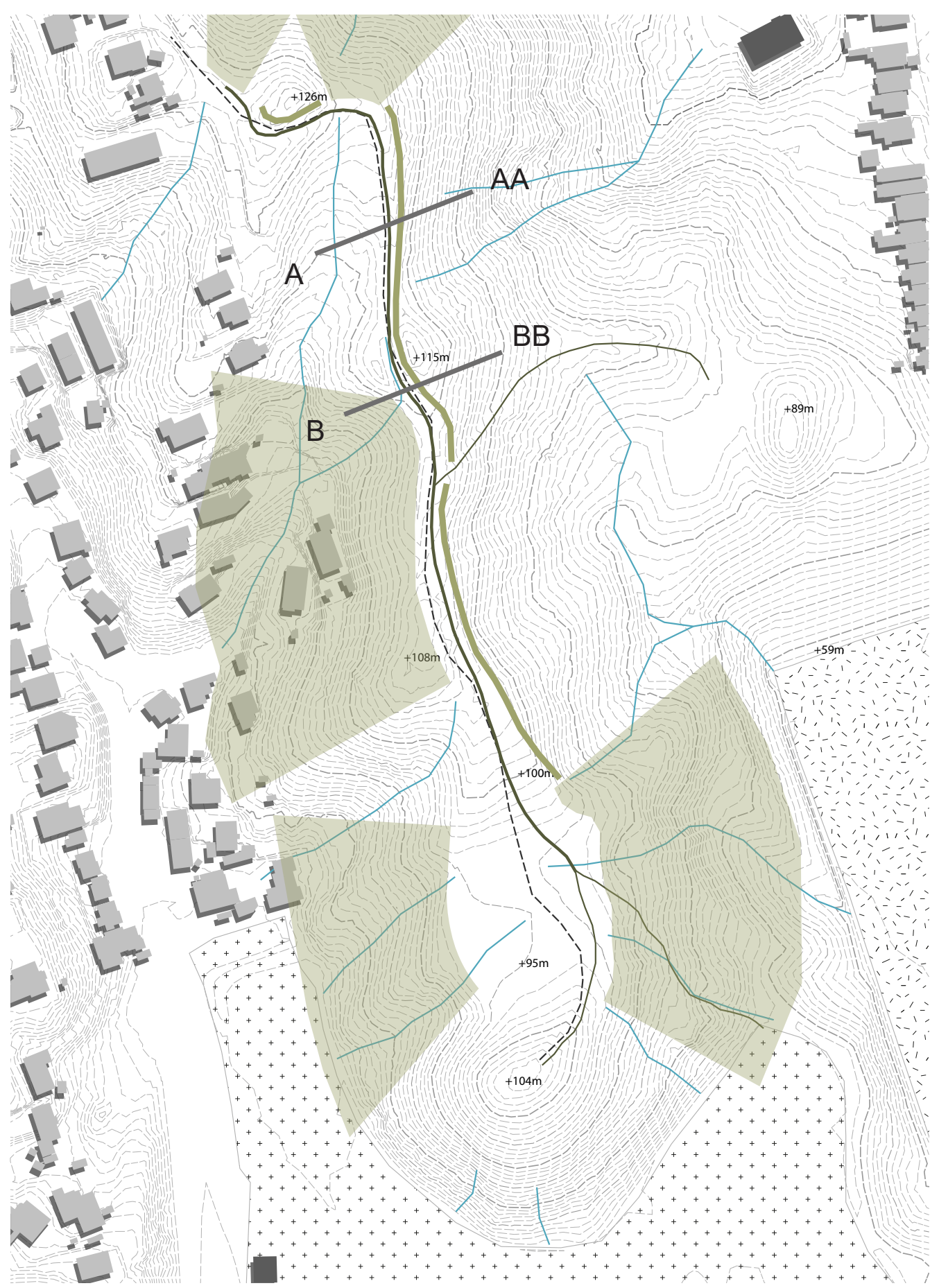


1 Fig 7.07.02 | Site Functionality

Scale 1:3,000@A3

\begin{tabular}{|c|c|}
\hline & Main Pathway \\
\hline & Sub Pathway \\
\hline & Water Line \\
\hline -ーーー & Ridge Line \\
\hline & 10m Line \\
\hline & $5 \mathrm{~m}$ Line \\
\hline & $1 \mathrm{~m}$ Contours \\
\hline++ & Short Grass \\
\hline$\therefore=1$ & Pine Trees \\
\hline 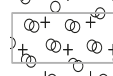 & Trees without Understory \\
\hline 0 & Mid High Shurbery \\
\hline
\end{tabular}

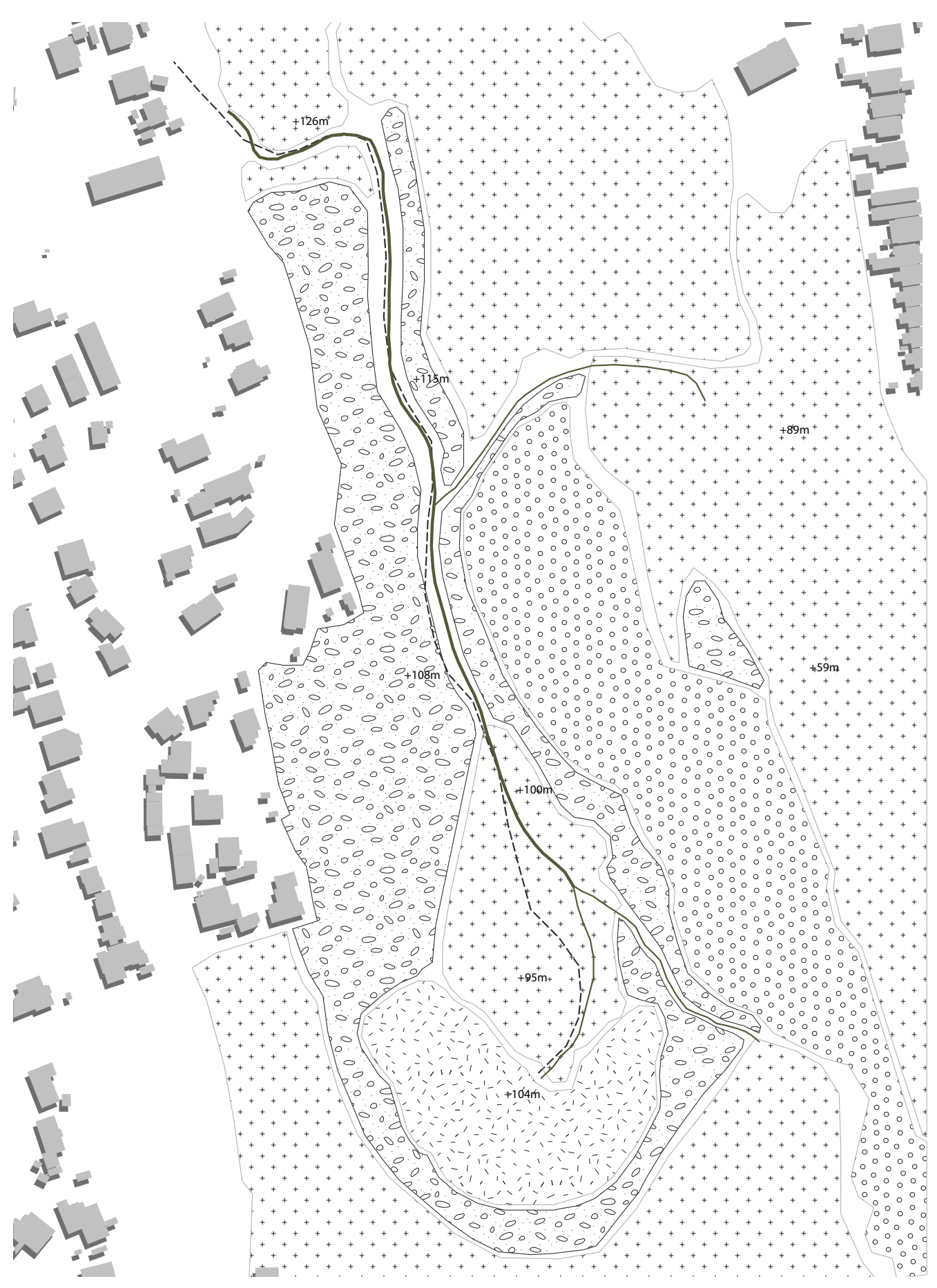




\section{+ SECTIONS}

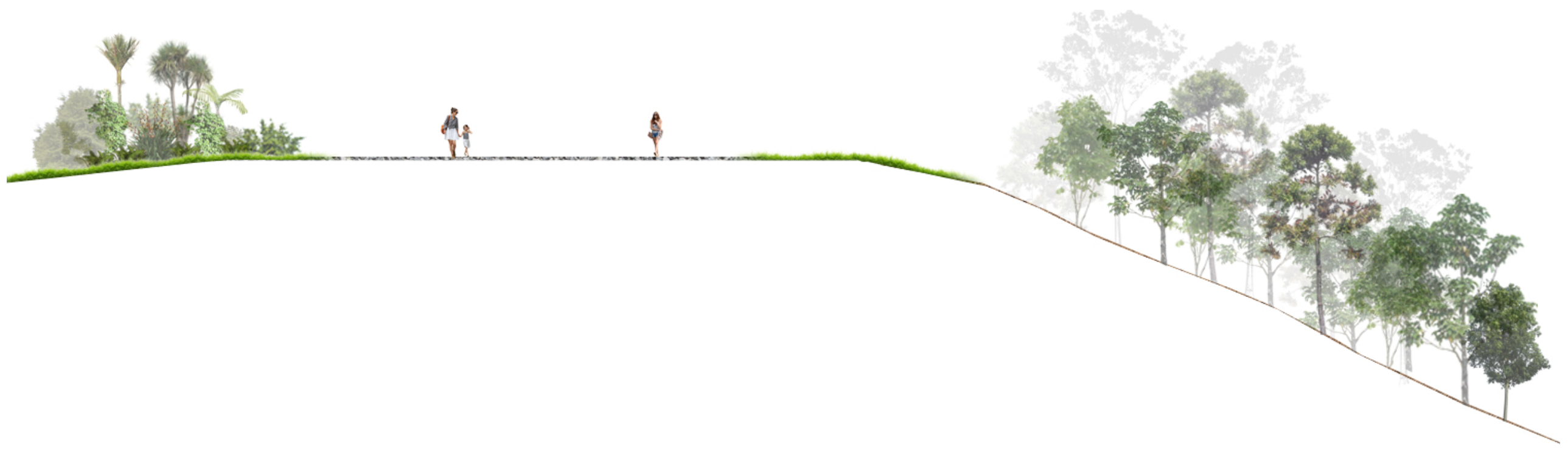

Fig 7.08 | A-AA | Ridge walkway, 1:500 @ A3

The lack of vegetation at the edges, results in a very exposed and windy site 


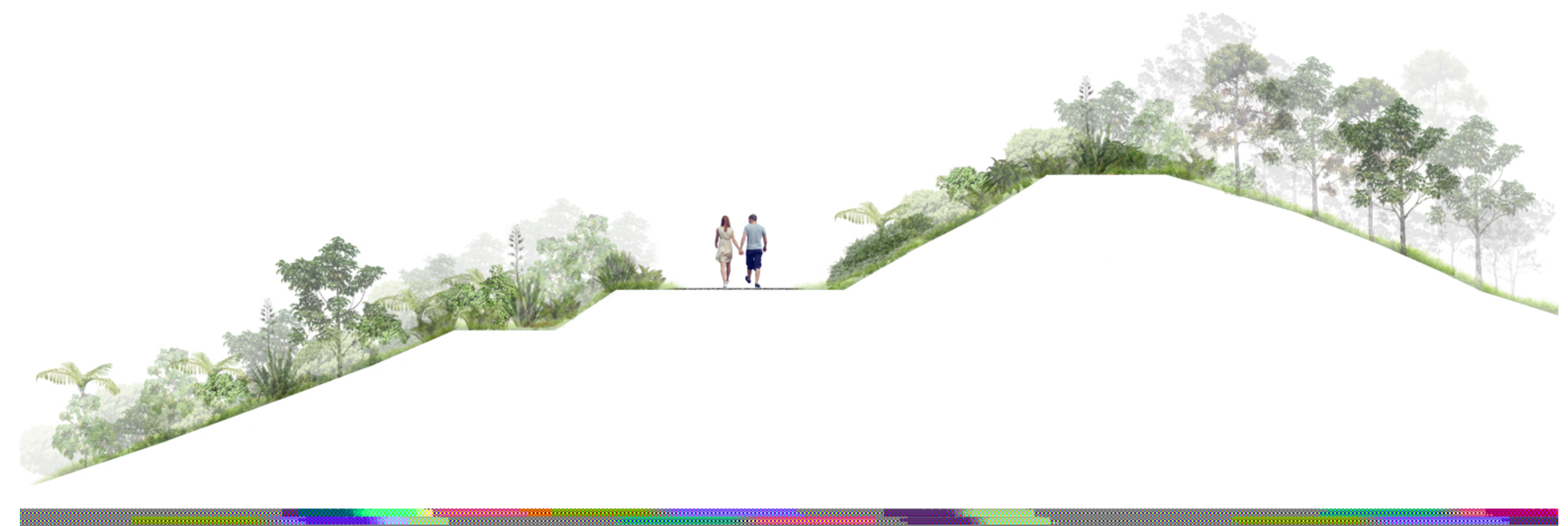

Fig 7.09 | B-BB | Cliff walkway, 1:500 @ A3

New planting on the left allows for a more native plant selection. 


\section{+ PATHWAY}

Figs 7.10 | Photographic pathway observations
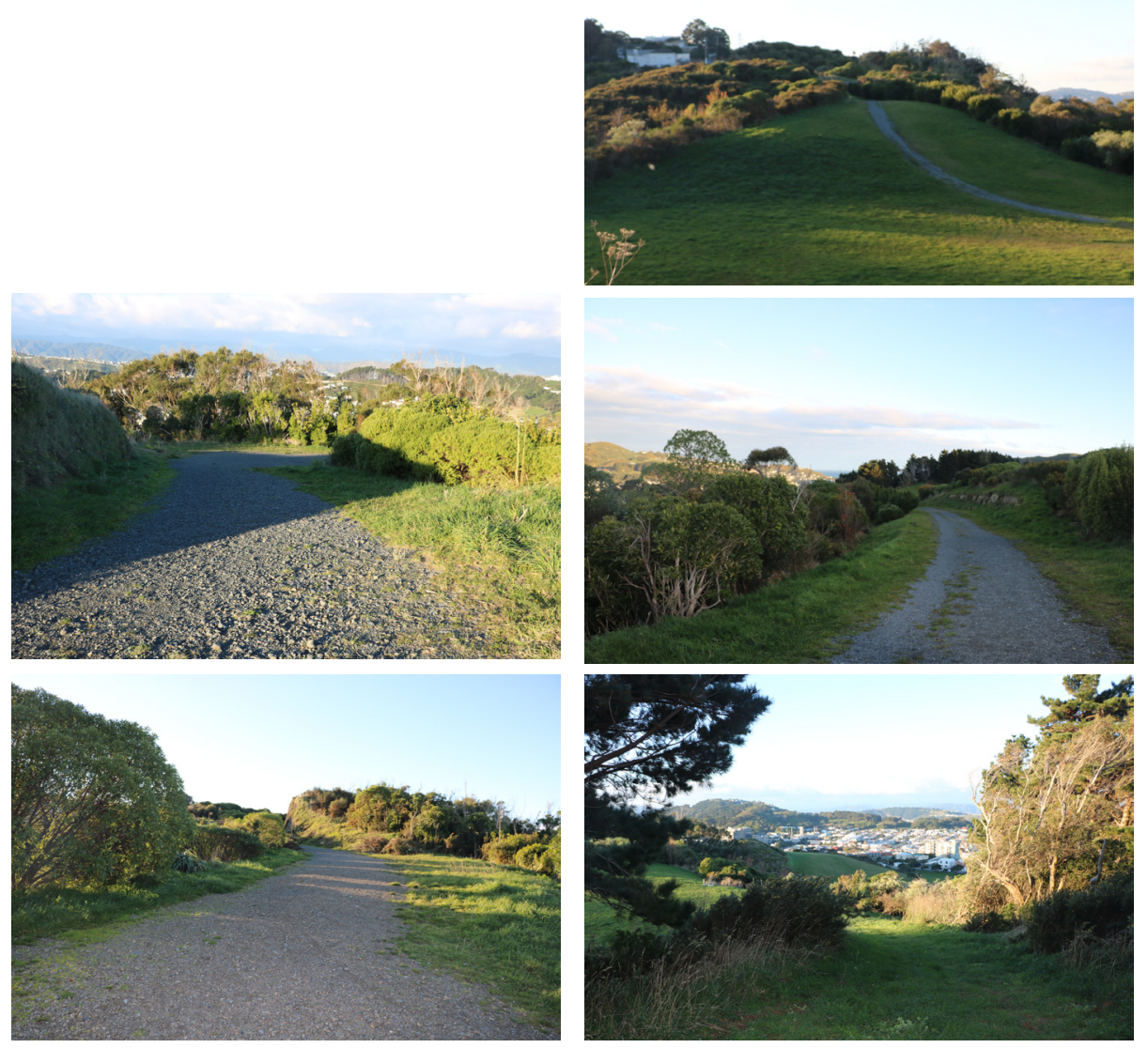

+ VEGETATION

Figs 7.11 | Photographic planting observations.
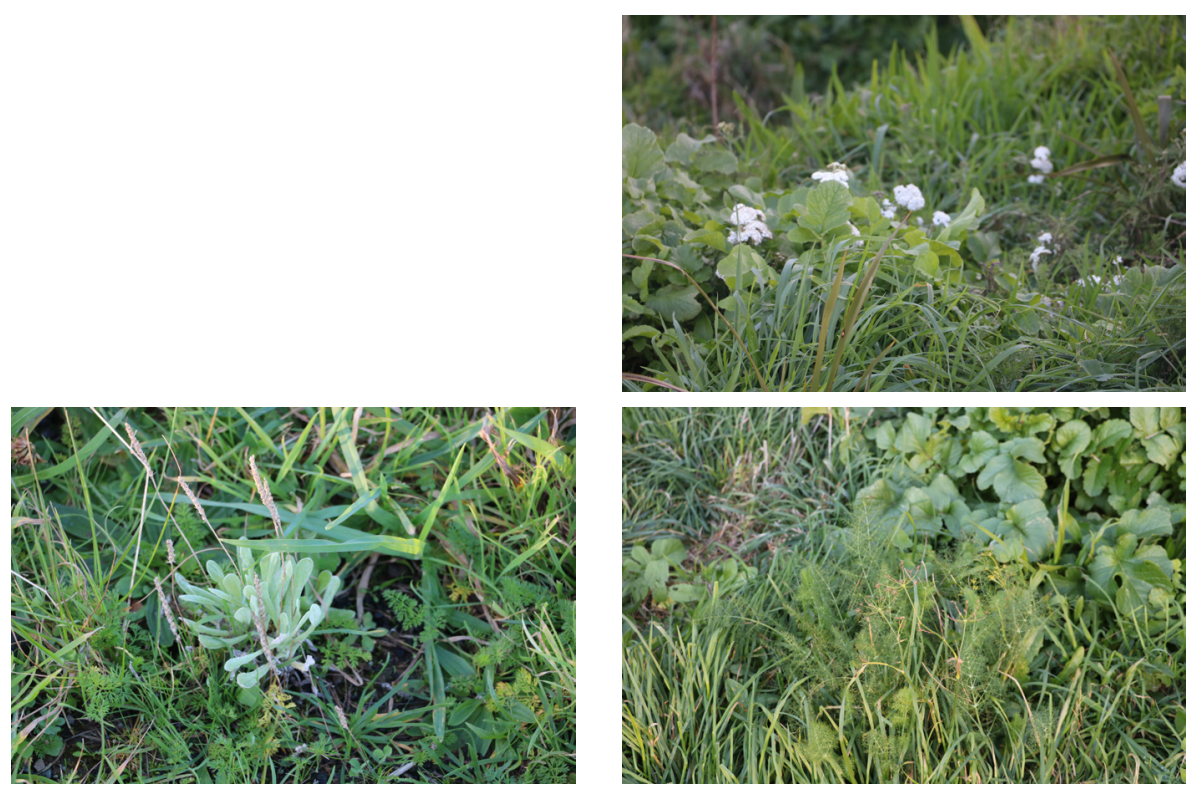

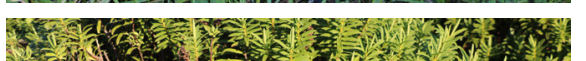

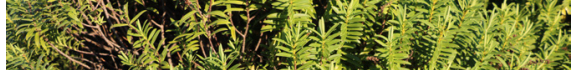

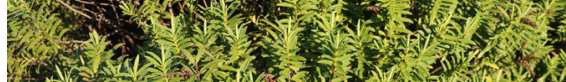

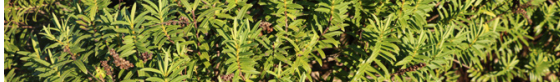

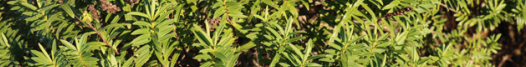
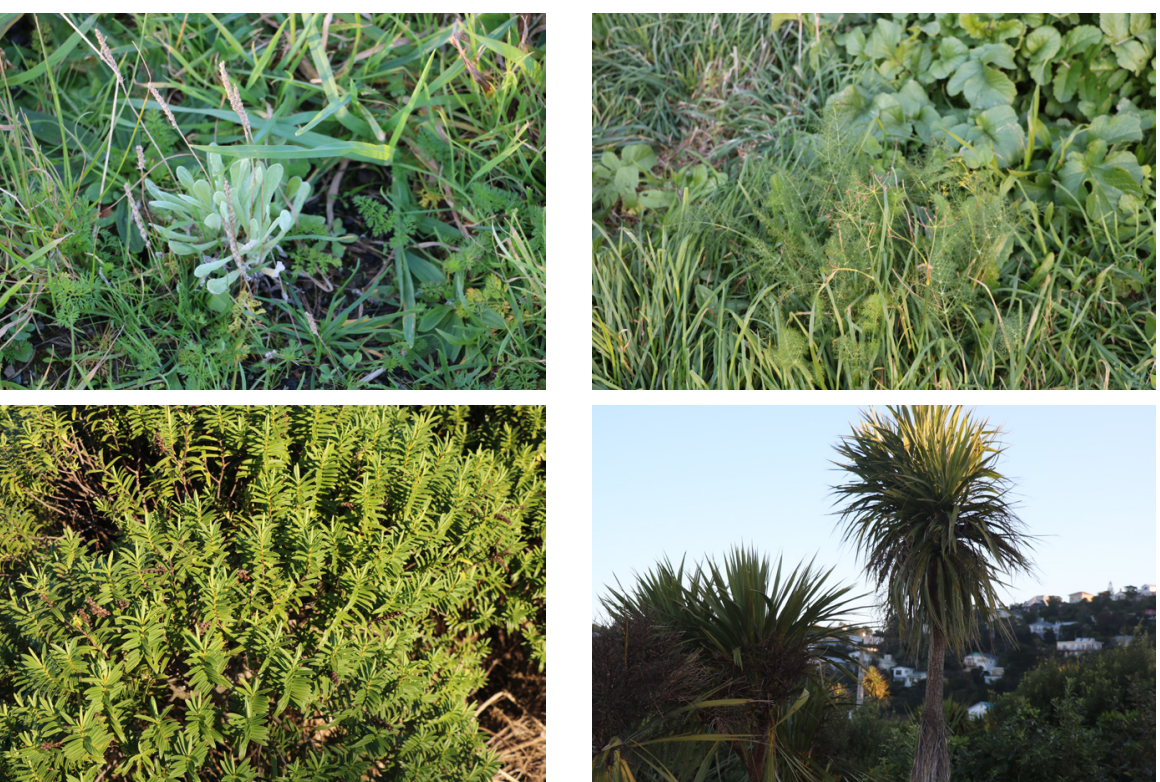


\section{+ SIGHT LINES}

Figs 7.12 | Photographic view point observations.

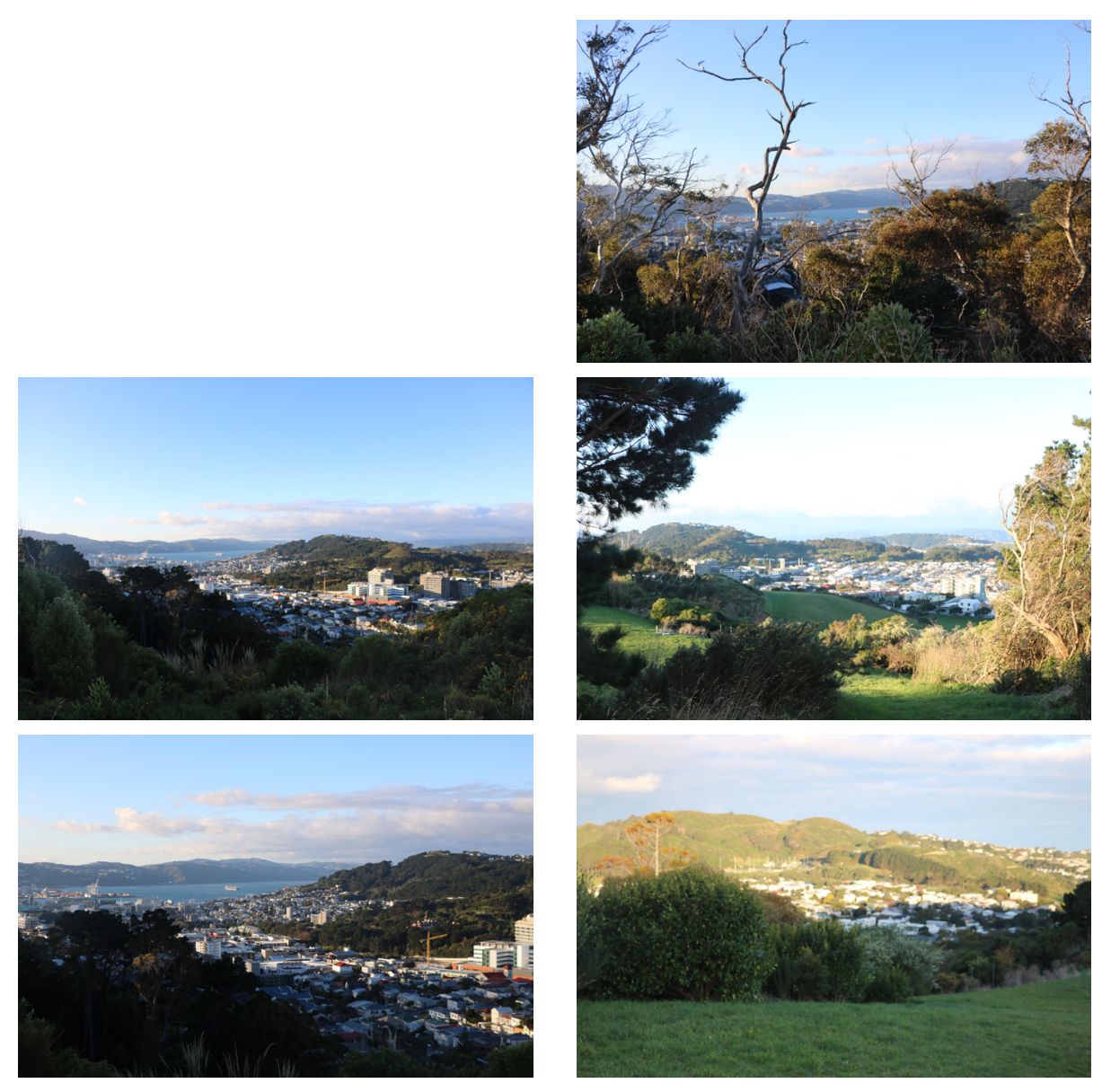

+ SOILS

Figs 7.13 | Photographic soil observations.

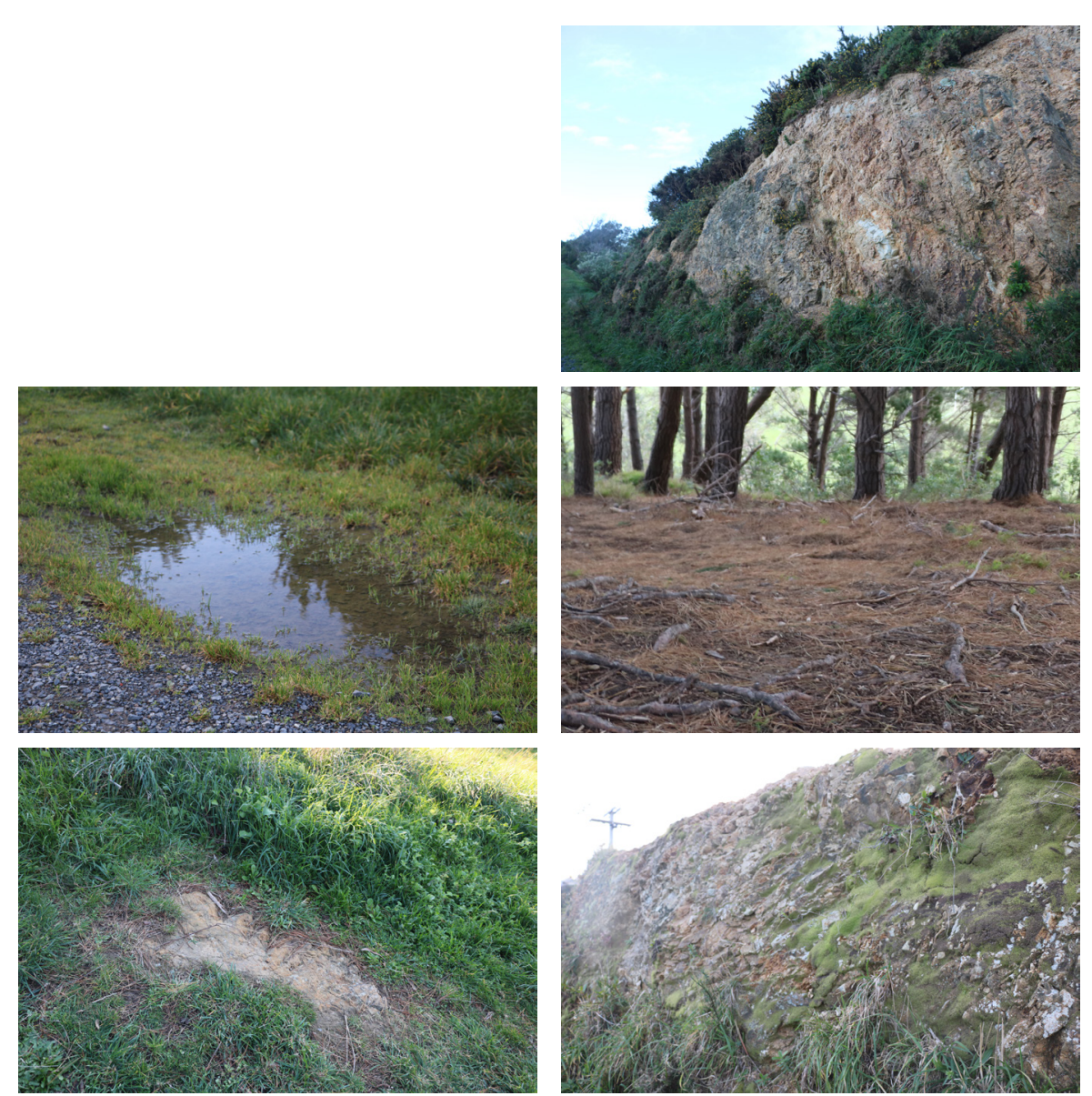




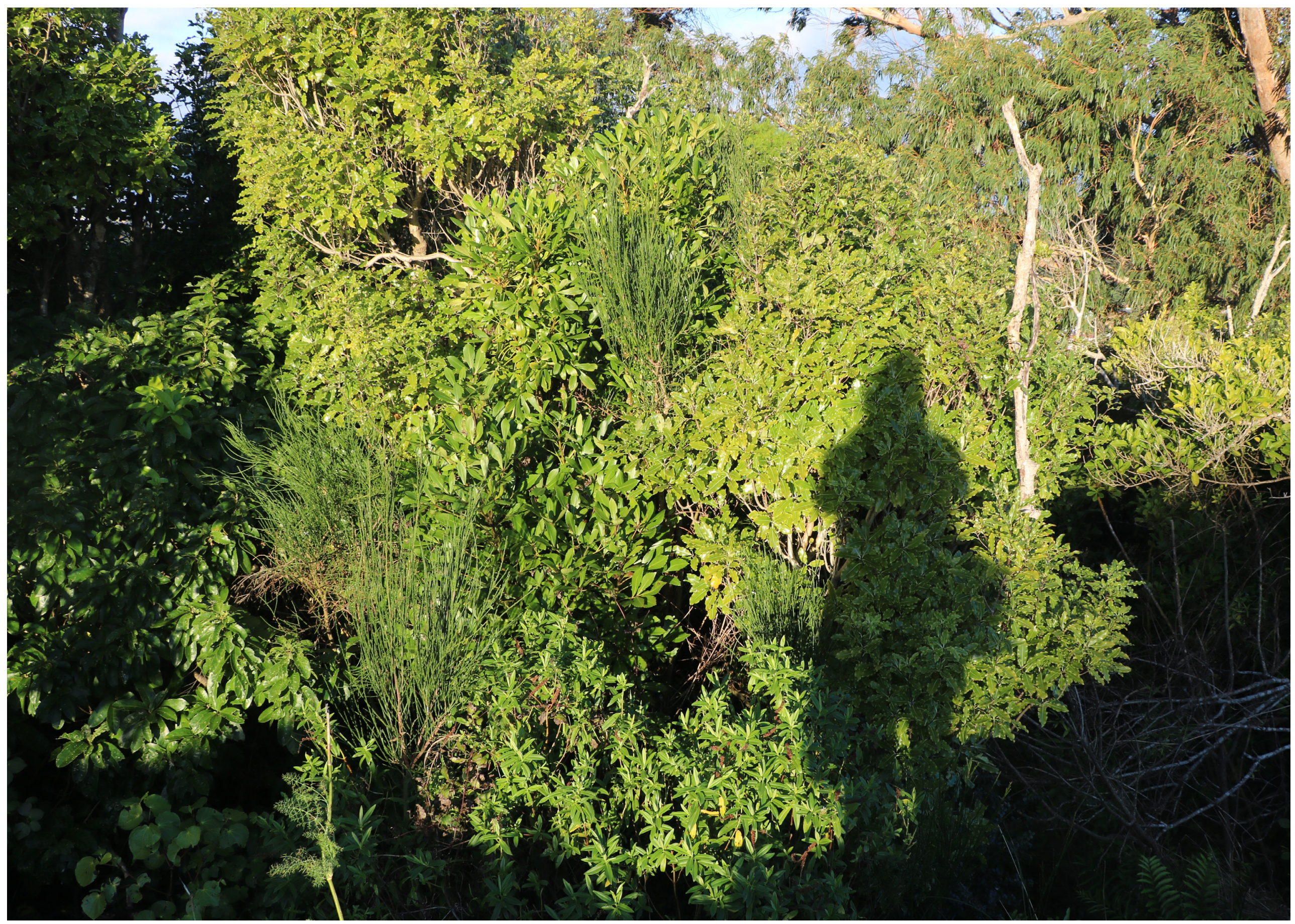




\section{+ VEgetation SPECIES}

Species of vegetation that were noted during site visits.

Corynocarpus laevigatus

Beilschmiedia tawa

Dacrydium cupressinum, Red Pine

Vitex lucens

Podocarpus totara

Piper excelsum, Kawakawa

Hedycarya arborea, Pigeonwood

Dicksonia squarrosa, Rough Tree Fern

Hoheria populnea, Lacebark
Weinmannia racemosa

Phormium tenax, NZ Flax

Carpodetus serratus, Marbleleaf

Griselinia littoralis, Broadleaf

Pittosporum eugenioides, Lemonwood

Schefflera digitata, Sevenfinger

Pseudopanax colensoi, Mount Fivefinger

Fuchsia excorticata, Tree Fuchsia

Blechnum discolor, Crown Fern

Fig 7.14 | Site Vegetation. 


\section{+ MASTER P A N}

The program for this site stemmed around the site analysis, in that the exposed ridge line created a site that was too windy for habitation. The introduction of native vegetation to the site all support bird life but there was none there.

Therefore this site aims to utilise 'nesting' as a way to encourage birds to settle in the space.
Fig 7.15 | Masterplan

Scale 1:1,500@A3
A | Lookout
B | Under-story Walkway
C | Nesting Pods
D | Archway
E | Open Green Space 


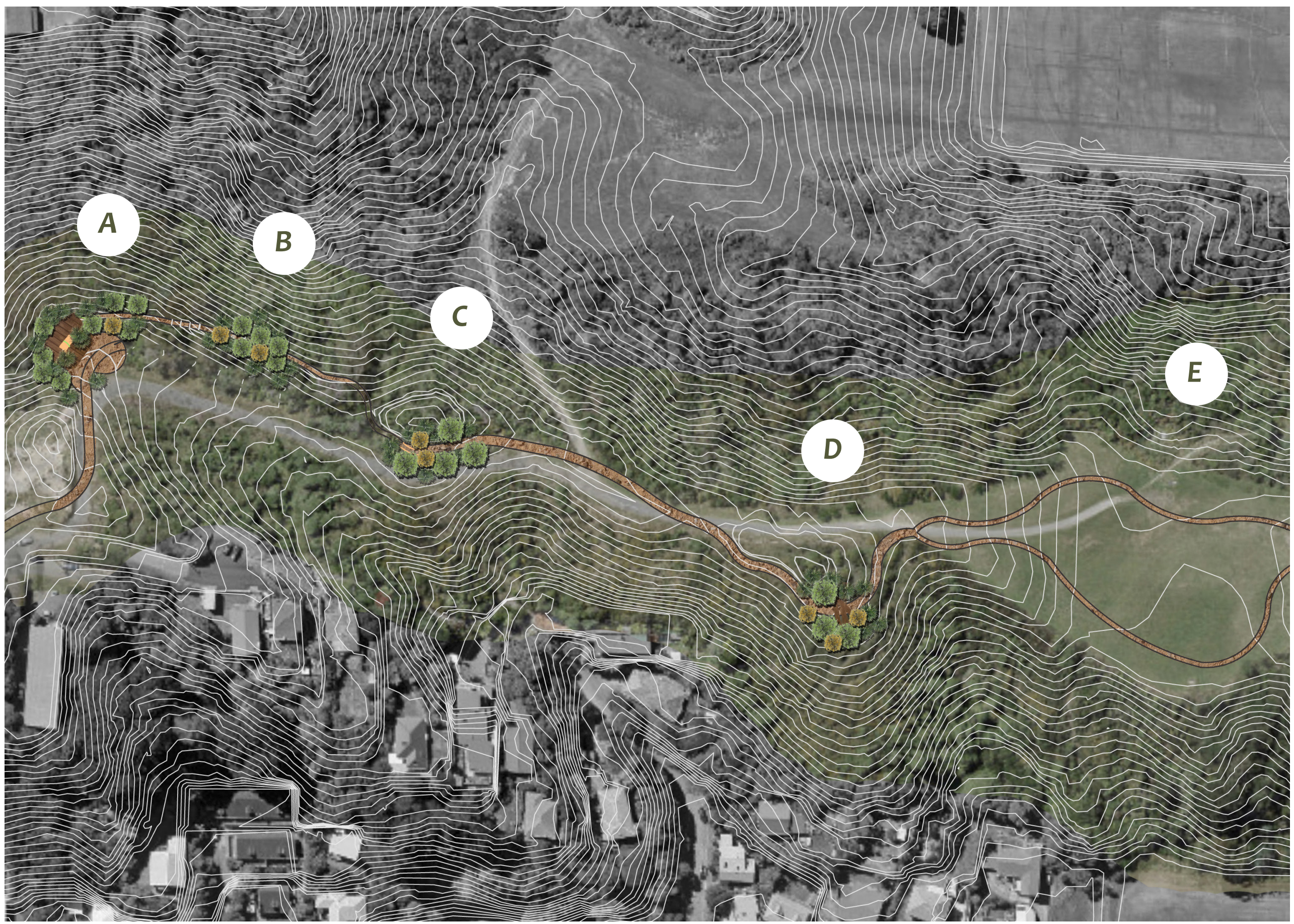




\section{+ CONCEPTUAL IDEAS}

Fig 7.16 | Initial design sketches.

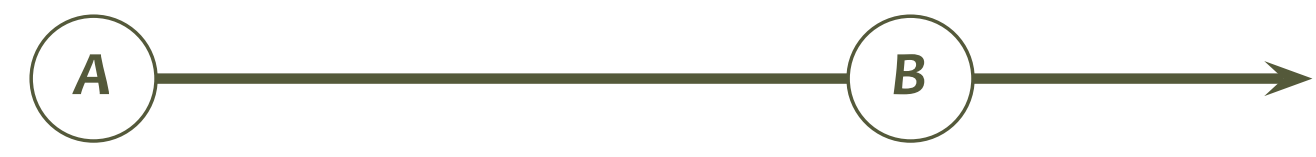

EVTNT

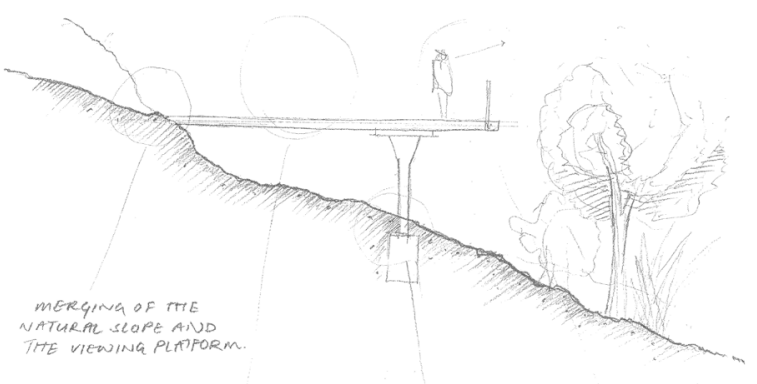

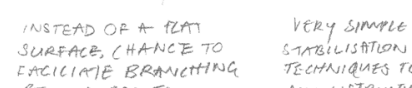

STRUCTURES TO
DTRACT HRDS TO THE

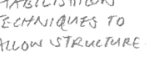

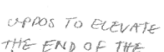

TRuCTURE, TO Pu
SOLLE ABOVE-THE

TeGETATION

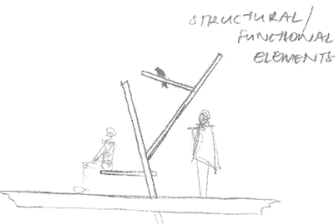

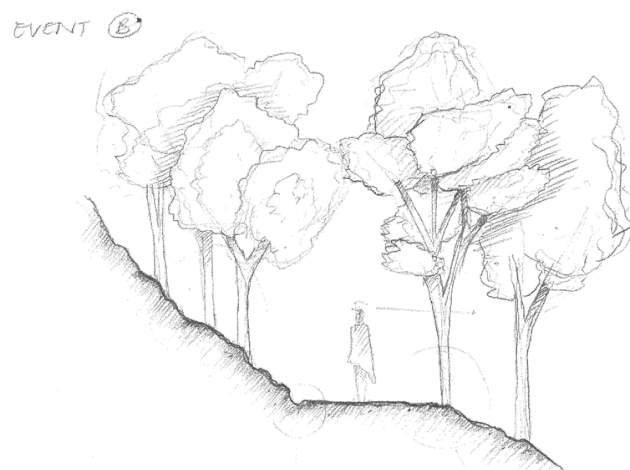

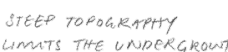

Limits THE UNDER

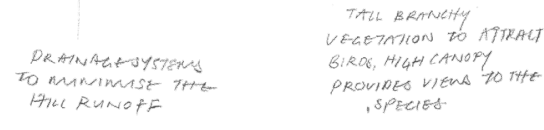


(c)

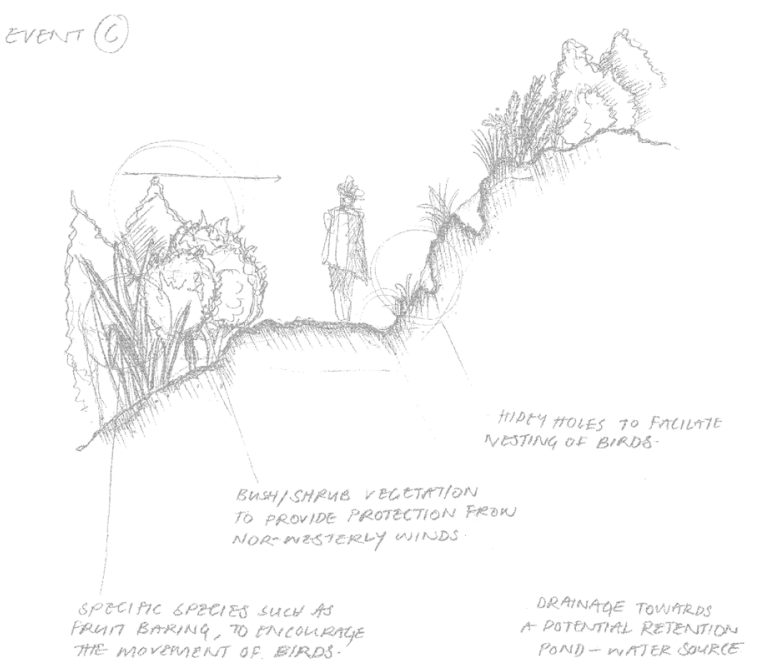

D
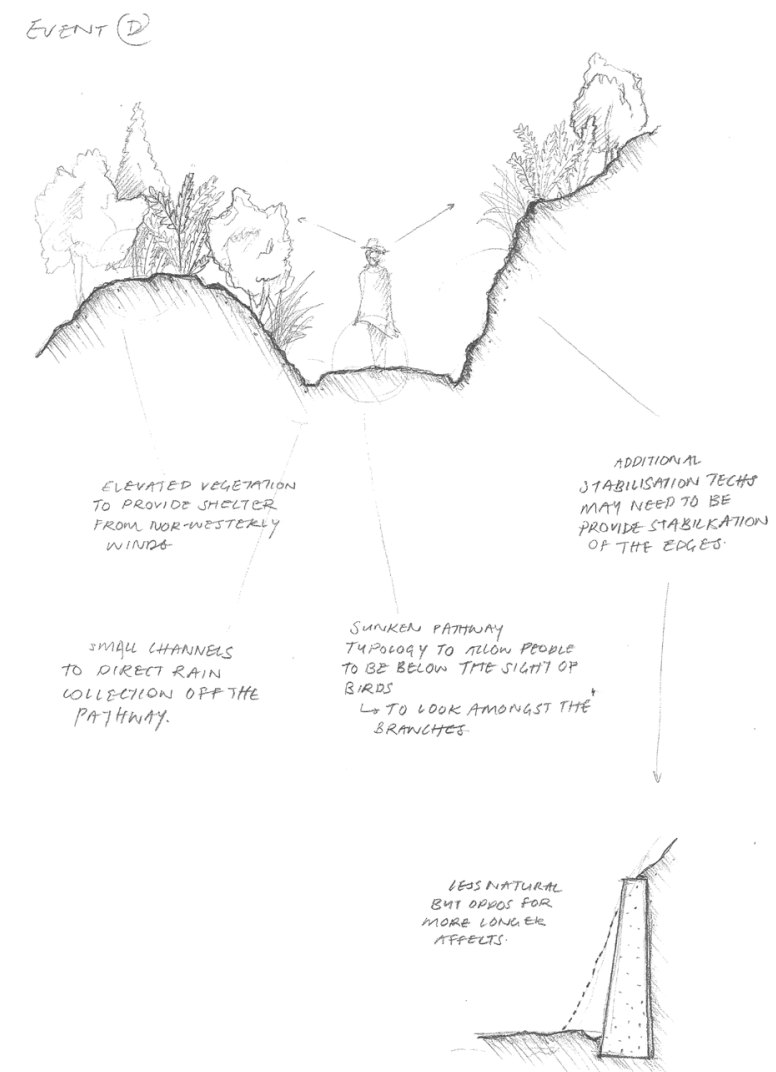

E

ENANT Es

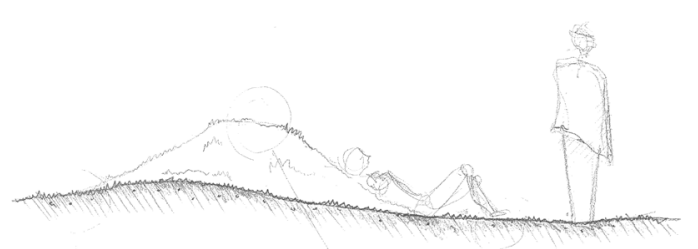

VRY GENTEE SLOME,
CAPTTLASING ON THE

GENTL mounNS THAT PROWDE
VARIATION TOAHE
GROWND PLAME OFFERS WAYYS TO SIT
ANID LOOK W MP 70 THE
SKY.

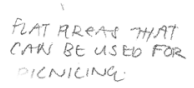


+ I NTERVENTION 1

\section{LOOKOUT FORM}

Fig 7.17 | Diagrams around the lookout's base.

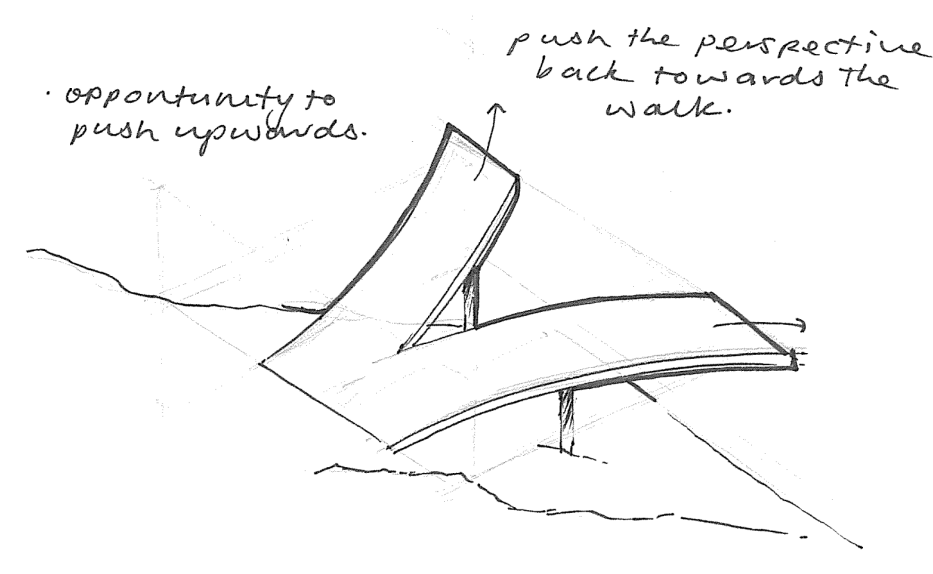

narrowed, forced dinectional view.

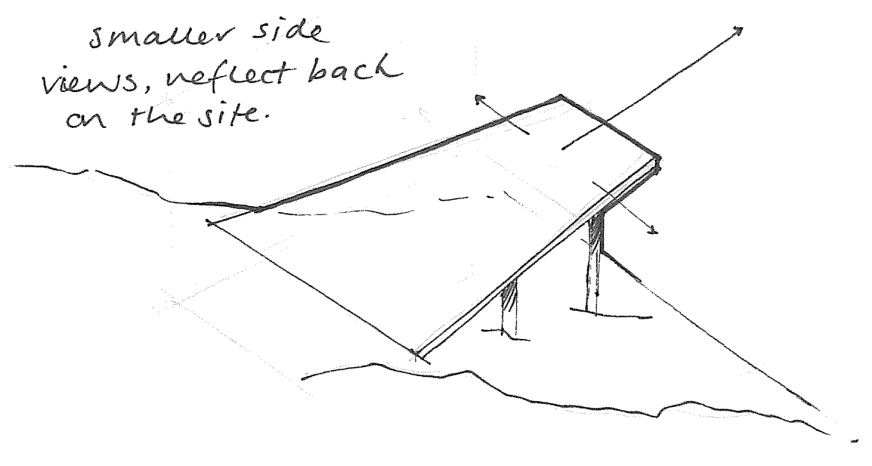

$360^{\circ}$ vews + divection

some what dinectional

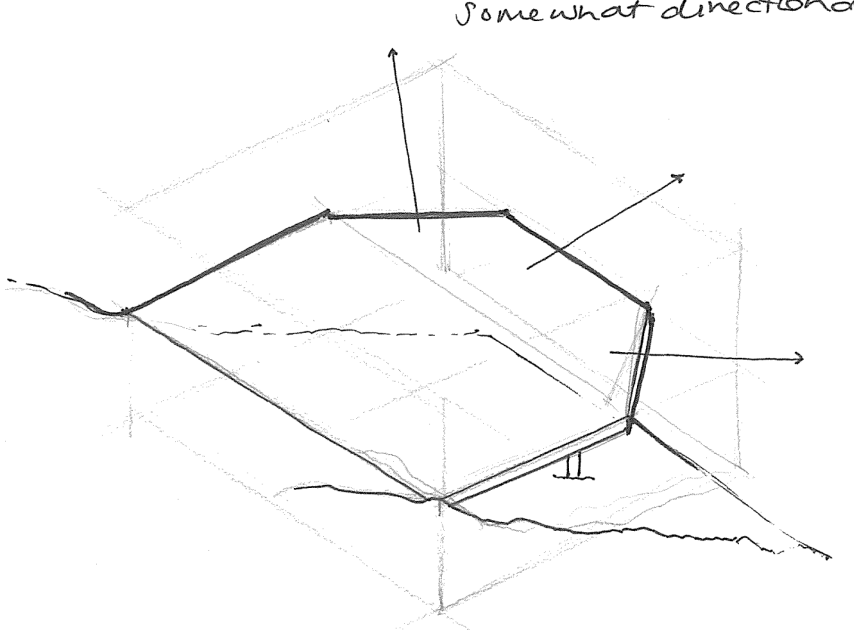



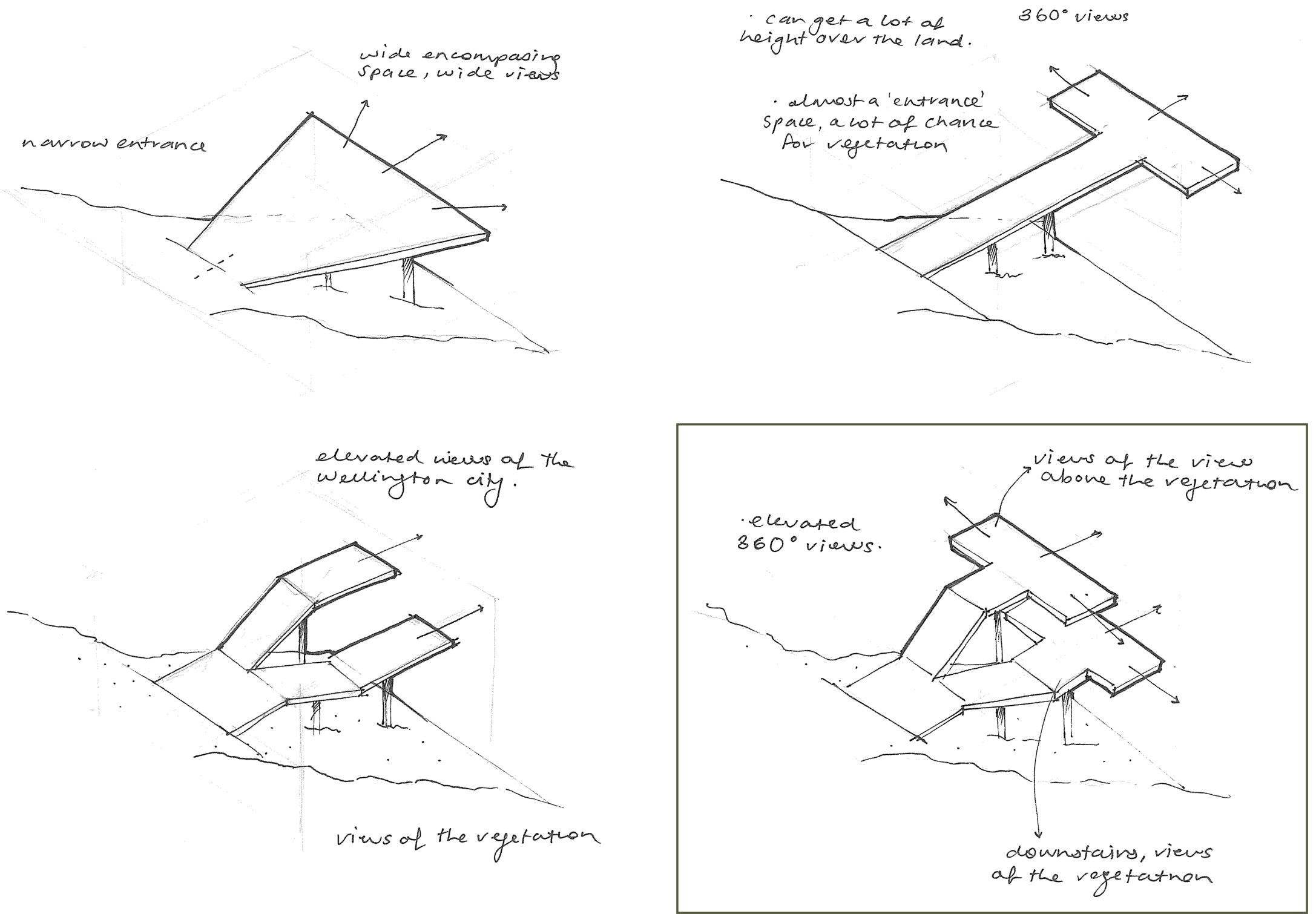
Fig 7.18 | Sectional exploration of form.

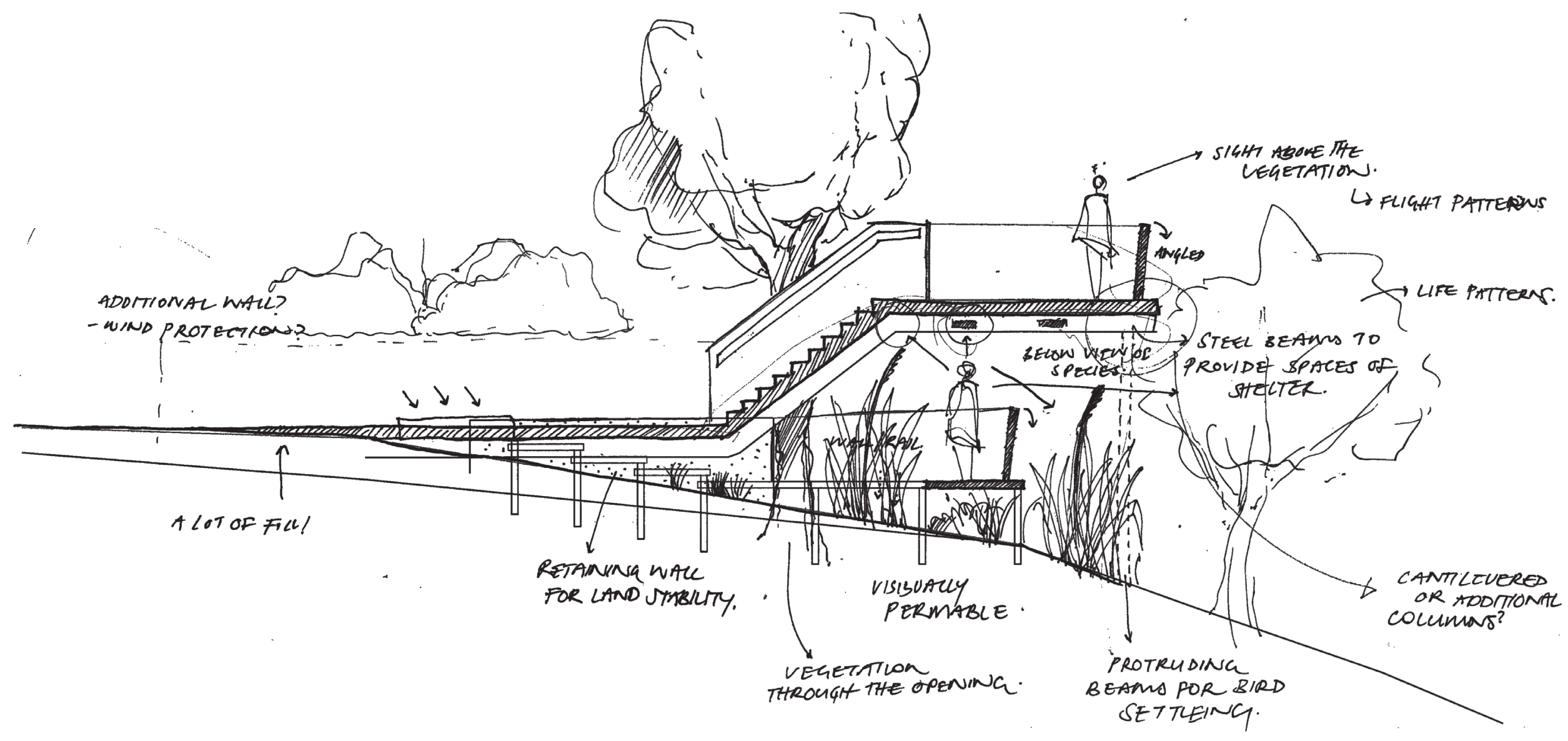


Fig 7.19 | Exploration of form in plan

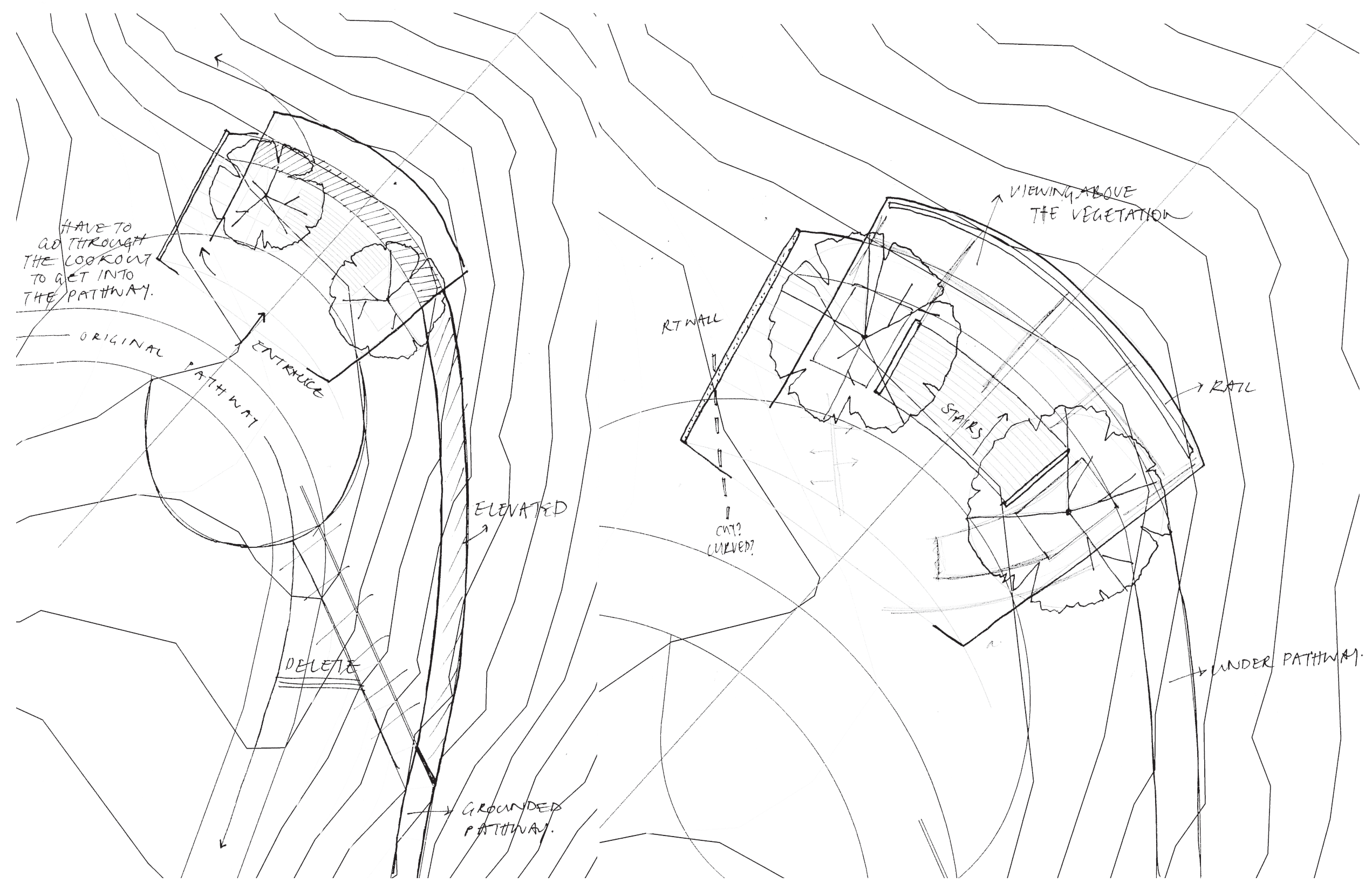


Fig 7.20 | Digital exploration of chosen form.

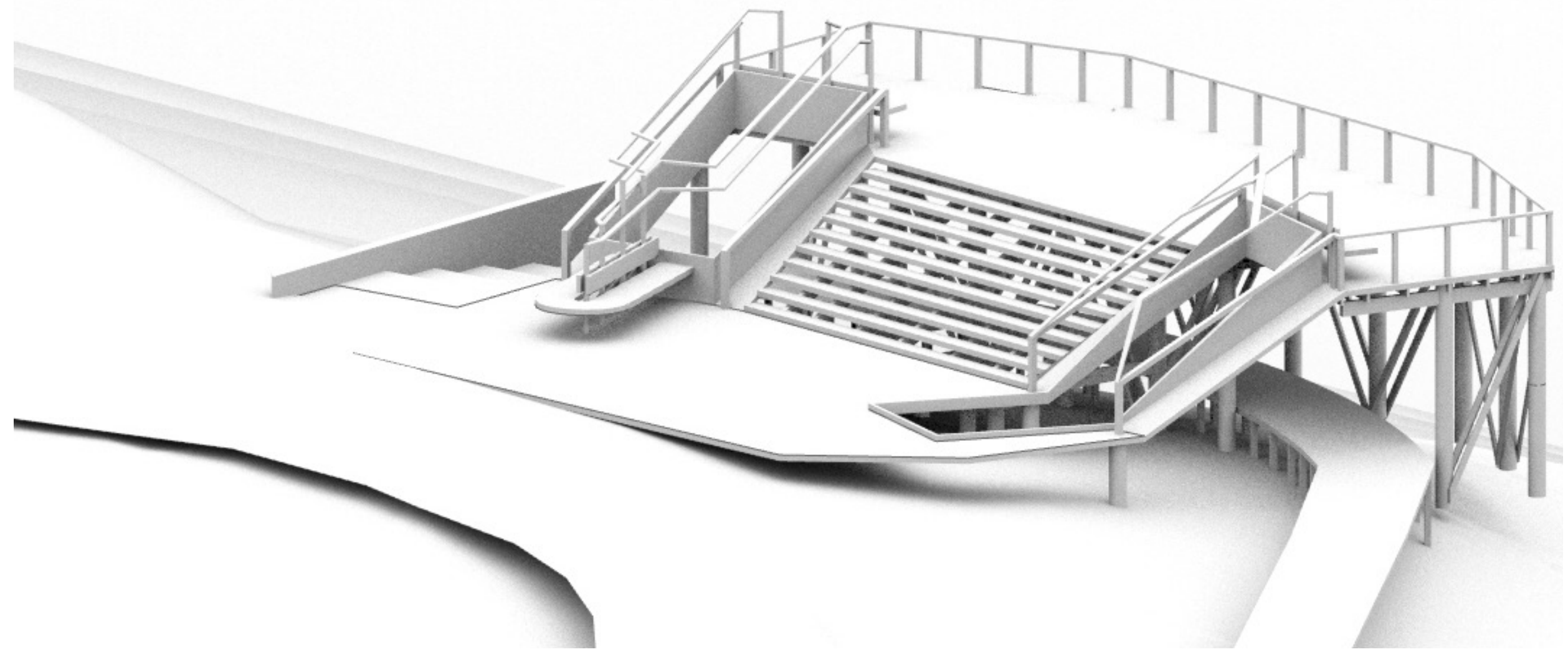


Fig 7.21 | Components of the form.

A | Retaining wall to protect a sunken path underneath the

C | Small seating structure that accommodates both humans structure. and wildlife.

B | Elevated perch that can be used by wildlife.

D | Sunken pathway underneath lookout.

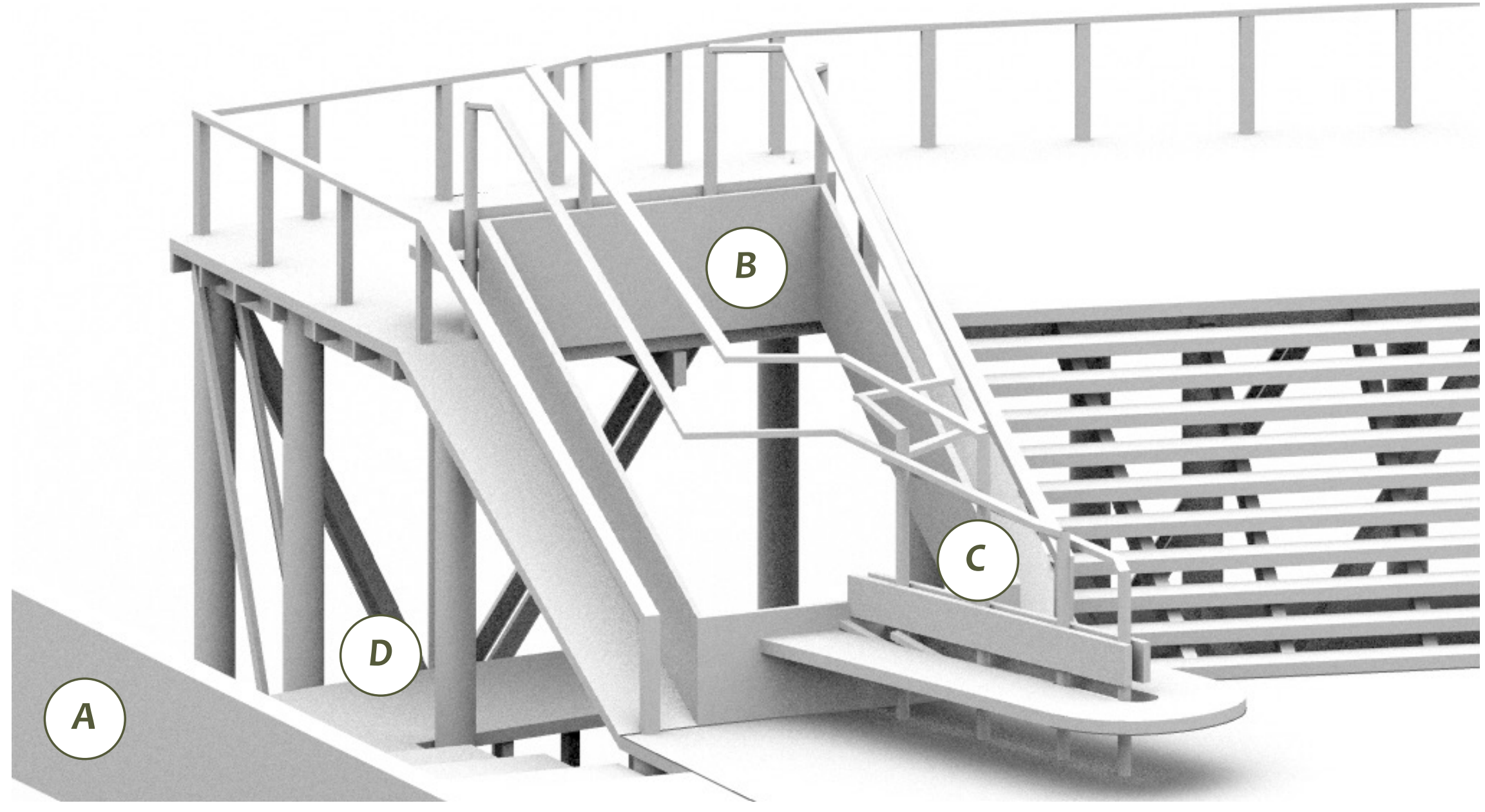




\section{+ REVIEW \# 2}

Aims:

The aim was to design only one of the chosen locations in high detail, instead of spreading through all three sites and presenting half-finished ideas. The feedback would be direct and the guest reviewers can gain an understanding of the entire project by proxy.

\section{Feedback:}

There were three main areas that were brought up within the presentation as areas to improve and further adjust. They are as follows:

$+\quad$ Although it was an area that was suggested within past presentations to only partly address, it is perhaps time to bring back focus and design intention towards insects and the role they can play with this project. Whether including them in sections as a way to communicate insects will also like and use these spaces, or more diagrams towards the system of dual benefits to birds and insects.

+ Focus has been so directed to understanding birds, more attention needs to be made towards people. It was suggested to look more at the human 'client' perhaps the elderly, due to the sites location and low topography. Adaption then needs to occur to understand movement in terms of universal access of the sites, both individually and as a whole. As the discussion advanced, smaller scales to this issue was also brought up, in that seating and places to stop should also be considered.

+ Some of the designed elements, specifically the lookout/site entrance need to embrace the principles from the precedent analysis. Discussion of the intentions of the space were orally 
communicated better than visually represented.

$+\quad$ There definitely needs to be more emphasis on making the entrance a proper entrance and statement within the wider design scheme. Further iterations will be beneficial to push this idea to become the statement that it was intended to be.

\section{Conclusion:}

After consideration of the given feedback, a series of adjustments and changes have and will be made. All of the feedback was relevant and will push the design to the next level when achieved.

Next:

As communicated within the presentation, talking to ecologists and ornithologists and presenting to them the same information that was shown in the review is the next step. They can provide feedback and advocate for the bird species, by discussing the behaviour and motives of birds within urban environments and whether specific species would be attracted to the designed spaces. Changes to the design will occur depending on the feedback after this. The other two sites will then go under this same process, of site analysis, initial concept design, consultation, and then final design detailing and refinement. 


\section{+ ETHICS}

Why

The interview process was decided upon when design decisions were ending with, "this could be beneficial to the birds, they might use this space". There was no confirmation towards the success rate of what was being designed with consideration towards avian life usability. This was where thoughts around talking to professionals, such as ecologists and ornithologists, would provide a more grounded final design.

The role of the designer then became to work with the human aspect of the thesis, bringing them to the site and designing infrastructure to encourage movement and resting points, whereas the interviewees would provide insight towards what types of environments birds will respond positively to. Their participation would support the thesis by advocating for the wildlife.
Who

The process towards finding individuals to contact varied as time went on. Initially looking into theoretical readings to find individuals was not successful so engagement with the Wellington community became the alternative. Pamphlets from Zealandia, suggestions from staff and plenty of emails lead towards three people that were contacted for this process, each offering unique perspectives to the design. Mr Paul Blaschke, from Victoria University, provided information pertaining towards the vegetation side of the design, suggesting alternative species and working around what the site currently offers. Dr Pascale Michel who works in Zealandia had the most informative comments around the birds, and ways to encourage interaction. Finally, Mr Tim Park works within the Wellington City Council, so he based his suggestions around the work he has done for parks and conservation efforts. 
How

Due to time constraints, only one of the design locations were shown, but the intention lied with the visual documentation and a question list to be a guideline for answers around spatial arrangements to be applied to all future design opportunities. The process to undertake the interviews relied upon not just having a list of questions, but also providing visual documentation, to allow them to understand the spatial qualities feedback was pertaining around. This resulted in starting the interview with a quick 15 minute summary of the project and Location 4, the Nesting Hide-Away. Explanation around each event along this pathway allowed the interviewee to get a sense of the intentions around the design, to then later judge its validity and potential successfulness. The list of questions were centred around avian interactions that they may have come across in their profession, to be incorporated further along the design process.

\section{Pests}

One of the most underlining issues that was brought up within this process is the current lack of attention towards pest management. All three members conveyed the importance towards how reducing the amount of pests, especially within a residential area, can truly define whether the site will be used by avian species. There are not as many solutions that offer the same amount of results as enclosing the entire site would have, which is very difficult to actualise and enforce. Simple changes to each intervention and the entrances of the site can be small alternatives that supplement the effect a fence would have. 
Lookout (Fig 7.22)

This received the most variation in feedback, stating a pressing need for change but they all proposed different ways that this could be achieved. Visualising the different levels of vegetation, due to emergence through the decking, was widely accepted as being a good way to experience different interactions within one space. The top of the vegetation has a different function than that of the under-story and trunk. The planting and establishment of this may be difficult however, it will take a long time for this space to grow as the images have represented them. Reducing the size of the overall structure will make it more attractive as a space to settle for birds, as the assumption that birds will not stop at heavily built areas contradicts the design of the lookout.

Although Mr Park understood that the main wildlife focus was towards bird species, he did propose the potential for working with lizards, as the question frames wildlife as what is being investigated. Changing the orientation of the deck to have an amphitheatre seating structure, facing down the ridge rather than to the sky could work towards introducing this habitat. Although this idea has a lot of merit, the full change from a lookout to a lizard sanctuary is difficult to change. But definitely adaptations to the decks structure could start to encourage lizard interactions as well as birds. Open sunny areas and plenty of rocks can facilitate this.

Regarding the beams under the structure, instead of just assuming insects will use and interact with the structure, more documentation to back up the process was needed. The interviewees suggested it is unlikely the spaces between the beams will be used by birds, specifically for nesting, but small adaptations can make it an attraction toward insects finding a home. Implementing insect focused design decisions will result in bird interest so the changes can still be beneficial towards the theme of bird interactions. Adding small vegetation species to the underside of the deck could also increase the insect life within the site. Species that need limited water and sun would be ideal. 


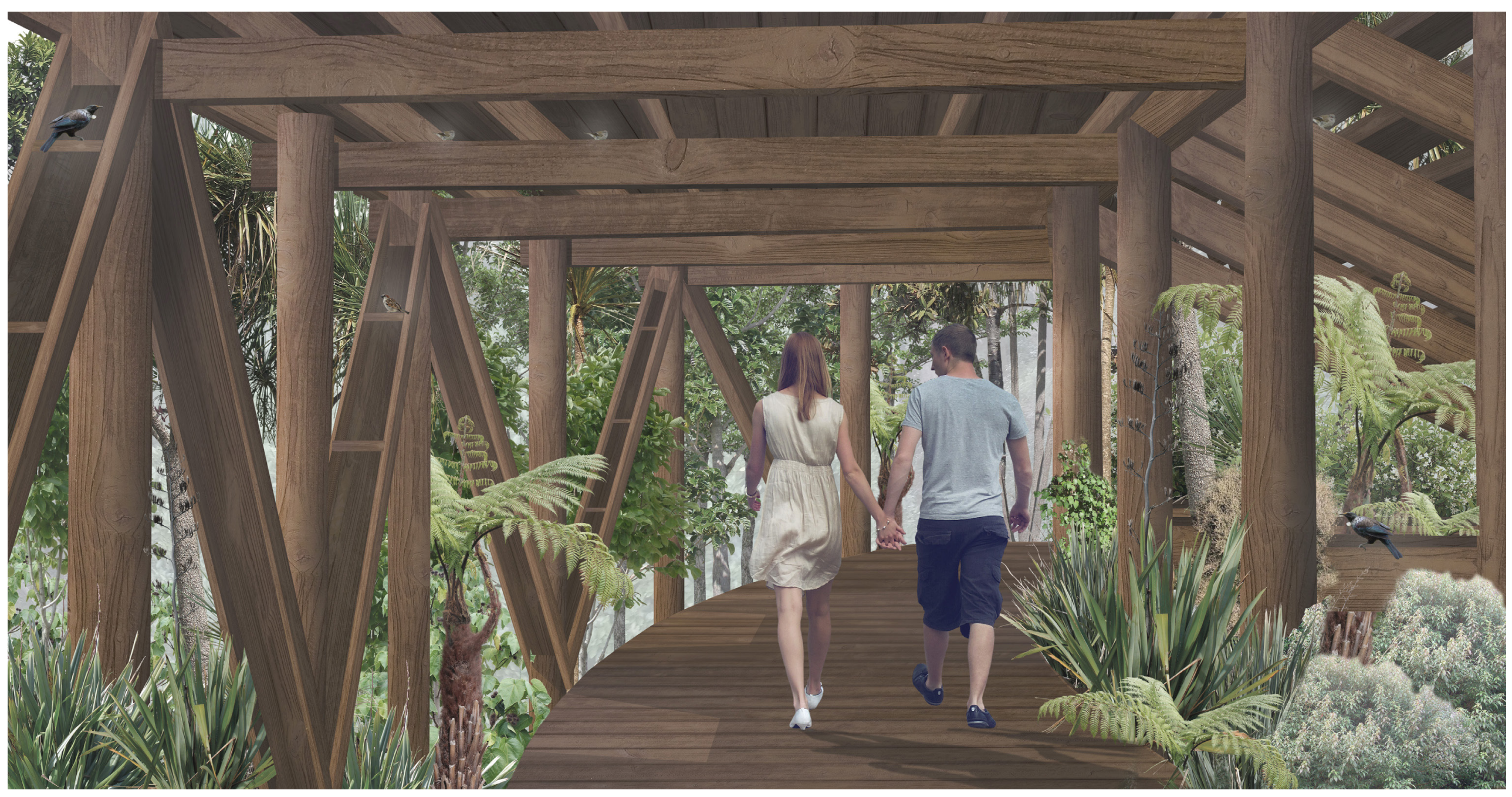

Fig 7.22 | The render showing the under passage of the lookout, presented to the interviewees. 
Arch (Fig 7.23)

This received the most consistent feedback through all of the participants. They all suggested a range of ways to improve and adapt the current structure to facilitate and encourage birds in the act of place making, to make a home.

Conceptualising the pest control management within the archway was easy as suggestions were direct and completely logical. The base of the structure is timber, as a way to enforce sustainable impacts, but the material is perfect for allowing common pests to climb up, reaching the vulnerable wildlife at the top. Changing the support columns to steel makes it infinitely more difficult for pests to climb.
Introducing vegetation to the top of the arch will make it more attractive to birds, particularly when flying overhead. Using the gaps that had been intended for nesting to instead plant small climbing species, will encourage settling. The theme of this site is still nesting, so leaving small spaces to do this is required. 


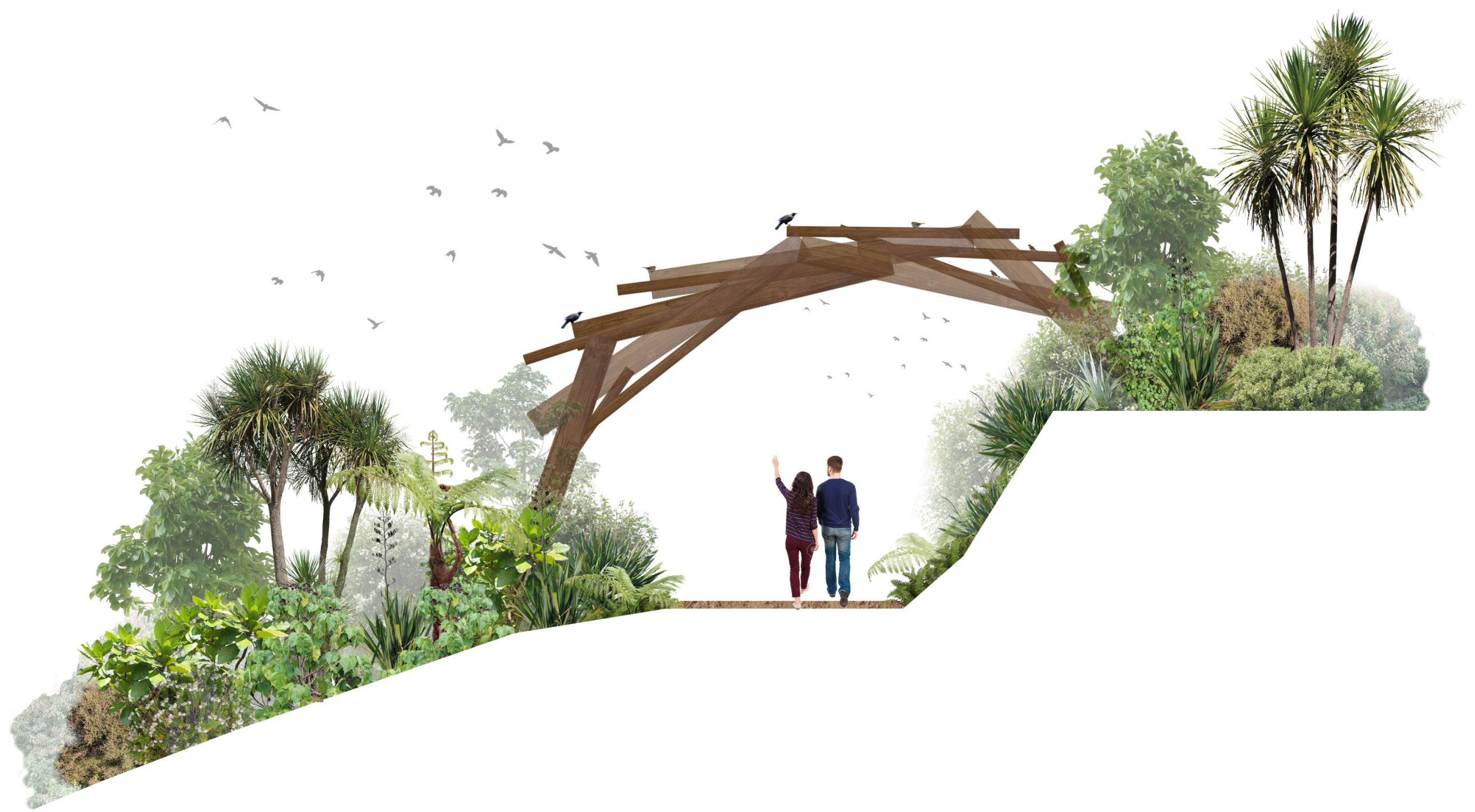

Fig 7.23 | The section of the archway, presented to the interviewees. 


\section{Nesting Boxes (Fig 7.24)}

Dr Pascale Michel, from Zealandia was the most informative towards nesting boxes and the relationship they can have to the activity of people within the site. Nesting boxes was an area that she was very passionate towards offering a lot of constructive criticism, something that was very much appreciated. She stated that nest boxes are an opportunity that can lead to several negative effects on the young. Boxes need to be constantly monitored, for cleaning and chick health care, so it becomes a location constantly wrought with human influence (Pascale, Personal Communication, 2019). The Department of Conservation, DOC, normally handle these types of interactions, with WCC being in charge of monitoring them (Pascale, Personal Communication, 2019).

Nesting boxes should be used purely as a method of conservation; Dr Michel (2019) stated that she felt it was ethically immoral observing young birds around nesting boxes, as they are at risk of not surviving youth. Mr Park (2019) offered an alternative that worked towards limiting the amount of access people have to the nesting boxes. Similar to Zealandia, planting fake nesting boxes along the pathway that does not provide birds with the access of the nest facilities, would be a way to communicate and education people around the process of what they provide for threatened and endangered species (Park, Personal Communication, 2019). An active nesting box could be implemented deeper within the vegetation, out of the way of where people are moving, to keep the young from being in vulnerable positions (Park, 2019). However this does not reduce the amount of human access as WCC will still need to visit the active boxes.

Weighing up these two options resulted in a lot of deliberation 


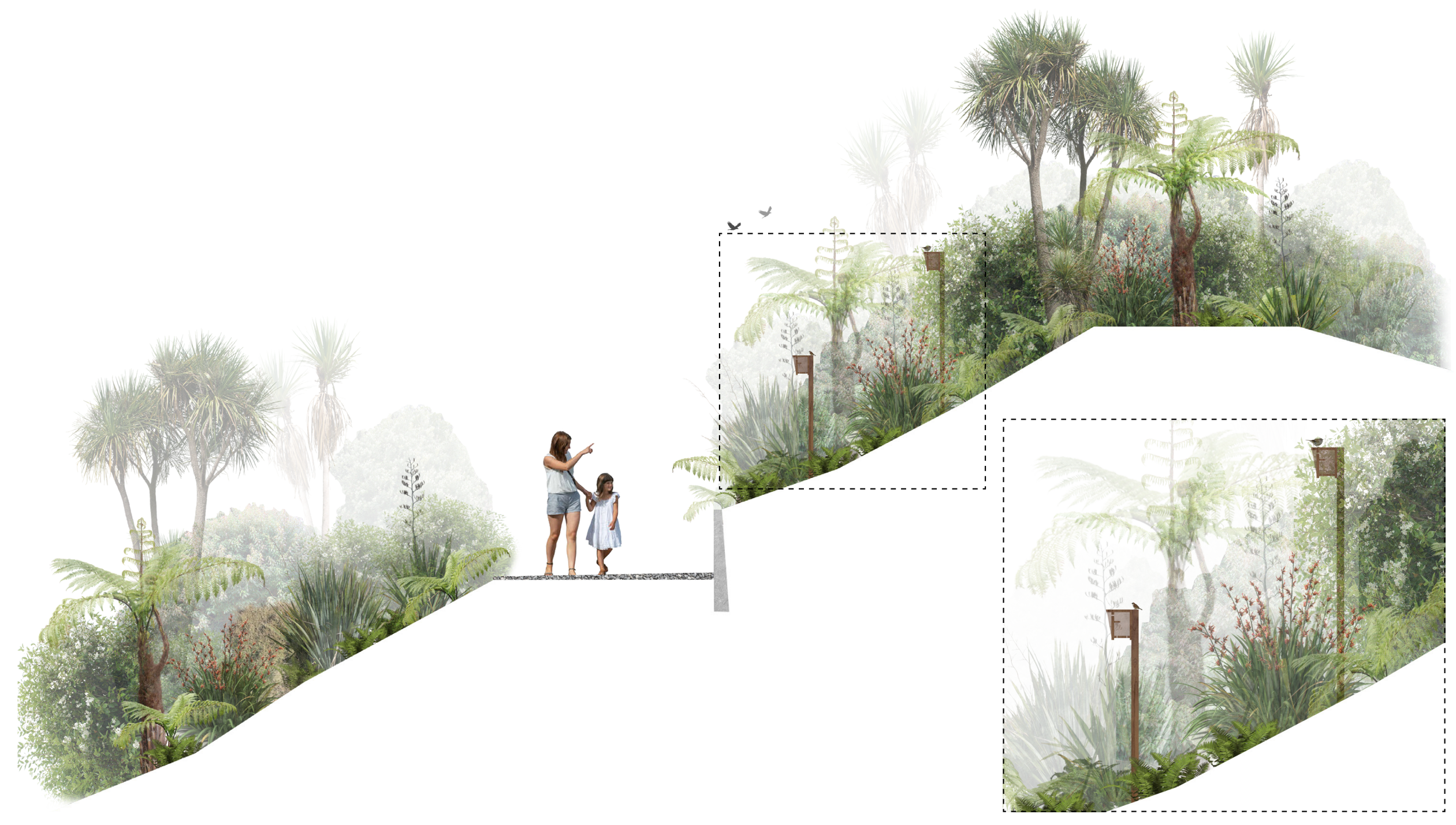

Fig 7.24 | The section showing nesting boxes, presented to the interviewees. 
around what overall affects were desired from implementing nesting boxes. If biodiversity towards endangered species was the aim the answer would be no, as too much relies upon pest management and the involvement of WCC. If species being targeted are common throughout Wellington, the boxes could become a backup for birds. The monitoring of the boxes then could be a community focus, where it is not WCC that is responsible for cleaning and maintenance, but the residents in the area. Involving regular people to this role could result in an infinitely more successful site as the interaction is constant and ongoing, relationships are being formed that have positive results towards strengthening the wildlife in Wellington.

Designing nesting boxes that are not intended for endangered species and instead supplement the surrounding natural environment will be the most successful. The phrase of natural over man-made was brought up as a potential forefront of design decisions, that the less built forms the better. Providing vegetation to nest in naturally will be more successful than any nesting boxes, particularly when the vegetation has structure, a mixture of different layers and species, offering the most advantages. Mr Paul Blaschke (Personal Communication, 2019) supported this claim by stating, "what elements of the nesting boxes are going to be attractive to the species when the natural resources are right alongside the man-made?" Having the boxes more open, as a shelter alternative when weather is bad, could prove the structure as needing less ongoing maintenance and place emphasise towards the natural vegetation within the site.

Therefore, the final solution for the implementation of nesting boxes is to function as backup towards the surrounding natural environment. The boxes close to the pathway act 
more as a sheltering space, resulting in less need for monitoring compared to if they were in full use. A place for perching, for huddling when it rains, a halfway home.

Partial shelters can still have a community engagement, although not an everyday focus, a weekly commitment can be established. If the surrounding site was further developed, the growth of vegetation to other sports fields, the possibility to establish a series of nesting boxes could be implemented, while the site becomes council owned and has a biodiversity focus. Although not at this stage yet, the future of this site has a lot of potential to become secondary to Zealandia.

\section{Discussion}

Ideally, if the year was longer and the intention to engage with the wider community was an earlier realisation, the potential to conduct these interviews for all design locations would have been the most valuable experience. The perfect way to conclude these interviews would have been to represent the Nesting Hide-Away with the adjusted design, to get final feedback towards where changes were done correctly and if it was what the interviewee had imagined. It would have been a more back and forth exchange rather than a one-time event. Along with this, the process could have been replicated towards all design sites that were covered in the thesis. But like what was mentioned previously, time frames and establishing ethics approval took a while to organise, however, still resulting in a widely beneficial presentation. 


\section{+ F I NAL DES IG N LOOKOUT (A)}

This space aims to act as the entrance to the entire Nesting Hide-Away location. It merges the built form of a lookout with landscape qualities such as planting to attract birds into the space. It is north facing to capture stunning views back into the city, looking down at the future pathways in the design.

(1) Fig 7.25 | Masterplan|1:1,500@ A3

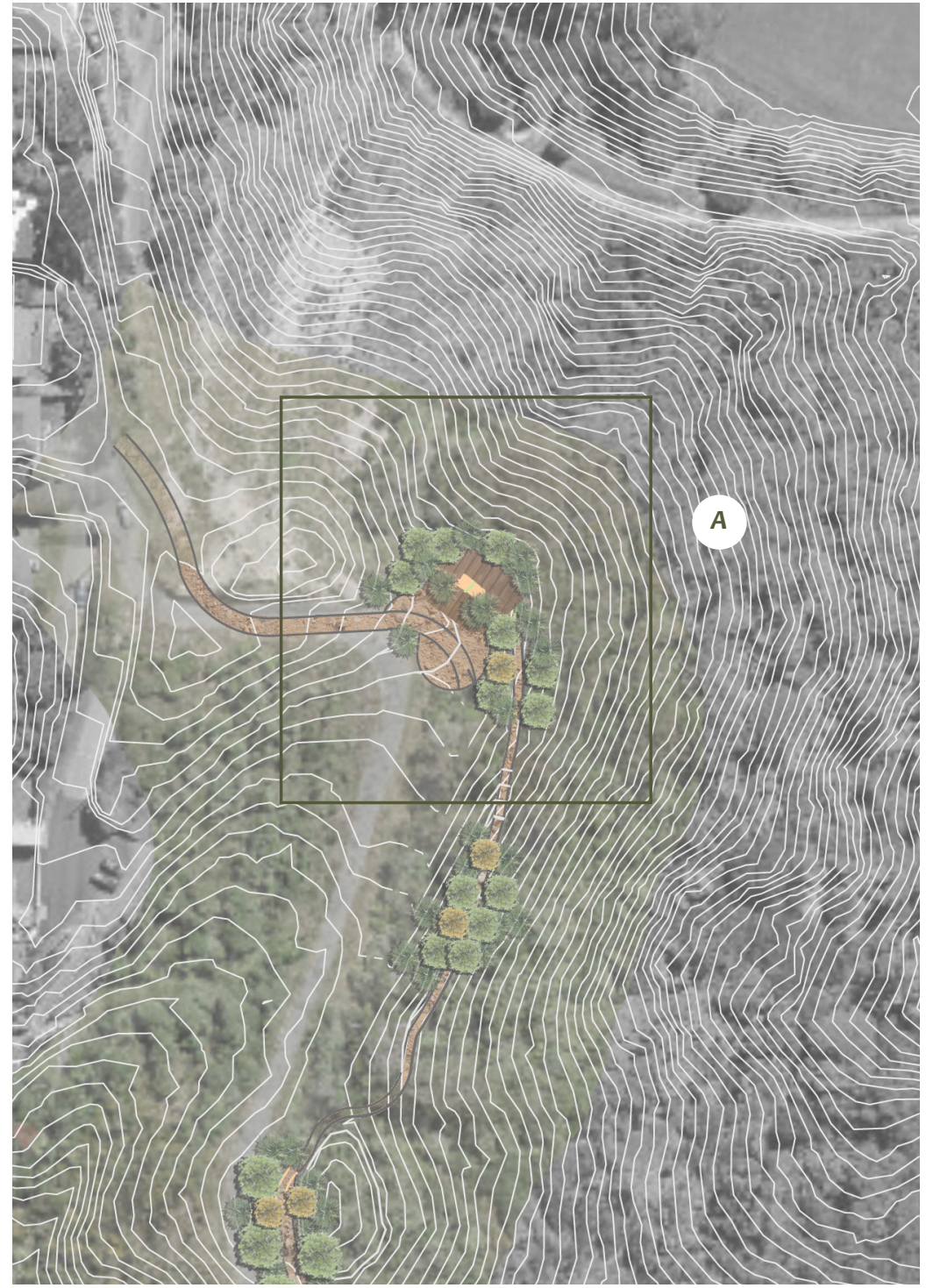




\section{+ PLANTING PLAN}

Planting within this area centres around providing attractive species that produce benefits to birds, such as flowers and fruit.

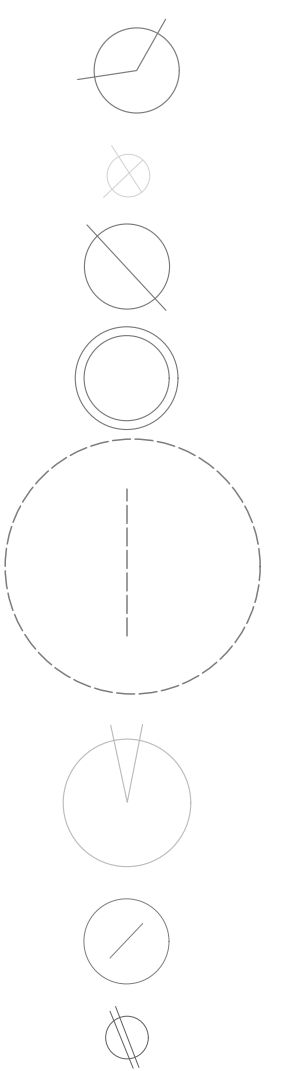

Coprosma propinqua | Mingimingi

Blechnum minus | Kiokio

Cordyline australis | Cabbage tree

Piper excelsum | Kawakawa

Hoheria sexstylosa | Lacebark

Aristotelia serrata | Wineberry

Phormium tenax | Flax

Arthropodium cirratum | Rengarenga

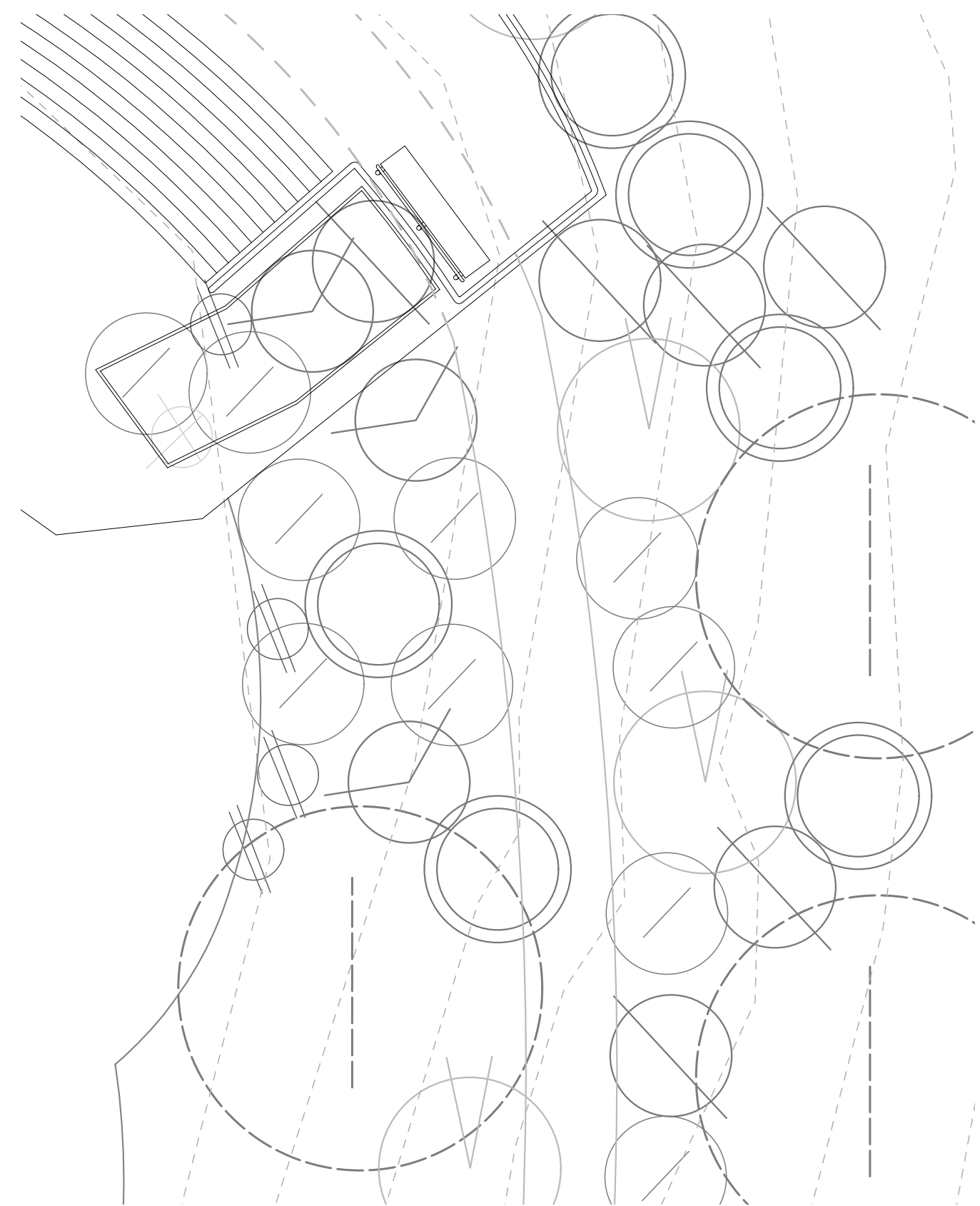

1 Fig 7.26 | Key for planting plan | 1:100 @ A3 


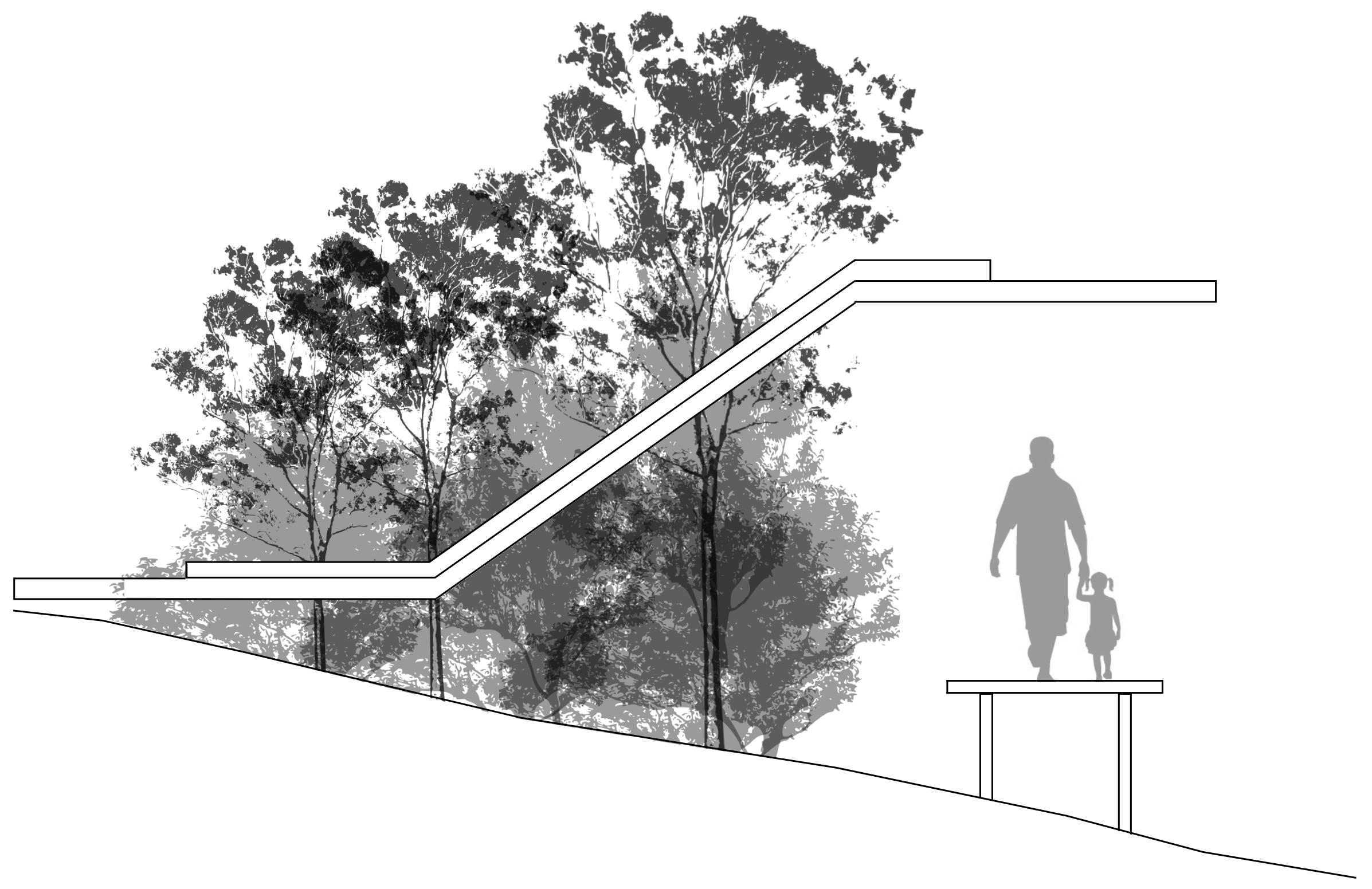

Fig 7.27 | A diagram showing the emergence of vegetation through the lookout. 


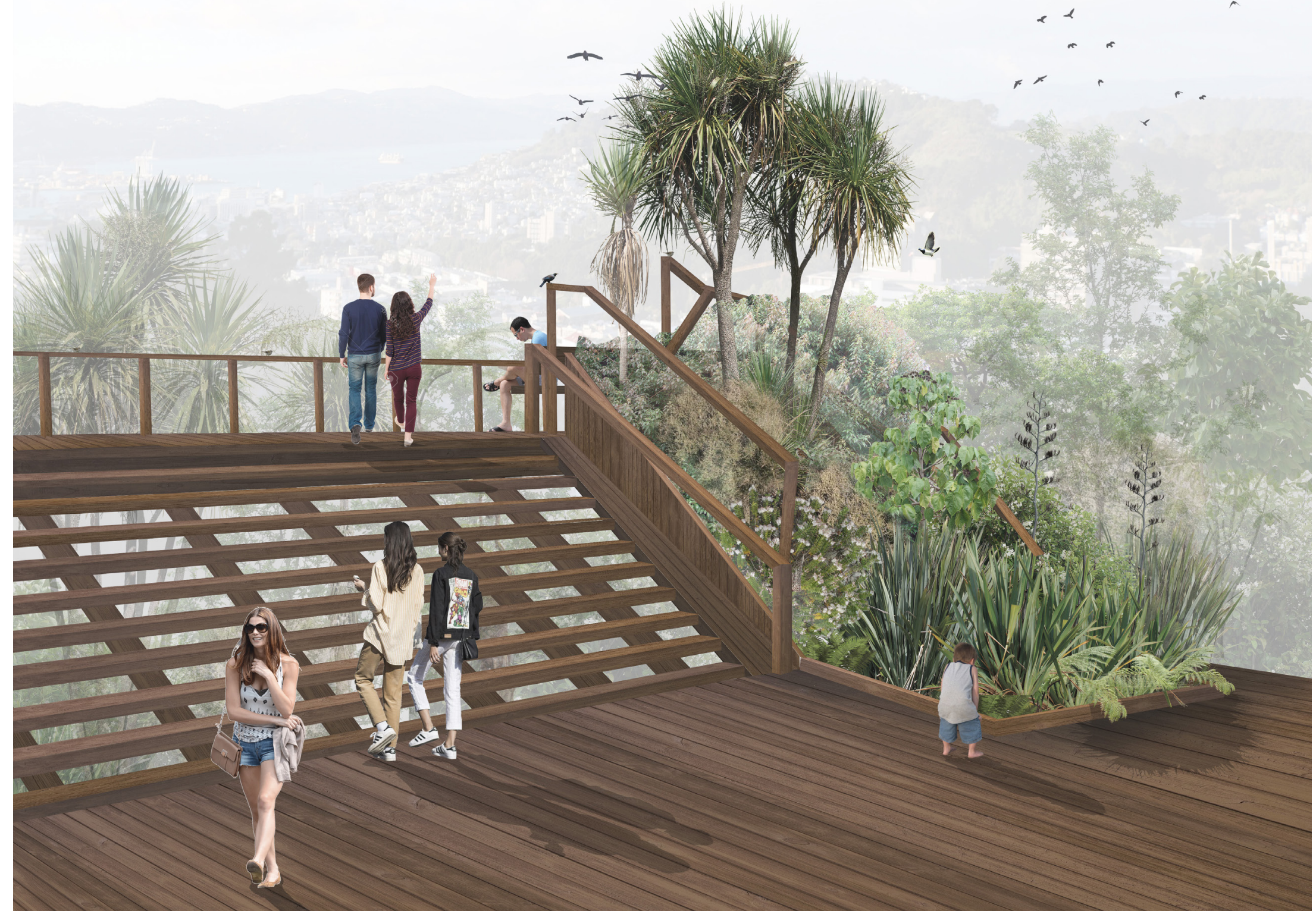




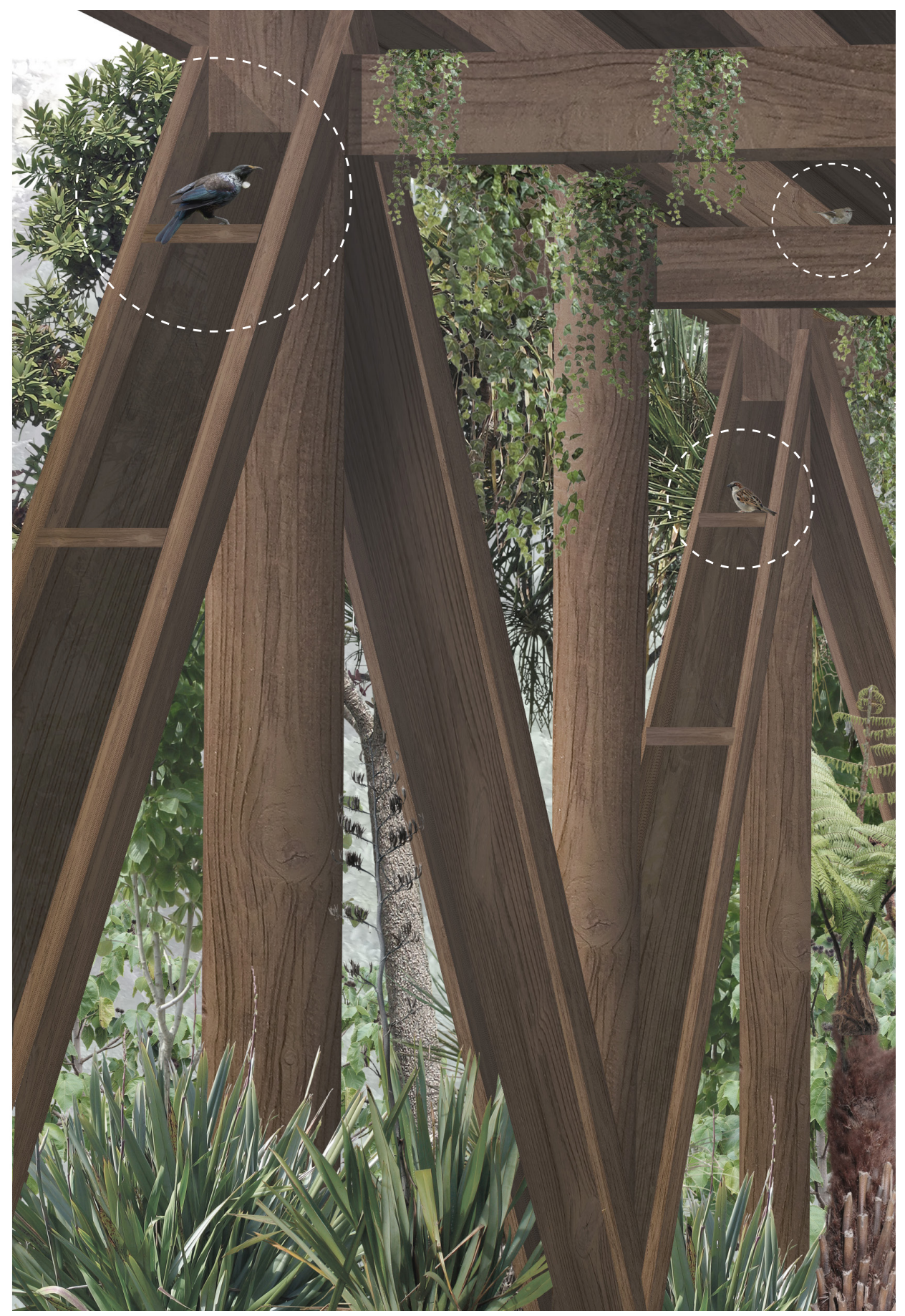









\section{+ FINAL DESIGN NATURAL NESTS (B)}

This site aims to explore a new pathway, protected from the exposed ridge, where the human users have the chance to reflect and look up to try and find naturally created nests.

1) Fig 7.30| Masterplan|1:1,500@ A3

+ Due to the location of being on the east side of the ridge, people are sheltered from the strong winds.

+ Semi enclosed walkway experience, where the vegetation acts as a shelter towards observing the sky.

+ Due to low levels of surrounding under-story vegetation, the gaze of the people will be directed upwards, towards natural nests that have formed.

+ Dirt/natural ground plane, to maximise the experience of being connected to nature as well as a low impact on the environment.

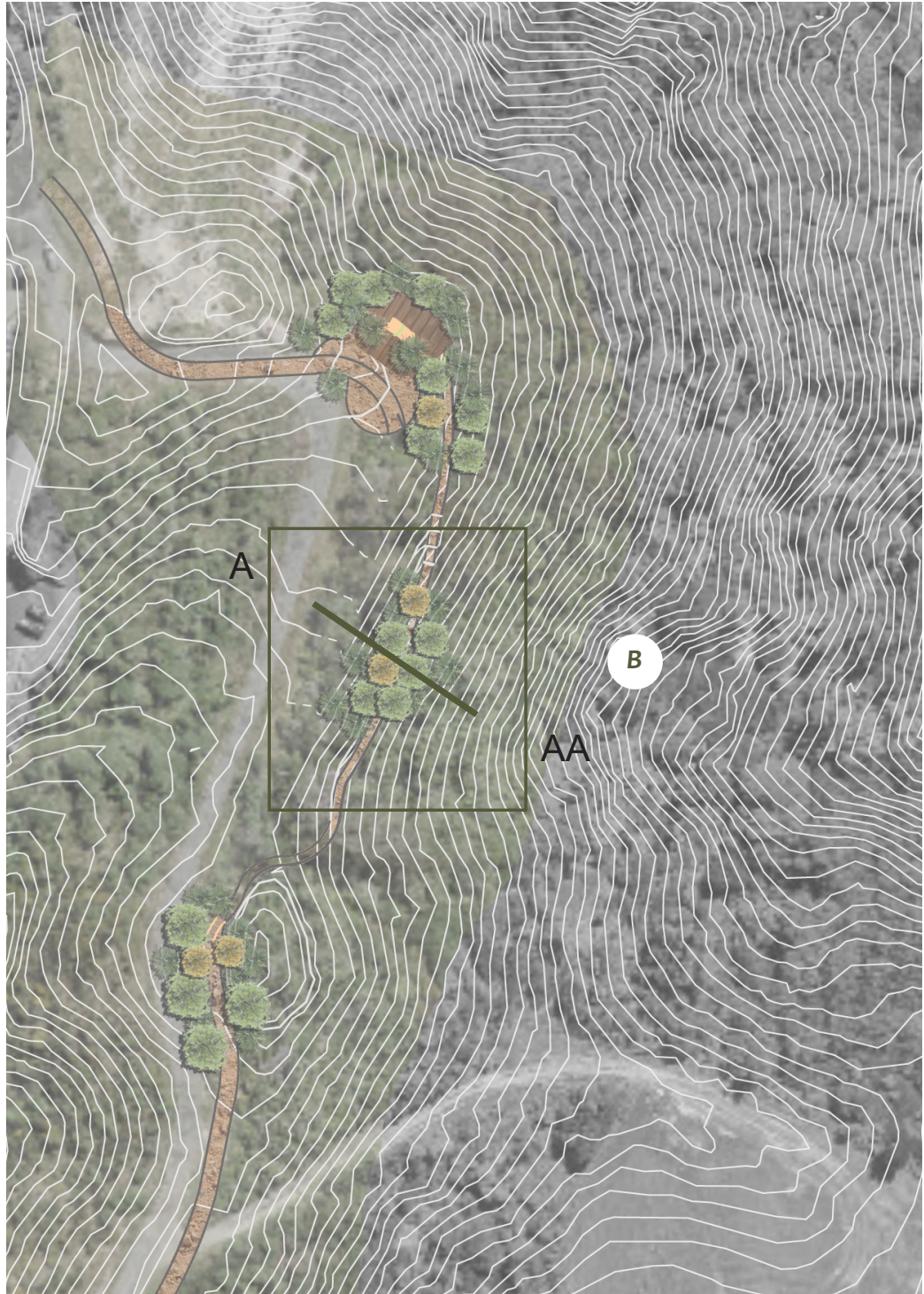




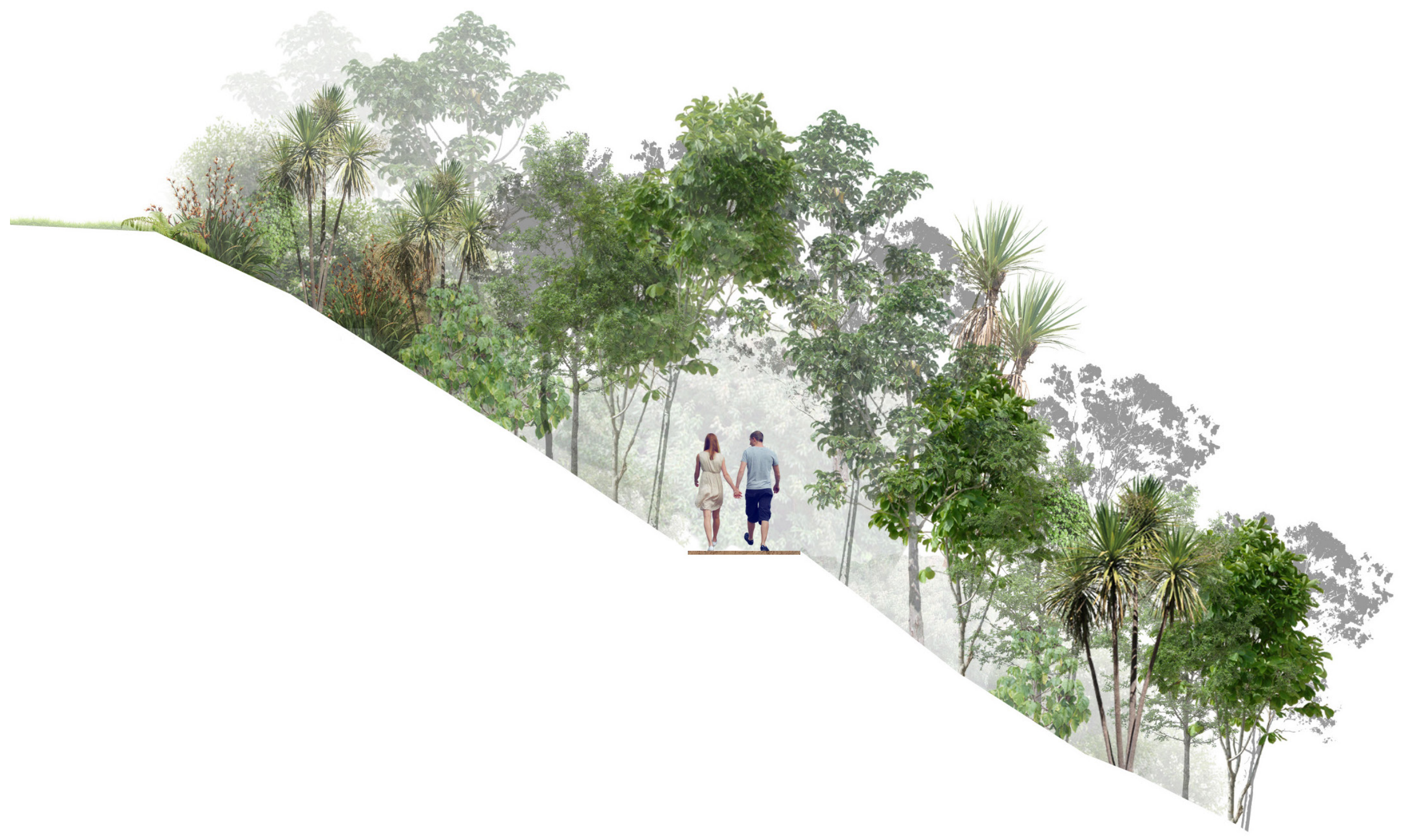

Fig 7.31 |A-AA | Natural Nests, 1:100 @ A3 


\section{+ FINAL DESIGN SHELTERS (C)}

Stemming from the interview process, these are a series of posts that facilitate perching of birds within the site, there are no nesting boxes any more. Instead the birds are encouraged to use the natural vegetation to make nests if required.

1) Fig 7.32 | Masterplan | 1:1,500@ A3

Fig $7.31|A-A A|$ Shelters, 1:75@A3

The vegetation acts to attract birds down to the posts to perch.

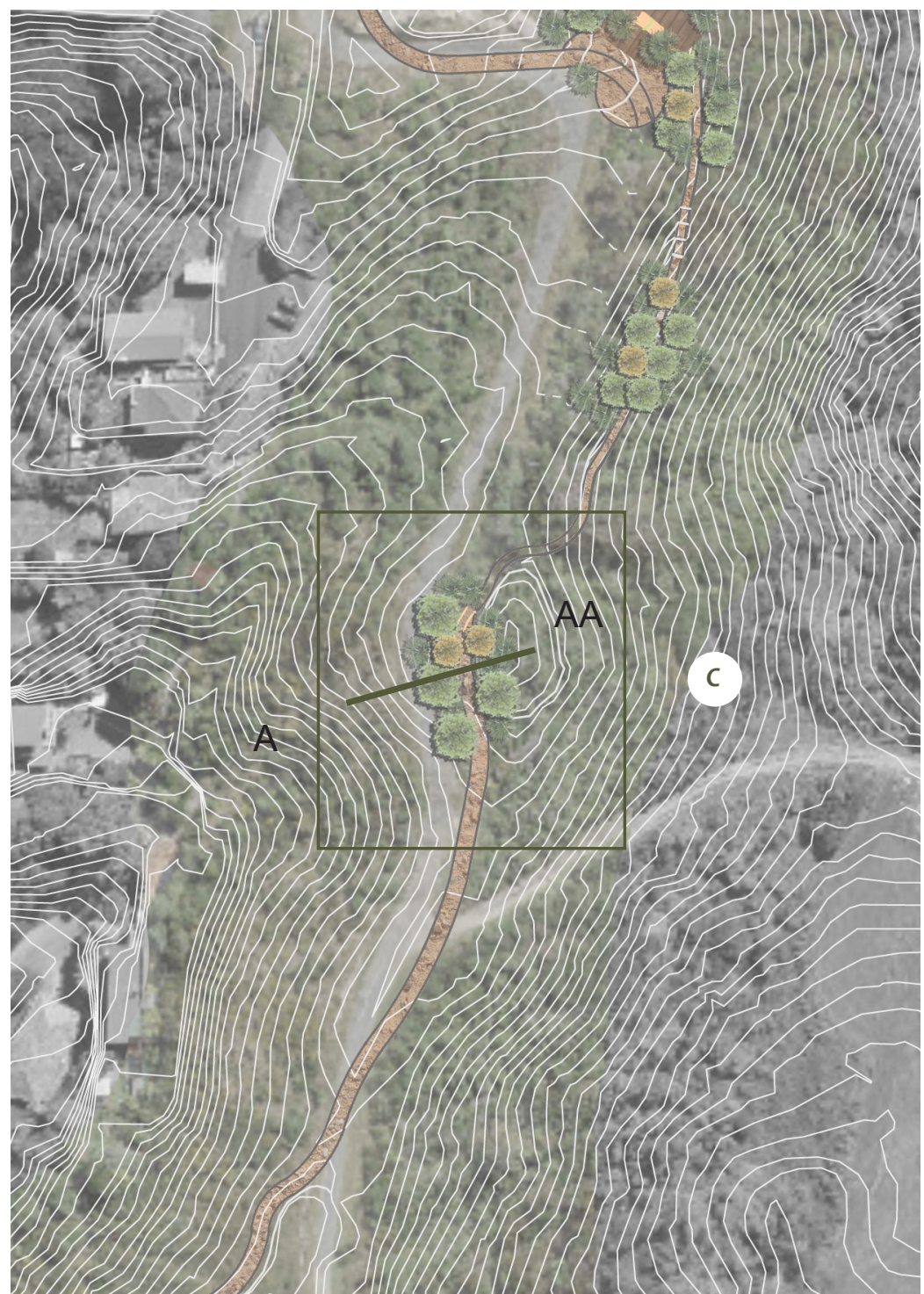


I Pseudopanax crassifolius, Lancewood

I Blechnum discolor, Crown Fern

III Cordyline australis, Cabbage Tree

II Coprosma lucida, Glossy karamu
II Piper excelsum, Kawakawa

II Pittosporum eugenioides, Lemonwood

I Kunzea ericoides, Kanuka

I Leptospermum scoparium, Manuka
I Dicksonia squarrosa, Rough Tree Fern

II Fuchsia excorticata, Tree Fuchsia

II Hoheria populnea, Lacebark

- Phormium tenax, NZ Flax

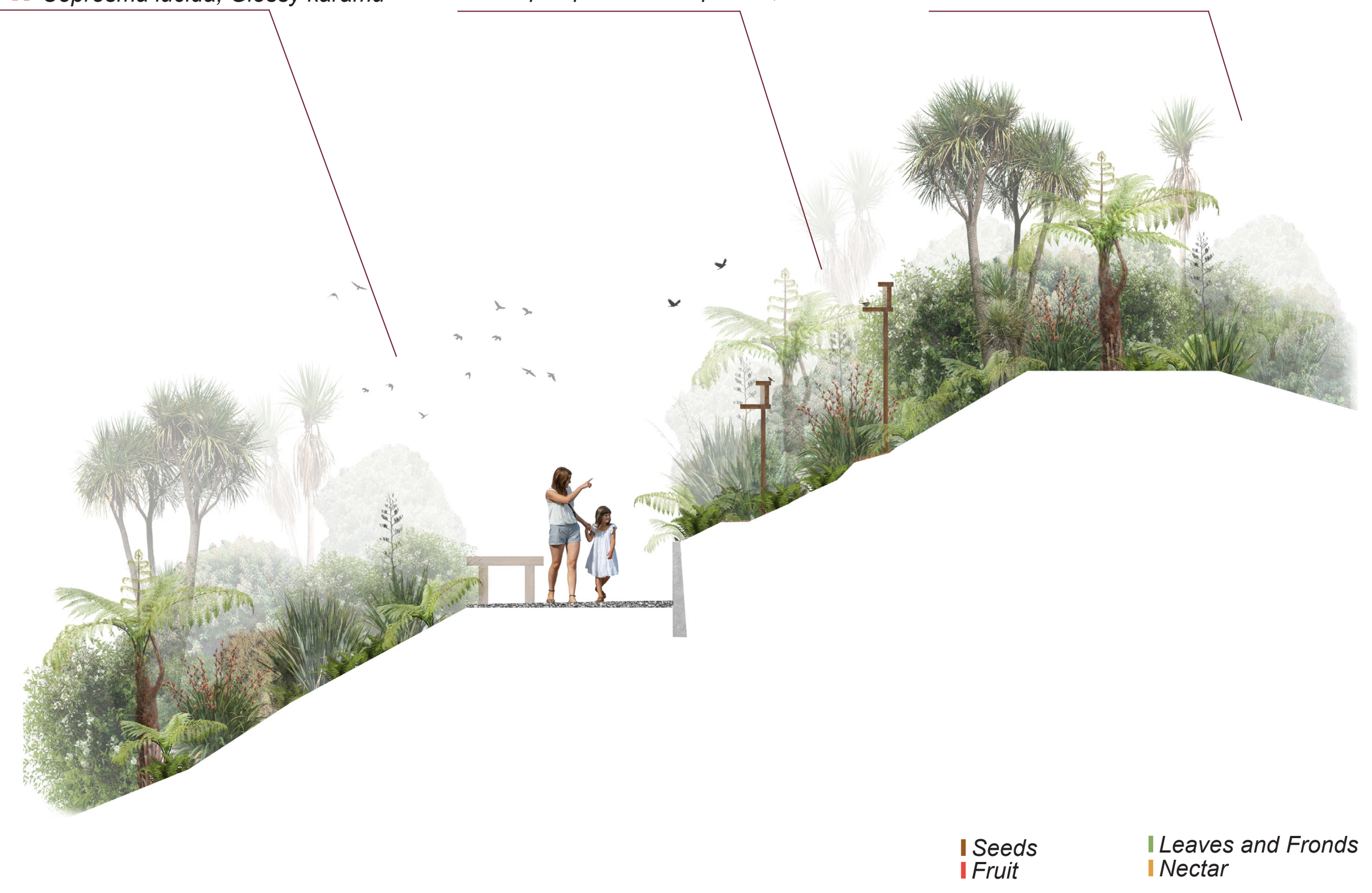


Fig 7.32 |The previous nesting box shape compared to the newly designed perching stations. This offers shelter for the birds without allowing them to use the space for breeding purposes.

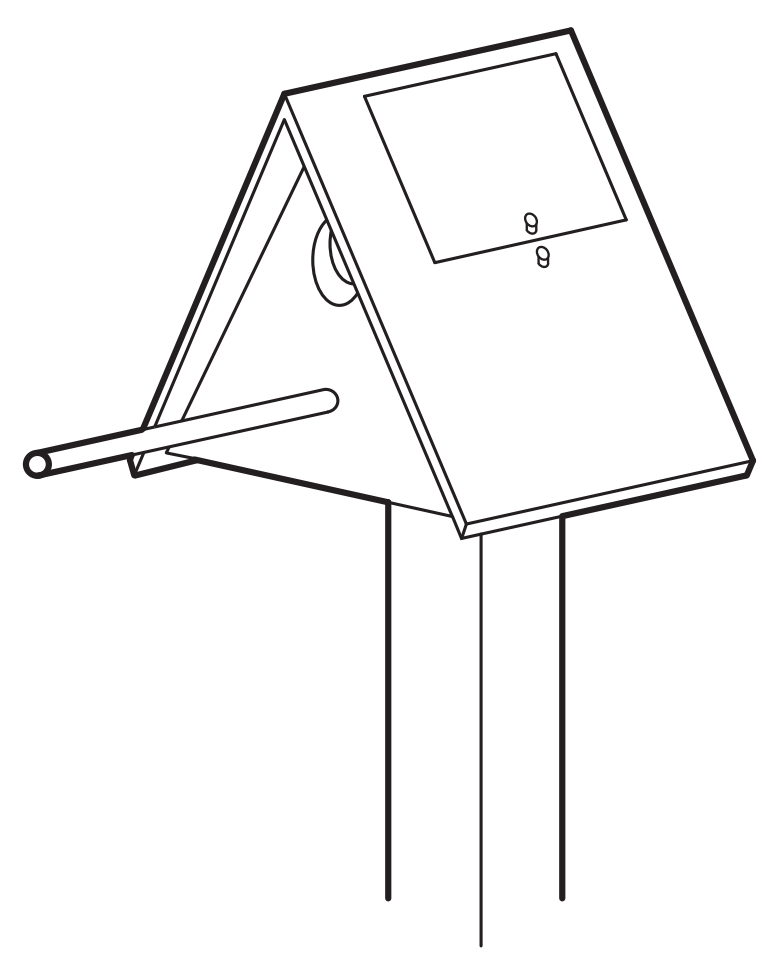

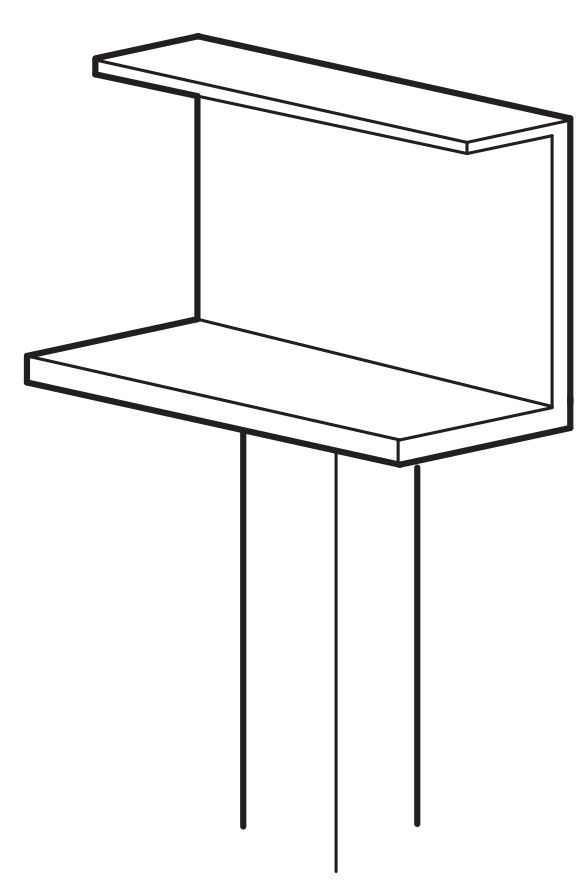




\begin{tabular}{|c|c|c|c|c|c|c|c|c|c|}
\hline \multicolumn{10}{|c|}{ Nesting Hide-Aways } \\
\hline Species & Latin Name & Common Name & Maori name & Mature growth & Weather & Seeds & Flowers & Fruits & Seasonal \\
\hline \multirow[b]{9}{*}{ Tree } & Aristotelia serrata & Wineberry & MakoMako & $6 \times 3 \mathrm{~m}$ & Shade & & & $\mathrm{Y}$ & \\
\hline & Coprosma robusta & & Karamu & $5 \times 3 \mathrm{~m}$ & Sun/Part & & & $\mathrm{Y}$ & \\
\hline & Cordyline australis & Cabbage Tree & Toi & $10 \times 2 \mathrm{~m}$ & & & & $Y$ & \\
\hline & Hoheria sexstylosa & Lacebark & Houhere & $8 \times 6 \mathrm{~m}$ & & & Y & $Y$ & FI - Su-A, Fr - May \\
\hline & \begin{tabular}{|l|} 
Kunzea ericoides \\
\end{tabular} & & Kanuka & $10 \times 4 \mathrm{~m}$ & & & $Y$ & & \\
\hline & Leptospermum scoparium & & Manuka & $4 \times 2 \mathrm{~m}$ & Sun/Part & & Y & & Oct - Dec \\
\hline & Pittosporum eugenioides & Lemonwood & Tarata & $12 \times 5 \mathrm{~m}$ & & & & & \\
\hline & \begin{tabular}{|l|} 
Schefflera digitata \\
\end{tabular} & Seven-Finger & Pate & $4 \times 3 \mathrm{~m}$ & Sun/Part & & & Y & \\
\hline & Sophora microphylla & & Kowhai & $6 \times 4 \mathrm{~m}$ & Sun/Part & & $\mathrm{Y}$ & & \\
\hline & & & & & & & & & \\
\hline \multirow[b]{2}{*}{ Fern } & Blechnum minus & & Swamp Kiokio & $0.5 \times 1 \mathrm{~m}$ & Sun/Part & & & & \\
\hline & Dicksonia squarrosa & Rough Tree Fern & & $4 \times 3 \mathrm{~m}$ & Partial & & & & \\
\hline \multirow{2}{*}{ Climbers } & Parsonsia heterophylla & NZ Jasmin & Kaihua & $10 \mathrm{~m}$ & & Y & $\mathrm{Y}$ & & Spr/Su/Aut \\
\hline & & & & & & & & & \\
\hline \multirow[b]{3}{*}{ Shrub } & Coprosma propinqua & & Mingimingi & $3 \times 2 \mathrm{~m}$ & Sun/Part & & & & \\
\hline & Phormium tenax & NZ Flax & Harakeke & $3 \times 2 \mathrm{~m}$ & Sun & & $Y$ & & \\
\hline & \begin{tabular}{|l|} 
Piper excelsum \\
\end{tabular} & & Kawakawa & $5 \times 2 \mathrm{~m}$ & $\mathrm{~S} / \mathrm{P} / \mathrm{Sh}$ & & & $\mathrm{Y}$ & \\
\hline
\end{tabular}

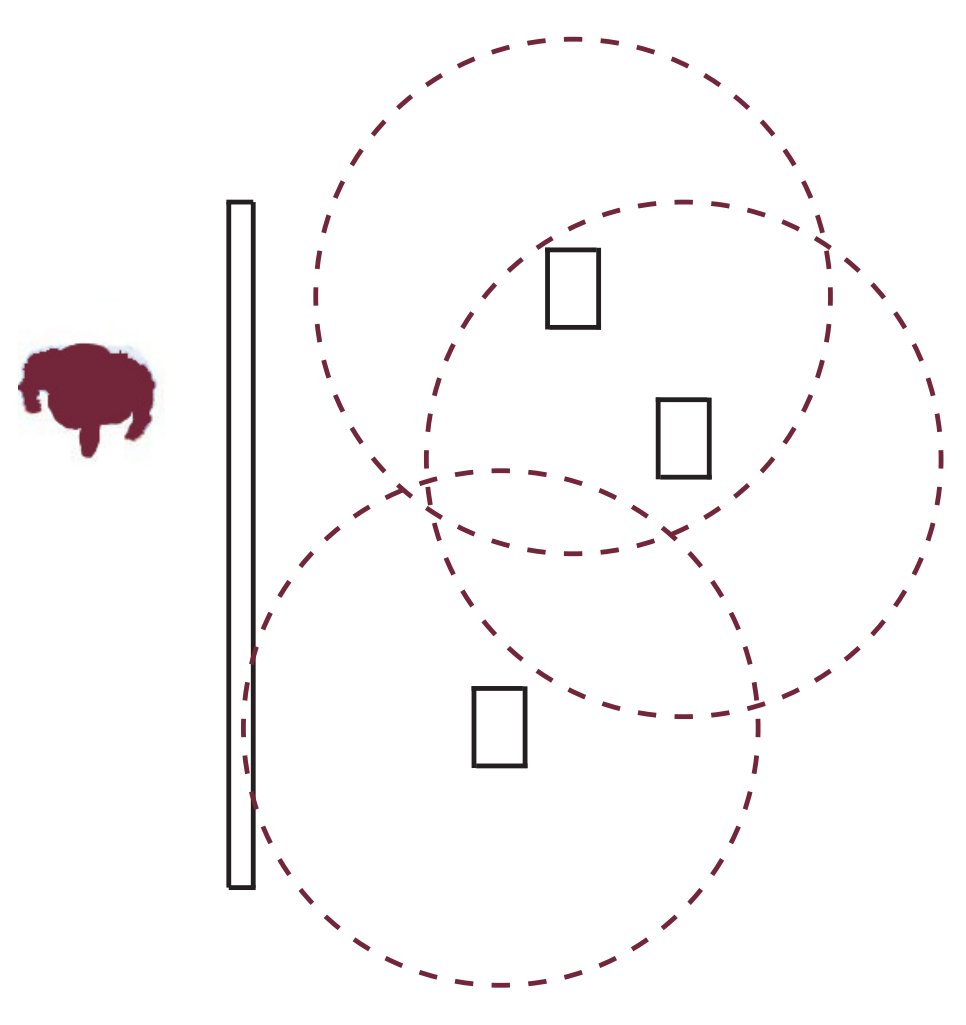

Table 7.01 Vegetation species that are being used in this location.

Fig 7.33 The proximity of people to the shelter spaces is $5 \mathrm{~m}$ in distance, to allow the species to feel safe enough to use the infrastructure. 


\section{+ F I N A DES I G N $A R C H-W A Y(D)$}

This design is an informal structure that supplies birds with the overhead opportunity to settle higher than people. The seat at the base allows for people to sit and listen to the birds, as the vegetation covered structure hides them within.

\section{1) Fig 7.34 | Masterplan| 1:1,500@ A3}

Fig $7.35|A-A A| 1: 75 @ A 3 \mid$ The archways acts as a natural feature, emerging from the vegetation.

+ Overhead sculptural bird nesting box, the panels of the wood contain holes for birds to explore and nest inside. It is a less formal take upon the above mentioned nest boxes.

+ Sunken pathway, where the surrounding vegetation and adjusted typography hide and protect the pathway/humans from view. Lending towards a more safer environment for the birds.

$+\quad$ The merging of steel and wood acts as a material deterrent towards pests.

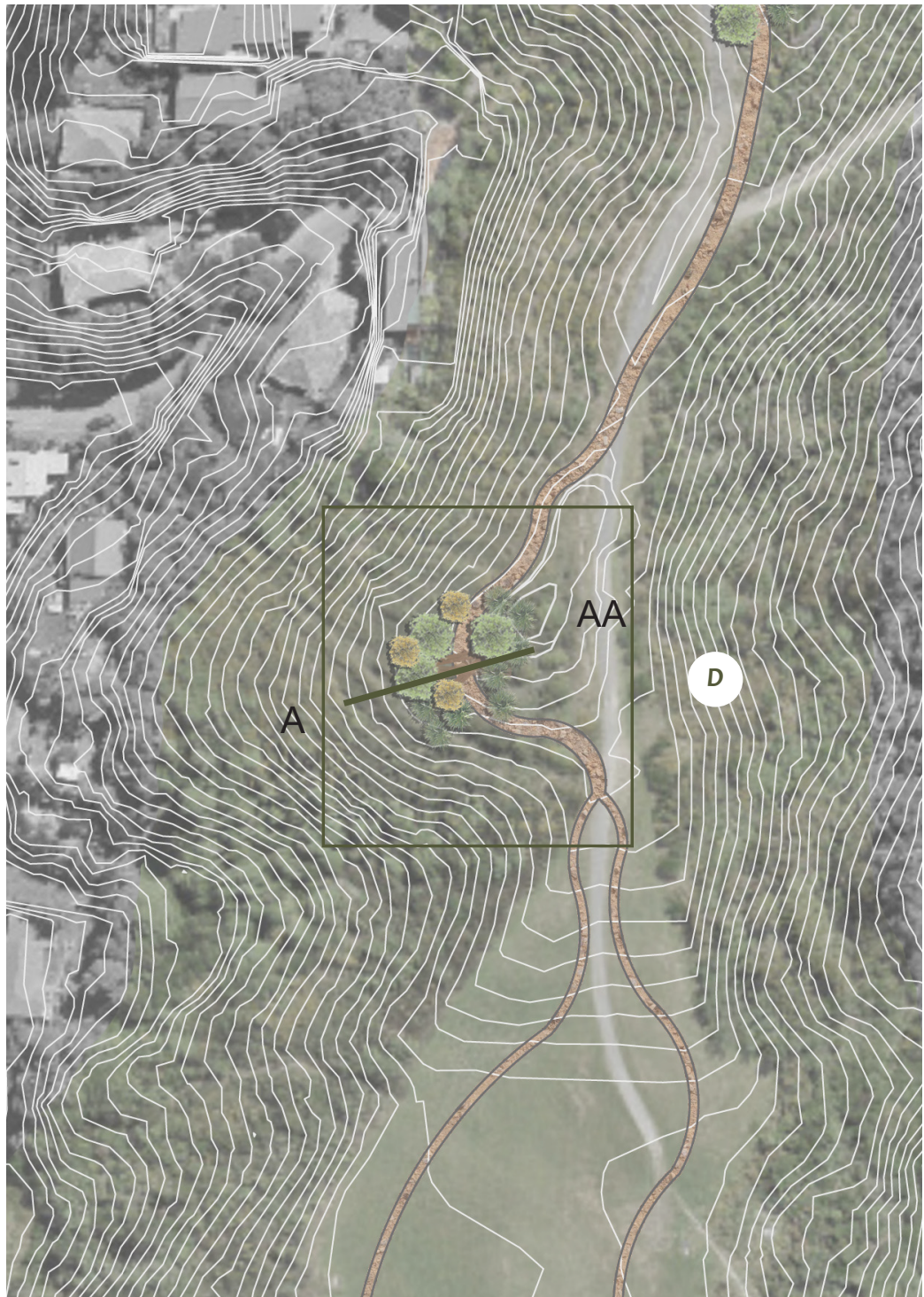




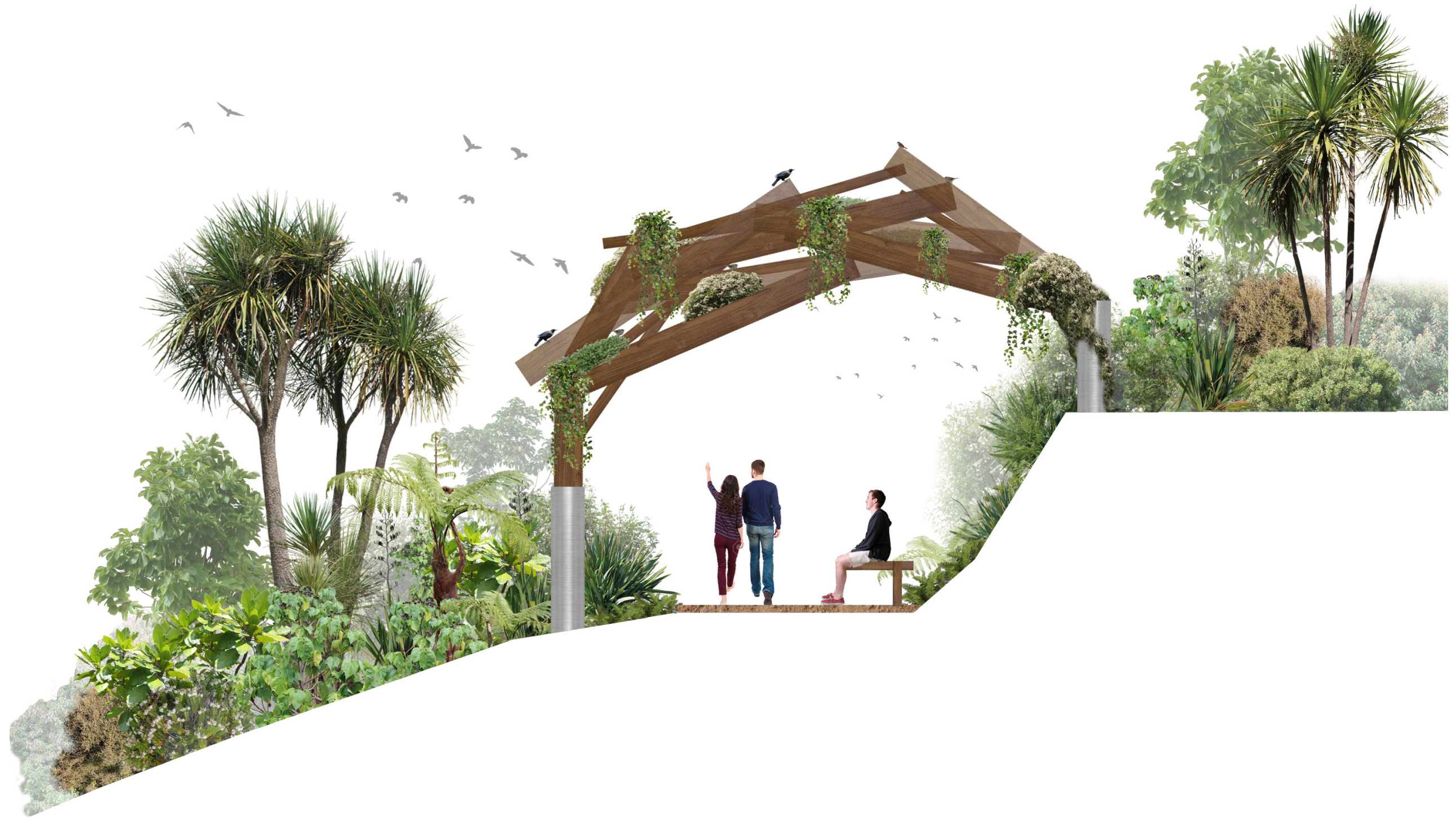




\section{+ CRITICALREFLECTION}

This was a very in depth design process. The act of working individually, presenting a review and conducting interviews resulted in a grounded and thorough design. Not only for this location, the information gained from the interviews will be applied in future designs. This site offers a lot of potential for future development, especially considering the large amount of unused space. A few years in the future, this site could start to develop the same conservation qualities as Zealandia. The design could be the establishment of a future rich with wildlife, the site itself developing towards an existing green space that smaller patches start to grow from. This would only occur if a change in program was implemented, but this design could bring awareness to the viability of this option.
Key findings:

+ The interview process was very humbling, it showed, like what has been written previously, that landscape architects work within the realm of landscape conditions and wildlife is not as relevant in these decisions. There were a lot of areas that worked within the architectural field but not at all for species. It was good to discover at this stage of the thesis, as it will allow for changes and stronger designs further on.

+ The largest area of information that was gained was related to the question that is framed, "-as well as providing elements for human/wildlife interaction". Initially the thesis aimed to explore a series of infrastructural elements that were revolutionary in the design field, focusing on bird and human wildlife. However, that cannot be further from how this design has gone. A large part of the Nesting Hide-Away location, is the self-reflection that comes from providing opportunities 
for people to want to interact with wildlife. The design allows for people to be attuned to nature and its inhabitants, rather than expecting the birds to perform for people, like what is expected from a zoo. The perspective of people needs to change for this thesis to be successful. This location begins the process for designing with this intention, however, as this was a late discovery, it was not as successful as it could be. The next location will aim to fulfil this.

$+\quad$ Sitting down and listening to birds speak is so powerful, it can become a highlight in a person's day. Pairing this with a design that provides spaces for people to search, all of the interventions achieve this, can be just as successful in terms of facilitating interaction, as physically petting them. The shift from a designer trying to micro-manage the way people and birds work together, to being more subtle and manipulative, has resulted in a much more real design that reflects realistic design boundaries. 


\section{+ LOCATION 3 |FRESH H2GO}

This site was chosen as it was a stark contrast between

location 4. Location 4 was suburban and dealt with issues around residents, this location is completely urban, settled within Wellington City. Kent and Cambridge Terrace have a rich ecological history, growing from a freshwater stream, it has now been piped and urban development has overtaken. 


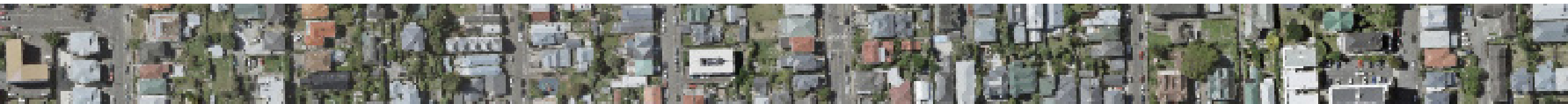

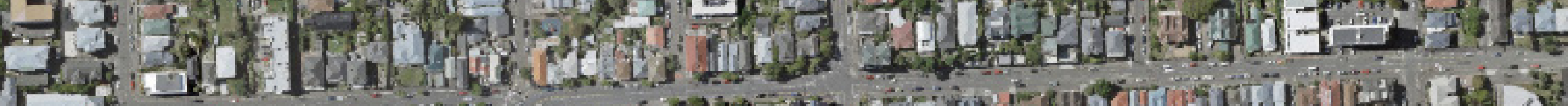

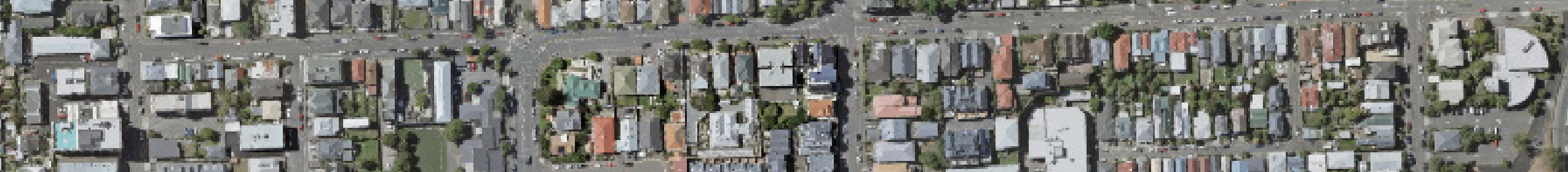

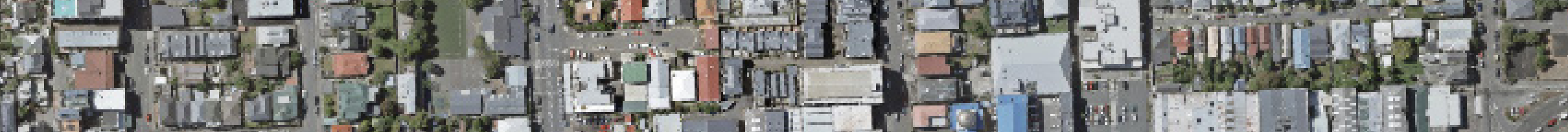

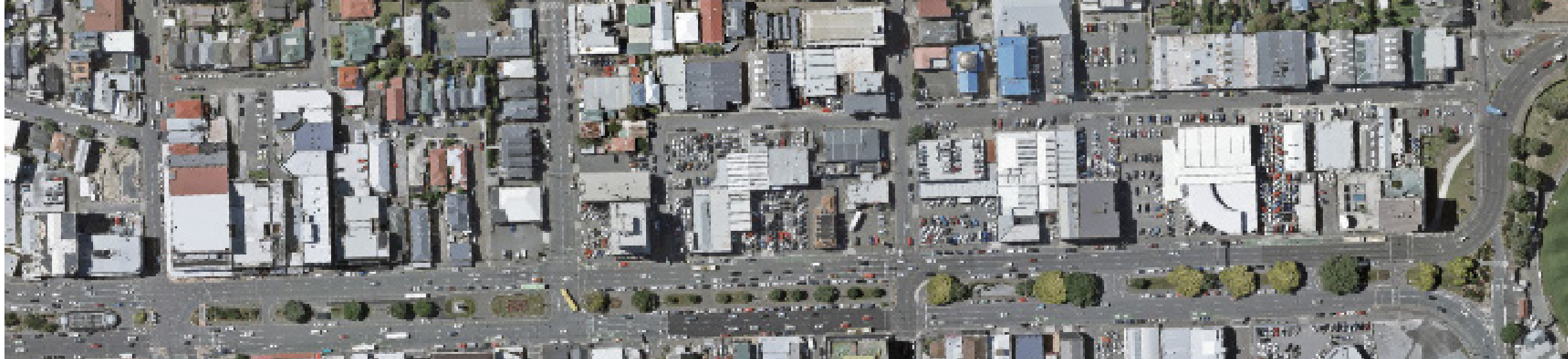

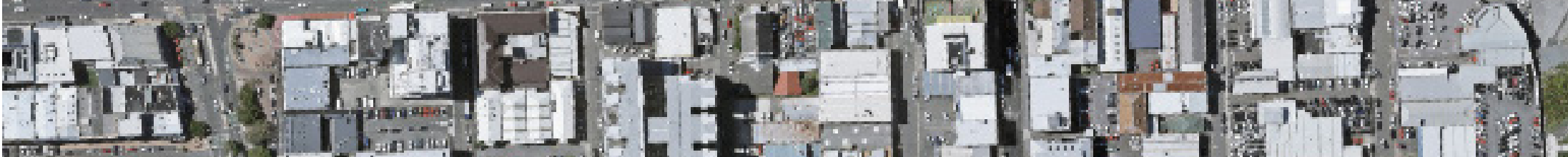

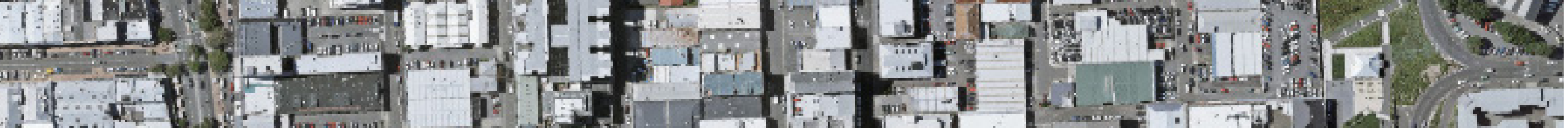
(1.

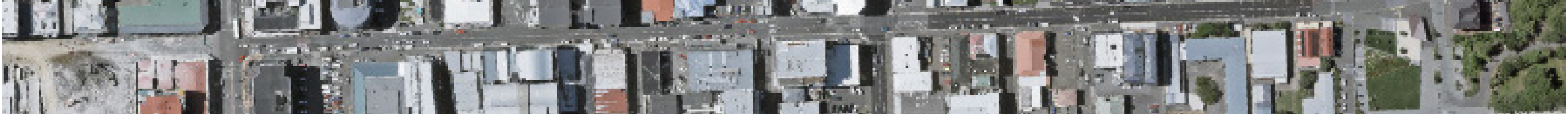


+ SITE A N A L Y S IS

DFig 7.37|1:2000@A 3 Water Systems Map.

- Stormwater Pipes Water Mains

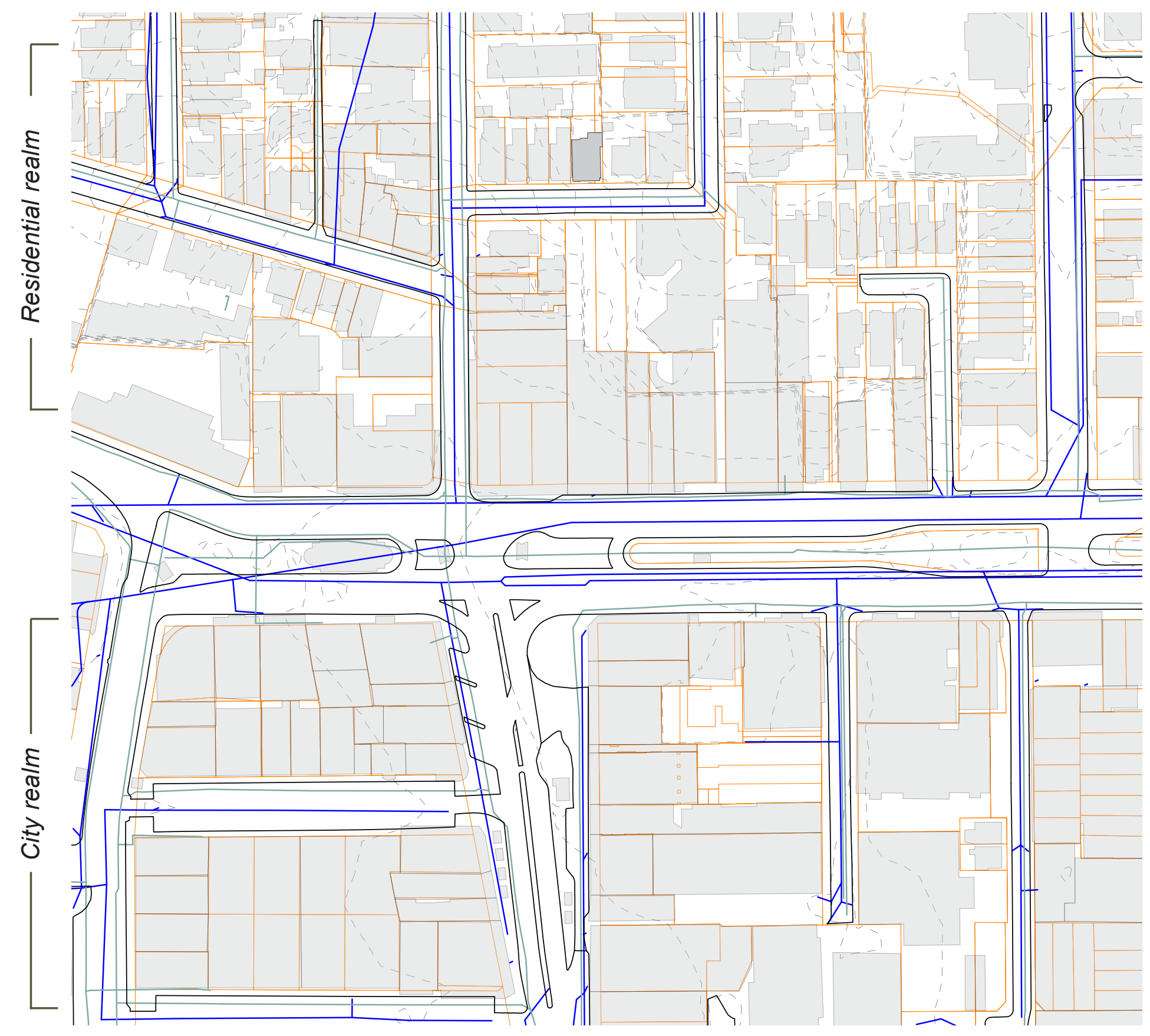




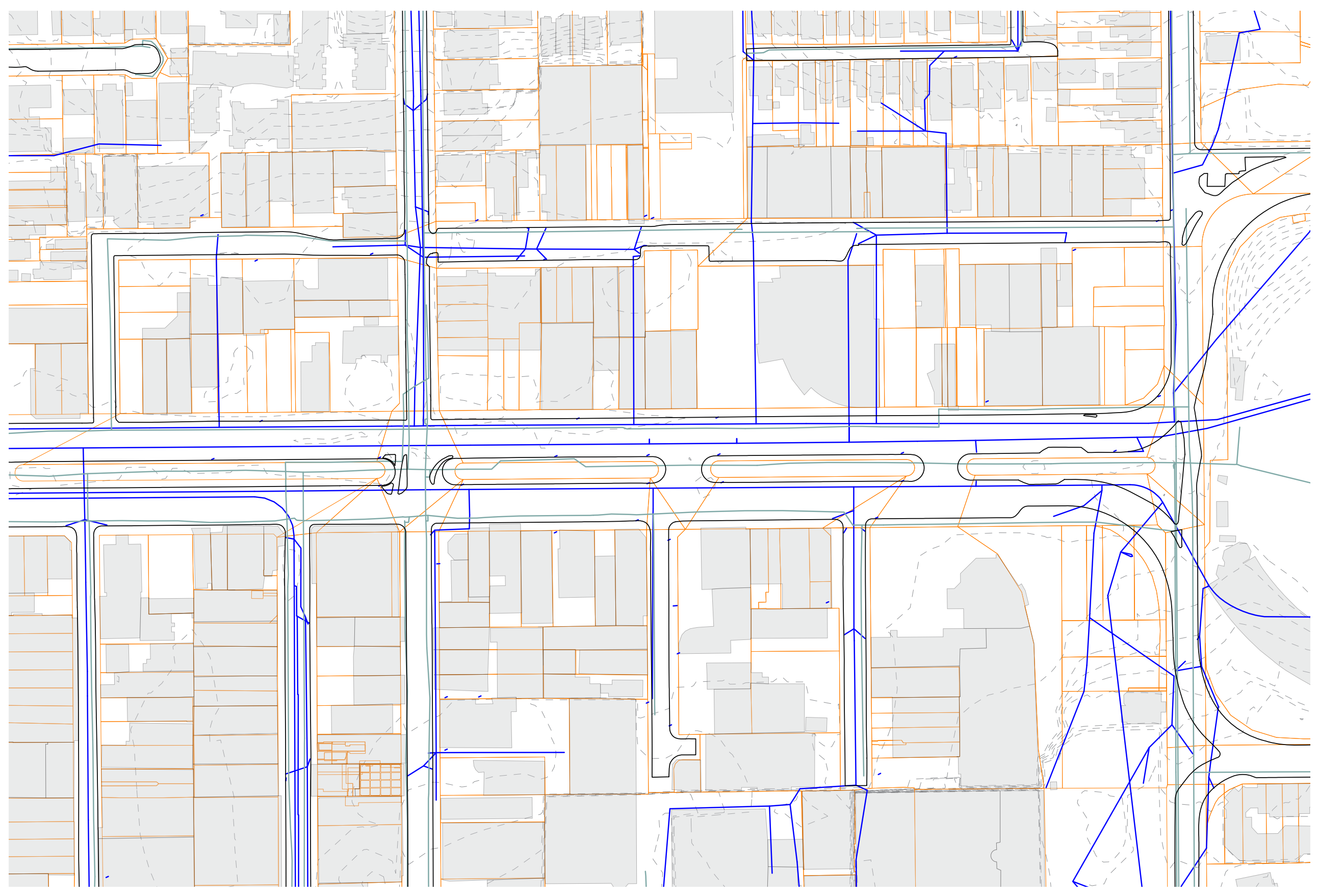


+ SITE A N A L Y S IS

- Fig 7.38|1:2000@ A 3 | Traffic Management map.
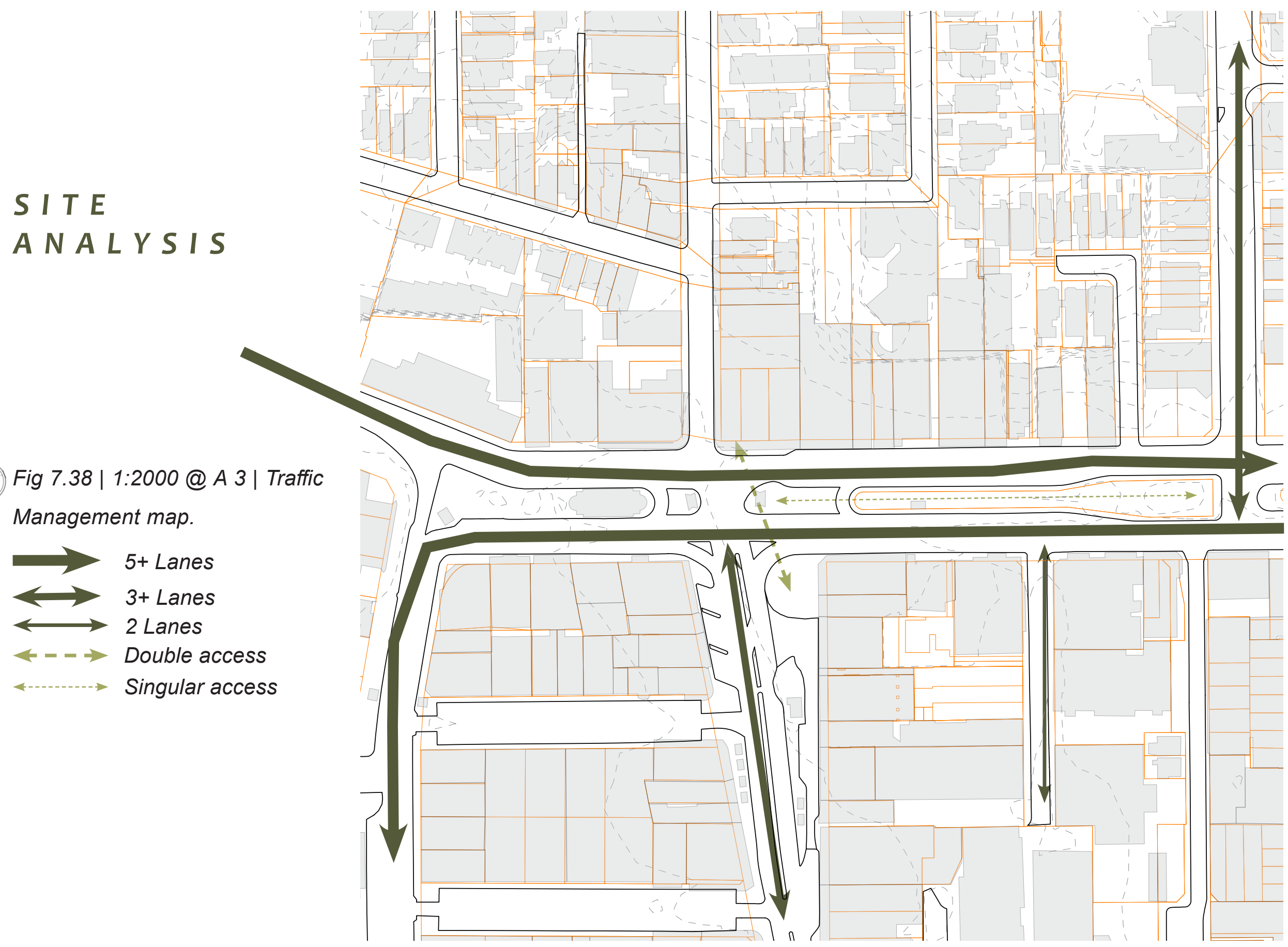


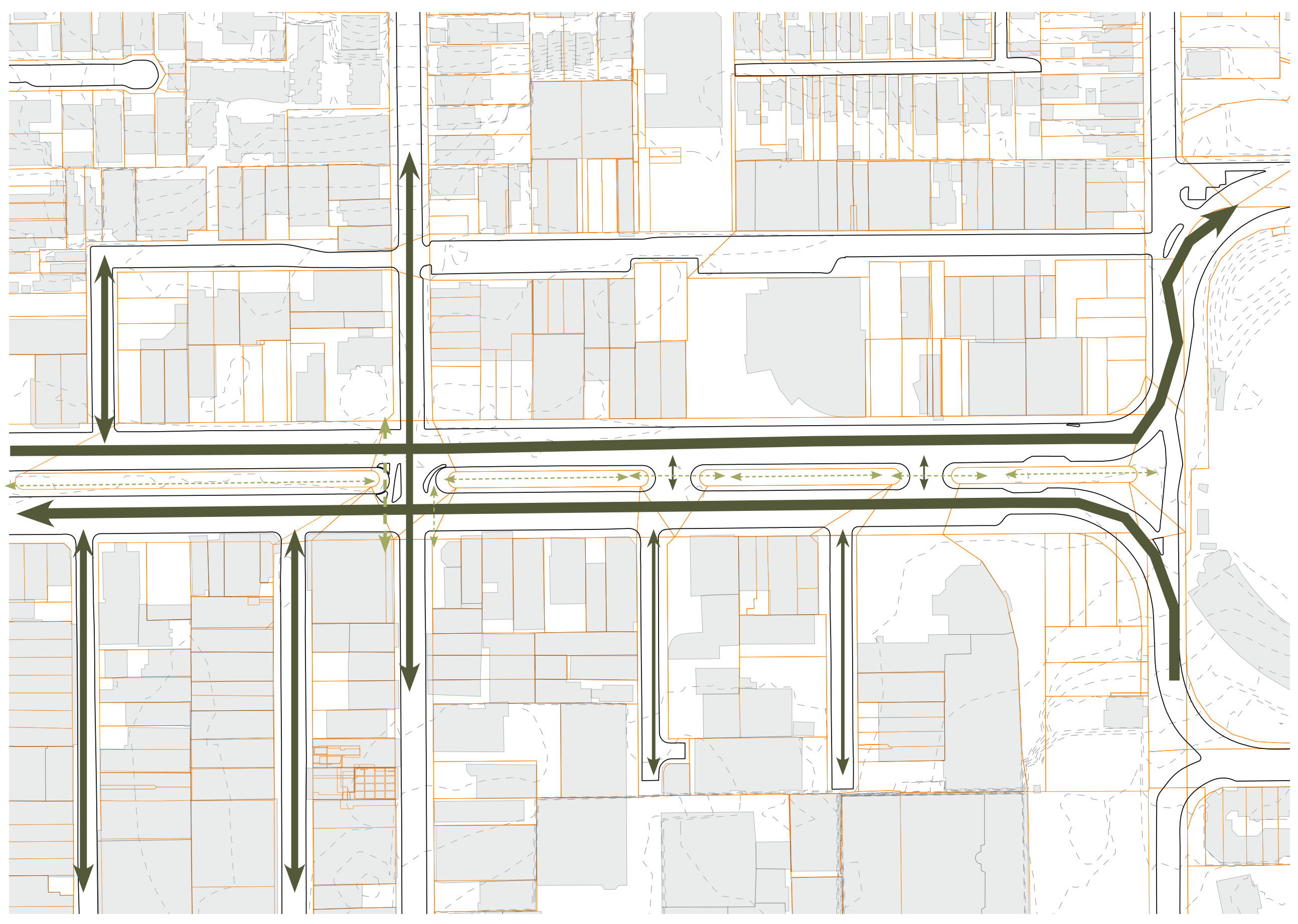




\section{+ B U I L F ORM S}

Fig 7.39 | Photographic built form observations.

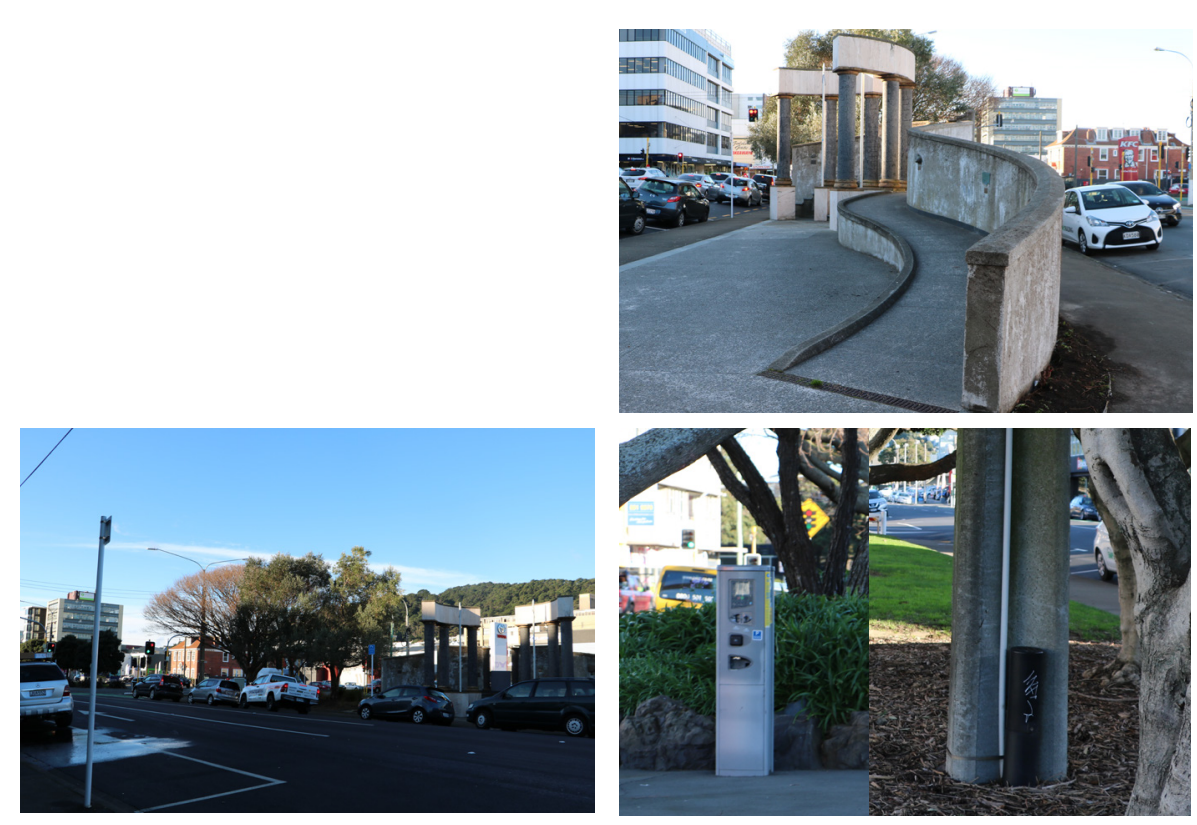

+ B I R D L I F E

Fig 7.40 | Photographic bird life observations.

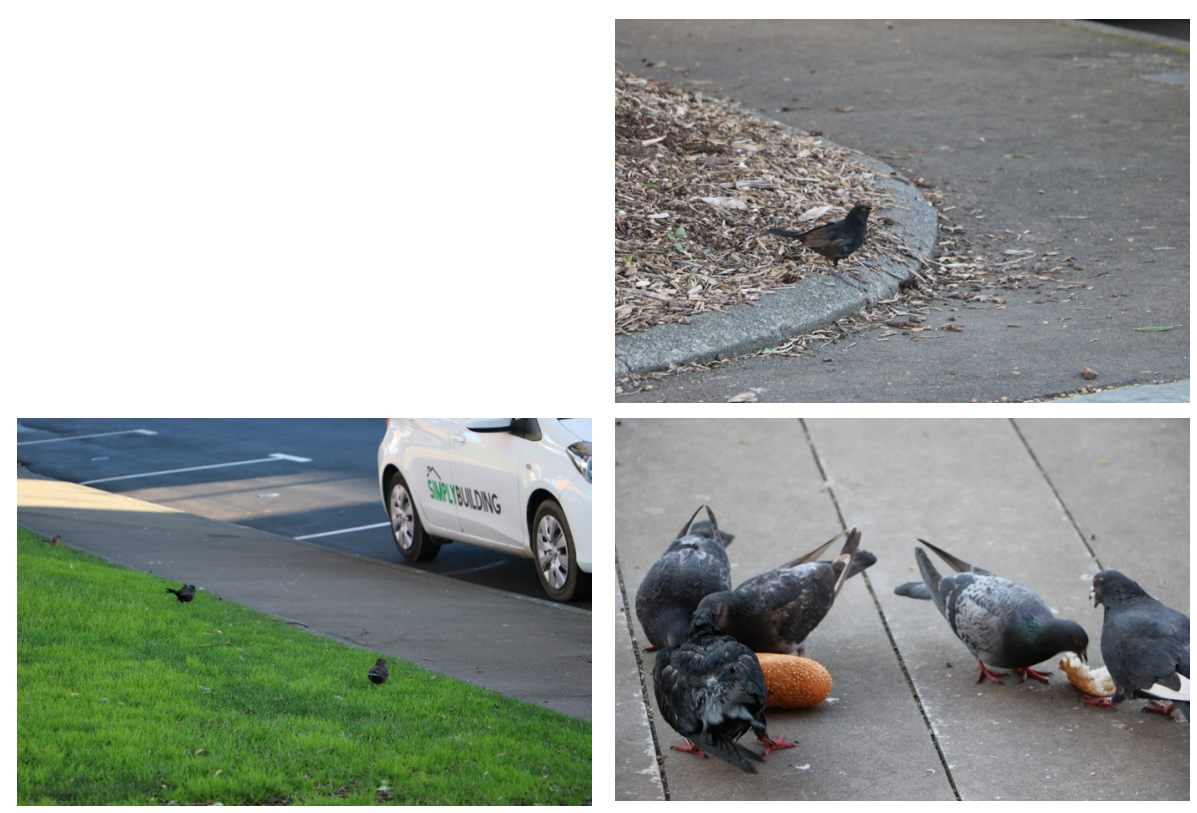


+ VEGETATIO N

Fig 7.41 | Photographic planting observations.

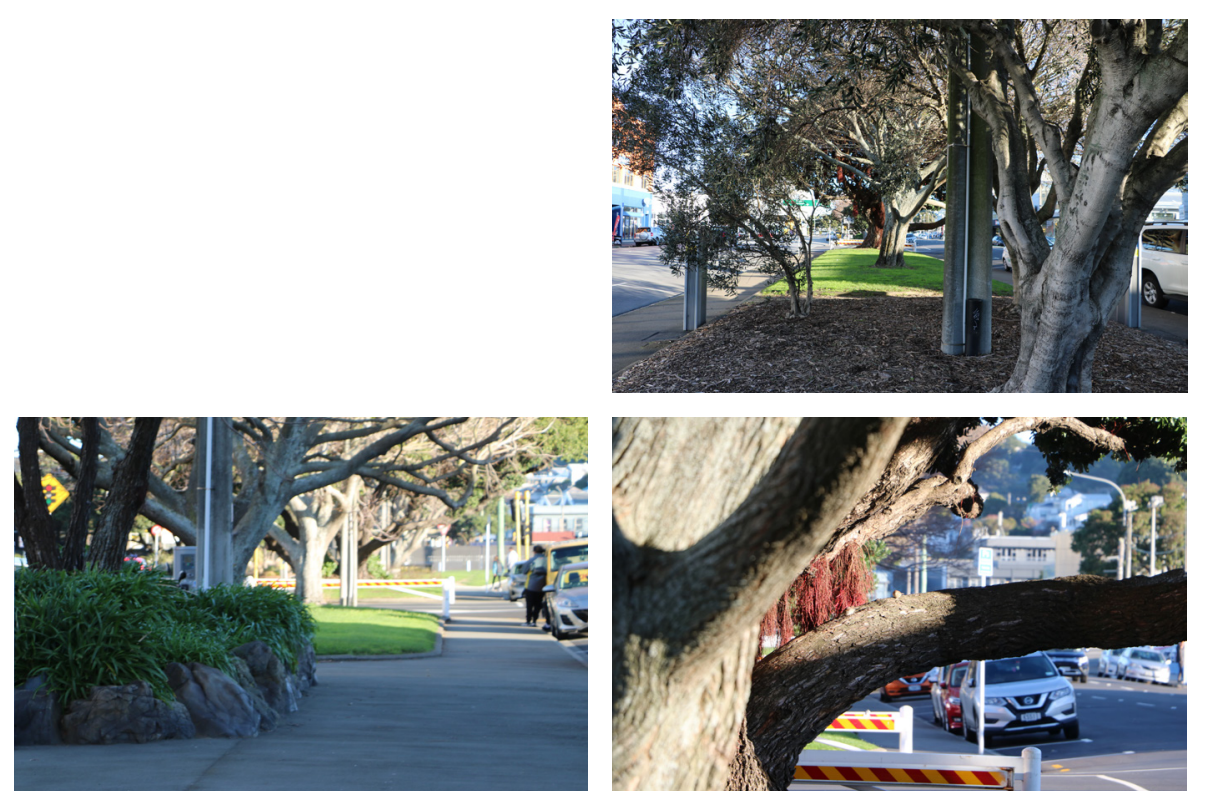




\section{+ STREET REDEVLOPMENT}

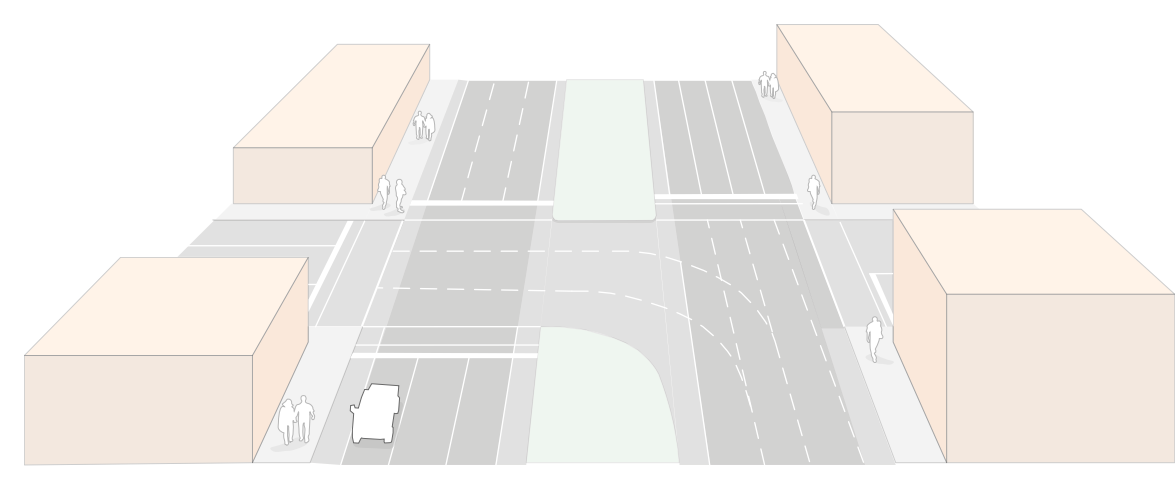

Fig 7.42 | The existing road formation, 5 lanes on each side.
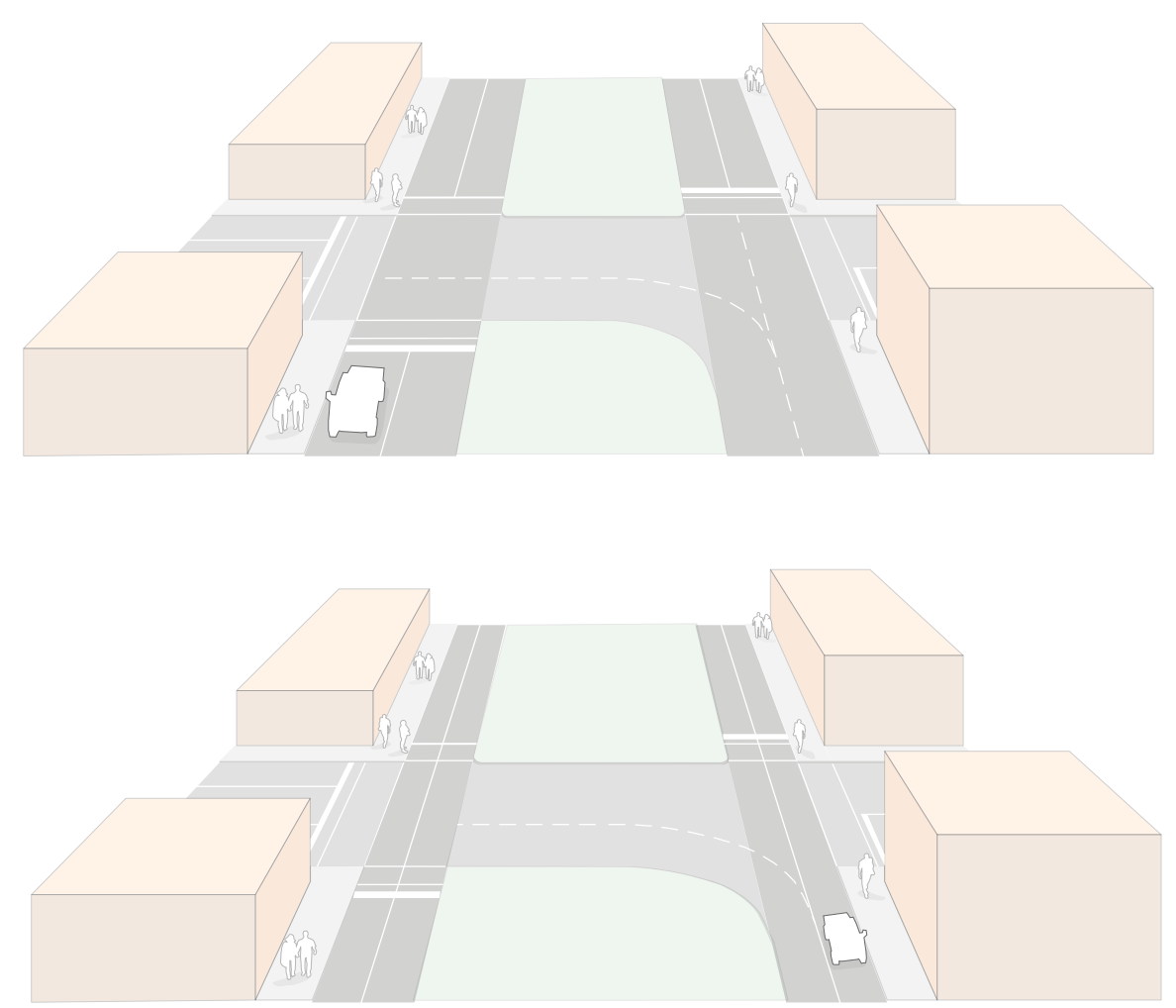

Fig 7.43 | Expansion of the middle green space, to make a wider natural corridor. 


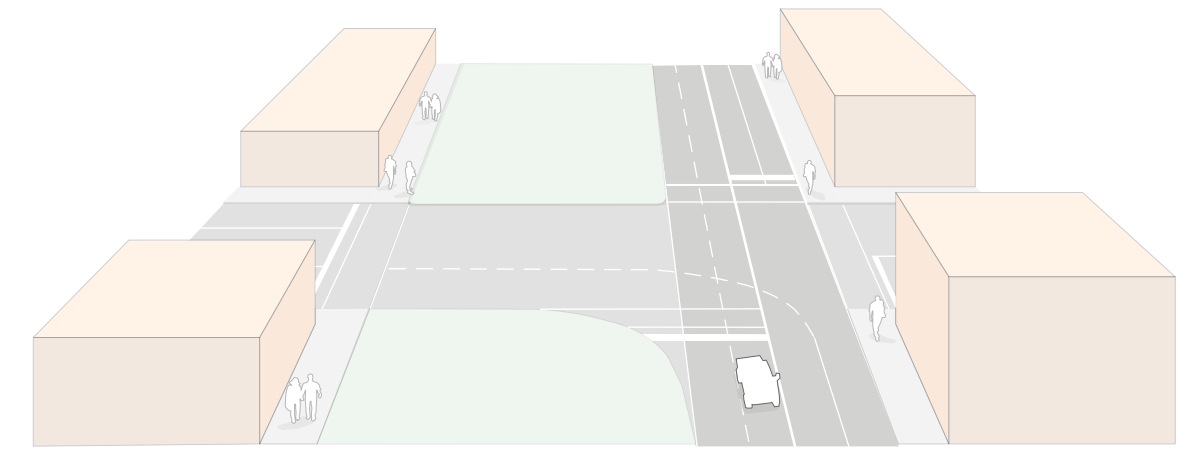

Fig 7.44 | Moving the green to the left of KCT, it becomes disconnected from the residential realm on the right.

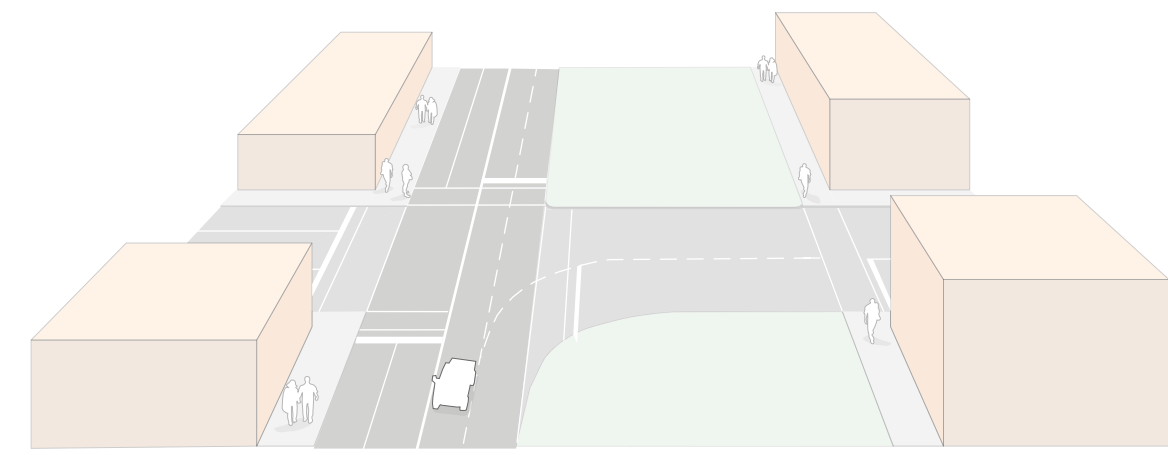

Fig 7.45 | Moving the green to the right of KCT, it connects back to the residents of the area. 


\section{+ DESIGN TYPOLOGIES}

+ Ponds are good for including wet species within the water.

+ Can become a large settling space for flooding areas, with no alternative way for the water to drain, as it is self-sustaining.

+ Many ponds would be needed for the large space rather than one feature.

Fig 7.46 | Drawing of the spatial qualities of a pond environment. 


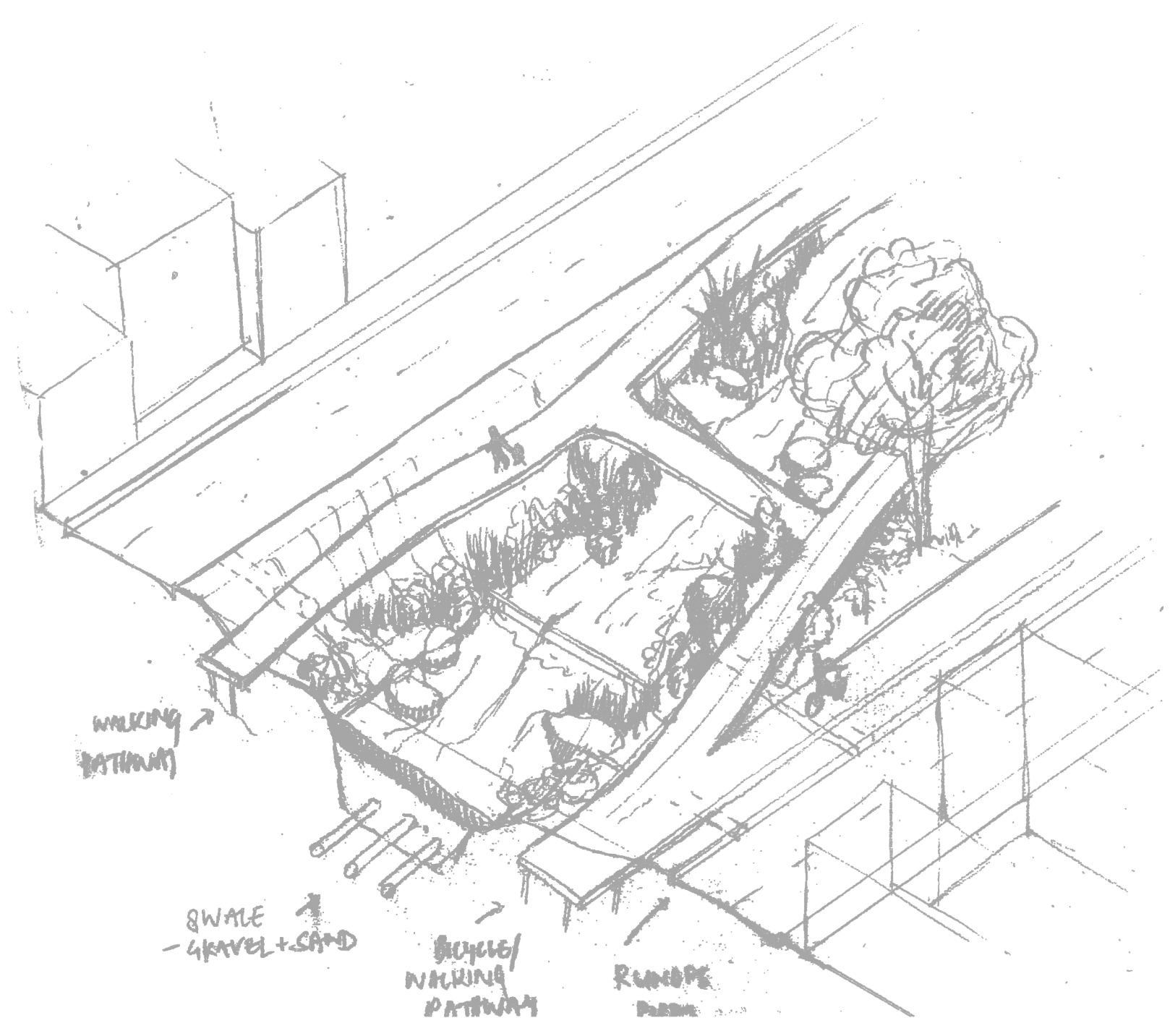

+ Swales are good for managing large quantities of water, specifically in flooded areas, due to drains and vegetation.

+ One continuous swale could occur along the entire site.

Fig 7.47 | Drawing of the spatial qualities of a swale

environment. 
$+\quad$ Streams are good for managing large quantities of water, specifically in flooded areas, due to drains and vegetation.

+ One continuous stream could occur along the entire site.

+ Shallow depth allows for interventions along the side of the stream.

Fig 7.48 | Drawing of the spatial qualities of a stream environment. 


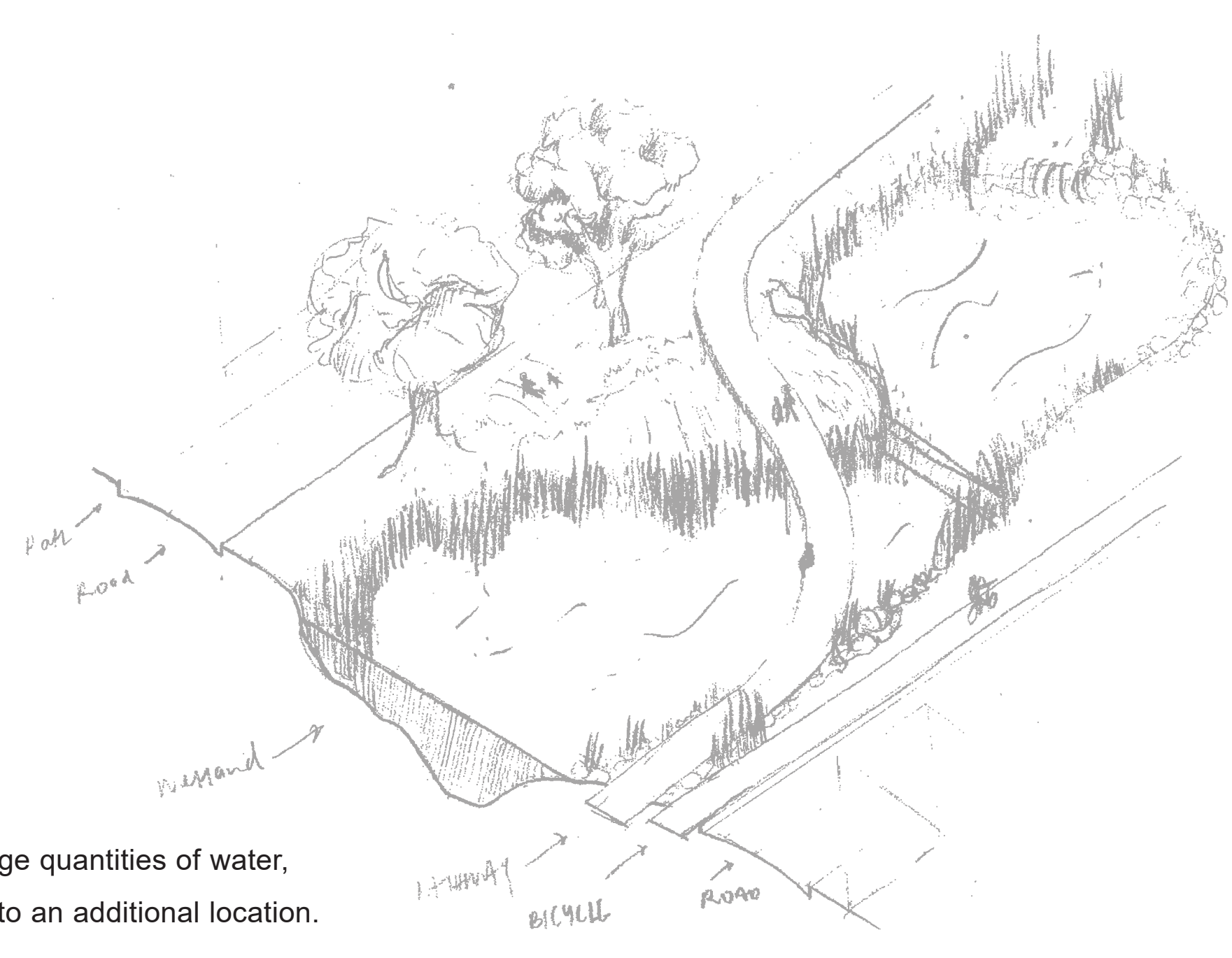

+ Wetlands are good for managing large quantities of water, they can clean the water and direct to an additional location.

+ One continuous wetland could occur along the entire site.

+ Shallow depth allows for interventions along the side of the stream.

+ Not a lot of interaction, for people, within a wetland.

Fig 7.49 | Drawing of the spatial qualities of a wetland environment. 
$\mathrm{T}=$ Trees

$S=$ Seating

$\mathrm{E}=$ Entrance

Fig 7.50 | Drawing of initial bubble diagrams, to define spaces in the design.

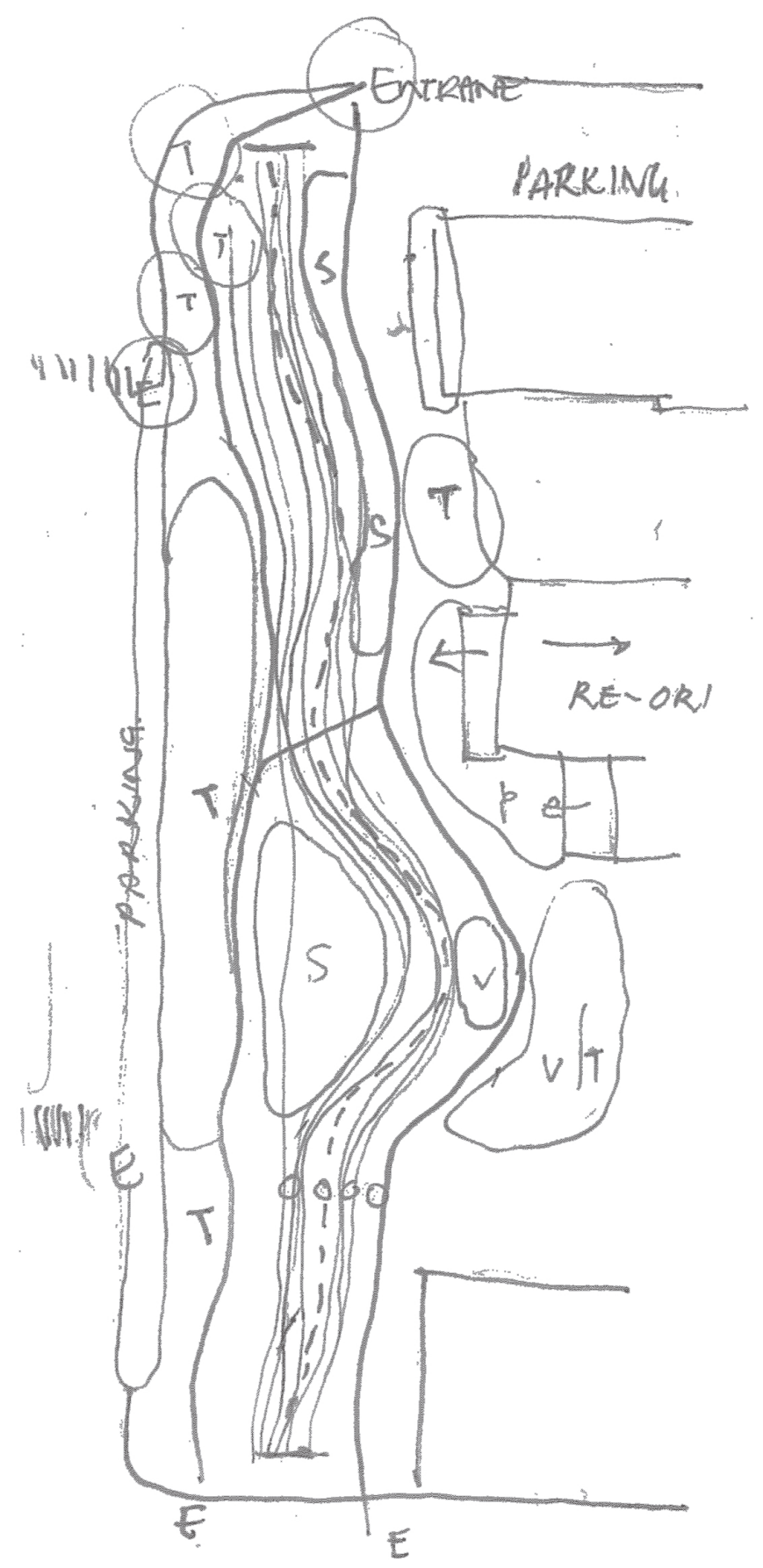



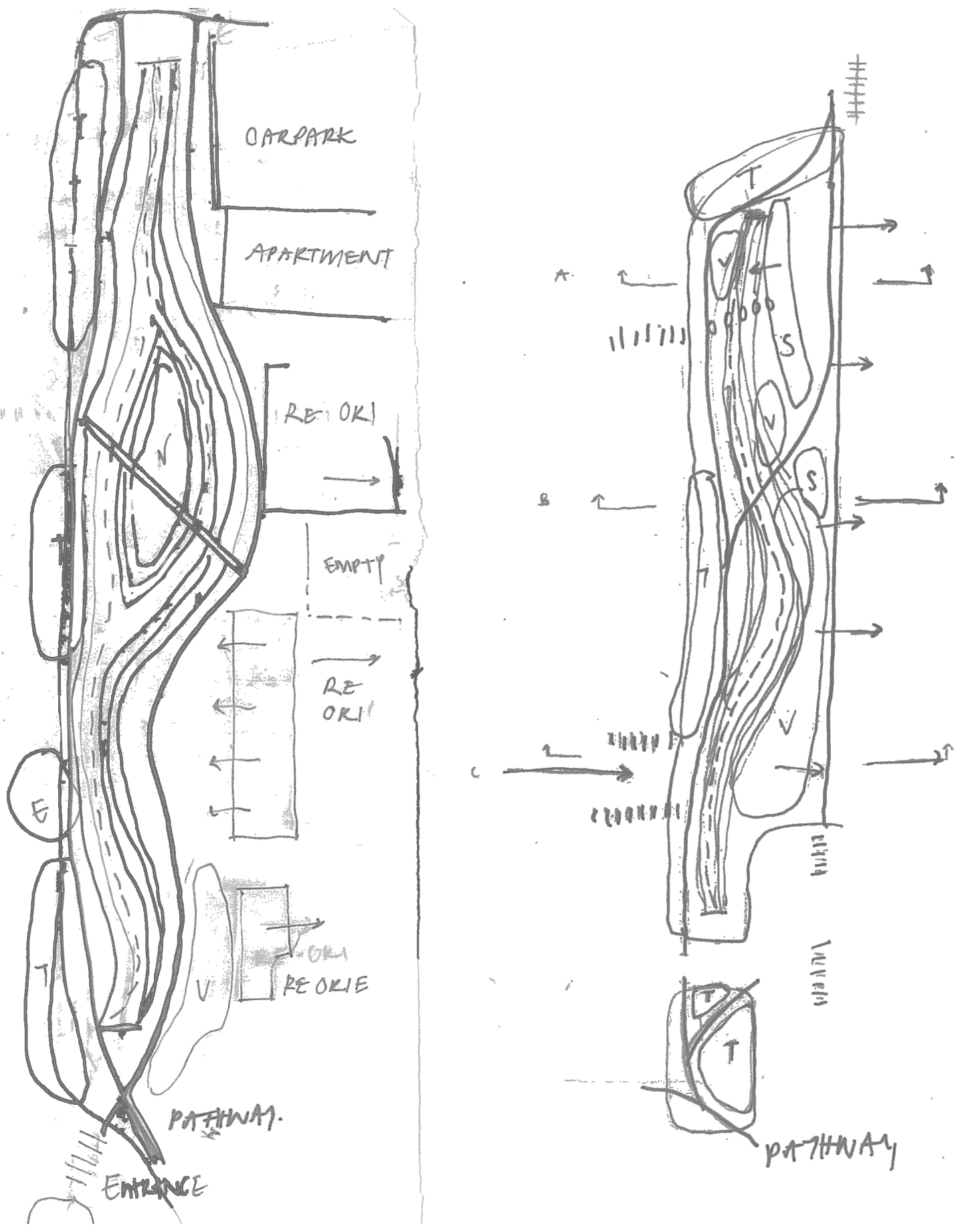


\section{+ Masterpla}

- Fig 7.51| Rendered Masterplan Scale1:1,100@A3

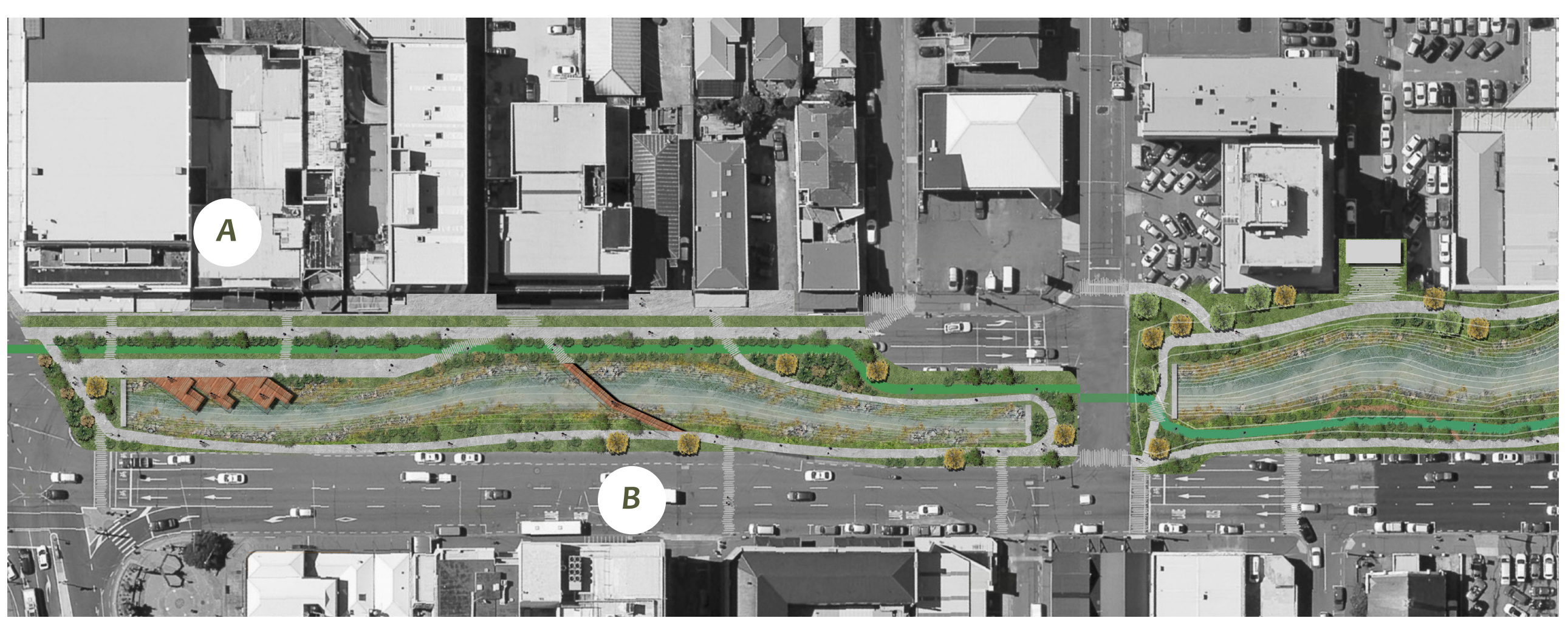



A | Terraced seating
E | Rocky bridge
B | Walkway
F | Outdoor seating
C | Triangular Bridge
G| Perching Crossway
D | Water Collection

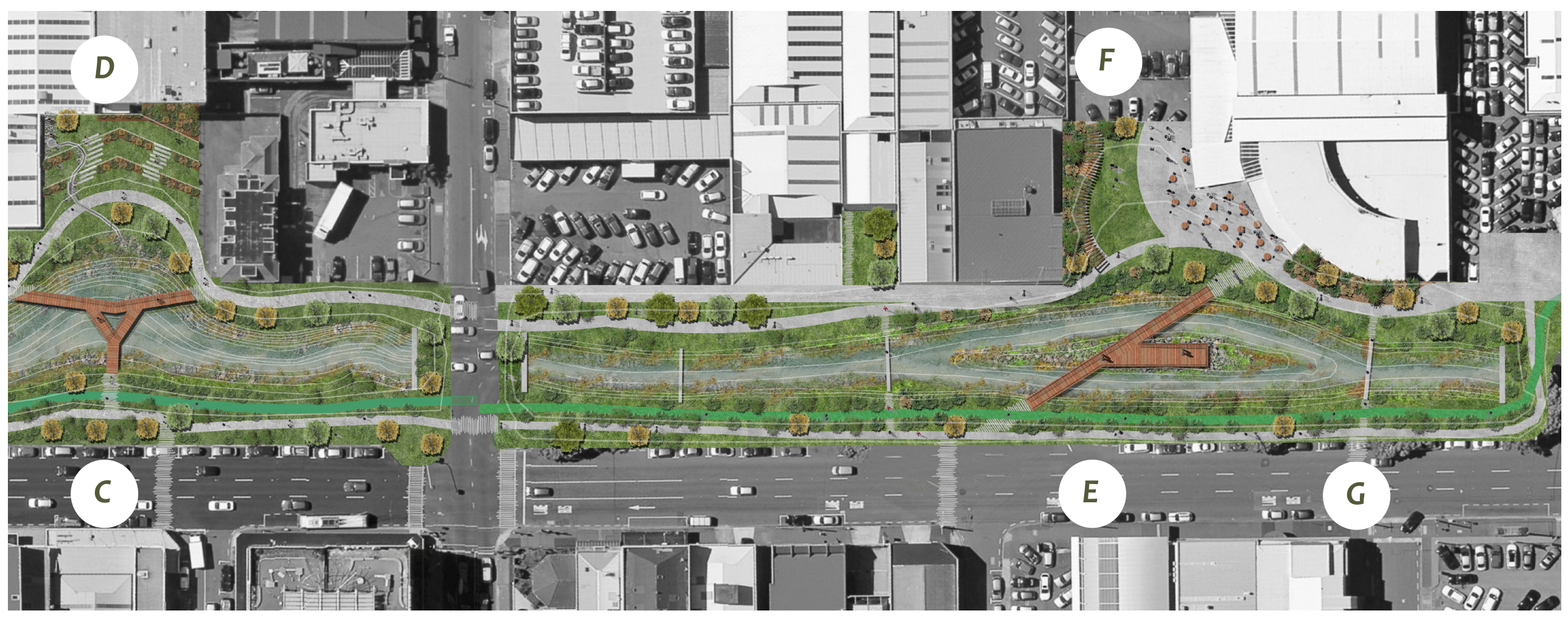



around the design. 1:1,100@A3

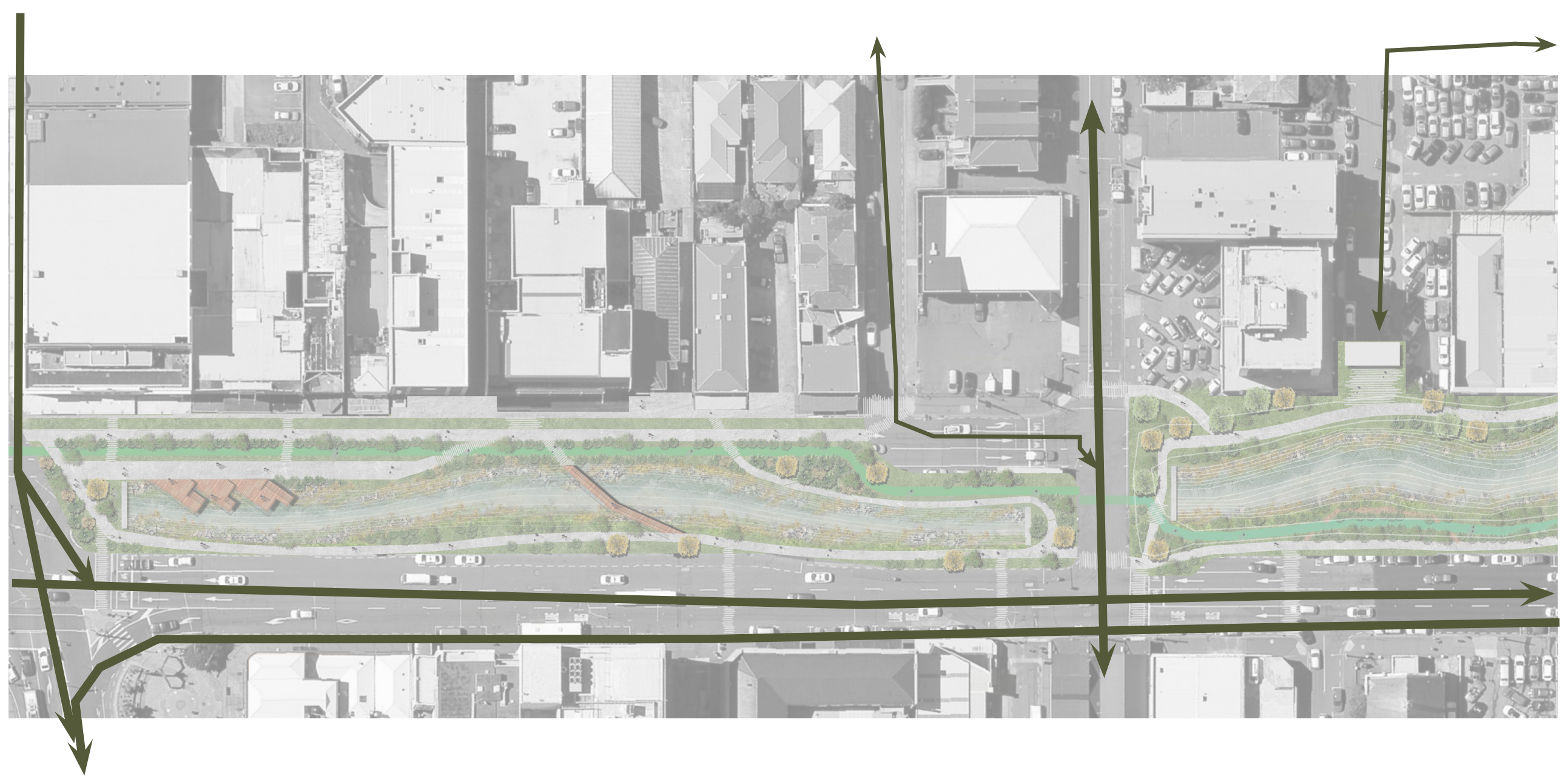



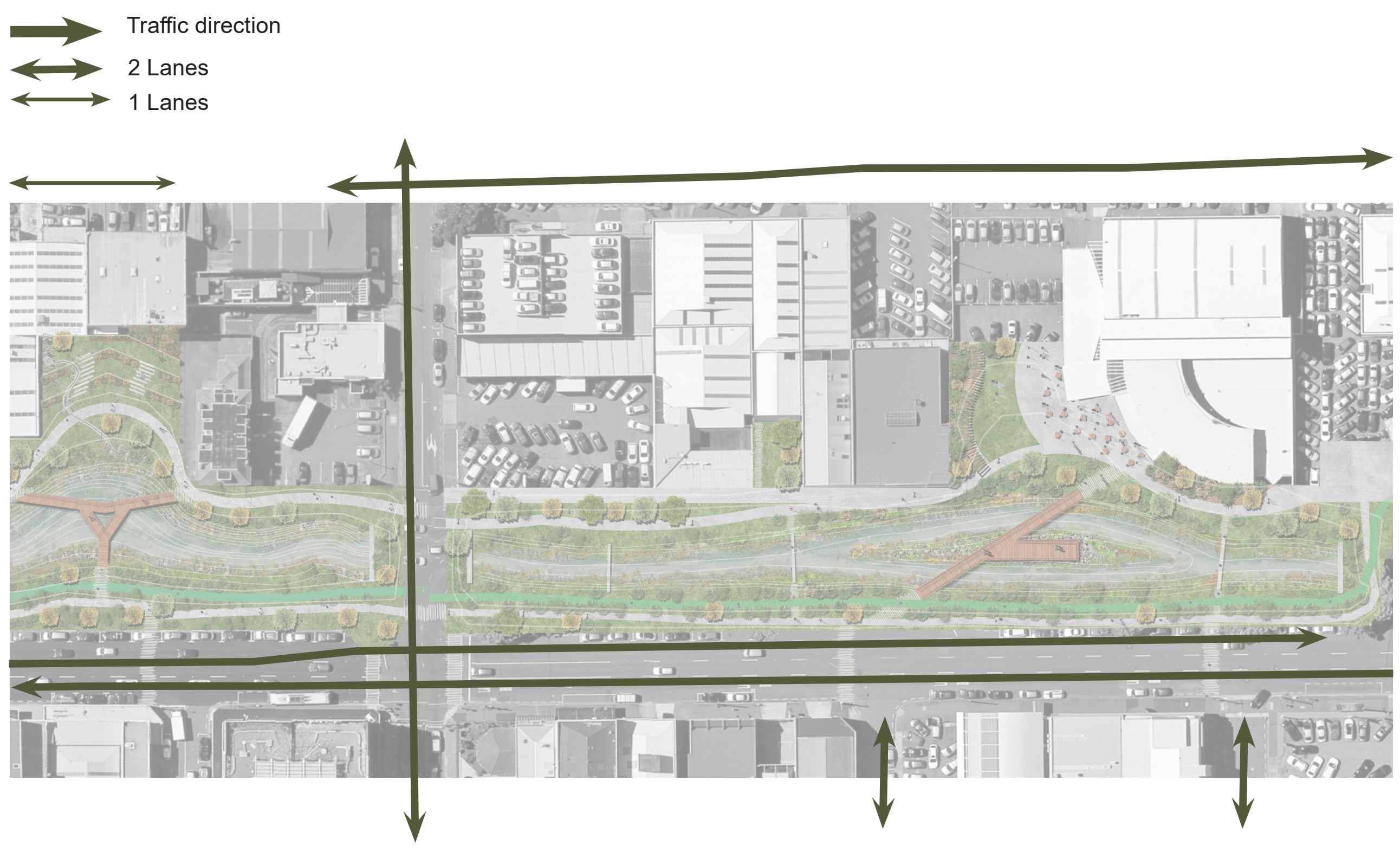


\section{+ FUNCTIONALDIAGRAM}

- Fig 7.53| Functional diagram explaining the areas of design. | 1:1,100@A3

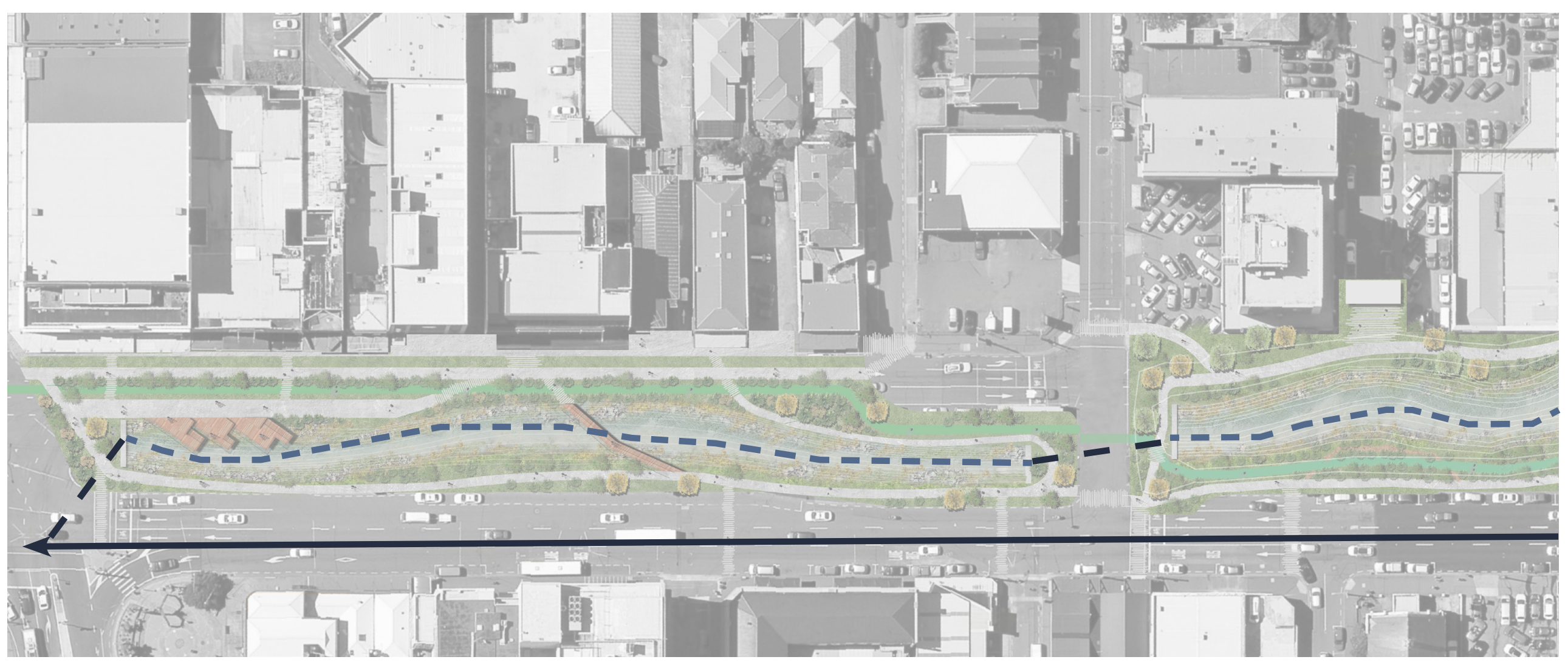


- Exposed Stream Water

Stormwater drain

- Additional piped drain

- Water Collection from

Water Mains

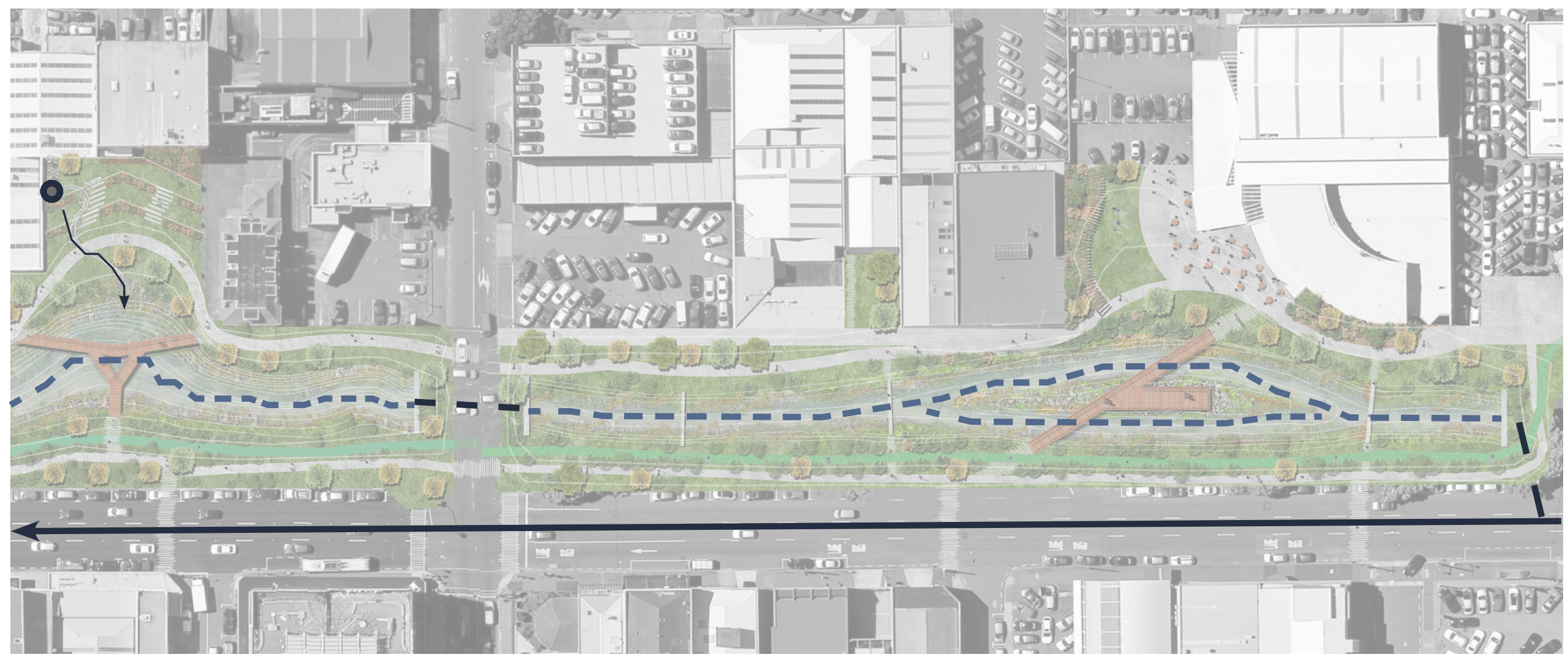




\section{+ PlANTING}

The planting of this area has a large focus towards both species that are good for wet environments and also producing benefits for wildlife. Refer to Table 7.02 for species selection. Representation of plant arrangement will be visualised in the amendments. 


\begin{tabular}{|c|c|c|c|c|c|c|c|c|c|c|}
\hline \multicolumn{11}{|c|}{ Fresh $\mathrm{H} 2 \mathrm{Go}$} \\
\hline Species & Latin Name & Common Name & Maori name & Mature growth & Water Depth & Weather & Seeds & Flowers & Fruits & Seasonal \\
\hline \multirow[b]{6}{*}{ Sedge } & Apodasmia similis & Jointed Rush & Oioi & $1.5 \times 1 \mathrm{~m}$ & $1-3 m$ & Sun & & & & \\
\hline & Carex Secta & & Purei & $1.5 \times 1.5 \mathrm{~m}$ & $0-0.2 m$ & Part/Shade & & & & \\
\hline & Carex dissita & & & $0.8 \times 0.8 \mathrm{~m}$ & & & & & & \\
\hline & Eleocharis sphacelata & Umbrella sedge & Kutakuta & $1.5 \times 0.5 \mathrm{~m}$ & $0.5-3 m$ & Sun & & & & \\
\hline & Juncus edgariae & & Wiwi & $1.5 \times 1 \mathrm{~m}$ & $1-3 m$ & Sun & & & & \\
\hline & Typha orientalis & Bullrush & Raupo & $2.5 \times 1 \mathrm{~m}$ & $0-0.4 m$ & Sun & & & & \\
\hline & & & & & & & & & & \\
\hline \multirow[b]{3}{*}{ Shrub } & Coprosma propinqua & & Mingimingi & $3 \times 2 m$ & $\mathrm{~L}$ & Sun/Part & & & & \\
\hline & Phormium tenax & Flax & Harakeke & $3 \times 2 m$ & $L-T$ & Sun & & $Y$ & & \\
\hline & Plagianthus dicaricatus & Salt Marsh Ribbonwood & & $2 \times 1.5 \mathrm{~m}$ & $\mathrm{~L}$ & Sun & & & & \\
\hline \multirow[b]{2}{*}{ Grass } & Cortaderia fulvida & & Toetoe & $1.5 \times 2 \mathrm{~m}$ & $\mathrm{~T}$ & Sun & & & & \\
\hline & Isachne globosa & Swamp Millet & & $1 \times 1 \mathrm{~m}$ & $L-E$ & Sun/Part & & & & \\
\hline GroundC & Arthropodium cirratum & & Renga Renga & $1 \times 1 \mathrm{~m}$ & & Part/Shade & & & & \\
\hline \multirow[t]{2}{*}{ Fern } & Blechnum minus & & Swamp Kiokio & $0.5 \times 1 \mathrm{~m}$ & $\mathrm{~L}$ & Sun/Part & & & & \\
\hline & & & & & & & & & & \\
\hline \multirow[b]{7}{*}{ Tree } & Coprosma robusta & & Karamu & $5 \times 3 m$ & $\mathrm{~T}$ & Sun/Part & & & $Y$ & \\
\hline & Cordyline australis & Cabbage Tree & Toi & $10 \times 2 \mathrm{~m}$ & $L-T$ & & & & $Y$ & \\
\hline & Hoheria sexstylosa & Lacebark & Houhere & $8 \times 6 \mathrm{~m}$ & & & & $Y$ & $Y$ & FI - Su-A, Fr - May \\
\hline & Leptospermum scoparium & & Manuka & $4 \times 2 m$ & $L-T$ & Sun/Part & & $Y$ & & Oct - Dec \\
\hline & Pitospermum scoparium & Lemonwood & Tarata & $12 \times 5 \mathrm{~m}$ & & & & & & \\
\hline & Schefflera digitata & & Pate & $4 \times 3 \mathrm{~m}$ & $L-T$ & Sun/Part & & & $Y$ & \\
\hline & Sophora microphylla & & Kowhai & $6 \times 4 m$ & $T$ & Sun/Part & & $Y$ & & \\
\hline
\end{tabular}

$E=$ Emergent Planting, fully submerged

$\mathrm{L}=$ Littoral Planting Zone, Semi submerged

$\mathrm{T}=$ Terrestrial Planting, Fully exposed

Table 7.02 | Planting schedule. 


\section{+ I NTERVENTIONA}

Intervention A centres around interaction of infrastructure and vegetation, a relationship that has being designed around facilitating water focused wildlife interaction.

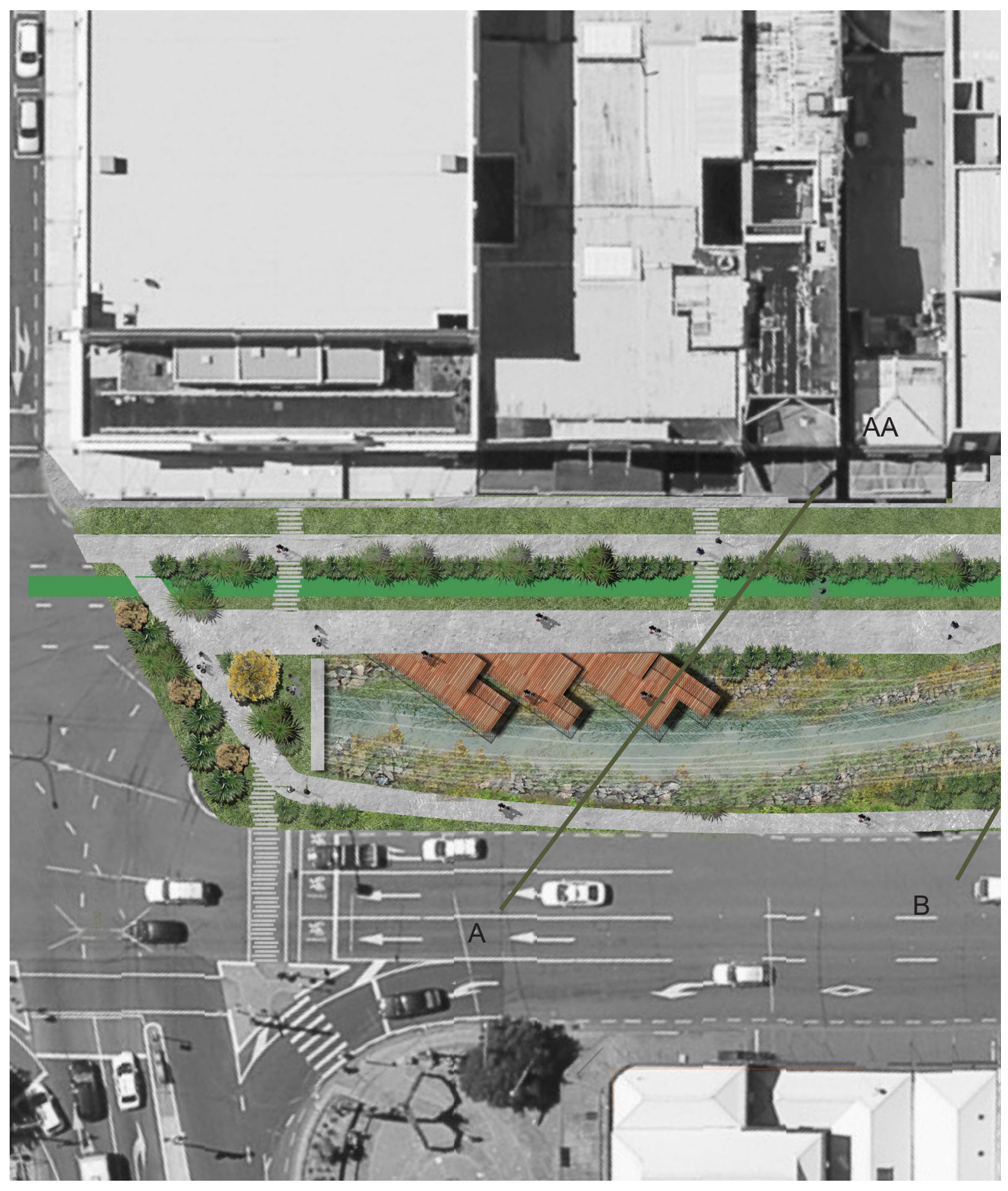

Fig 7.54 | Rendered masterplan Scale 1:1,100@A3 


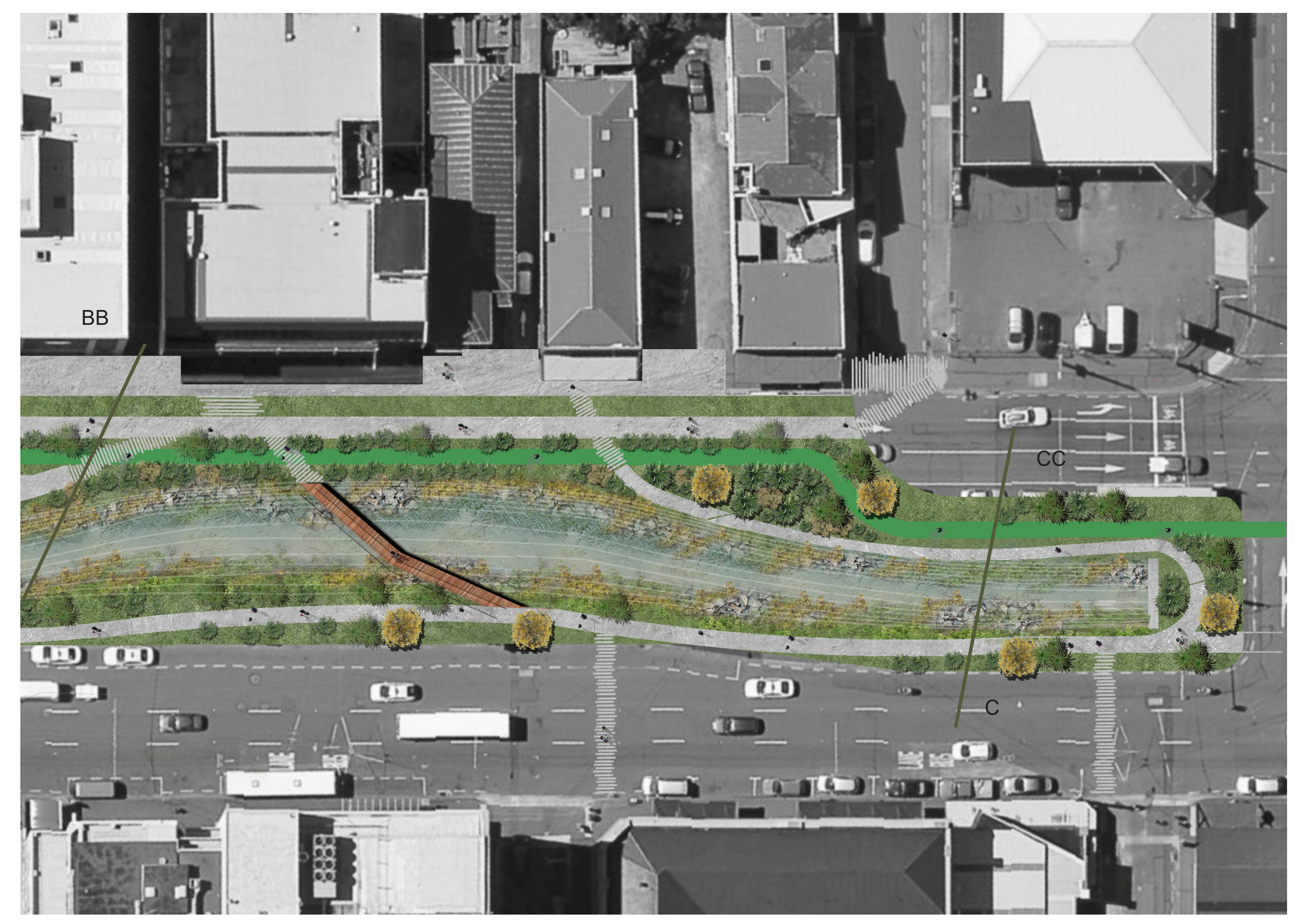




\section{+ INTERVENTION}

\section{A SECTION}

This space offers different levels and openings that encourage people to get closer to the water, via different methods of movement. Open edges for the fencing allows perching for birds and people within the same space.

Fig 7.55| Scale 1:1,100 @ A3, Section $A-A A$

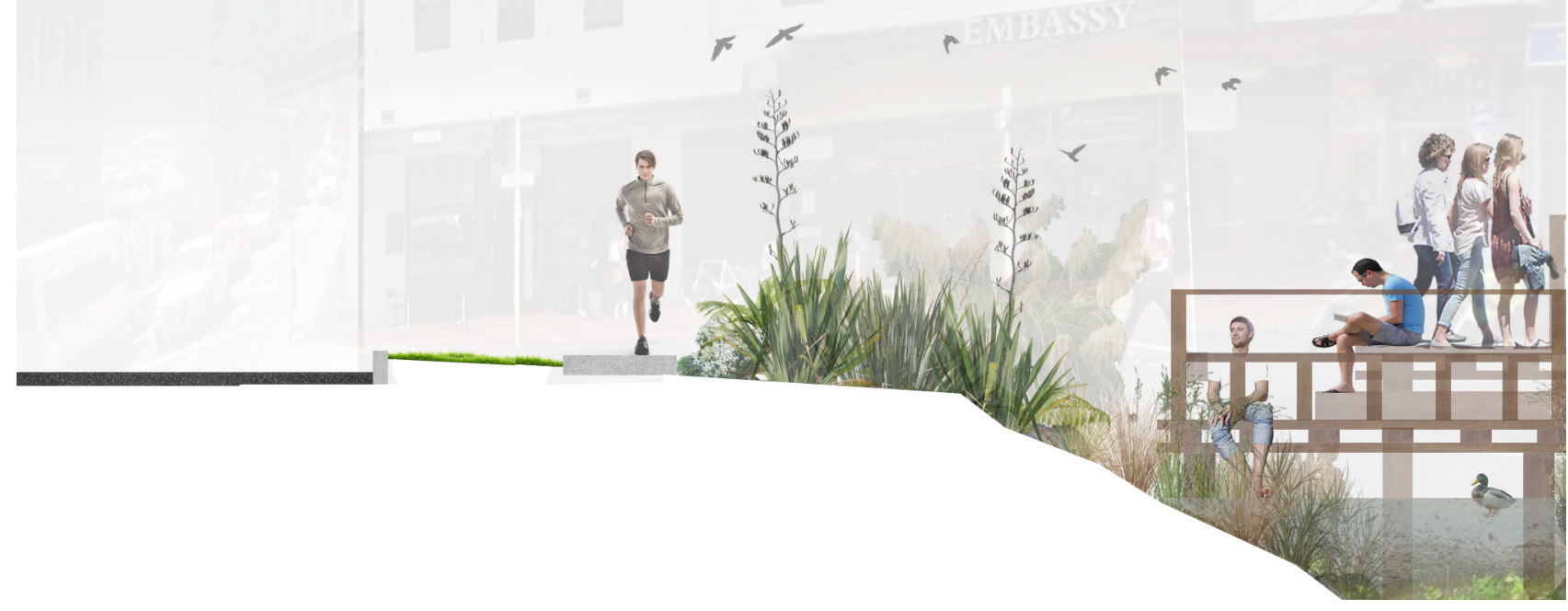




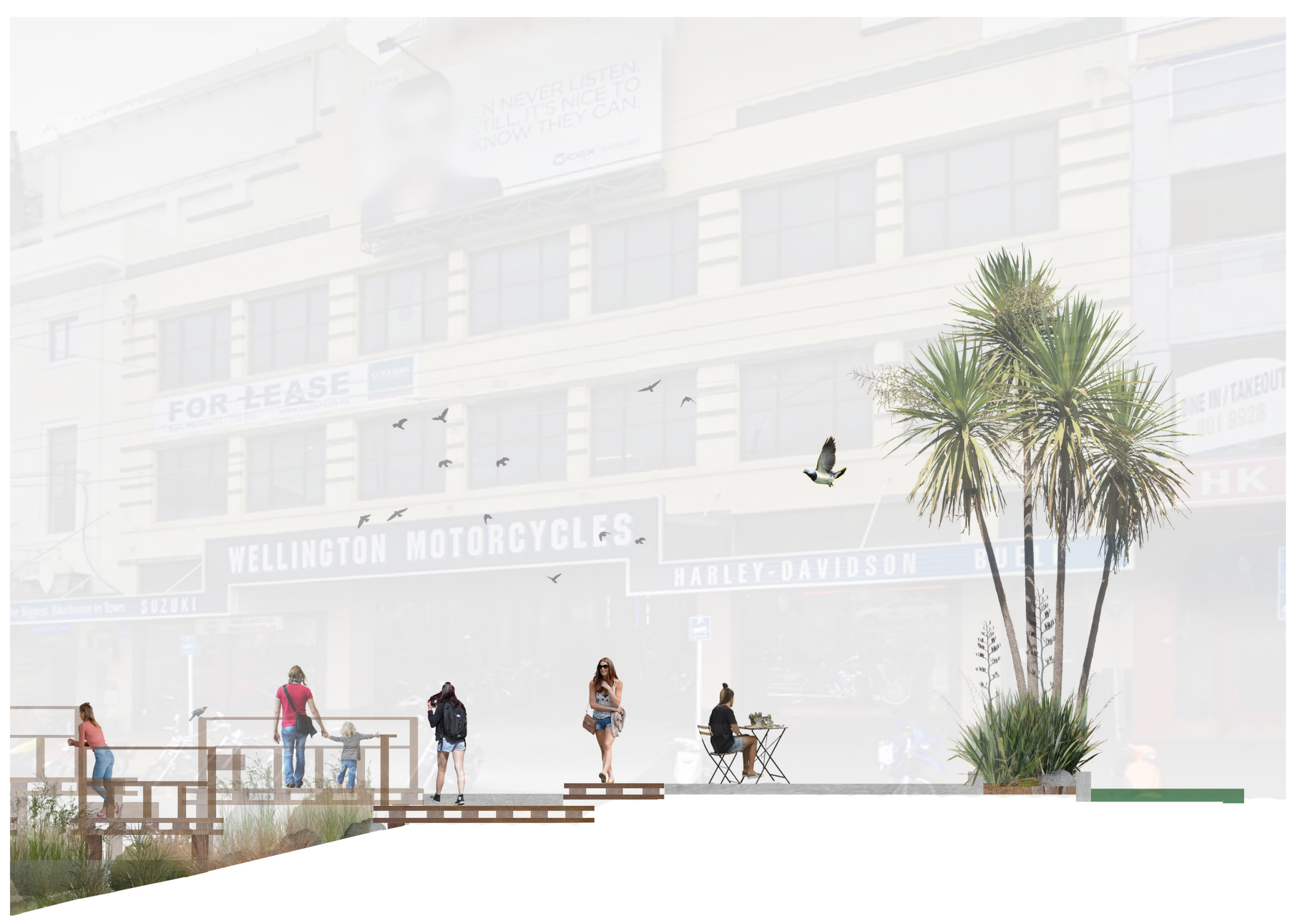



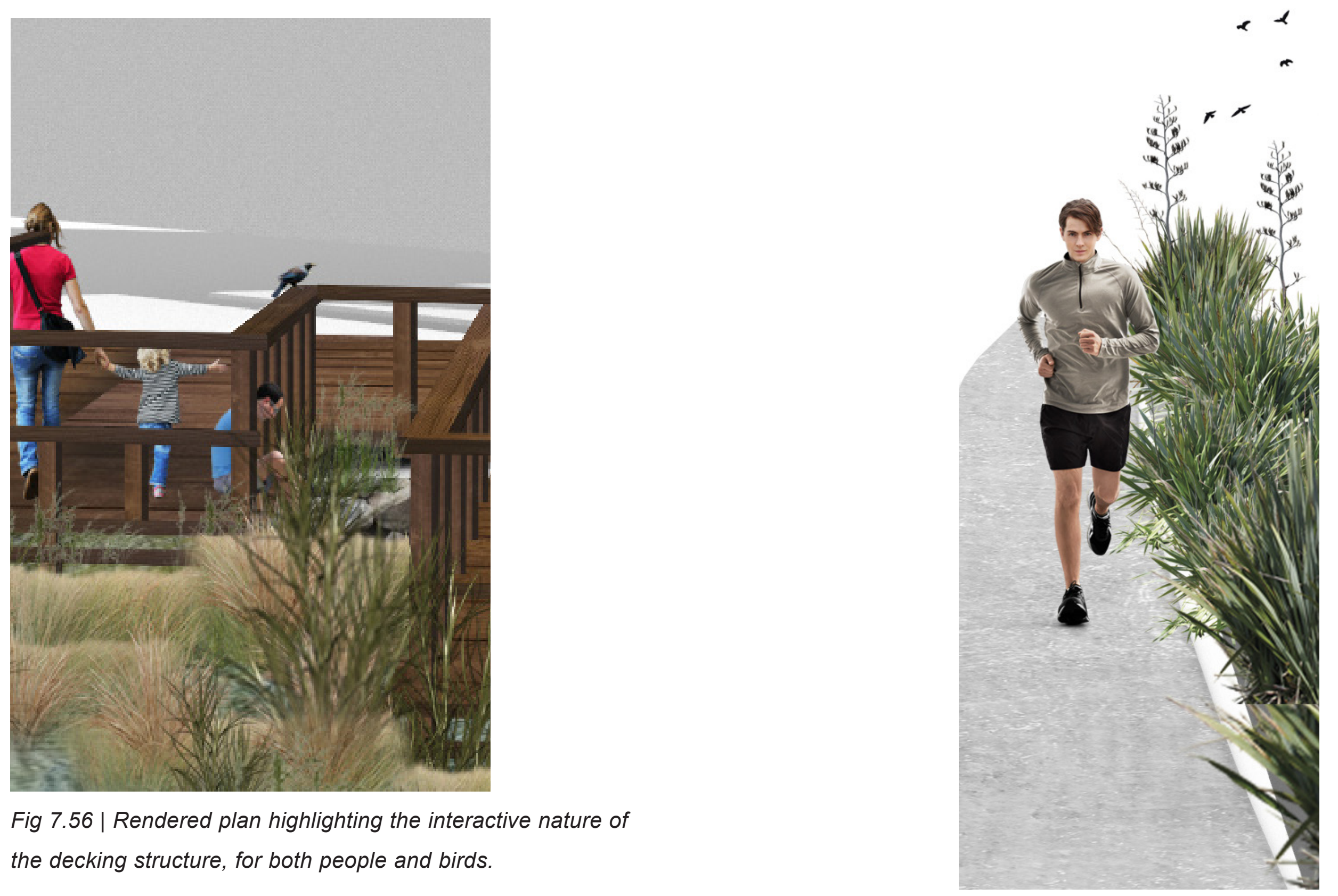

Fig 7.56 | Rendered plan highlighting the interactive nature of the decking structure, for both people and birds. 


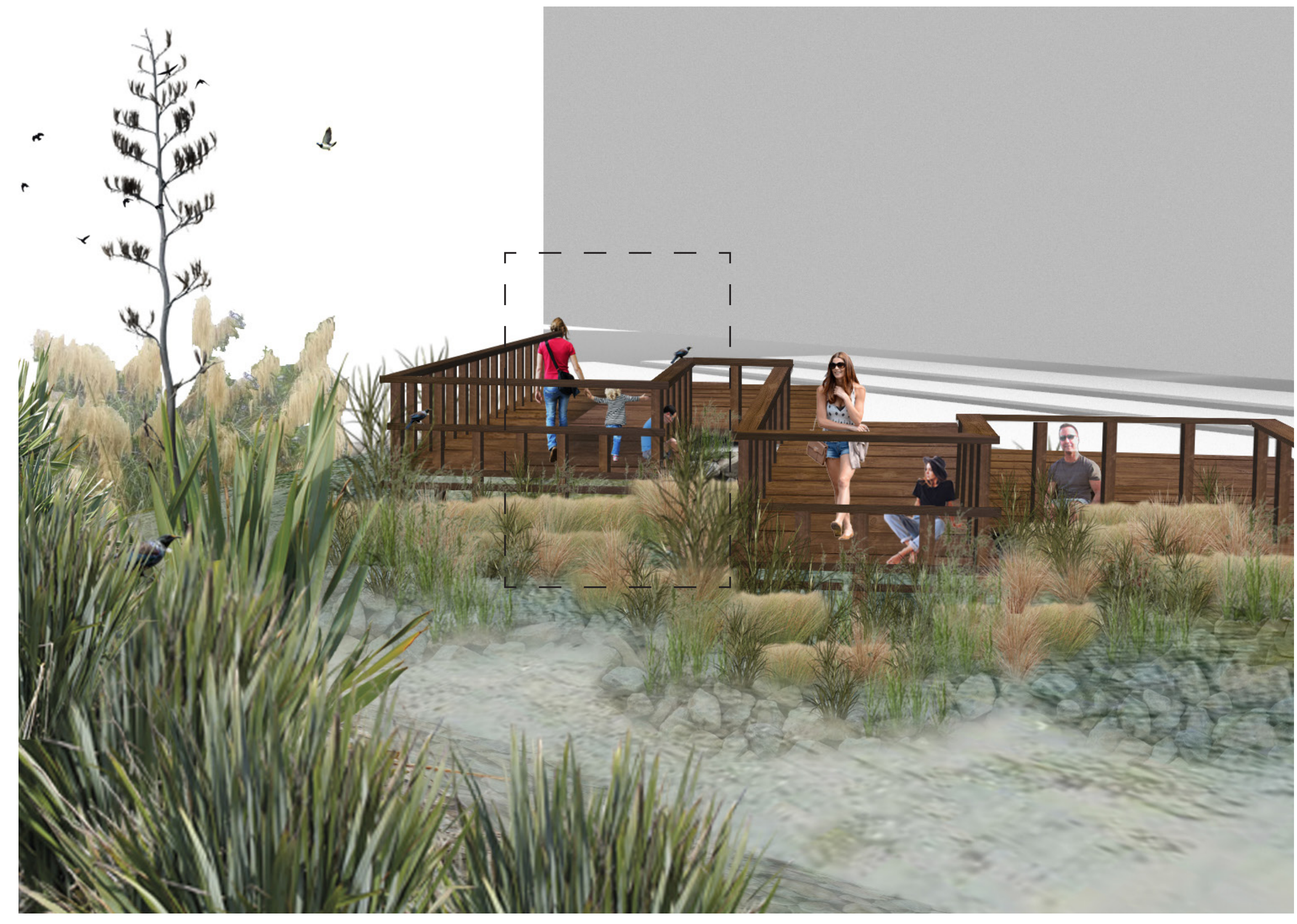




\section{+ I NTERVENTIONASECTION}

Fig 7.57 | Sectional drawing showing the relationship between

the bridge and the vegetation.

B-BB | Scale 1:300@A4

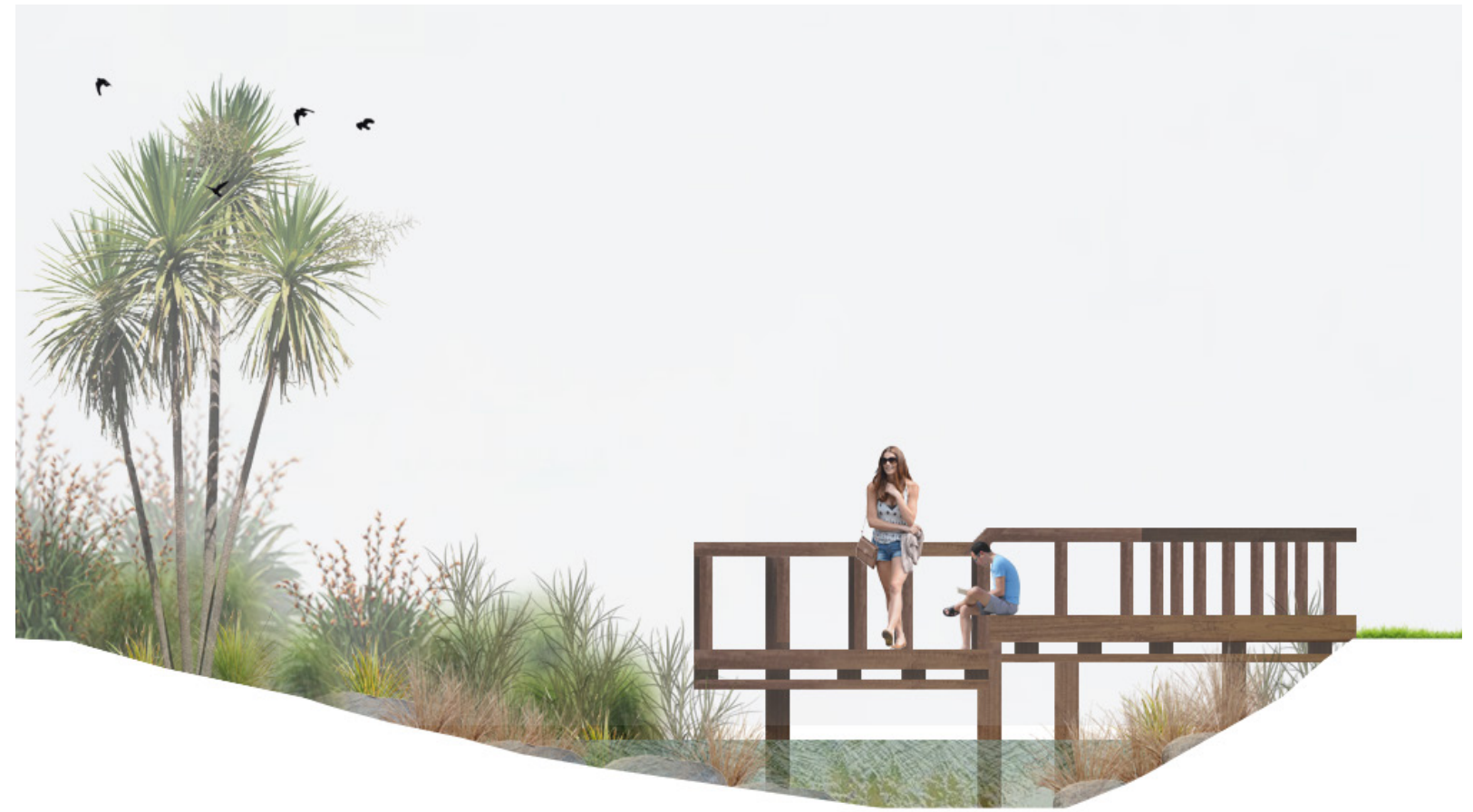




$$
2
$$




\section{+ I NTERVENTIONASECTION}

Fig 7.58 | Sectional drawing showing the relationship between the pathway and the vegetation.

C-CC | Scale 1:150@ A4 


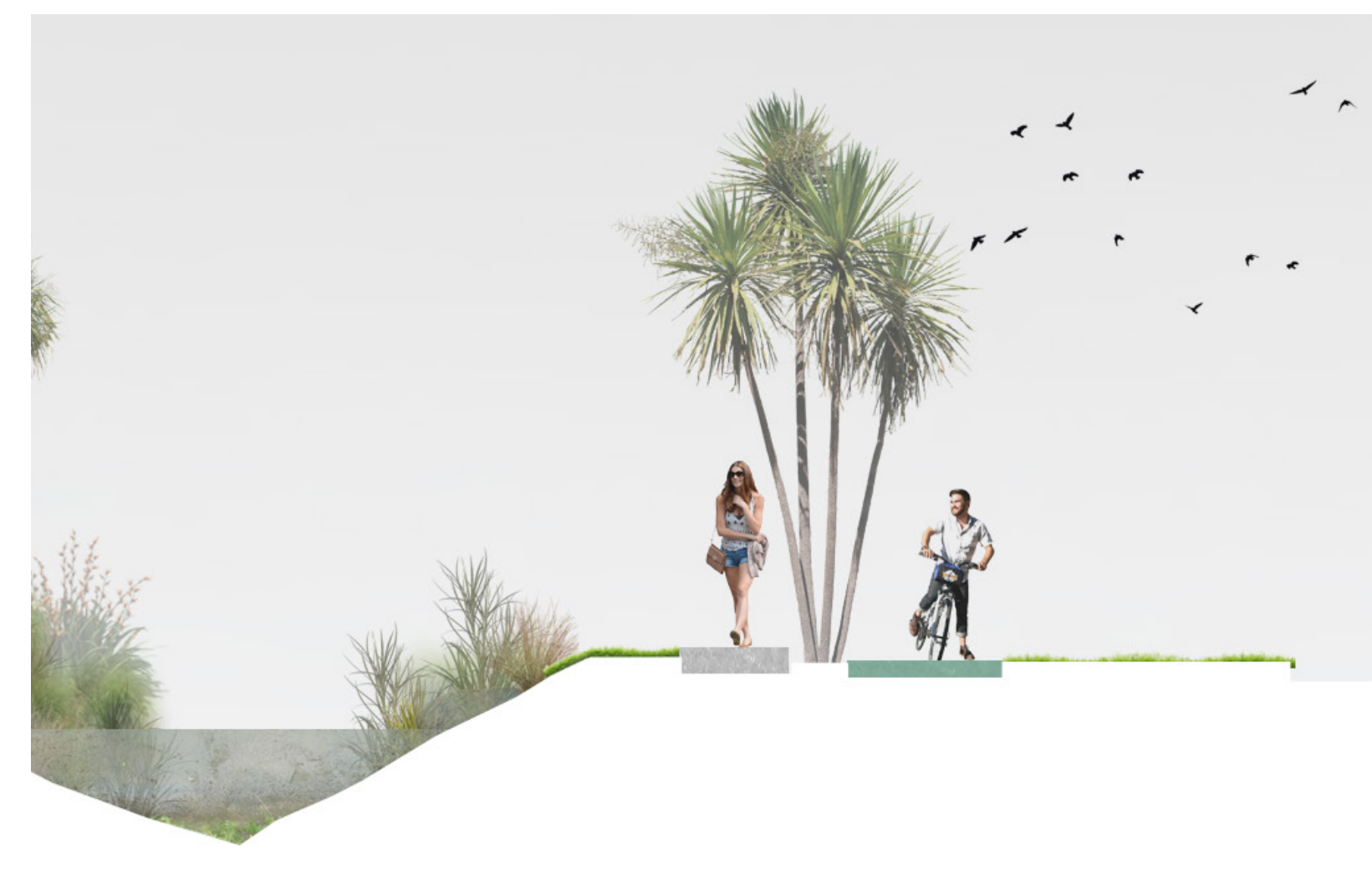


Fig 7.59 | 3D render showing the cycle lane and the surrounding vegetation that attracts multiple bird species, which can then be directed to the water. 


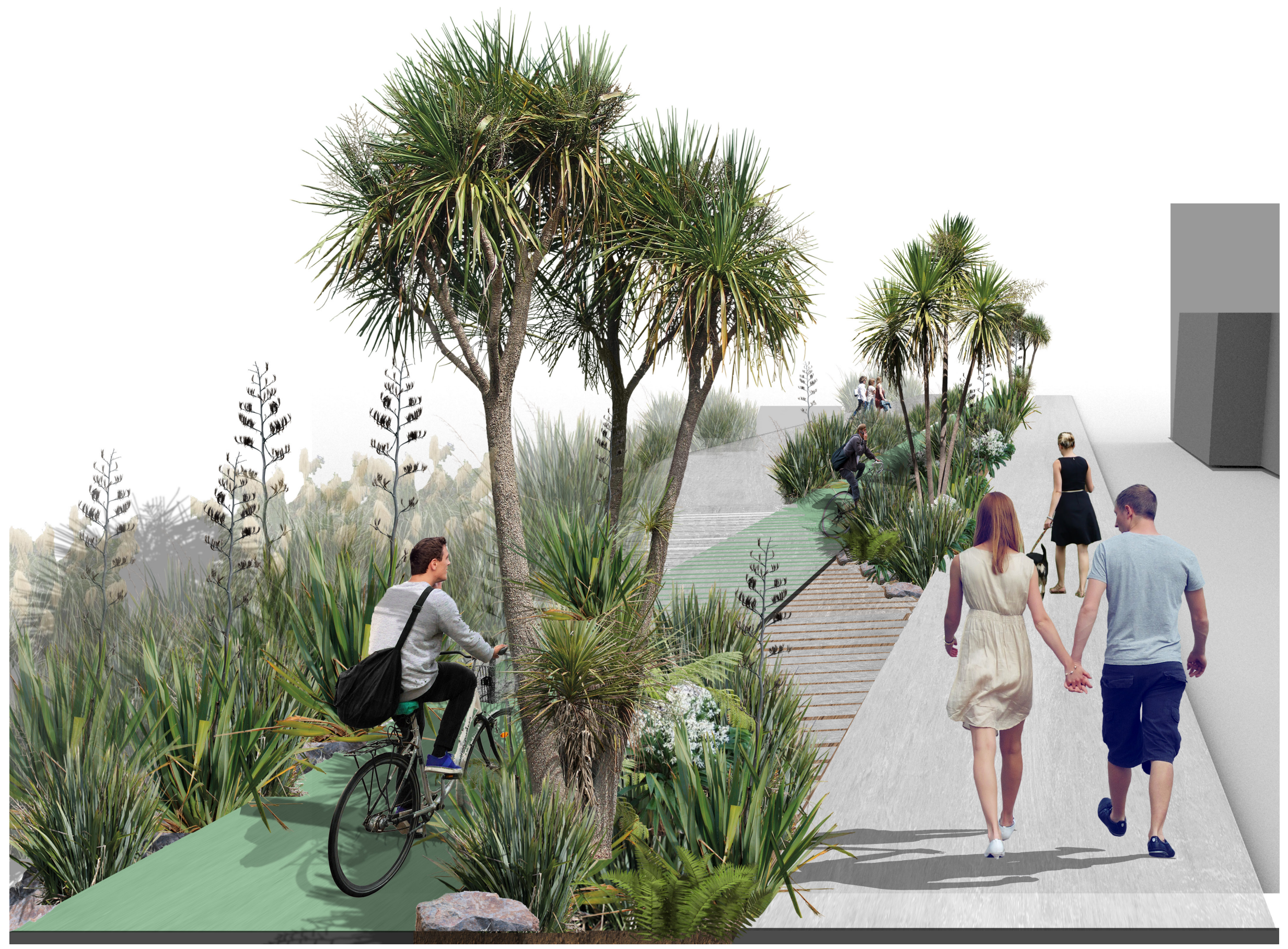




\section{+ I NTERVENTIONB}

Intervention B centres around interaction of fresh water that has been pumped from the water pipes underneath the site.

- Fig 7.60| Rendered masterplan Scale 1:1,100@A3

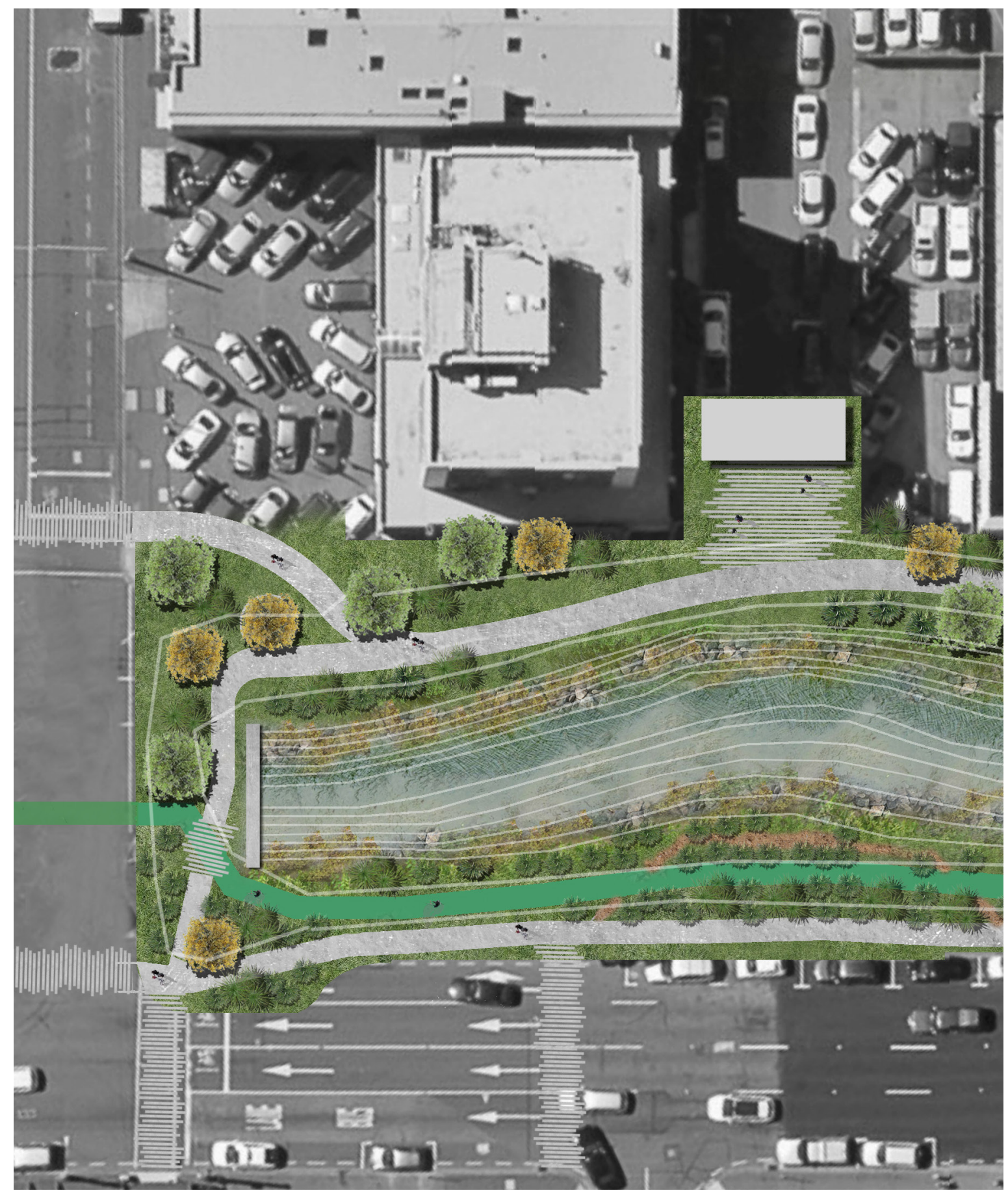




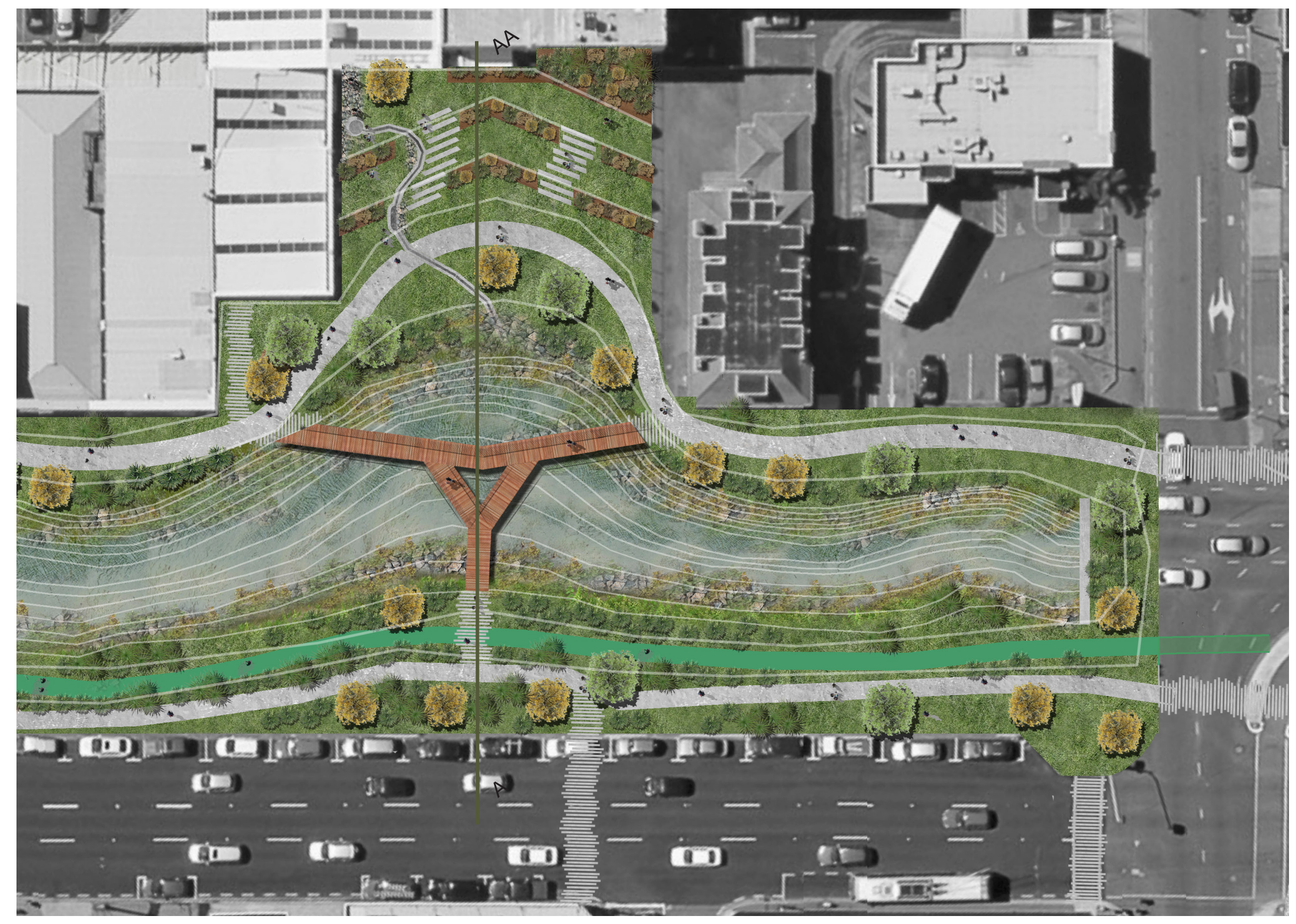




\section{+ I NTERVENTIONB SECTION}

Scale 1:1,225@A3, Section A-AA

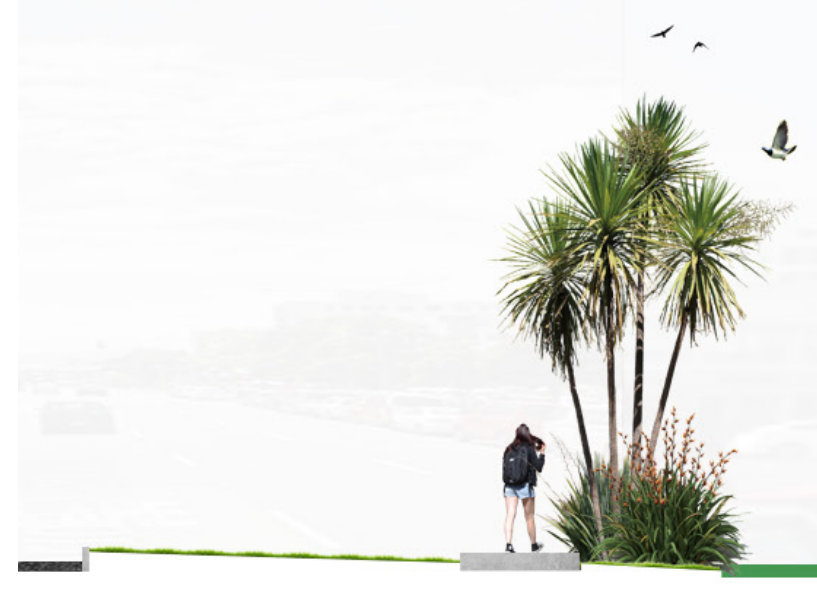

Fig 7.61 | Sectional drawing explaining the increase of land into what used to be a car park, to create small terraces that are vegetated, attracting in numerous amounts of wildlife. 
This area used to be a car dealership company, one of six that face onto this road. Re-orientating the building, facing it back to the secondary road, has made a large free space that has been used to create a wet location, perfect for perching, cleaning and drinking activities by both humans and wildlife. 


\section{+ I NTERVENTION B PERSPECTIVES}

Fig 7.62 | Small perspective images that reflect the spatial experience of the water features.

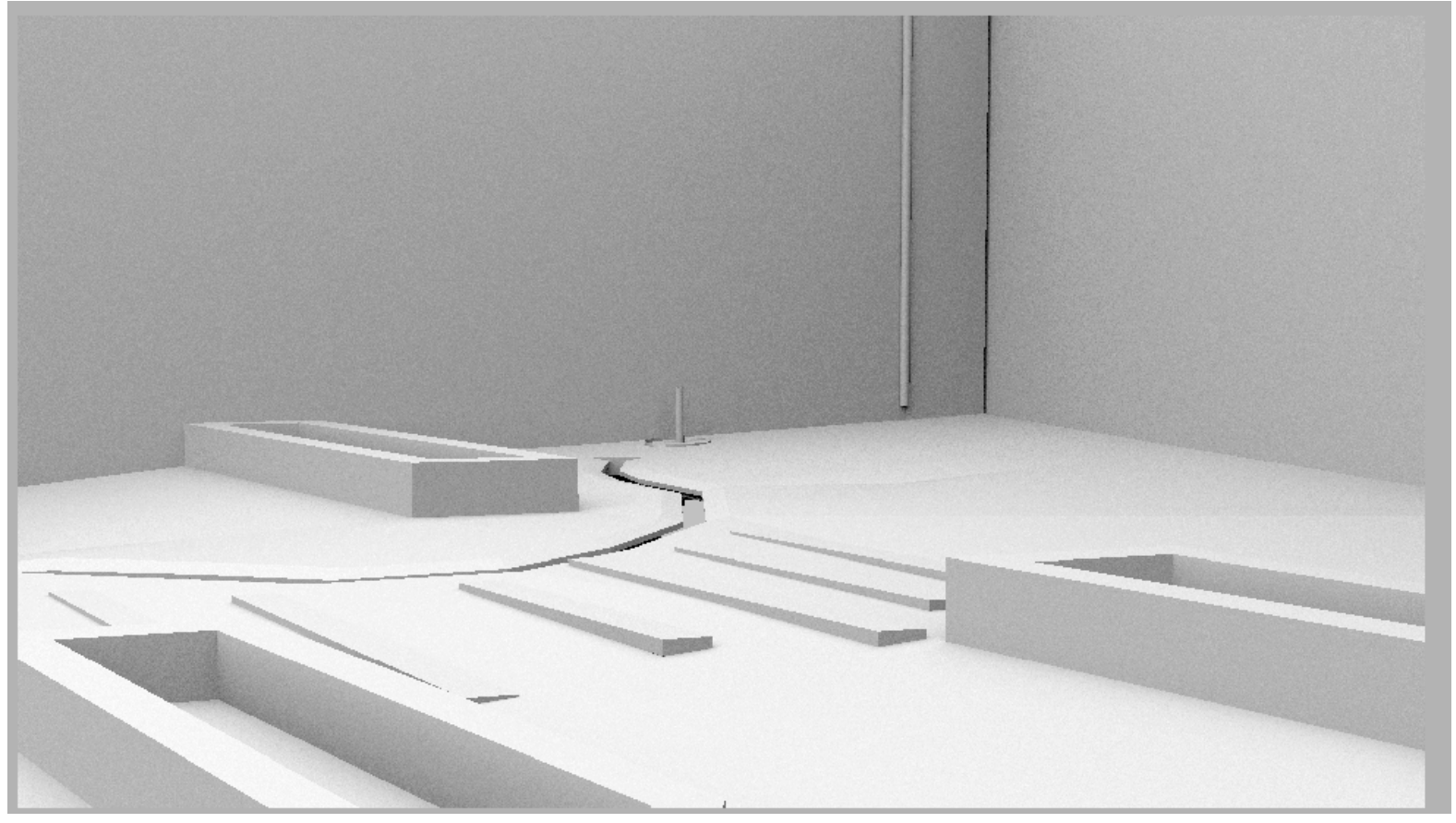


1 | Water falls down the drain from the collection area, located on the roof of the car dealership buildings. It lands on a collection of rocks that push it towards the fresh water pump.

2 | The water follows a depression in the landscape that briefly stops in a small pool, with the water pump, then continues down to join the stream system implemented in KCT.

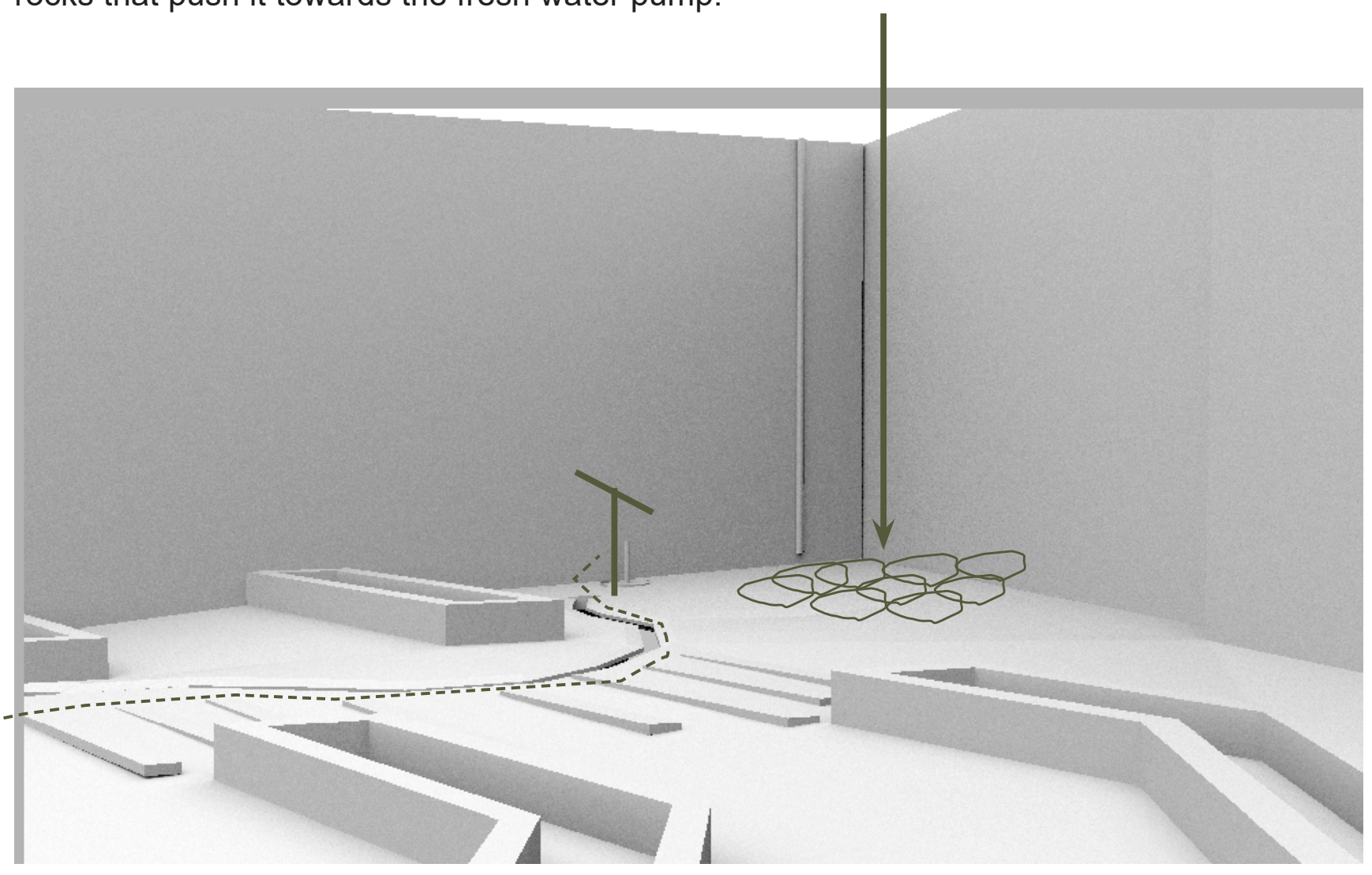




\section{+ INTERVENTIONC}

Intervention C centres around interaction with the beginning exposure of the stream. An open deck that creates a small island in the water flow, combined with the rocky vegetation, makes it easily accessible to get amongst the water with the birds. The mixture of land and wet vegetation provides multiple attractions for the wildlife.

The changing of the car dealership building, to a restaurant setting, allows for a connective interior/exterior that allows for the spaces to have an informal eating assemblage.

Fig 7.63 | Rendered masterplan Scale 1:1,100@A3

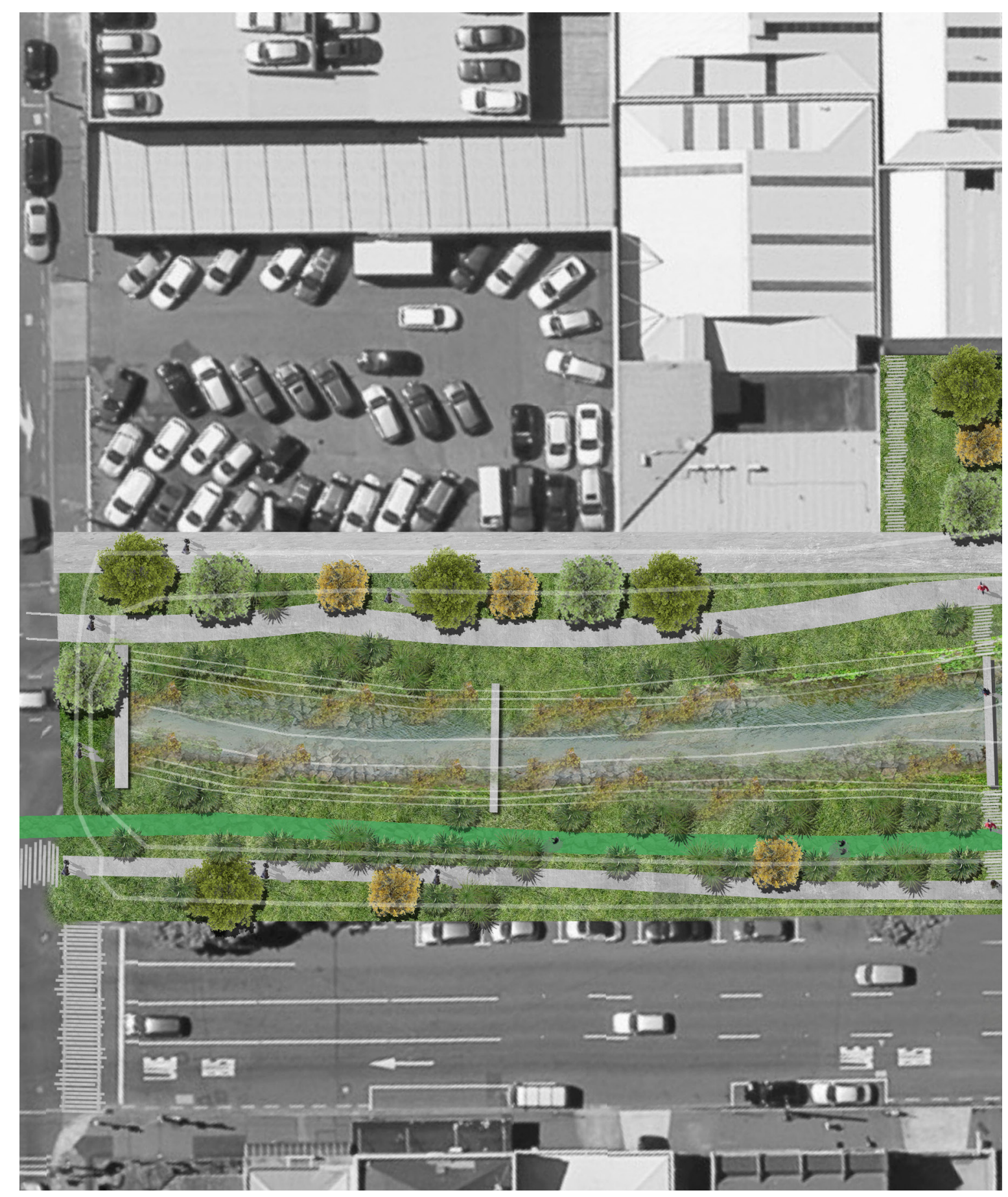




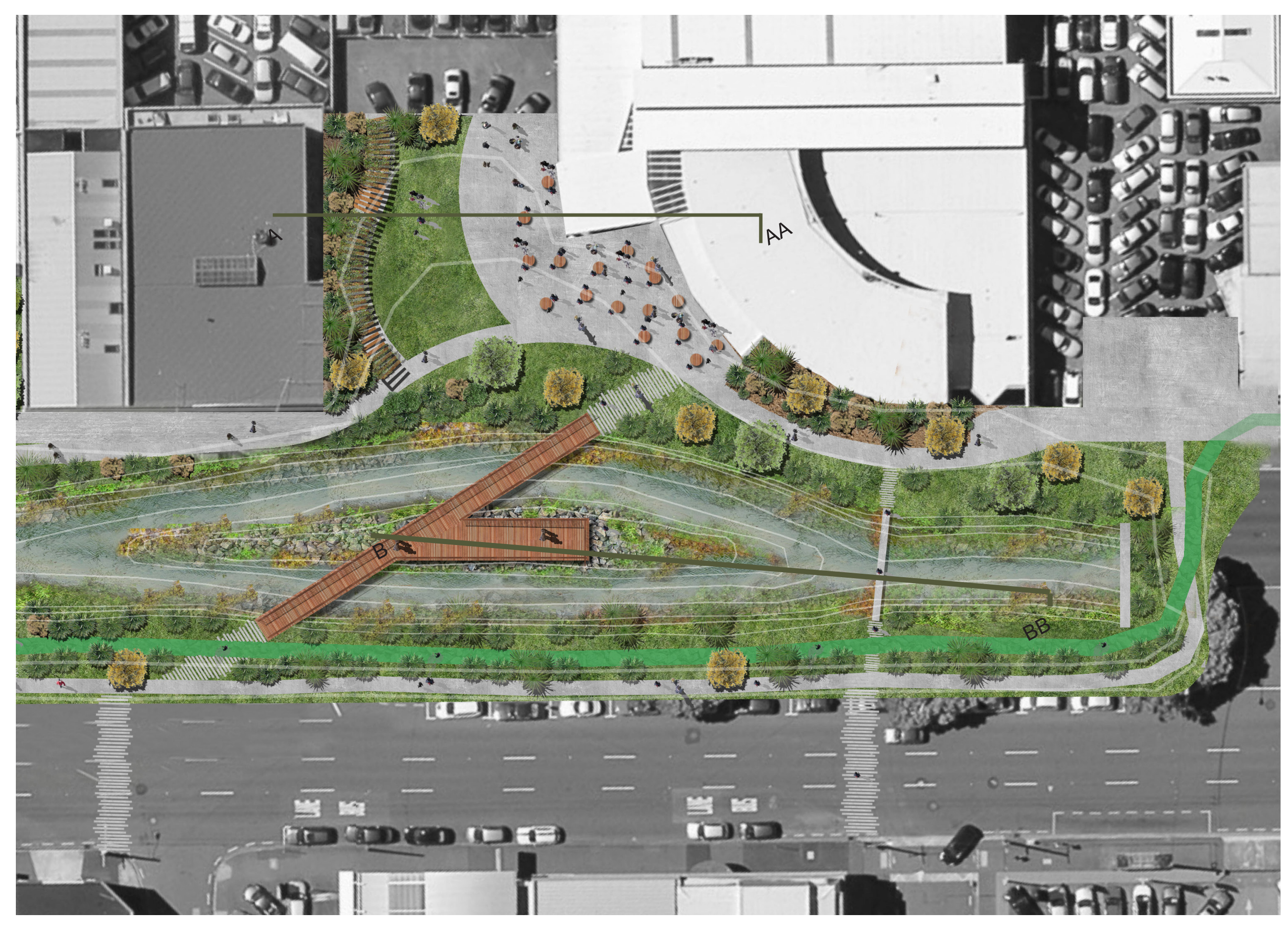




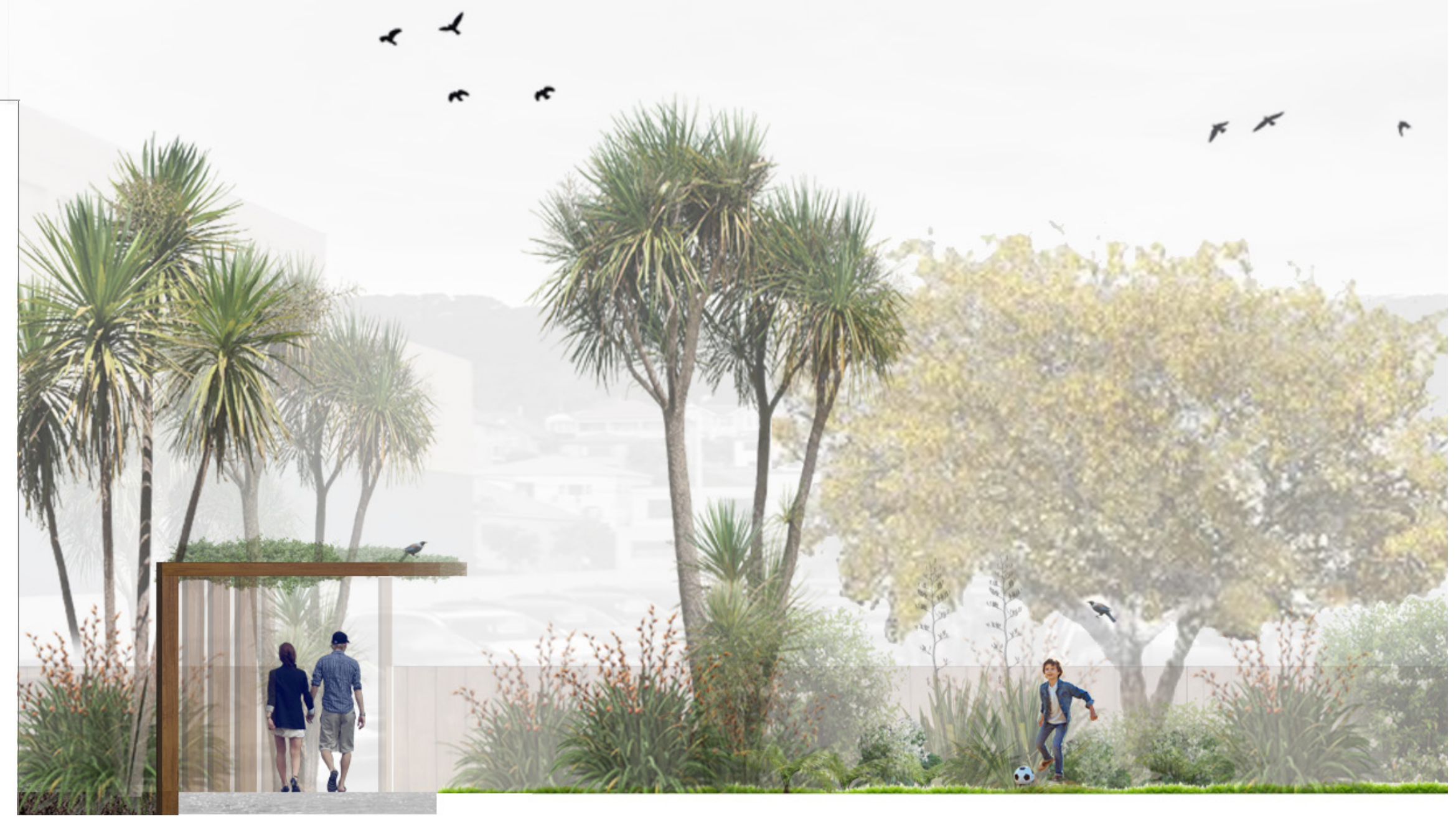




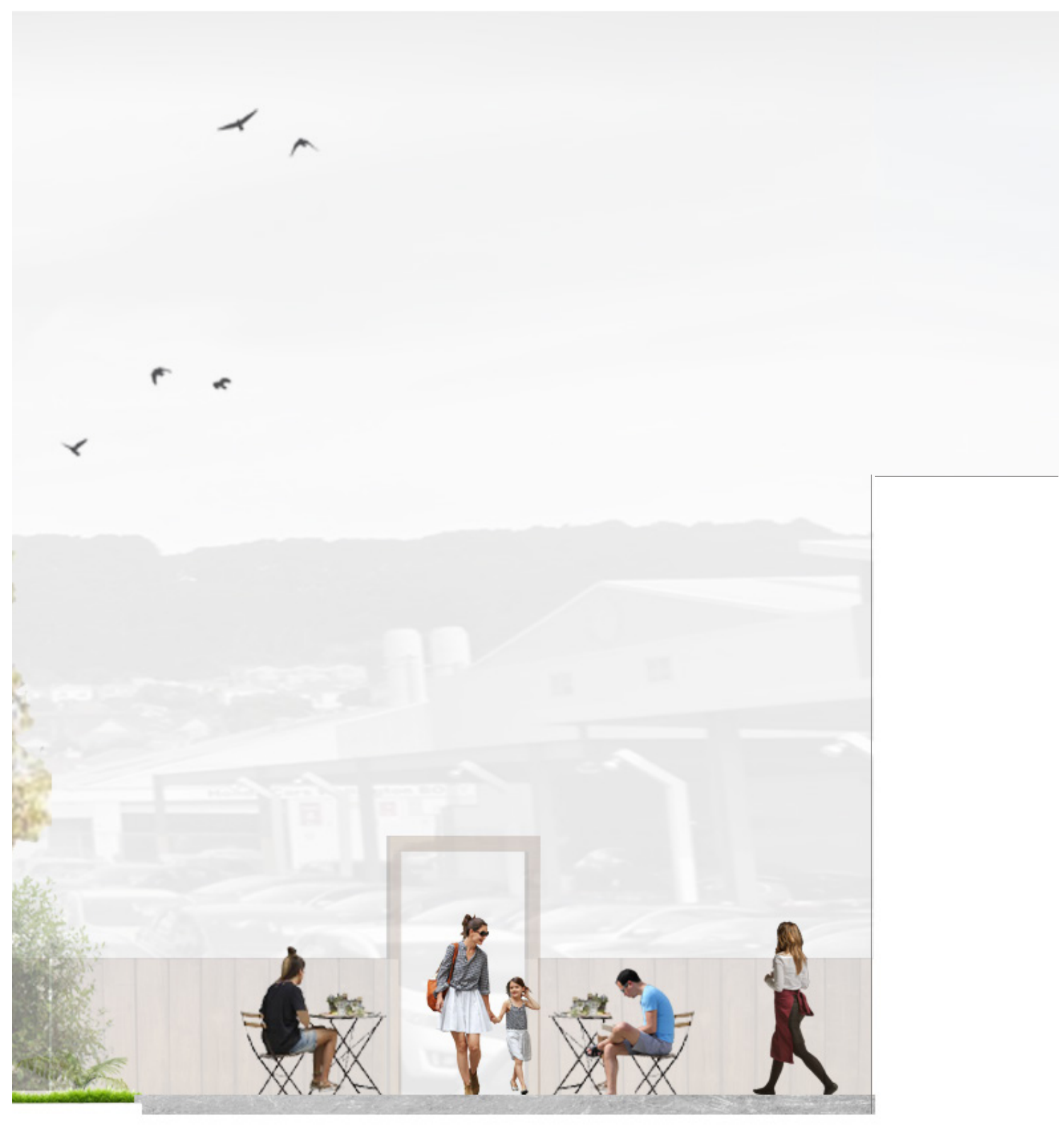

Fig 7.64 | A-AA |Sectional study of space separations. Scale 1:150@A3

The surrounding exterior of the space is heavily vegetated, with species that have been identified in previous designs as being attractive for people and beneficial to birds.

Spatially allowing this on the edge provides a required separation, due to proximity distances that make the species feel safe in an active area. 


\section{+ INTERVENTIONCSECTION}

Fig 7.65 B-BB | Scale 1:200@A3

Sectional drawing showing the water management of the long site.

The passage over top of the retaining wall is a multi-use place for both people and birds, as a place to travel as well as perch.

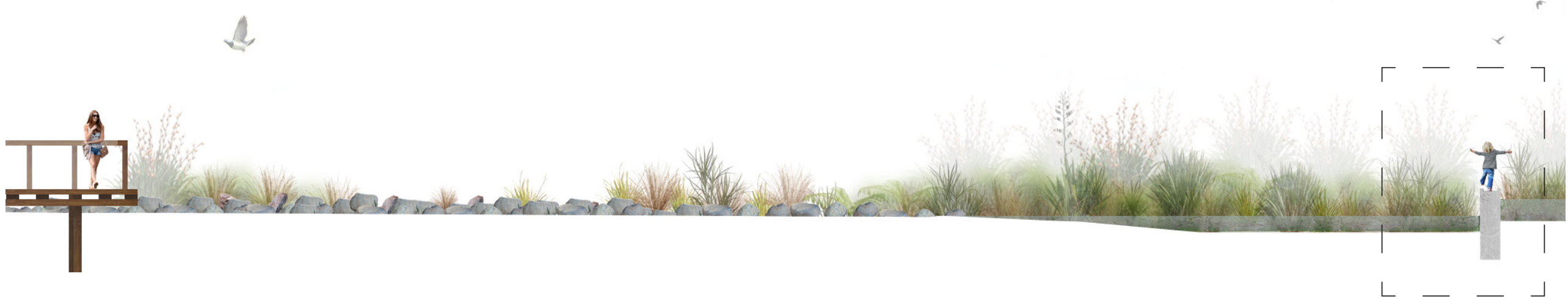



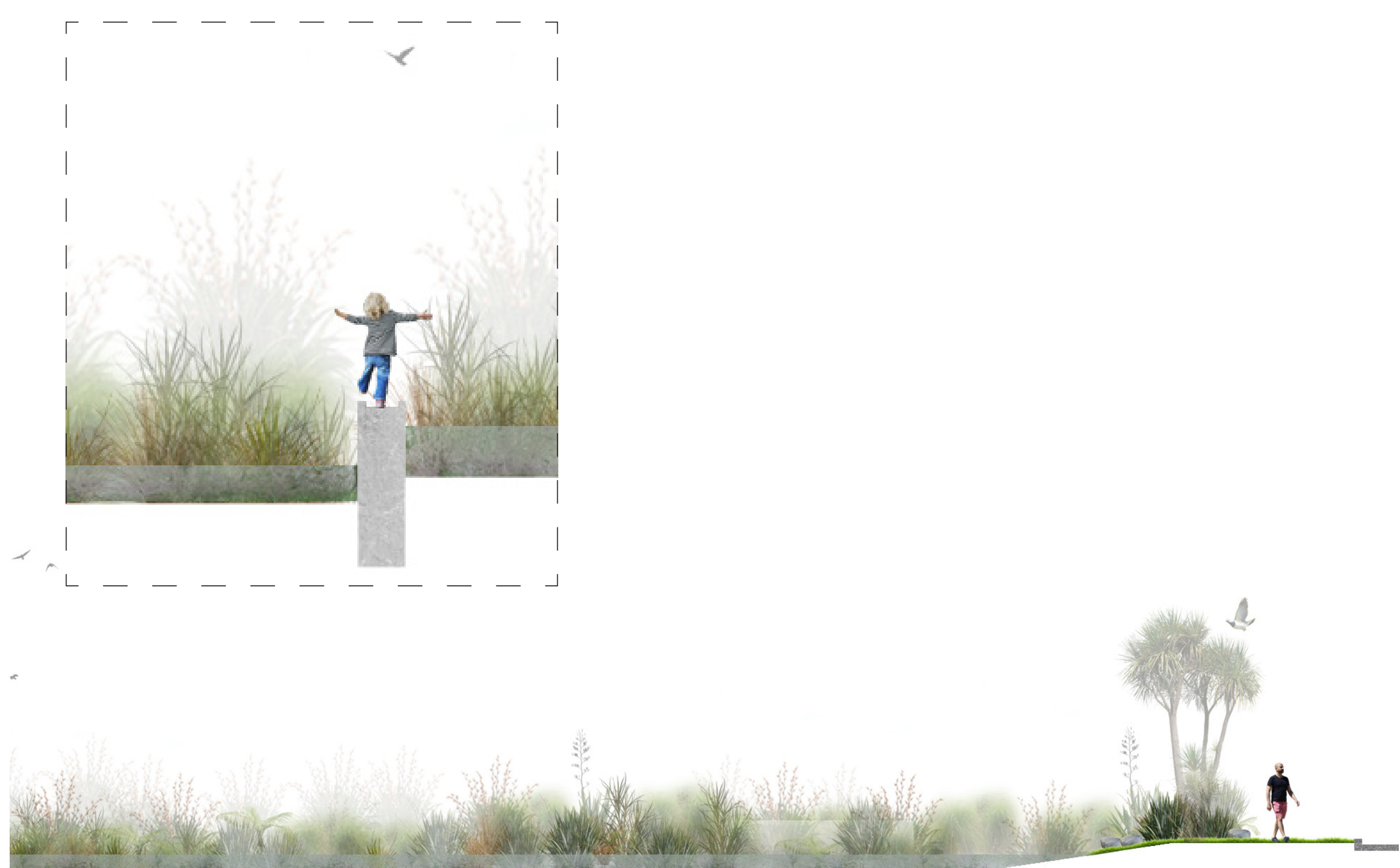
Fig 7.66 | Perspective showing alternative view from the wooden platform. Visualisation of the open fences shows the permeability and multi-functionality of the design for both clients.

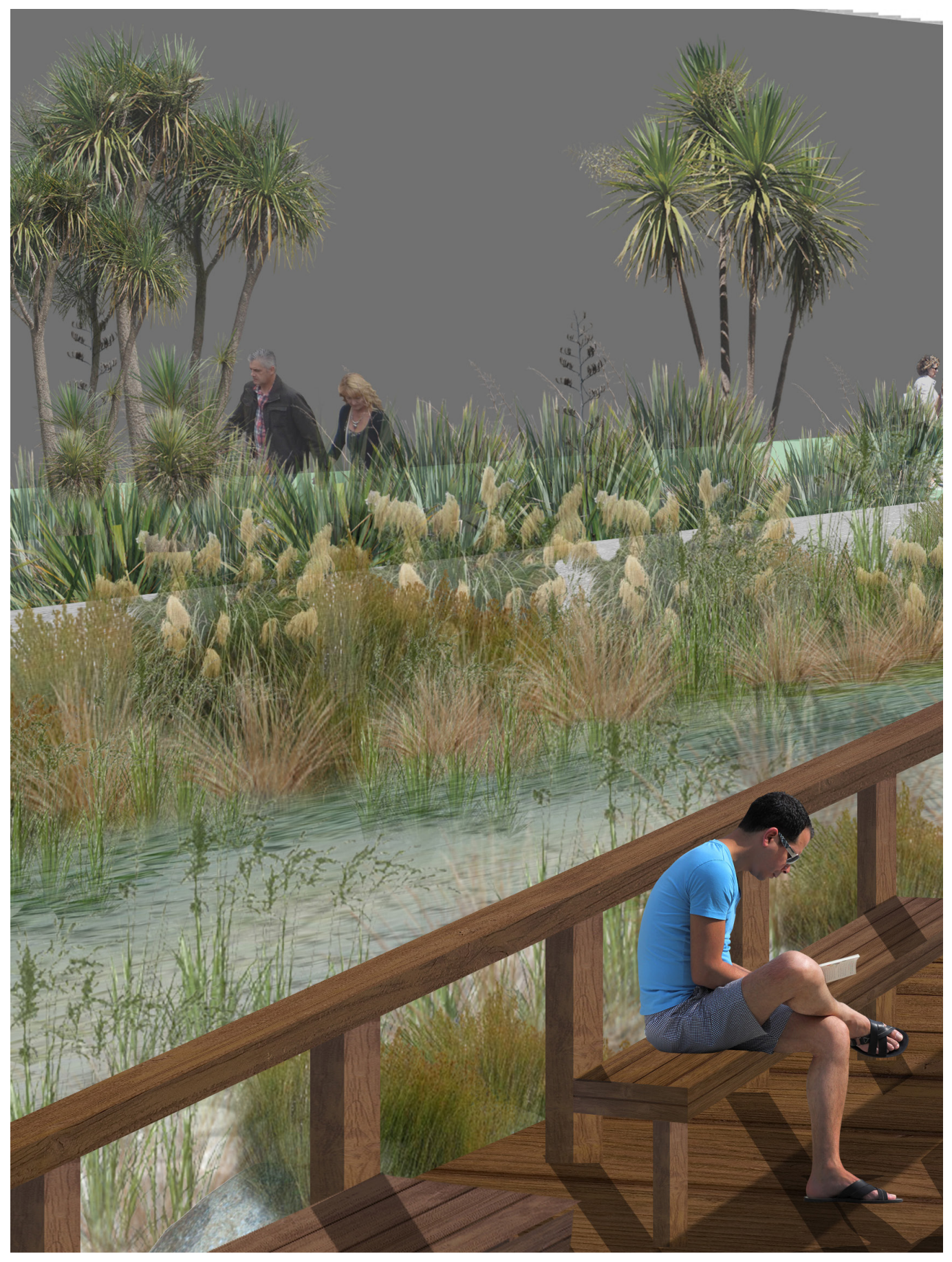




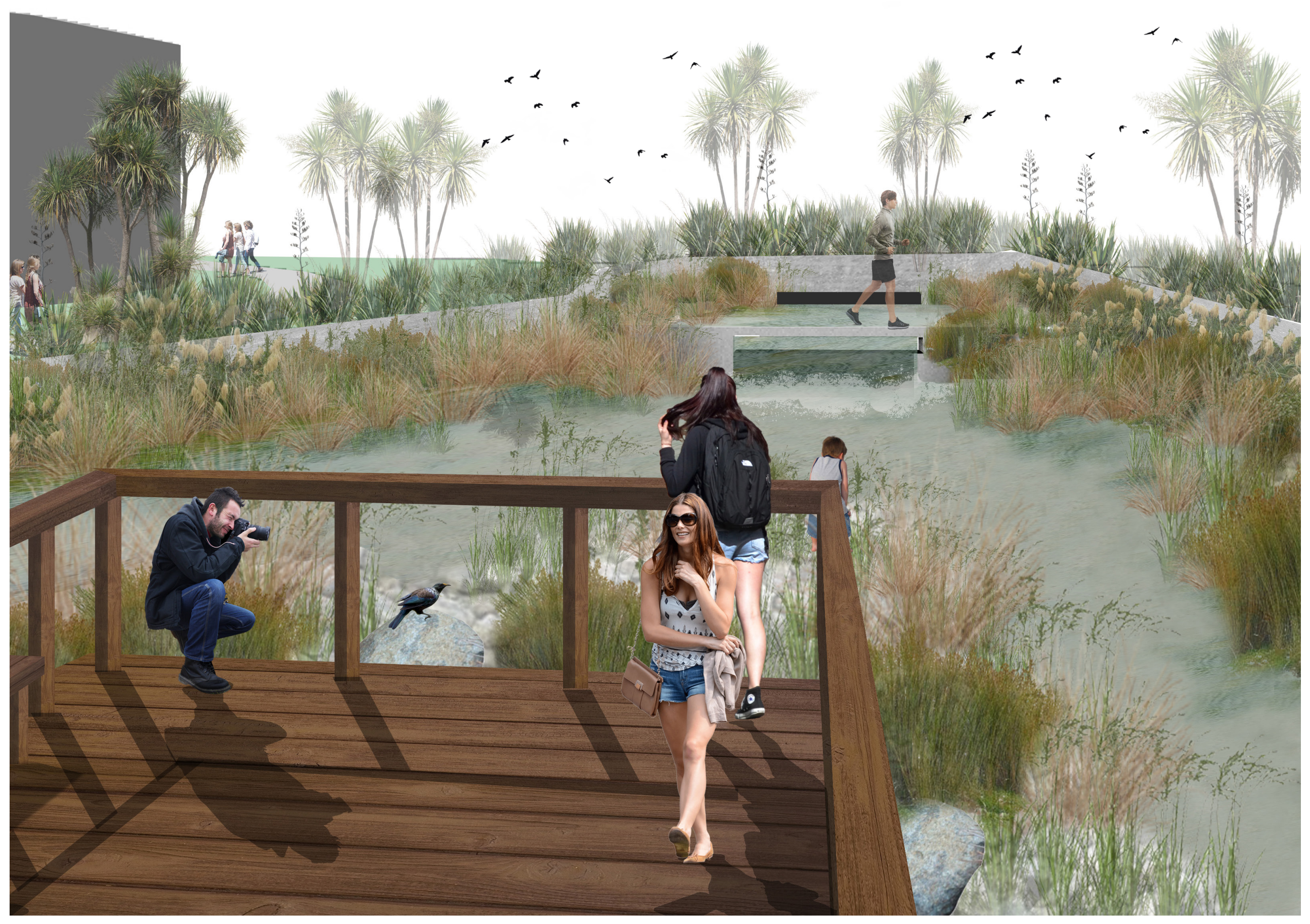




\section{+ CRITICALREFLECTION}

It is clear from this process that attention needs to be applied to this stage. Ways that this could have been achieved is through implementing the same technique of conducting interviews for each design stage. This would have resulted in a clear and thorough developed design. This location was very tricky to design as it somewhat fell below the requirements for the macro analysis stage, in that it did not have a suitable interior space. However, despite this, the location was still included in the thesis, as the intention lied in this being a starter site for future change. Ideally, the efforts that have been achieved here would enact change within the area, allowing it to grown into the urban environment, reaching back towards $\mathrm{Mt}$ Vic, and providing that interior space.
However, aside from this, the designs that were completed offered a range of findings that have been vital when considering the other three locations. They are as follows:

+ One, working within an urban environment such as Kent and Cambridge Terrace, is very difficult when considering the built limitations. Space allocation is very limited and affects the amount of work that can be achieved when designing. Not much can be done with this, but for future designs, it is critical to know before hand. 
$+\quad$ Two, water is a very interesting medium when working with wildlife. Behaviour around these spaces are vast but narrowing down the role water needs to play can reduce the scope greatly. Additionally to this, bird species does not have any affect in the way that they experience water, this proved beneficial and it reduced the amount of attention needed when designing. It was very different to have general species in this site, compared to the last location that relied heavily with individuality. 


\section{+ OTHERLOCATIONS}

The other three locations have not yet be designed, aside from a series of physical models. The program of the sites have been established and a basic spatial composition has been decided upon.

The lack of detail within these areas can be attributed towards limited time available and the process of this thesis. The literature reviews, particularly macro, took a long time to understand and spatialise, the other areas of the design process could not be developed in depth as a result.

The exploration within model space helps to bridge the lack of information but still allow for a continuity of design practices.
Wellington's Stepping Stone Locations Fig 7.67 | Scale 1:50,000 Existing Green Space Stepping Stone Locations SS Locational Flight Distance, $294 m$ EGS Locational Flight Distance, $294 m$ Sea

+ LOCATION 1 |PECKING PICNICS

+ LOCATION 2 |SHELTERED HUTS

+ LOCATION 3 |FRESH H2GO

+ LOCATION 4 |NESTING

HIDE-AWAYS

+ LOCATION 5 | SOCIAL SPECIES 


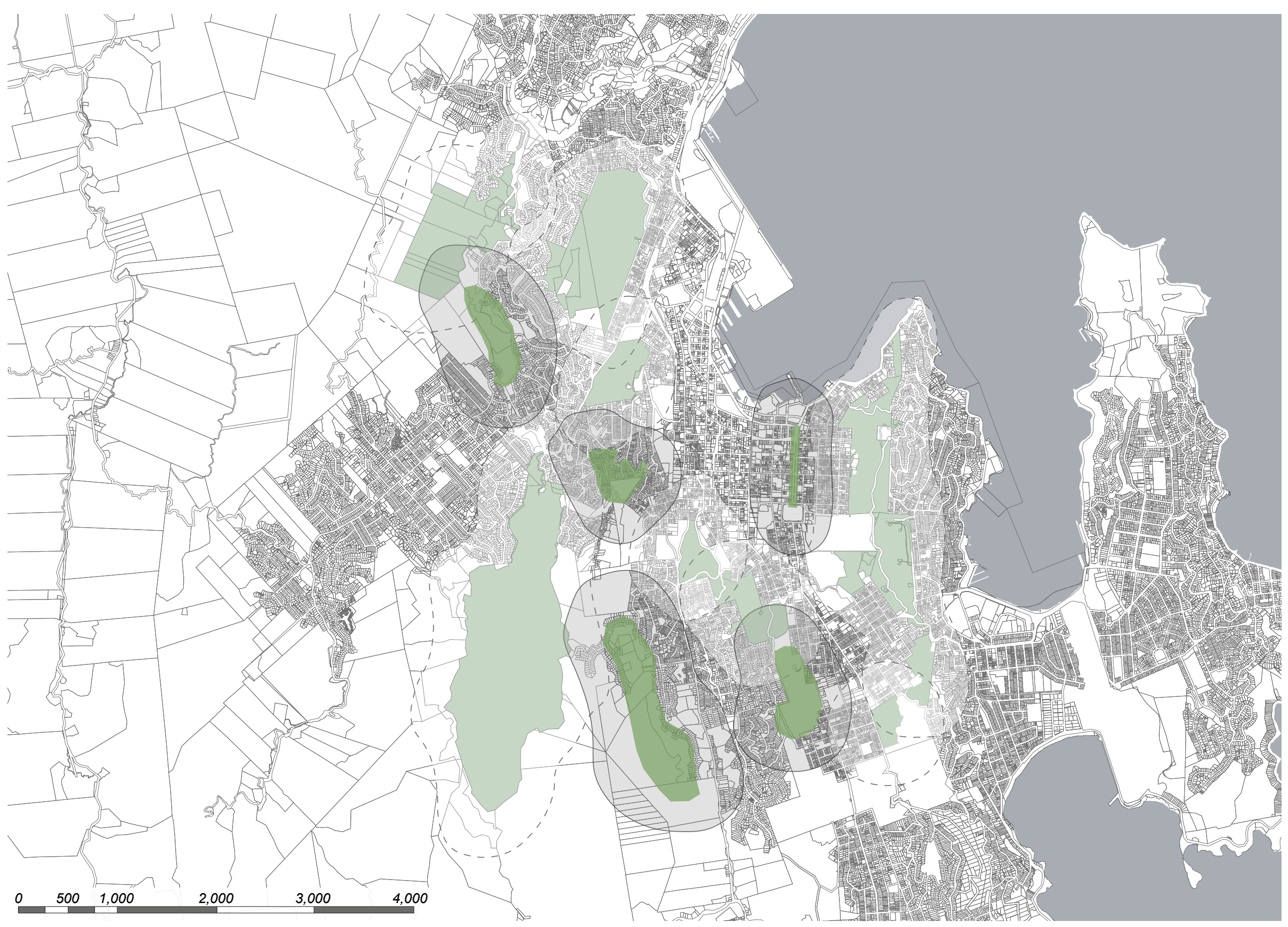




\section{+ CONCLUSION}

This thesis revolved around addressing fragmentation and biodiversity loss through implementing a series of design scales that looked into the different layers of design. The macro scale proves the success and use of stepping stone locations as a way to move wildlife to specific areas, particularly within the urban realm. Once wildlife was 'present' in these spaces, it was up to the meso scale, connective corridors, to encourage the movement of people to these spaces. This allows for the two clients, humans and bird wildlife, to be present in one space. This resulted in the final step of this thesis, exploring different ways to allow humans and birds to interact.
Question

+ Rounding this design thesis back to the original question of "How can urban habitats accommodate native wildlife species as well as providing elements for human/wildlife interaction?" brings around the discussion of success. The beginning section of the question, how can urban habitats accommodate native wildlife species, was answered in the macro scale. It addressed the issue of limitations around including patch like locations that act as stepping stones between the existing green sites that were full of wildlife. Specifications from the literature provided a framework for implementation that worked well with the site specific adaptations within Wellington City Council. Abstractly in placement of locations, this part of the question has been answered. It is through consideration of patch distances, patch area and species selection. 
+ The second area of the question, providing areas that can promote the relationship of interactive unity, has also been addressed. Having a stepping stone locations/patches will always provide some sense of accomplishment when addressing biodiversity and fragmentation, additionally when realising people moving through these spaces is an indirect form of inclusion and interaction.

+ A key lesson was realising that there is no way to really focus on these interactions without knowing the species that were being targeted for positive impact.
+ One of the major findings within this document, was the simplicity that was needed for this interaction. Realising that there is no need or reason to micro-manage all design intents was crucial to allow for more flow in the design. With having two clients, there is not a lot of opportunity to fully cater for both, especially when working with wildlife, as they have no sense of rules or boundaries of built form. A lot of the design resolves around merely providing utensils such as chairs, or pathways or vegetation, while always considering proximity to 'bird' focused infrastructure and human focused architecture. It is the role of the people to be aware of interaction purposes and intent, it is not up to the birds to be performing for people. Therefore design interventions that encouraged people to reflect and want to interact, was the key for this thesis question. 


\section{Further Explorations}

This type of thesis exploration relies heavily on individuals either spending time researching wildlife species behaviours or already having this knowledge. As an individual student that had no prior knowledge of bird life, it was very difficult to unwrap, resulting in a long theoretical process that limited the amount of time being spent designing. Ideally this project would be approached with a team like structure that includes a range of disciplines, such as landscape architects, ecologists, and urban designers etc, to make it as successful as possible. Not only for wildlife, but application back into the existing urban realm.

If there was more time that could have been spent on these designs, more application towards the meso scale and interior habitats within the micro could have grounded the project more. This is an issue that needs a lot of time to understand however, and was sacrificed in the design process. Also working more closely with Wellington City Council and the urban strategy they have set up for biodiversity conservation, could have been an interesting relationship for the thesis.

The main area that would be touched upon, if there was more time, would be the work that centred on ethics approval.

Conducting this process, with more individuals and at each design stage, would have been very beneficial to refining the built forms, an area that was lacking in Location 3. 


\section{+ AMENDMENTS}

During the time between the submission and final

presentation, additional work was completed. It is as follows.

\section{Models}

To help further explain the intentions for the sites that were not visually explored, a series of small sketch models were utilised.

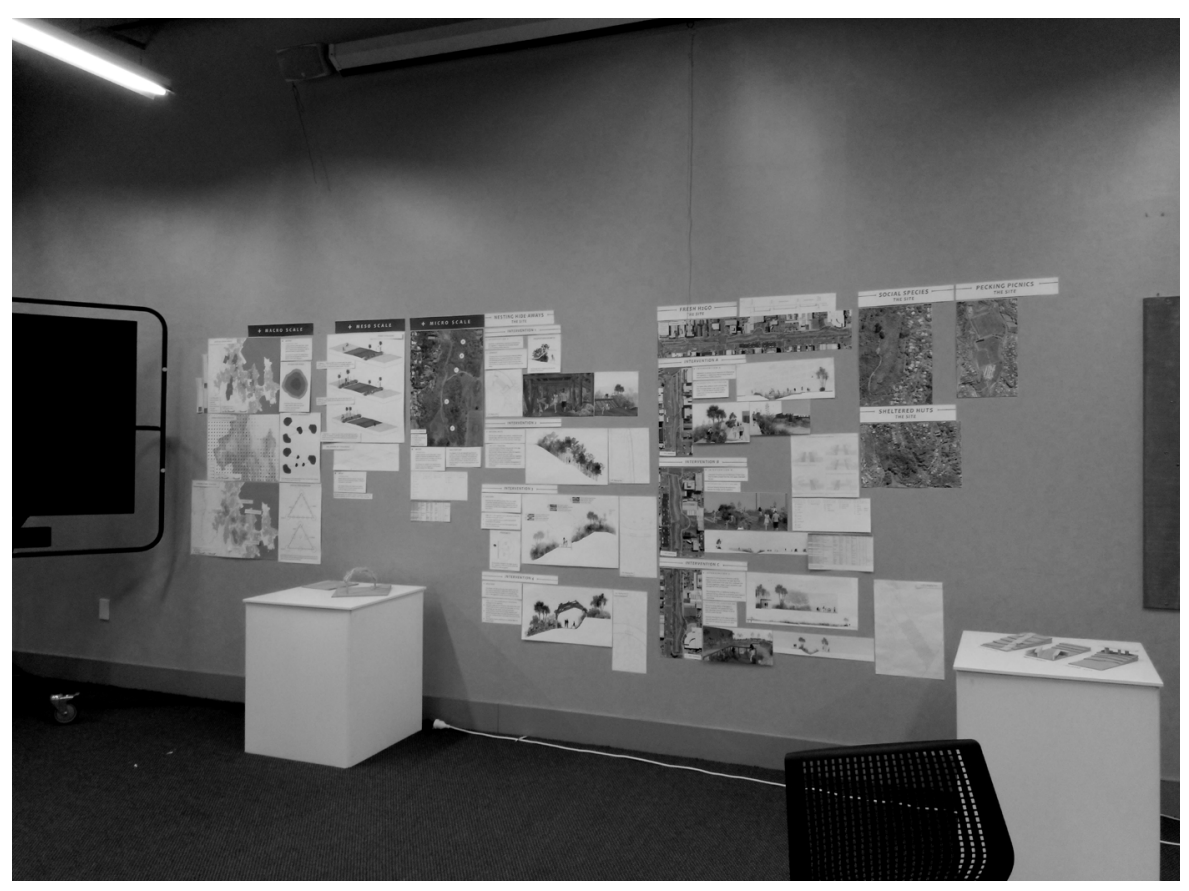

Fig 7.68 | The room set up that showcased the new and important work pertaining around this thesis. 


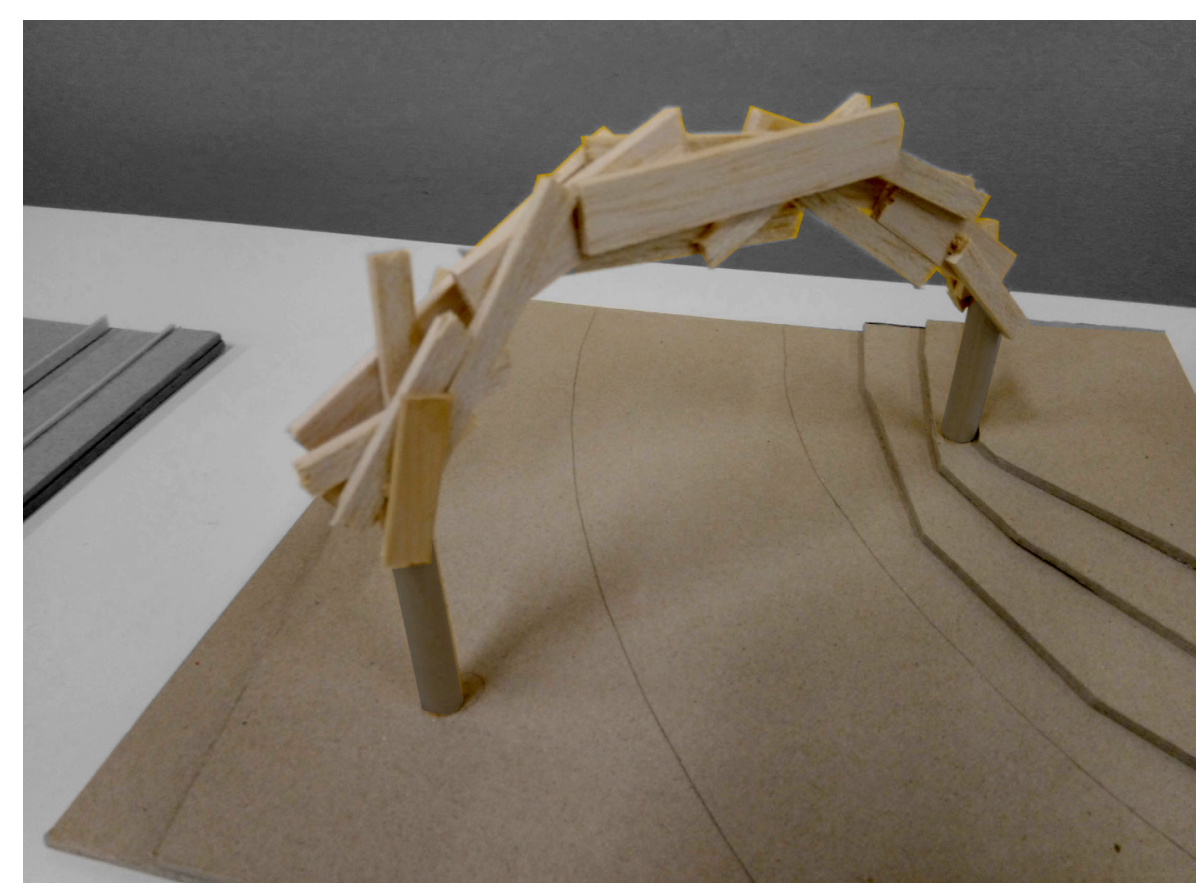

Fig 7.69 | The nesting archway that was designed and explored within Location 4, Event C. This model aims to spatialise the depth and movement of the wooden panels.

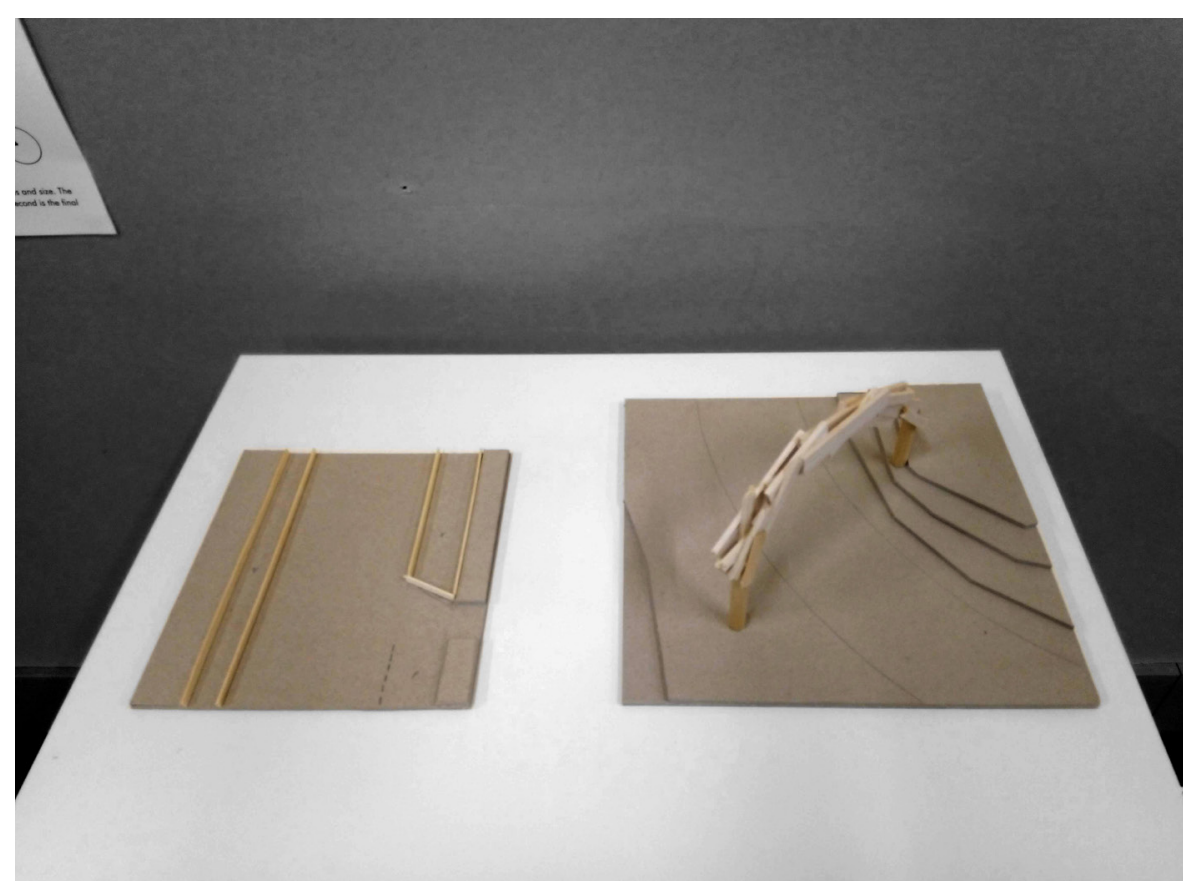

Fig 7.70 | The left model works towards spatialising how the different street typologies can work together within one location. 
Fig 7.71 | These three models look into simple modifications to the landscape following the site's program.

Social Species explores how small adjustments to the landform can encourage settling, to listen and engage alternative senses.

Pecking Picnics looks into ways to separate community gardens with vegetation that birds will also enjoy.

Sheltered Huts encourages man-made manipulations to provide secret and covered areas for humans and birds alike. 


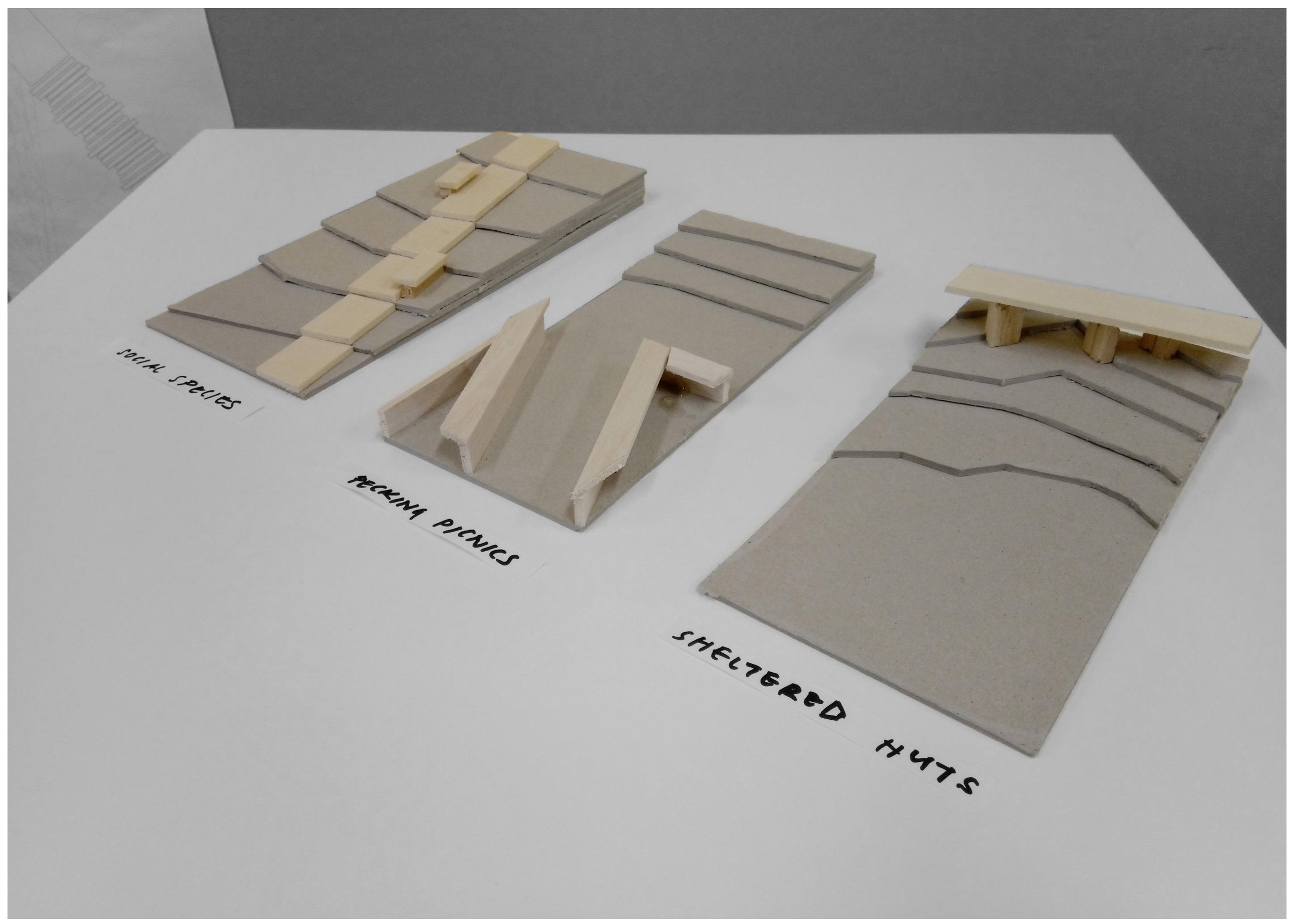


Renders

Fig 7.72 | A Render exploring the interactive water installations, to be seen after page 201.

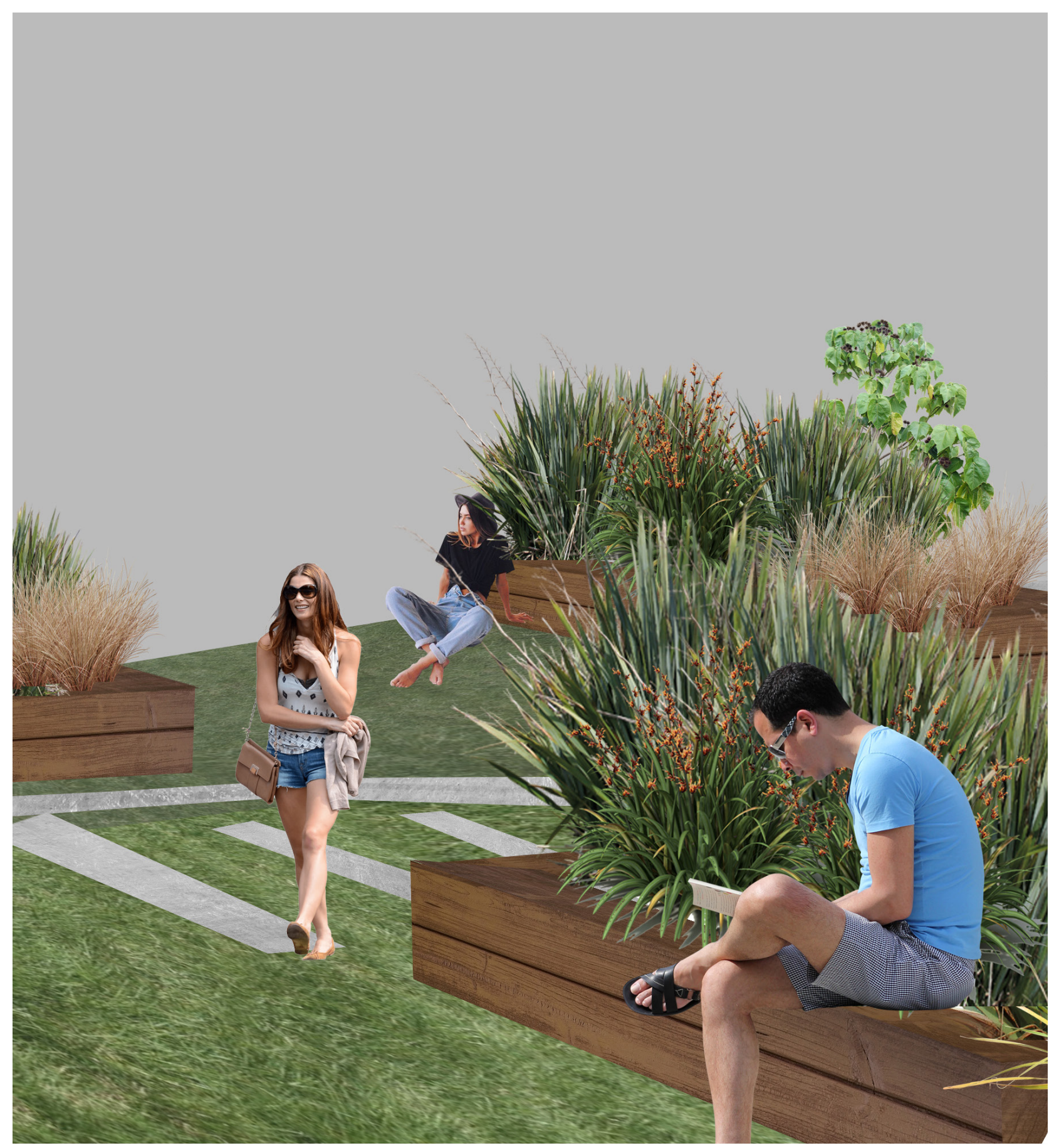




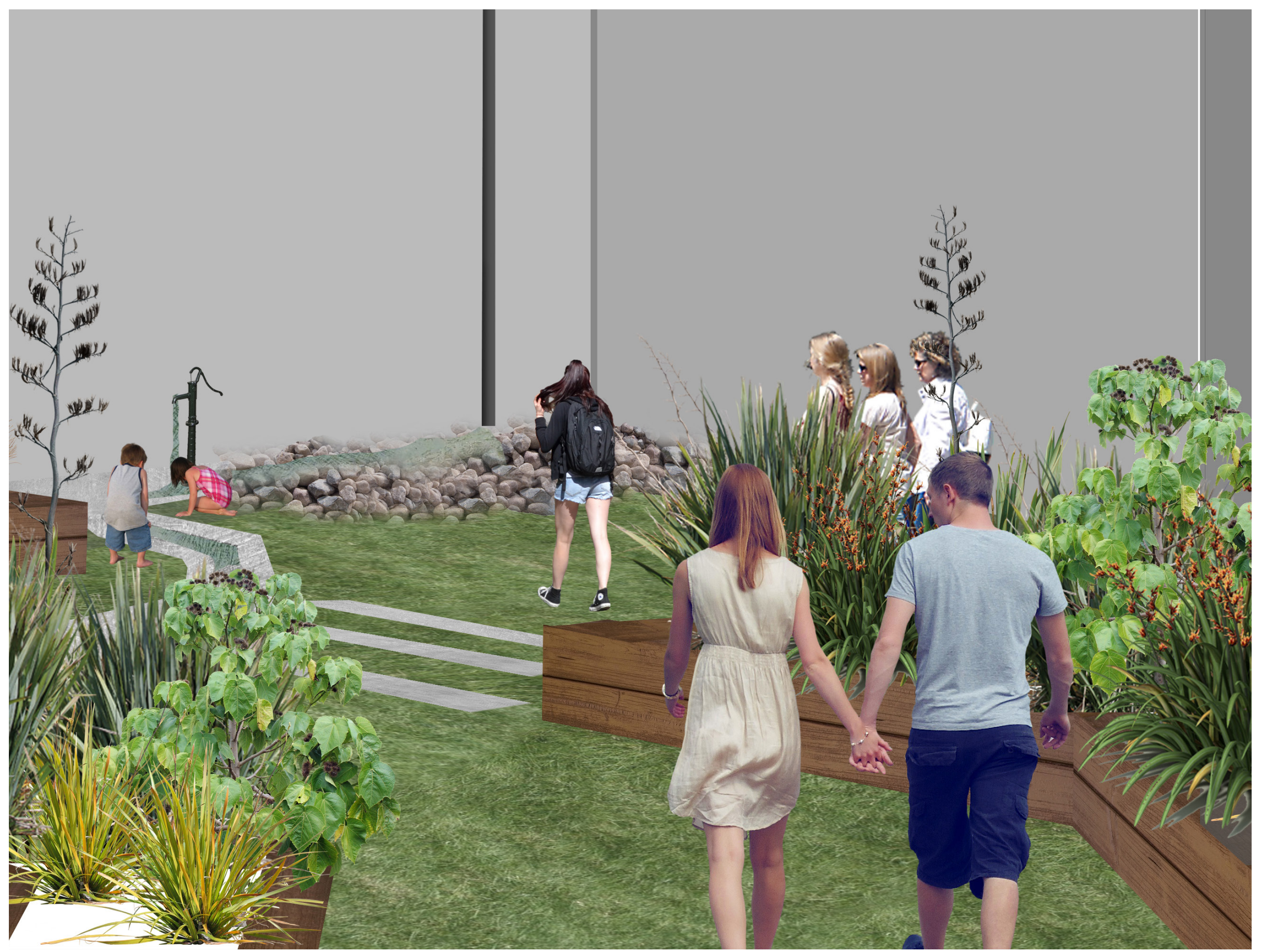


Planting Plans

These planting plans explore the relevance towards vegetation and the role it can play for attracting wildlife to the designed interventions within a site.

1) Fig 7.73| Scale 1:1100@ A3. Location 4, Event B Planting plan

Coprosma propinqua | Mingimingi

Blechnum minus | Kiokio

Cordyline australis | Cabbage tree

Piper excelsum | Kawakawa

Hoheria sexstylosa | Lacebark

Aristotelia serrata | Wineberry

Phormium tenax | Flax

Arthropodium cirratum | Rengarenga

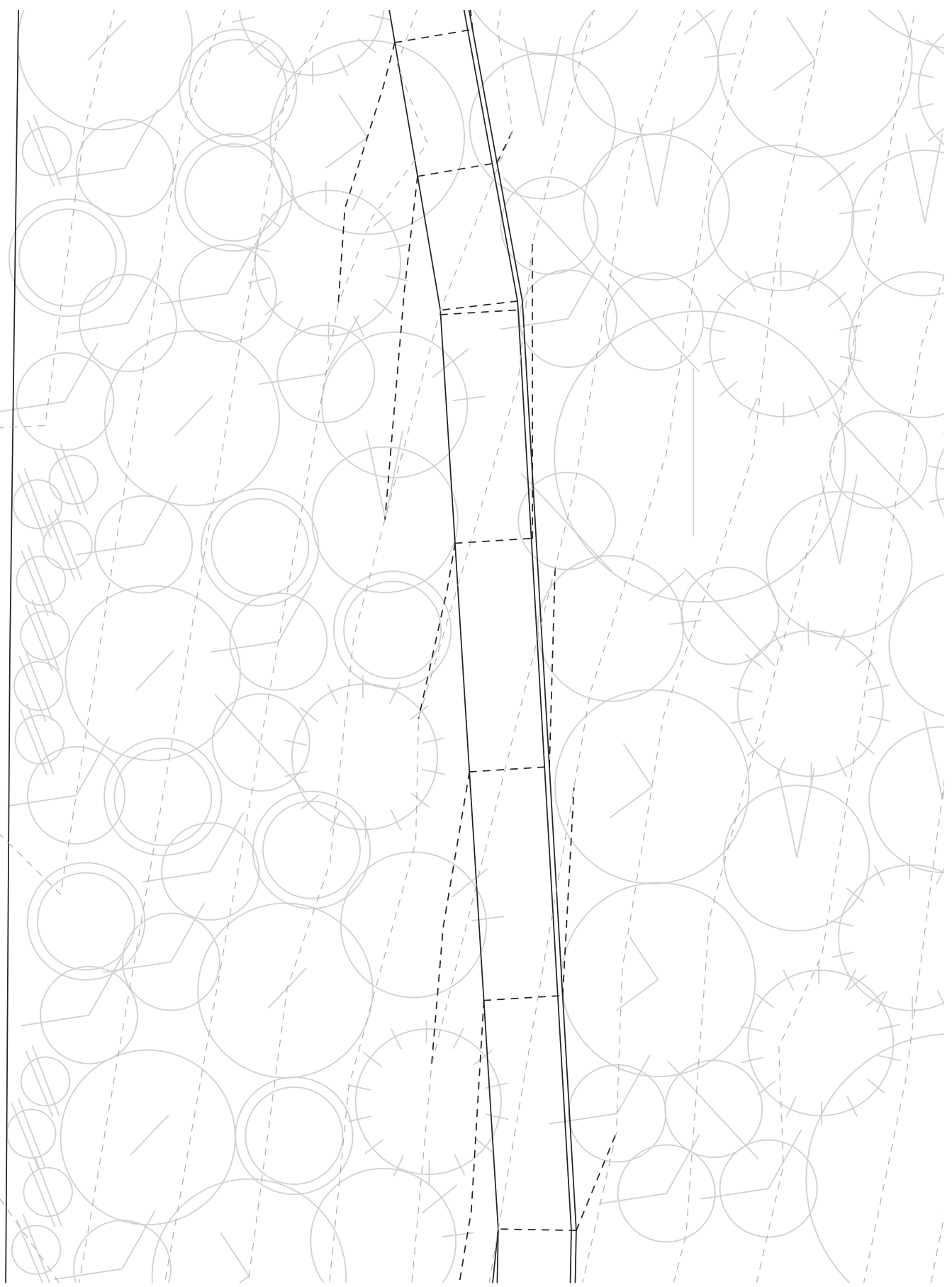




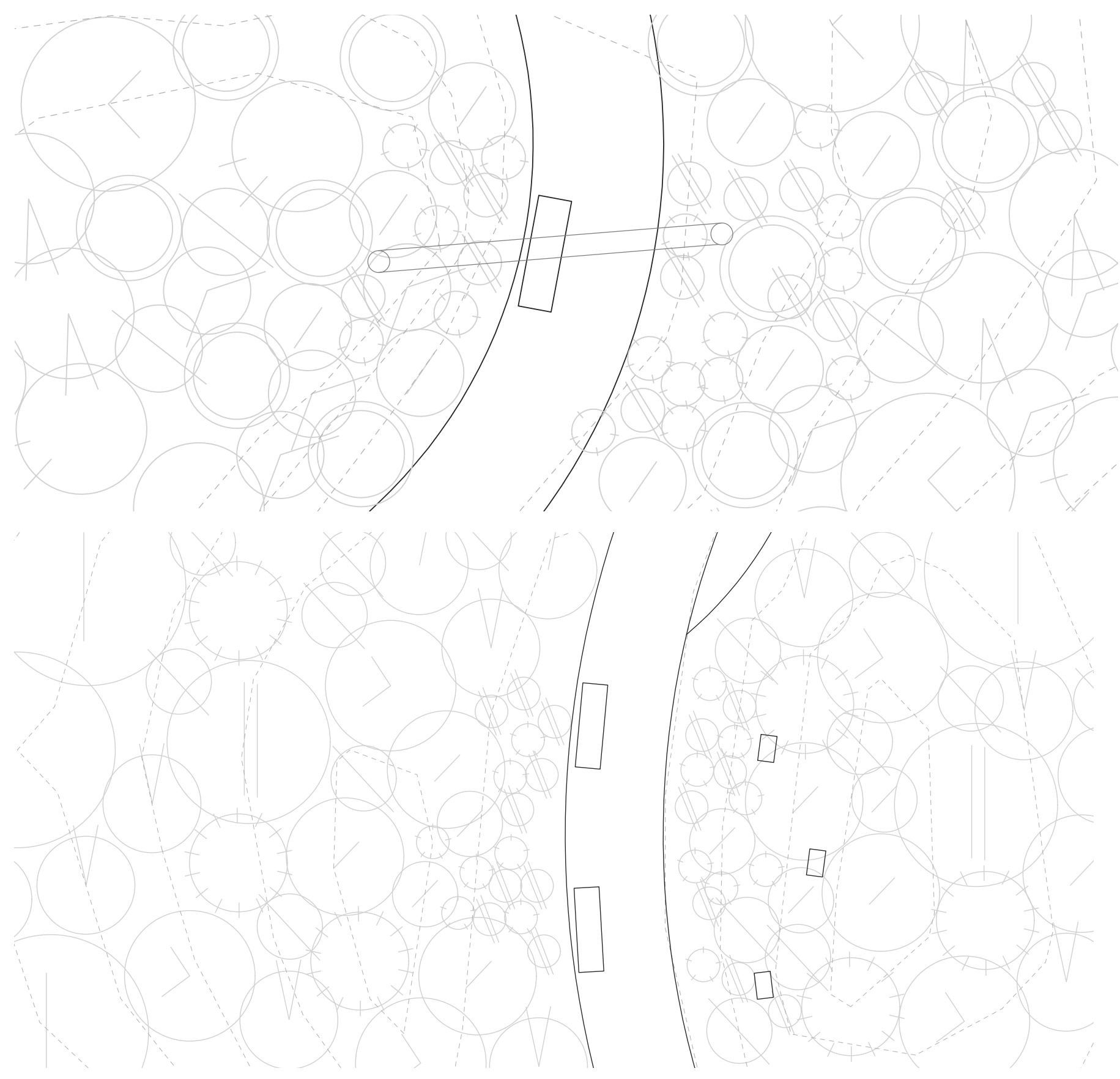

(1)

Fig 7.74 | Scale 1:1100@A3.

Location 4, Event D Planting Plan

(1)

Fig 7.75| Scale 1:1100 @ A3.

Location 4, Event C Planting Plan 
Conclusions

Within the final presentation of the thesis, additional work was simplified the conclusions that were discovered from the process of the thesis research investigation. They were presented in a sideshow.

Fig 7.76 | Collaboration Process Slide

+ CONCLUSIONS AND OVERALl FINDINGS

Collaborative Process

+ This thesis aims to prove that landscape architects should start the design process with the intention to work collaboratively

Working with additional people, such as members of the council, Zealandia and professional teaching facilities, adds a layer of information to the design process, making it more

+ Ideally, this process with the Ethics Committee and the series forth process, to utilise the most of the information being offered.

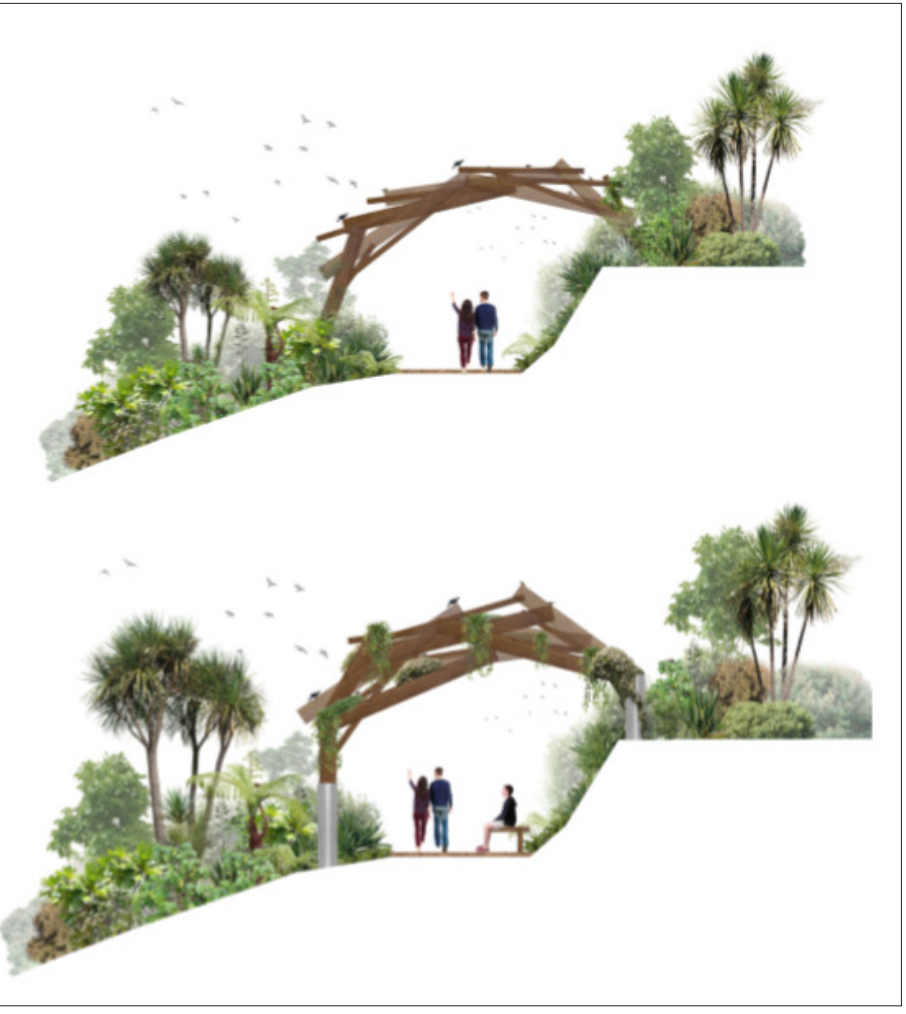


Fig 7.77 | Wildlife Knowledge Slide

Fig 7.78 | Changing Perspective Slide
2. Wildlife Knowledge

Knowing the species that ore to be targeted is the most conter.

The more that is known about the willifie species in the design
process the more precise the design will be, which is important process the more precise the design will be, which is import
as it helps to meosure how successful the design might be
when in tis not realised and built in the real world $\left.x^{3}\right)^{4}$

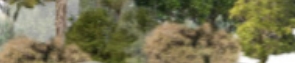

$x^{x}=-y^{2} \cdot 2$

+ Kereru.

+ Tơi.

+ Hihi.
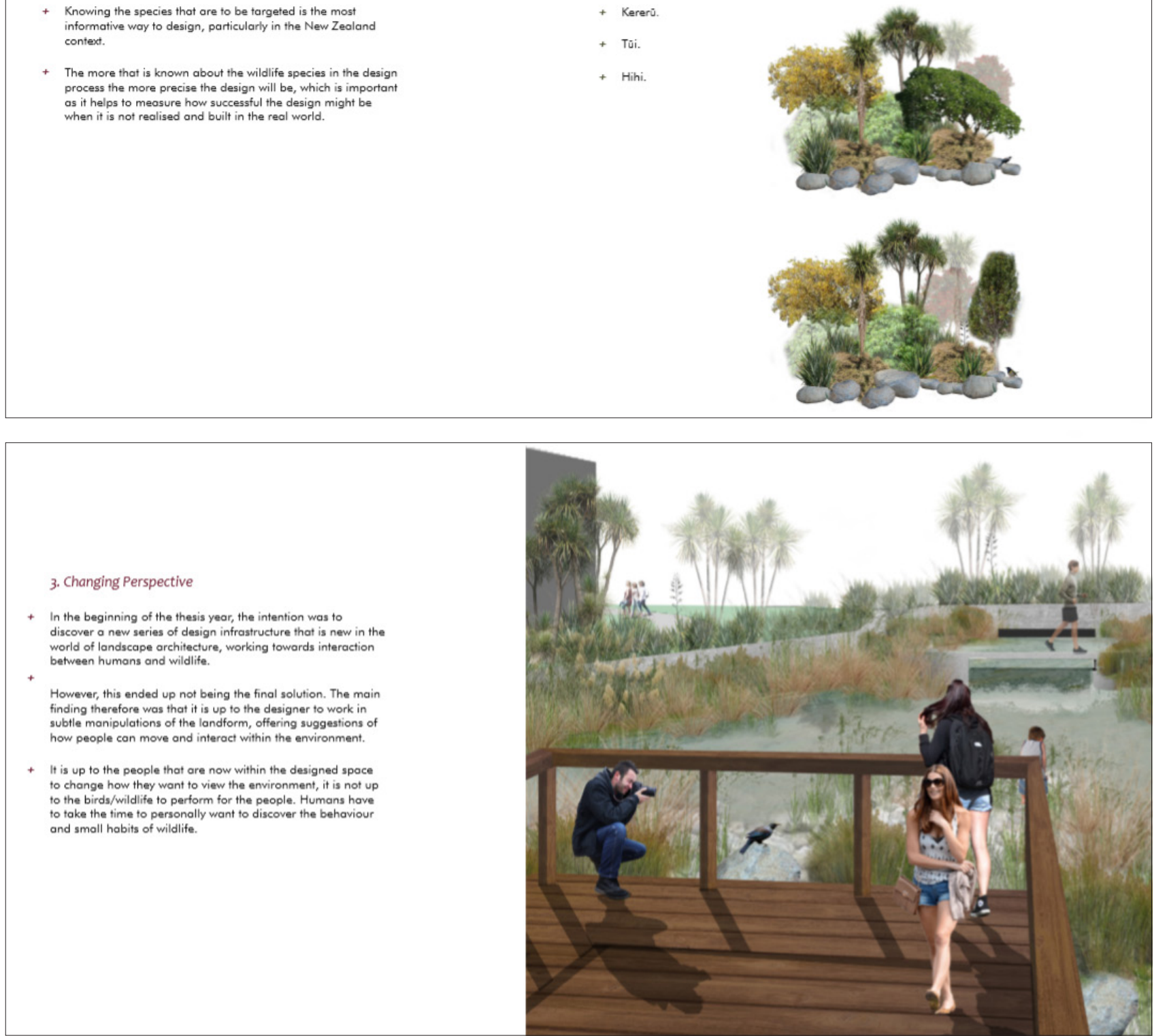


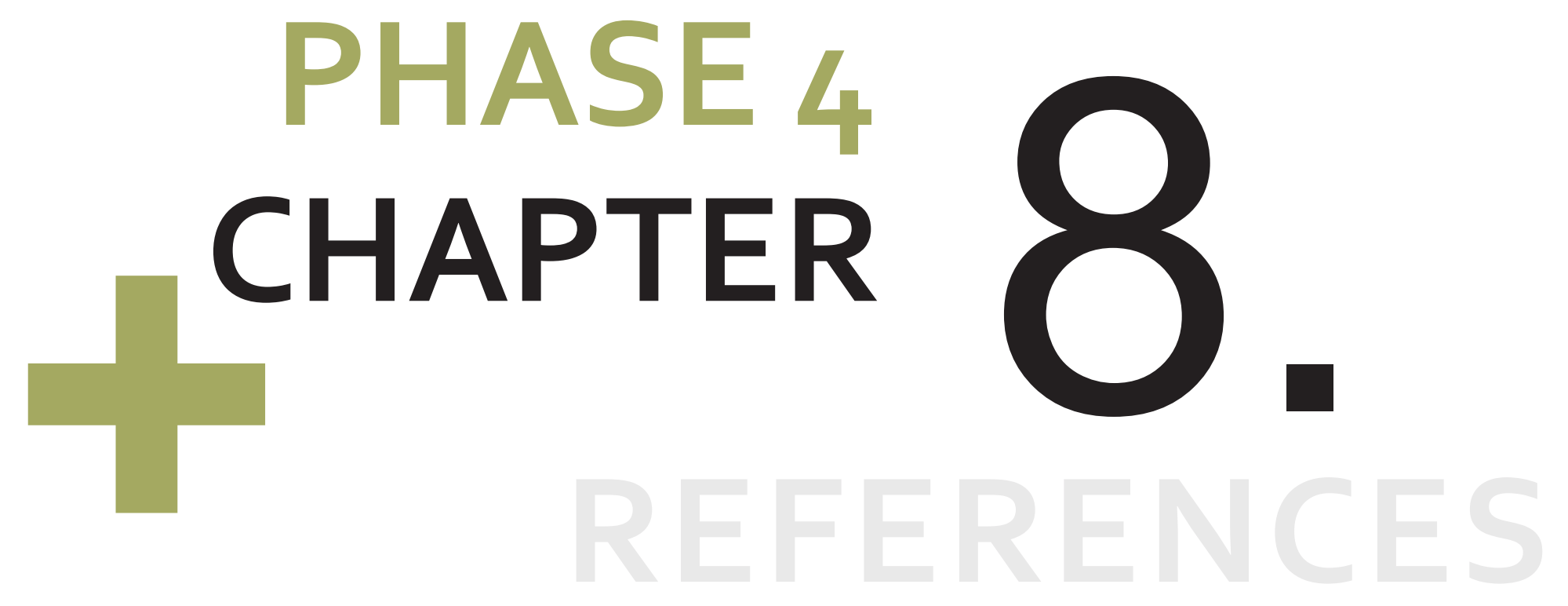


Barrett, M. (Ed.). (2015). Coast. Country. Neighbourhood. City. Isthmus. New Zealand: Six point press.

Blaschke, P. (2019). Interview 1, Personal Communication. Paul Blaschke.

Brunton, D. H., Evans, B. A., \& Weihong, J. (n.d.). Assessing natural dispersal of New Zealand bellbirds using song type and song playbacks. New Zeland Ecological Society.

Campbell-Hunt, D. (2002). Developing a Sanctuary, The Karori Experience. Wellington, New Zealand: Victoria Link Ltd.

EII, G. (1981). ENCOURAGING BIRDS in the New Zealand GARDEN. Auckland, New Zealand: Bush Press Communications Ltd.

Engwicht, D. (1992). Towards an Eco-City Calming the Traffic. Sydney: Envirobook.

Fabos, J. G. (2004). Greenway planning in the United States: Its origins and recent case studies. Landscape and Urban Planning, $68,321-342$

Fea, N. (2019, September 19). Wellington Urban Ecology Research Symposium 2019. Presented at the Zealandia. Zealandia.

Forman, R. T. T. (1995). Land Mosaics, The ecology of landscapes and regions. Great Britian: Cambridge University Press.

Forman, R. T. T. (2010). Urban Ecology and the Arrangement of Nature in Urban Regions. In Ecological Urbanism (pp. 312-323) Harvard University: Lars Muller Publishers.

Freedman, B. (2014). Keystone Species. In The Gale Encyclopedia of Science (5th ed., Vol. 5, pp. 2469-2470). Retrieved from https://go.gale.com/ps/i.do?p=GPS\&u=vuw\&id=GALE\%7CCX3727801384\&v=2.1\&it=r 
Fuller, R. A., Irvine, K. N., Davies, Z. G., Armsworth, P. R., \& Gatson, K. J. (2012). Interactions between People and Birds in Urban Landscapes. In Studies in Avian Biology (Vol. 45, pp. 249-266). Retrieved from https://www.fullerlab.org/wp-content/ uploads/2010/01/Fuller-et-al-2012.pdf

Meurk, C. D., \& Hall, G. M. J. (2006). Options for enhancing forest biodiversity across New Zealand's managed landscapes based on ecosystem modelling and spatial design. Avian Conservation and Ecology. Retrieved from https://www.researchgate. net/publication/242181030_Natal_Dispersal_in_the_North_Island_Robin_Petroica_longipes_the_Importance_of_Connectivity_ in_Fragmented_Habitats_Dispersion_natale_chez_le_Miro_de_Garnot_Petroica_longipes_importance_de_la_connectivi/ link/5587c5b208ae7bc2f44d565e/download

Michel, P. (2019). Interview 2, Personal Communication, Pascale Michel. Zealandia.

Ministry for the Environment. (2019, May). Environment Aotearoa 2019 Summary [NZ Government]. Retrieved October 18, 2019, from Ministry for the Environment Manatu Mo Taiao website: https://www.mfe.govt.nz/Environment-Aotearoa-2019-Summary

NZILA. (2019). What is a Landscape Architect [Landscape Architecture Firm]. Retrieved August 16, 2019, from NZILA New

Zelaand Institute of Landscape Architects website: https://nzila.co.nz/intro

Park, T. (2019). Interview 3, Personal Communication, Tim Park. Wellington City Council.

Payton, I. J., Fenner, M., \& Lee, W. G. (2002). Keystone species: The concept and its relevance for conservation management in New Zealand. Department of Conservation Wellington, New Zealand. 
Pedersen Zari, M. (2018). Regenerative Urban Design and Ecosystem Biomimicry. Routledge.

Penguin Pocket Guides. (1996). New Zealand's Native Birds Of Bush and Countryside. Auckland, New Zealand: Penguin Books. Power, M. E., Tilman, D., Estes, J. A., Menge, B. A., Bond, W. J., Mills, L. S., ... Paine, R. T. (1996). Challenge in the Quest for Keystone. Oxford University Press, BioScience 46, 609-620. https://doi.org/10.2307/1312990

Rastandeh, A., Brown, D., \& Pedersen Zari, M. (2018). Site selection of urban wildlife sanctuaries for safeguarding indigenous biodiversity against increased predator pressures (Vol. 32). https://doi.org/10.1016/j.ufug.2018.03.019

Rastandeh, A., \& Pedersen Zari, M. (2018). A spatial analysis of land cover patterns and its implications for urban avifauna persistence under climate change (Vol. 33). https://doi.org/10.1007/s10980-018-0613-4

Rastandeh, A., Pedersen Zari, M., \& Brown, D. (2018). Utilising exotic flora in support of urban indigenous biodiversity: Lessons for landscape architecture. Routledge Taylor and Francis Group.

Riley, M. (2005). Know Your New Zealand Birds. Paraparaumu: Viking Sevenseas NZ Ltd.

Santiago, S. (2014). Science for Environment Policy: Stepping stone patches of habitat help reduce effects of fragmentation. Journal of Applied Ecology.

The Sanctuary. (2018). Retrieved from Zealandia website: https://www.visitzealandia.com/About

Wellington City Council. (2015). Our Natural Capital (p. 21). 
Wittern, A. K., \& Berggren, A. (2007). Natal Dispersal in the North Island Robin (Petroica longipes): The Importance of Connectivity in Fragmented Habitats. Avian Conservation and Ecology, Vol 2(2).

Wotton, D. M. (2007). Consquences of dispersal failure: Kereru and large seeds in New Zealand (Thesis). University of Canterbury. 
If images do not have a reference, reference becomes 'authors own drawing/image/diagram/collage'.

Maps throughout this thesis were created using ArcGIS $®$ software by Ersi. ArcGIS $®$ and ArcMap ${ }^{\mathrm{TM}}$ are the intellectual property of Ersi and are used herein under license. Copyright (c) Esri. All rights reserved.

Data has been sourced from Wellington City Council Open Data Portal, https://data-wcc.opendata.arcgis.com/ search?tags=WCC. Additional manipulation of the data was completed by the author within Adobe software.

Fig 1.01 | Diagram of design intentions

Fig 2.01 | Vegetation species map. Arc Map GIS, data sourced from WCC Open Data.

Fig 2.02 | Green spaces map. Arc Map GIS, data sourced from WCC Open Data.

Fig 2.03 | Water systems map. Arc Map GIS, data sourced from WCC Open Data.
Fig 2.04 | Flight movements map. Arc Map GIS, data sourced from WCC Open Data.

Table 2.1 | Showing the species that were found inhabiting the existing green sites.

Fig 2.05 | Understanding of the species location can lead towards assumptions of what birds are flying where and potential pathways that they are taking.

Fig 2.06 | The location of Boyd Wilson Walkway. Sourced from Arc Map GIS, Eagle Technology Group Ltd.

Fig 2.07 | Sectional diagram of Boyd Wilson Walkway.

Fig 2.08 | Plan of Willis St. Sourced from Arc Map GIS, Eagle Technology Group Ltd.

Fig 2.09 | Sectional diagram of Willis St.

Fig 2.10 | Plan of Cobblestone Park. Sourced from Arc Map GIS, Eagle Technology Group Ltd.

Fig 2.11 | Sectional diagram of Cobblestone Park. Section C-CC.

Fig 3.01 | The location of Zealandia, Wellington. Sourced from 
Arc Map GIS, Eagle Technology Group Ltd.

Fig 3.02 | The KererŪ.

Fig 3.03 | A collage showing a few preferred vegetation species.

Fig 3.04 | The TŪī

Fig 3.05 |. A collage showing a few preferred vegetation species.

Fig 3.06 | Female Hihi.

Fig 3.07 | A collage showing a few preferred vegetation species.

Fig 4.01 A spatial render that aims to communicate an informal pathway within vegetation.

Fig 4.02 | A spatial render that aims to explore ways people can move along a pathway within an under story.

Fig 4.03 | Drawings of the typologies that were gathered from an initial precedent analysis.

Fig 4.03.1 | Networked Green Spaces.
Fig 4.03.2 | Dispersed Hubs.

Fig 4.03.3 | Informal Pathways.

Fig 4.03.4 | Formal Pathways.

Fig 4.04 | Another spatial render that aims to communicate facilitating different levels of interaction in vegetation.

Fig 4.05 | The initial attempt at using Kererū flight patterns to determine five stepping stone locations. ArcMap, GIS.

Fig 4.06 | Visual representation of the continuity of the three design scales. Base imagery sourced from Arc Map GIS, wCC Open Data.

Fig 5.01 | Visual representation of the spatial stepping stones, one large central stepping stone or a variety of several smaller ones..

Table 5.01 | The small details that need to be considered when choosing sites for birds.

Fig 5.02 | Visualisation of the rings of interaction. 1. Edge conditions, both humans and birds 2. A mixture, more birds 
however 3 . Interior, bird focused.

Fig 5.03 | Species richness compared to patch size.

Reprinted from Land Mosaics The Ecology of Landscape and Regions (pg 72) by R.T.T. Forman, 1995, Great Britian: Cambridge University Press. Copyright 1995 by Cambridge University Press.

Fig 5.04 | Species richness compared to patch distance. Reprinted from Natal Dispersal in the North Island Robin (Petroica longpipes): The Importance of Connectivity in Fragmented Habitats (pg 9) by A.K. Wittern and A. Berggren, 2007. Copyright by Avian Conservation and Ecology Vol 2(2).

Fig 5.05 | A New Zealand focused framework for stepping stone distances and size. Reprinted from Options for enhancing forest biodiversity across New Zealand's managed landscapes based on ecosystem modelling and spatial design. (pg 141) by C.D. Meurk and G.M.J. Hall, 2006. Copyright from Avian Conservation and Ecology.

Fig 5.06 | A New Zealand focused framework for stepping stone distances and size. The first is a diagram within the additional changes in area, the second is the final sizes and spacing. Authors own diagrams, stemming from Fig 5.05

Fig 5.07 | Stepping stone map. Arc Map GIS, data sourced from WCC Open Data.

Fig 5.08 | Stockholm map and the visual green wedges. Sourced from Map Data: Google, TerraMetrics, 2019.

Fig 7.01 | A TŪī cleaning itself in a gutter.

Fig 7.02 | Nesting box requirements. Reprinted from Encouraging Birds in the New Zealand Garden, (pg 40) by G. Ell, 1981, Auckland: New Zealand: Bush Press Communications Ltd. Copyright 1981 from Bush Press Communications.

Fig 7.03 | Different ecological environments.

Fig 7.04 | Signage for education.

Fig 7.05 | Fake nesting boxes for education.

Fig 7.06 | Sound ques to attract species. 
Fig 7.06.01 | Overhanging vegetation.

Fig 7.06.02 | Hidden pathways to unique social spaces.

Fig 7.06.03 | From both the literature and precedent analysis, these seven typologies were extracted to understand spatial qualities when designing.

Fig 7.06.04 | Wellington's Stepping Stone Locations. Arc Map GIS, data sourced from WCC Open Data.

Fig 7.07 | Location 4. Sourced from Arc Map GIS, Eagle Technology Group Ltd.

Fig 7.07.01 | Contours and Water Lines. Arc Map GIS, data, contours and footprints sourced from WCC Open Data.

Fig 7.07.02 | Site Functionality. Arc Map GIS, data sourced, contours and footprints from WCC Open Data.

Fig 7.08 | A-AA | Ridge walkway, 1:500 @ A3

Fig 7.09 | B-BB |Cliff walkway, 1:500 @ A3

Fig 7.10| Photographic pathway observations.
Fig 7.11| Photographic planting observations.

Fig 7.12| Photographic view point observations.

Fig 7.13| Photographic soil observations.

Fig 7.14 | Site Vegetation.

Fig 7.15 | Masterplan.

Fig 7.16 | Initial design sketches.

Fig 7.17 | Diagrams around the forms base.

Fig 7.18 | Sectional exploration of form.

Fig 7.19 | Exploration of form in plan.

Fig 7.20 | Digital exploration of chosen form.

Fig 7.21 | Components of the form.

Fig 7.22 | The render showing the under passage of the lookout, presented to the interviewees

Fig 7.23 | The section showing the archway, presented to the interviewees.

Fig 7.24 | The section showing nesting boxes, presented to 
the interviewees.

Fig 7.25 | Masterplan | 1:1,500 @ A3

Fig 7.26 | Key for planting plan | 1:100@ @3

Fig 7.27 | A diagram showing the emergence of vegetation through the lookout.

Fig 7.28 | A render of the space.

Fig 7.29 | A render of the adjusted lookout pathway.

Fig 7.30 | Masterplan |1:1,500 @ A3

Fig 7.31 | A-A | Natural Nests, 1:100 @ A3

Fig 7.32 |The previous nesting box shape compared to the newly designed perching stations. This offers shelter for the birds without requiring them to use the space for breeding purposes.

Fig 7.33 | The proximity of people to the shelter spaces is $5 \mathrm{~m}$ in distance, to allow the species to feel safe enough to use the equipment.
Fig 7.34 | Masterplan | 1:1,500@A3

Fig 7.35 | A-AA | 1:75 @ A3 |The archways acts as a natural feature, emerging from the vegetation.

Fig 7.36 | Kent and Cambridge Terrace. Sourced from Arc Map GIS, Eagle Technology Group Ltd.

Fig 7.37 | 1:2000 @ A 3 | Water Systems map. Arc Map GIS, data, sourced from WCC Open Data.

Fig 7.38 | 1:2000 @ A 3 | Traffic Management map. Arc Map GIS, data, sourced from WCC Open Data.

Fig 7.39 | Photographic built forms observation

Fig 7.40 | Photographic bird life observations

Fig 7.41 | Photographic planting observations.

Fig 7.42 | The existing road formation, 5 lanes on each side.

Fig 7.43 | Expansion of the middle green space, to make a wider natural corridor.

Fig 7.44 Moving the green to the left of KCT, it is 
disconnected from the residential realm on the right.

Fig 7.45 | Moving the green to the right of KCT, it connects it back to the residents of the area.

Fig 7.46 | Drawing of the spatial qualities of a pond environment.

Fig 7.47 | Drawing of the spatial qualities of a swale environment.

Fig 7.48 | Drawing of the spatial qualities of a stream environment.

Fig 7.49 | Drawing of the spatial qualities of a wetland environment.

Fig 7.50 | Drawing of initial bubble diagrams, to define spaces in the design.

Fig 7.51 | Rendered masterplan | Scale 1:1,100 @ A3.

Fig 7.52 | Functional diagram explaining the movement around the design. 1:1,100@A3.
Fig 7.53 | Functional diagram explaining the areas of design. | 1:1,100@A3.

Table 7.02 | Planting schedule.

Fig 7.54 | Rendered masterplan Scale 1:1,100 @ A3.

Fig 7.55 | Scale 1:1,100 @ A3, Section A-AA

Fig 7.56 | Rendered plan highlighting the interactive nature of the decking structure, for both people and birds.

Fig 7.57 | Sectional drawing showing the relationship between the bridge and the vegetation. B-BB | Scale 1:300 @ A4

Fig 7.58 | Sectional drawing showing the relationship between the pathway and the vegetation. C-CC | Scale 1:150 @ A4

Fig 7.59 | 3D render showing the cycle lane and the surrounding vegetation that attracts multiple bird species, which can then be directed to the water.

Fig 7.60 | Rendered masterplan. Scale 1:1,100@A3 
Fig 7.61 | Sectional drawing explaining the increase of land into what used to be a car park, to create small terraces that are vegetated, attracting in numerous amounts of wildlife.

Fig 7.62 | Small perspective images that reflect the spatial experience of the water features.

Fig 7.63 | Rendered masterplan. Scale 1:1,100 @ A3

Fig 7.64 | A-AA |Sectional study of space separations. Scale 1:150@A3

Fig 7.65 | B-BB | Scale 1:200@ A3

Fig 7.66 | Perspective showing alternative view from the wooden platform. Visualisation of the open fences shows the permeability and multi-functionality of the design for both clients.

Fig 7.67 | Scale 1:50,000 Wellington's Stepping Stone Locations. Arc Map GIS, data sourced from WCC Open Data.

Fig 7.68 | The room set up that showcased the new and important work pertaining around this thesis.
Fig 7.69 | The nesting archway that was designed and explored within Location 4, Event C. This model aims to spatialise the depth and movement of the wooden panels.

Fig 7.70 | The left model works towards spatialising how the different street typologies can work together within one location.

Fig 7.71 | These three models look into simple modifications to the landscape following the site's program.

Fig 7.72 | A Render exploring the interactive water installations, to be seen after page 201.

Fig 7.74 | Scale 1:1100 @ A3. Location 4, Event D Planting Plan

Fig 7.75 | Scale 1:1100 @ A3. Location 4, Event C Planting Plan

Fig 7.76 | Collaboration Process Slide

Fig 7.77 | Wildlife Knowledge Slide

Fig 7.78 | Changing Perspective Slide 


\section{+ APPENDIX}

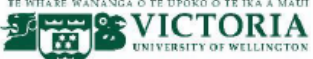

Bridging the Distance: Accommodating Wildlife Interaction in an Urban Setting

\section{MFORMATION SHEET FOR PARTIIIPANTS}

You are invited to take part in this research. Please read this information before deciding if you decide not to participate, thank you for considering this request

\section{Who am I?}

My name is Michaela Thomson and lam a Masters student in the Landscape Architecture programme at Victoria University Wellington. This research project is work towards my thesis.

\section{What is the aim of the project?}

This project aims to utilise landscape architecture as a way to explore how humans and avian wildifie species can possibly interact within urban environments. The urban environment in question is the Wellington context, with a variety of small locations spread throughout. I am hoping to discover a series of ways to design infrastructure that encourages humans and birds to interact within one space. Your participation will support this research by advocating for the wildlife. As a designer, I will be working within the human perspective; I would like you to provide insight towards what types of environments birds will respond postively to. This

\section{How can you help?}

You have been invited to participate because you have knowledge about either willife as a whole, specific species or ecological processes. If you agree to take part I will interview you within a location that is familiar to both parties and chosen in equal agreement. I will ask you questions about wildiffe behaviours in response to specific designed scenarios. The interview

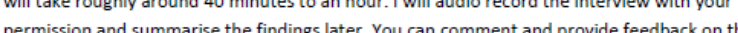
summsion of the interview, if vou desire You can choose to not answer any a interview at any time, without giving a reason. You can withdraw from the study by contantine me at any time, within two weeks after you have received the interiew sur

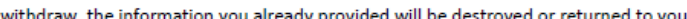

What will happen to the information you give?

The research is not confidential, and you will be named in the final report. Only my supervisors

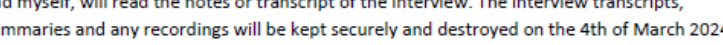

What will the project produce?

The information from my research will be used in my Master's thesis and potentially journal articles if the opportunity is presented.

you accept this invitation, what are your rights as a research participant? rou do not have to accept this invitation if you don't want to. If you do decide to participate, you have the right to:

choose not to answer any question;

with the recorder to be turned off at any time during the interview, ask any questions about the study at any time

receive a copy of your interview recording

read over and com

De abe to

If you have any questions or problems, who can you contact?

If you have any questions, either now or in the future, please feel free to contact me:

studen

Supervisor:

Human Ethics Committee informatio

of the research you may contact the Victoria University HEC Convenor: Dr Judith Loveridge. Email hec@vuw.ac.nz or telephone +64- 


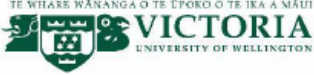

Bridging the Distance: Accommodating Wildlife Interaction in an Urban Setting

CONSENT TO INTERVIEW

This consent form will be held for 5 years.

Researcher: Michaela Thomson, School of Architecture, Victoria University Wellington-

Thave read the Information Sheet and the project has been explained to me. My question have been answered to my satisfaction. I understand that I can ask further questions at

- I agree to take part in an audio recorded interview

\section{I understand that:}

- I may withdraw from this study at any point before two weeks after receiving the written summary, and any information that I have provided will be returned to me or destroyed.

- The identifiable information I have provided will be destroyed on the $4^{\text {th }}$ of March, 2024.

I understand that the findings may be used for a Master's thesis and potential journal articles if the opportunity is presented.

- I consent to information or opinions which I have given being attributed to me in any reports on this research:

Yes $\square$ No $\square$

I would like a copy of the recording of my intervew.

Yes $\square$ No $\square$

- I would like a summary of my interview:

Yes $\square$ No $\square$ - I would like to receive a copy of the final report and have added my email Yes $\square$ № $\square$ 
